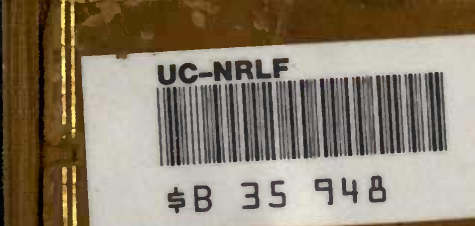




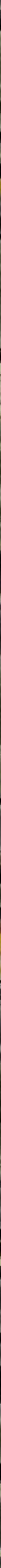





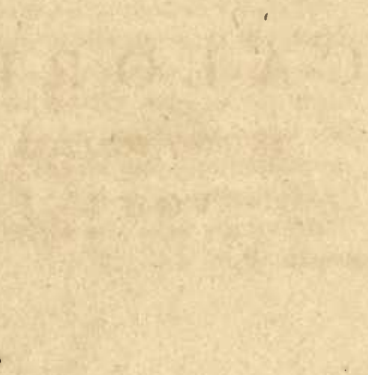


C A L O R I C

IN TWO VOLUMES

VOL I 
"To every form of being is assigned An active principle : howe'er removed From sense and observation, it subsists In all things, in all natures, in the stars Of azure heaven, the unenduring clouds, In flower and tree, in every pebbly stone That paves the brooks, the stationary rocks, The moving waters, and the invisible air. * * $\quad$ from link to link It circulates, the soul of all the worlds." WORDSWORTH. 


\section{A L O R I C}

ITS MECHANICAL CHEMICAL AND VITAL

\section{AGENCIES IN THE PHENOMENA}

\section{OF NATURE}

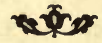

BY SAMUEL L. METCALFE M.D.

OP TRANSYLVANIA UNIVERSITY

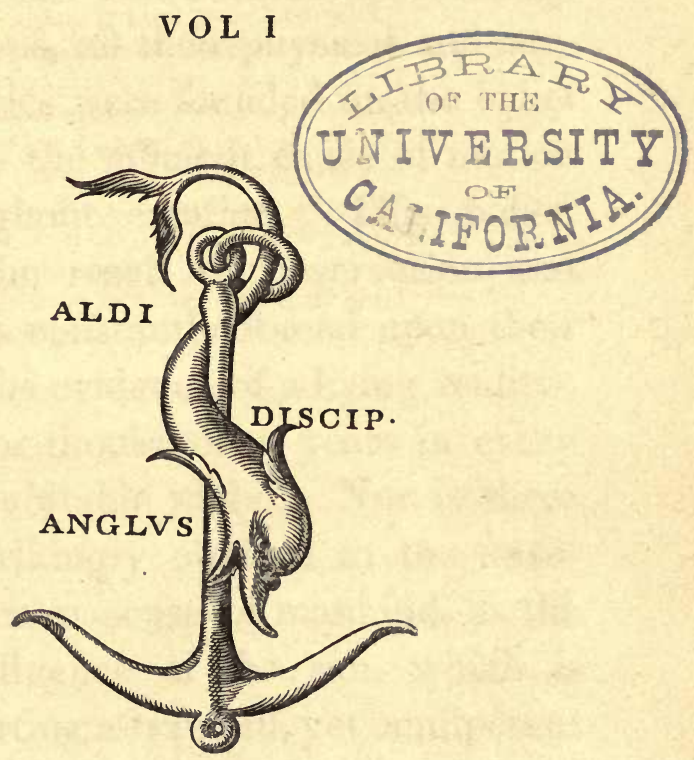

\section{LO N D O N}

W ILLIA M PICKERING 


\section{$39(1), 12$}

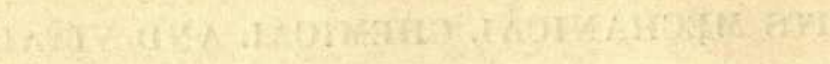

$$
a_{1}^{17^{3}}
$$




\section{PREFACE.}

In the primitive ages of the world, when men gazed on the wonders of nature with the freshness of childhood, and before the vivid information of the senses had become obscured by fabulous traditions, all their physical and metaphysical theories were founded on the belief that solar fire is the efficient cause of motion and life throughout creation. This belief, so manifestly the result of observation and experience, was constantly forced upon their minds with all the evidence of a living reality; and prevailed for thousands of years in every quarter of the habitable globe. Nor is there anything so strikingly obvious to the unsophisticated common sense of mankind, as the omnipresent influence of the sun, which is perpetually exerting a tranquil, yet omnipotent energy, throughout the air, the ocean, and the solid ground. He regulates all the phenomena of climate and season, evaporation and rain, the circulations of the atmosphere, 
the flowing of waters, the transformations of chemistry, the operations of vitality, and the revolutions of the heavenly bodies.

But as the ancients never explained the laws by which elementary caloric operates in the generation of force and motion, nor the manner in which it is related to electricity and light; their speculations have exerted little influence on the physical theories of modern philosophers, who have, strangely enough, disregarded nearly all that was most valuable in the science of antiquity. At the present time, it remains undecided, whether caloric is an exceedingly subtile and active essence, as maintained by the early Hindoos, Egyptians, Phœnicians, Chaldeans, Persians, and Arabians, as well as the more enlightened Greeks and Romans; or whether it consists in mere motion and vibration among the particles of ponderable matter, as supposed by Bacon, Boyle, Hooke, Rumford, Davy, Young, and others.

One of the most important modern discoveries was that of latent or combined heat, by Dr. Black. When he proved by accurate experiments, that definite measures of caloric are required to convert solids into liquids, and that 
the same subtile fluid is obtained from the atmosphere by respiration, he laid the foundation of its true theory. But as he did not extend his researches to its agency in the mechanical, chemical, and vital phenomena of nature, his labours have not been followed by results corresponding with the magnitude of his discovery, - if we except the improvement of the steam engine by $\mathbf{W}$ att.

Nor has any one, either among the ancients or moderns, ever attempted to give a regular and systematic history of the mode in which caloric operates in all the molecular and aggregate forces of matter. Mr. Whewell observes, in his late History of the Inductive Sciences, that "we have no hypothesis regarding thermotics, which, being assumed in order to explain one class of phenomena, has been found to account exactly for another." Yet he adds, " it is one of the cardinal points on which the doors of physical knowledge must turn, which have hitherto remained closed."

Within the last hundred years, electricity has been regarded by many persons as a key by which to unlock all the secret cabinets of nature. We have had electrical theories of chemistry, of life, and of the universe. Yet 
no one has explained what electricity iswhether a separate and distinct agent - a modification of some other exceedingly refined and more comprehensive principle - or a mere effect, condition, or property of ponderable matter. The celebrated Faraday at one time adopted the simple and rational theory of Franklin, that it is a material fluid, definite measures of which belong to each element of ponderable matter. And yet he speaks of it very often as if he considered it to be a compound fluid. But when treating of its chemical agency, he represents it as " a modification of the exertion of chemical forces."

Again; when by following up the discoveries of Erstedt, Davy, Arago, and Schweigger, who found that electricity is capable of producing all the phenomena of magnetic action on a small scale, he succeeded in obtaining an electric spark from a permanent magnet;- he arrived at the conclusion that electricity and magnetism are identical ; except that in the latter " the axis of power" is greater than in the former. Yet, as if not satisfied with any of the foregoing hypotheses, he suggests, at another time, that electricity may be resolved into undulations of an æther ; 
and, at another time, that all the more important electrical phenomena may be resolved into polarization of the particles of ponderable matter, or what has been called atomic polarity. But he does not explain what he means by the axis of power, and electric polarity; nor how chemical affinity and magnetism, which are merely effects or modes of action, can be identical with their cause; nor does he inform us what causes the æther to vibrate. Such have been the difficulties of this important department of physical science, that its most distinguished votaries have hitherto failed to present us with a consistent theory of electrical phenomena. But I hope to make it appear that most of these perplexities have arisen more from defective methods of inquiry, than from any inherent obscurity of the subject.

Among the physical speculations of Oken, light, heat, and weight, are represented as a trinity of powers, to which all the phenomena of nature may be referred : while it was maintained by Coleridge, that electricity, galvanism, and magnetism, are the three fundamental principles of action in nature, and identical with the three primary dimensions of space-length, breadth, and depth. Yet, he observes, that 
"the sole factors in all electrical phenomena consist in attractive and repulsive forces, independent of any material substrate." Such is the reverence of mankind for mysteries, that the most obscure and visionary fancies are often regarded as profound. It was long ago remarked by Longinus, that darkness is a source of the sublime : and it must be admitted that objects are magnified by looming through a fog.

In all ages of the civilized world, light has been recognised as a powerful agent in the work of the universe. As the great painter of nature, it gives to the dome of heaven its azure hue,- - to the rainbow, its gorgeous red, brilliant yellow, refreshing green, and lovely blue, shading into the softer violet. It is solar light which touches the morning and evening clouds with its celestial pencil, when they glow with vivid tints of ruby, sapphire, and gold. It adorns the flowery fields with an endless variety of beauteous colours; while it is perpetually modifying the taste, odour, and other sensible properties of whatever it touches.

But it is still an unresolved problem, whether light be a material substance, as maintained by Pythagoras, Democritus, Leucippus, Empedocles, Plato, Epicurus, Newton, and Brew- 
ster; or whether it consist in the mere vibrations of some unknown æther, as supposed by Huyghens, Hooke, Euler, Young, Sir John Herschel, Arago, and others. Nor is it yet finally settled whether white light is composed of seven primitive rays, as supposed by Newton, or of only three fundamental colours, as maintained, with many cogent reasons deduced from experiment, by Sir David Brewster. On the same subject, the advocates of the undulatory or wave theory are equally at variance among themselves : for while Huyghens maintained that solar light is composed of only two elementary colours, yellow and blue, Hooke reduced all its modifications to red and violet; whereas Young reduced the whole to red, green, and violet.

What is still more remarkable, neither of the two great rival parties has ever yet attempted to ascertain the relations of light to caloric and electricity; nor in what way they perform so many wonderful effects in the moving drama of the universe. But if they be connected in action, they must be united in theory. And it will be a leading object of the following work to prove, by a careful generalization of facts, that caloric and electricity are mutually convertible into each other; consequently, that 
they are modifications of one and the same essence, which is the active principle in light, and in all the phenomena of nature.

Since the time of Sir Isaac Newton, it has been generally supposed that all the molecular changes of matter may be referred to attractive and repulsive forces. Yet the cause of attraction and repulsion has not been identified with any known principle capable of demonstration. The orbits of planets, and the times of their revolutions have been measured with mathematical precision; but the cause of their eternal motion has never been clearly distinguished from projectile and gravitating forces. The relative magnitudes of the particles or atoms of ponderable matter have been, to a certain extent, ascertained by the refined analyses of modern chemistry: yet the cause of chemical affinity is still confounded with inherent properties, occult qualities, and undefined powers. The composition of plants and animals has been discovered, and their intimate structure explored: yet the organizing principle remains a profound mystery. What was said by Descartes two hundred years ago, is equally true at the present day. " In Philosophia nihil adhuc reperiri, de quo non in utramque partem disputatur." 
It has been a complaint of long standing in the world, that nature has spread a veil over the first principles of things, which man can never hope to remove. But there is reason to believe that all the great truths of science which are of the highest importance for us to know, are no less remarkable for simplicity, than for the wide extent of their application ; and that when fully unfolded, they will be selfevident propositions. It is true enough, that the most familiar phenomena of nature, when viewed separately, or through the mystical interpretation of visionary theorists, are as " inscrutable as the scattered leaves of the Sibyl :" but when traced to their origin, the hidden meaning of every thing is gradually disclosed, and order springs from chaos. It was profoundly observed by Sir Edward Bulwer, that " the key to all mystery is the desire to know,"- -and that " there is only a single step from a truism to a great discovery."

If we are destined ever to arrive at a perfect theory of nature, it must be founded on a true history of the grand original, and a complete knowledge of the prime mover. Nor is it possible that men should avail themselves fully of the powers which are in nature, without knowing the cause of these powers. It 
was from the elastic force of the latent caloric that belongs to nitre, sulphur, and charcoal, that man, unconsciously, obtained the power of gunpowder; the invention of which has essentially modified the condition of the human race: for it thenceforward secured the uninterrupted progress of civilization, which can never again be arrested by the incursions of barbarous hordes, nor the light of knowledge be extinguished in embryo, as during the early periods of history. It was by discovering that a piece of metal called the loadstone, when horizontally balanced on a pivot, is constantly directed to certain points in the polar regions, that commerce and civilization have been extended to the remotest parts of the earth. But men have yet to learn that the same principle which directs the compass-needle to the poles, guides the planets in their orbits, and fills them with life.

It was by seizing the grand lever of nature as a moving agent, that man was enabled to create the steam-engine, which has brought about a more important revolution in the condition of nations, than all the united discoveries of antiquity for thousands of years. Nor can there be a reasonable doubt that a complete 
knowledge of the same agent, as it operates in all the phenomena of nature, would augment the resources of happiness a thousand fold-dispel the clouds of error which have so long hovered over the sciences, and enlarge the empire of man over the material world, in an endless variety of ways. It is animating to think how soon this grand result might be brought about, if all the talents now wasted on fruitless speculations were rightly employed in the study of nature.

It may be right to inform the Reader that a brief outline of the leading views contained in the following chapters was first promulgated by the Author in an Essay entitled " A New Theory of Terrestrial Magnetism," published at New York in 1833; and somewhat extended in a series of papers in the Knickerbocker Magazine of 1834-5. The Author also feels it due to himself, and to those friends who have been long expecting this Work, to state, that the first three books were originally intended to be published separately, and were actually printed in 1837 , the preliminary chapter excepted. But as more enlarged views of the subject opened to him, he clearly perceived that a development of the physiological and 
pathological laws of caloric was essential to the completion of his undertaking; which at that time he supposed would not require more than twelve months :-

" But more advanced, beheld, with strange surprise, New distant scenes of endless science rise."

The performance of this task required a vastly greater amount of laborious research than he was prepared to expect, until he had proceeded too far to desist. In the mean time he had the satisfaction of perceiving that, with every additional knowledge of facts, he was conducted to a more elevated point of view, and to more comprehensive generalizations: the consequence of which has been, that in the Preliminary Chapter, he has entered more fully into the rationale of geological and astronomical phenomena, than he had ventured to do in the second and third Books.

In addition to the many difficulties encountered at every step, much precious time was lost owing to ill health, by which the work has been still further and most painfully delayed,- to the disappointment of the Publisher, whose liberality and forbearance merit the grateful acknowledgments of the Author. 


\title{
GENERAL CONTENTS.
}

\author{
BOOK I.
}

Chap. II. On the Atomic Constitution of Matter, and the relative Quantities of Caloric in different Bodies... 46-96

Chap. III. On the Forces of Caloric in elastic Fluids.Theory of their Expansion and Contraction.-Constitution of Liquids $\ldots \ldots \ldots \ldots \ldots \ldots \ldots \ldots .97-155$

\section{BOOK II.}

Chap. I. Theory of Cohesion, Conduction, and Radiation.

$156-195$

Chap. II. Chemical Attraction in general ....... 196-224

Chap. III. Theory of Solution, and of Freezing Mixtures.

$225-252$

Chap. IV. Theory of Capillary Attraction, and the Connexion of molecular with aggregate Forces of Matter.

$253-279$

\section{BOOK III.}

Chap. I. Electricity - atmospheric, identical with the Caloric which causes Evaporation ............ 280-32 I

Cuap. II. Theory of Winds, and their connexion with Electrical Phenomena. - Rationale of Tornadoes, Hailstorms, \&c................... 321-347 
Chap. III. The Barometer.-Theory of Dew, Mists, Fogs, and of the Aurora Borealis............. 348-370

Criap. IV. Theory of Voltaic Electricity, and of Subterranean or Volcanic Forces ............... 371-417

Chap. V. Hypothesis of two Electric Fluids examined.Relations of Caloric and Electricity ....... 418-454

\section{BOOK IV.}

Chap. I. Life-History of ancient and modern Opinions concerning it.................. 455-506

Chap. II. Ultimate Elements of organized Bodies.-Why they unite into ternary and quaternary Compounds, so as to form living Tissues. - Spontaneous Generation.Theory of Animal Heat, as connected with Respiration.

$507-559$

Chap. III. Influence of Respiration on the Temperature and vital Energy of different Animals.-Cause of the Heart's Action, and of the Capillary Circulation $560-623$

Chap. IV. Theory of Digestion, Sanguification, Coagulation, Secretion, Nutrition, Muscular Motion, Sensation, and of Disease.-Analogies of the Macrocosm and Microcosm ....................... 624-689

\section{BOOK V.}

Cris. I. Influence of Climate on the physical, intellectual, and moral Character of the Human Race..... 690-728

Cir a P. II. Origin of Races, Nations, Languages, and Mythologies.-Unity of the Human Race, and of Organi. zation.-Longevity of Nations .......... 729-778 
Chap. III. Influence of Climate and Season on the Diseases of Mankind.-General Laws of Epidemics, and on the Nature of Malaria, or bad Air ........... 779-827

Chap. IV. Theory of Hybernation, suspended Animation, warm and cold Bathing............ 828-852

\section{BOOK VI.}

Chap. I. On Air and Exercise $\ldots \ldots \ldots \ldots \ldots \ldots$. 853-886

Chap. II. On Aliments,-Wine, Spirits, and Malt Liquors.

$887-937$

Chap. III. Theory of Sleep.-Influence of the Mind on Health.-Modus Operandi of Medicines and Morbific Agents ....................... 938-985

Chap. IV. Theory of Temperaments.-Of Hydrophobia, Tetanus, and other Spasmodic Diseases..... 986-1032

Cinap. V. Theory of Fever, Inflammation, and other Diseases,-with the best Methods of Prevention and Treatment ...................... 1033-1100 


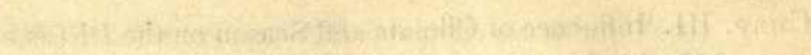

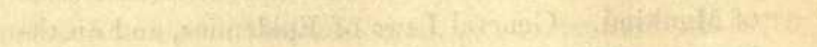

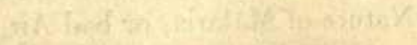

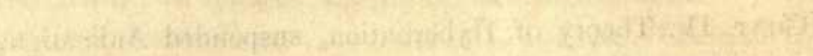

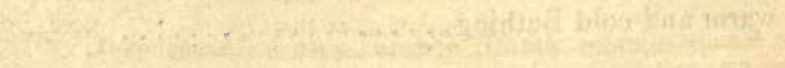

$$
\text { 1. } 12009
$$

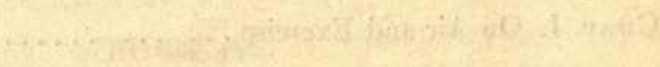

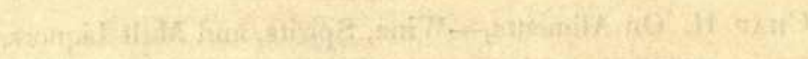

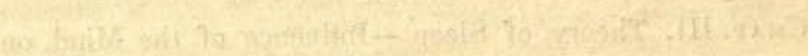

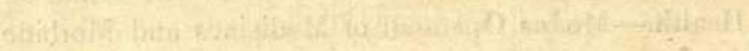

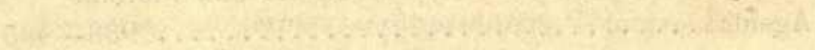

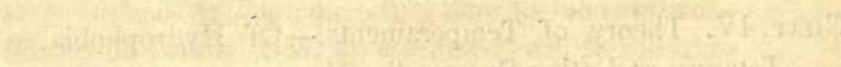

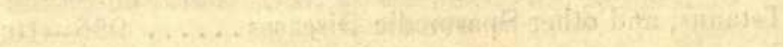

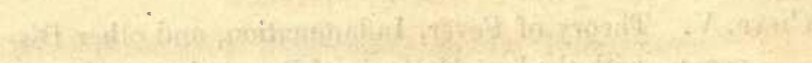
1. 


\section{CORRIGENDA.}

THe Reader is requested to observe, that, as the Preliminary Chapter, and the latter part of Chapter III. Book I. were cancelled after the Work was printed, some few of the subsequent references to them will be found not to correspond with the present paging.

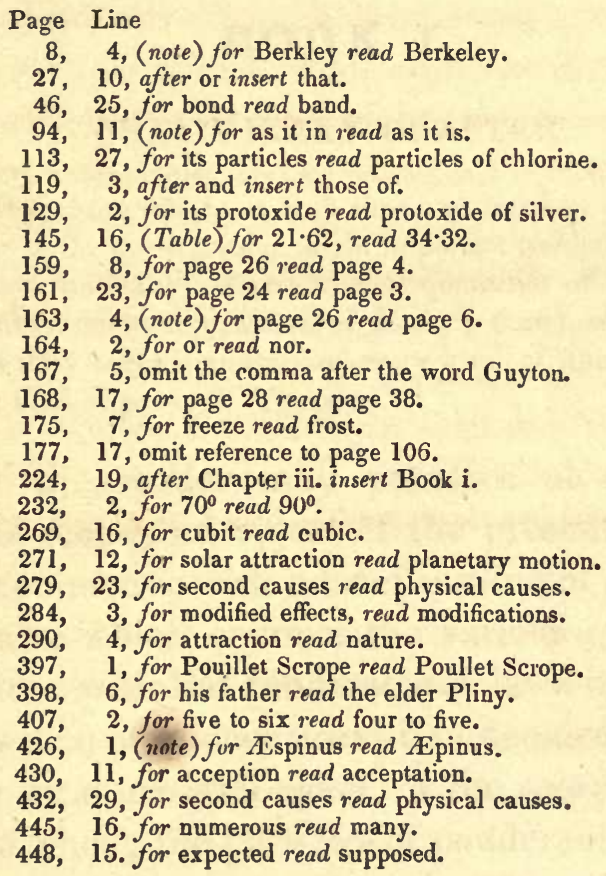





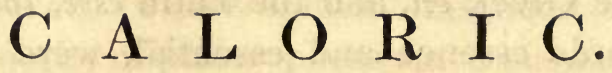

\section{BOOK I.}

\section{PRELIMINARY CHAPTER.}

" $\mathrm{O}$ that those who have both time and intellect at command adequate to the investigation, might in perfect tranquillity, search into nature, until they ascertain what quantities of heat are required to produce every action of matter; that mankind might then not only become masters of every kind of knowledge, but of every kind of power." Telesius.

That the reader may perceive at once the general scope and object of the present work, I shall commence with a brief outline of the leading facts, which connect the various operations of nature with the fundamental laws of caloric. But as men of science are still undecided whether caloric be a material agent, or the mere effect of motion among the particles of ponderable matter, it becomes necessary to examine the evidence on which these opposite views have been founded.

Among the most enlightened nations of antiquity, elementary fire was regarded not only as the most refined and spiritual of all the elements, but as a universal and self active principle, which they considered as identical with exist- 
ence or being. It has been amply proved by Bryant, Calmet, and other learned etymologists, that the Greek ssi, and the Latin esse, to be, like our words essence and essential, were derived from the Hebrew $\boldsymbol{E} E s h$ or $E s$, the fire; and that Vesta, the goddess of that element, had her name from the Chaldee אשתא Eshta or Esta. They have also shown that the word $A$ s $A m$ denoted both heat and existence, among the early Egyptians; who, believing it to be the cause of motion and organization throughout nature, inscribed it on the great door of one of their temples.

We are further informed by the learned and philosophical Parkhurst, that the sacred mystical letters In $I e$, which were inscribed over the door of the temple at Delphi, dedicated to Apollo, (who was a mythological personation of the sun or solar fire,) were taken from the Hebrew $\pi, Y e h$ or $Y a h$, signifying existence or being. Nor is it unworthy of notice, that the Greek $\pi v \rho$ fire, was derived from the Hebrew פור pur, to break, dissolve, and separate; actions which clearly imply mechanical and material agency. So much for the primitive meaning of words employed by the ancients to represent the essential nature of what is called heat, but which I shall generally denominate caloric, for the purpose of distinguishing the cause from the mere sensation of heat. Let us now examine the views which have been entertained by the moderns on this important subject. 
In the Novum Organum, and in his Treatise entitled De Forma Calidi, it was maintained by Lord Bacon, (whose opinion has been adopted by a majority of philosophers since his day,) that the very essence of heat is motion and nothing else. In accordance with this doctrine, Sir H. Davy observes, in his Chemical Philosophy, that " the cause of heat is motion, and the laws of its communication are precisely the same as the laws of the communication of motion." But in the Treatise on Life and Death, as also in his Natural History, Bacon maintains that "there is in every tangible body, a spirit or body pneumatical, which fills the pores of all gross bodies:-that it is not some virtue, or action, or trifle, but a real and quantitative substance, though rare, invisible, and without weight." Moreover, that this spirit or body pneumatical, was only another name for what Hippocrates and other Greek authors called $\theta \varepsilon \rho \mu o v$ heat, (and sometimes $\pi \nu \varepsilon v \mu a$ spirit,) is equally manifest from the fact, that Bacon represents it as the cause of evaporation, and of many other effects which are predicable of caloric alone. And Sir Humphrey Davy observes in his Agricultural Chemistry, that "whatever theory we adopt, it is certain that there is matter moving in the space between us and the heavenly bodies, capable of communicating heat." It is therefore evident, that neither of these distinguished men can be fairly ranked as advocates of the immaterial 
theory; and that, in reality, they had no fixed or settled opinions on the subject.

The authority of Sir Isaac Newton has been often cited in support of the doctrine, that caloric is not a material substance. But it is worthy of special notice, that in all the latest works of that great man on physical science, he maintains the existence of what he calls " an exceedingly subtile and elastic æthereal substance, which is diffused through all places, fills the pores of gross bodies, and forms a large constituent of their bulk or volume." In a letter addressed to the celebrated Boyle in 1678, the object of which was to explain his views of the æther, he represents it as " the cause of cohesion, capillary attraction, and of the force by which menstruums pervadeand dissolve solid bodies." Headds in another sentence, "I conceive the atmosphere to be composed of the particles of all sorts of bodies of which the earth consists, separated and kept at a distance from one another by the same active principle."*

* The above views were still further expanded in a scholium at the close of the second edition of the Principia, published in 1713 ; and in the form of queries, they were reiterated at the close of the Optics, published in 1717. In both of these great works, he represents the æther as the cause of gravity, cohesion, capillary attraction, solution, elasticity, the emission, reflexion, refraction, and inflexion of light. He also maintained that the æther is the cause of animal motion. Yet he observes, that he knows not what the æther is; and that "we have not that sufficiency of experiments which are requisite to an accurate determination of the laws by which this subtile spirit operates." 
But if the æther be the cause of solution, and of the elastic force of the atmosphere, it is manifestly identical with caloric. It is true that in the fifth query, towards the close of the Optics, Newton represents heat as consisting in a vibratory motion among the particles of bodies, - and that the whole theory of the Principia was founded on the hypothesis that space is a vacuum; which is certainly at variance with the foregoing views of the æther. It is also inconsistent with his doctrine of light, which he regarded as a material substance, perpetually flowing from the sun and fixed stars through space. But that caloric does not consist in mere motion or vibration among the particles of ponderable matter, would appear from the following considerations:-

1. That it may be added to and subtracted from other bodies, and measured with mathematical precision, as all good thermometers demonstrate :-

2. That it augments the volume of bodies, which are again reduced in size by its abstraction :-

But if Newton had traced the word æther to its primitive roots, he would have found that it was a Greek noun, which was derived from two Phœnician or Hebrew words, Ath or Aith the sun, and $U r$ fire, meaning the solar fire,-a discovery which probably would have modified all his physical investigations, and have given a totally new aspect to the whole circle of the Sciences. The truth is, that a complete Etymological Dictionary would sweep away innumerable misconceptions, errors, and metaphysical subtleties, which have gradually arisen from the revolutions in language, and the adoption of words, the primitive meaning of which has not been understood. 
3. That it modifies the forms, properties, and conditions of all other bodies, in an endless variety of ways :-*

4. That it passes by radiation through the most perfect vacuum that can be formed by means of the air pump, in which it produces the same effects on the thermometer as in the atmosphere:-

5. That it exerts mechanical and chemical forces which nothing can restrain, as in volcanos, the explosion of gunpowder and other fulminating compounds :-

* It was first ascertained by Dr. Black, that on mixing a pound of water at $172^{\circ} \mathrm{F}$. with a pound of ice or snow at $32^{\circ}$, the latter was melted, when the temperature of the mixture stood at $32^{\circ}$; showing that $140^{\circ}$ of caloric had been transferred to the ice, and intimately combined with its particles. Since then it has been found, as predicted by Black, that definite measures of caloric are required to convert all other solids into the liquid and gaseous states:-that when a pound of steam at $212^{\circ}$, is mixed with 7 pounds of ice at $32^{\circ}$, the latter is converted into water of the same temperature; showing that $7 \times 140$, or $980^{\circ}$ are thus transferred from the steam to the ice, and employed in melting it, without producing in it any elevation of temperature. This is what Black called the latent heat of water and steam. It has also been discovered, that a cubic inch of water at $212^{\circ}$, is expanded to the dimensions of a cubic foot, or about 1720 -fold on passing into the gaseous state,-proving that 1719 parts by volume of steam at the same temperature, are occupied by the caloric which surrounds its particles. The same fact is still more remarkably illustrated in hydrogen gas, the volume of which is nine times greater than that of the same weight of steam, ceteris paribus: so that above 15,000 parts of the space occupied by hydrogen, must be filled by that subtile form of matter called heat. 
6. That it operates in a sensible manner on the nervous system, producing intense pain, and disorganization of the tissues when in excess.*

But if caloric were a mere property or quality, how could it be taken from one body and added to another? Or if it augment the volume of other bodies, must it not itself have volume, occupy space, and therefore be a material agent ? Would it not be mere jargon to speak of the radiation, reflexion, convection, and conduction of a mere quality, or immaterial property? And if caloric were only the effect of vibratory motion among the particles of ponderable matter, how could it radiate from hot bodies without the simultaneous transition of the vibrating particles? But it is certain that when iron, copper, and other metals are heated to any temperature below the point of ignition; like boiling water, they give off caloric freely, without any sensible loss of ponderable matter.

* The same reasoning on which is founded all belief in the material existence of the outward universe applies equally to caloric. No metaphysical sophistry can refute the belief of mankind, that whatever operates in a sensible manner upon material organs, must be a material substance; for the obvious reason, that " there can be no virtue without substance," as maintained by Newton. It was an axiom among the ancients, that nothing can be said to exist, unless it can be recognized by the senses. " Nihil esse potest, nisi quod attigimus, aut vidimus." And it was observed by an able writer in the Church of England Review, that our words thing, and think, were derived from the Greek verb $\theta \iota \gamma \gamma-\varepsilon v$, to touch; that is, a thing is what we first 
It has been said, that " the material theory contains an inherent vice, by assuming the existence of a body, which has never been obtained in the separate form." But if caloric do not exist in a separate state while passing through a vacuum, all our reasonings about it are fallacious and unintelligible. Nor is it possible to explain in a simple and satisfactory manner, any single one of the phenomena ascribed to it by all parties, in accordance with the hypothesis that it is identical with motion, which is manifestly not an agent, but merely some body in the act of moving, and always implies the existence of a mover.

If the vibratory theory were true, caloric ought to be generated by all impulses which throw the particles of bodies into a state of violent agitation. But such is not the fact; for if the atmosphere, the ocean, and the solid strata of the earth, were kept in a state of perpetual tremor, their temperature would not be materially altered. The advocates of the immaterial theory have never explained what causes bodies to vibrate; nor what

touch, and then think upon. And he adds that all impressions on the senses are resolvable into touch. But there is nothing in nature which operates so powerfully on the sense of touch as caloric.

"When Bishop Berkley said there was no matter,

And proved it-'twas no matter what he said."

And when men say that caloric is not matter, they reject the evidence of their senses, subvert the foundation of all knowledge, and pave the way to universal scepticism. 
keeps the particles of solids, liquids, and gases, at a distance from each other while quiescent, or free from vibratory motion.* And it is worthy of special notice, that caloric is disengaged by pressure, friction, or percussion, only so long as bodies undergo condensation. For it has been

* It was supposed by Bacon, that the essential nature of heat is motion, and nothing else, because it accompanies the motion of friction, percussion, combustion, ebullition, violent exercise, \&c. Count Rumford was led to adopt the same opinion from the following experiments: Into a cannon weighing $113 \mathrm{lbs}$. and cast solid, he caused a hole to be bored 3.7 inches in diameter, and $7 \cdot 2$ inches in depth. Into this hole, he introduced a blunt steel borer, that was made to rub against the bottom by horse power, with a force equal to about $10,000 \mathrm{lbs}$. avoird., the cylinder being turned at the rate of thirty-two times per minute. At the expiration of thirty minutes, when the cylinder had made 960 revolutions about its axis, its temperature was found to have risen from $60^{\circ}$ to $130^{\circ} \mathrm{F}$. In another experiment, the cylinder was wrapped round with flannel to prevent the loss of heat, and inclosed in a wooden box containing $18.77 \mathrm{lbs}$. of water, which at the beginning was at the temperature of $60^{\circ}$. After the experiment had proceeded for an hour, it was raised to $107^{\circ}$, -in thirty minutes more, to $142^{\circ}$, -in two hours, to $178^{\circ}$, - and in two hours and a half, to $210^{\circ}$. At the close of the experiment, he found that 4145 grains of metallic dust and scales had been detached from the bottom of the cylinder by the rubbing of the borer, or above eight ounces. And as he found that the capacity, or what has been called the specific heat of the scales, was the same as that of an equal weight of solid iron, he arrived at the conclusion, that heat is not a material substance, but the mere effect of motion. (Philosophical Transactions, 1798.) But it will be shown hereafter, that what is called capacity or specific heat, is not a measure of the quantity in different bodies; and that this mode of estimating their latent or combined caloric is fallacious. 
proved by the experiments of Berthollet, Biot, and Pictet, that when pieces of gold, silver, and copper of the same size and shape, are suddenly and forcibly struck, as when stamped in the process of coining, they were condensed, and caloric evolved, but more by the first than second blow; whereas after the third blow, when they had arrived at the limit of condensation, there was no perceptible increase of temperature. (Thomson on Heat and Electricity, p. 339.)

In accordance with these facts, it is well known that the smith often kindles his furnace by hammering a piece of iron until it becomes red hot, without any material loss of metallic dust or scales; and that after he has reduced it to the limit of condensation, it becomes cold under the hammer. It is therefore evident, that caloric is not generated de novo, by the friction of rubbing dry sticks of wood against each other, the pressure of wire drawing, and by rubbing the hands together; but that it is merely forced out of the pores of bodies, in the same way that water is disengaged from the pores of a sponge by pressure. And it will be proved hereafter, that the caloric which is disengaged by rubbing the hands together briskly, is resupplied by the rapidly circulating blood, which obtains it by respiration.

Should it be urged that caloric is disengaged by rubbing two pieces of ice together in the vacuum 
of an exhausted receiver, as in the experiments of Sir Humphrey Davy, I answer that there is an enormous amount of caloric locked up in a state of chemical combination with ice, as shown by the rapidity with which it melts frozen mercury, nitrate of potass, chloride of lime, chloride of sodium, and many other salts which have a strong attraction for caloric. There is, therefore, no good reason why caloric should not be separated from ice by friction as well as from other solid bodies. And it may be asserted with confidence, that if all the latent caloric contained in a pound of ice could be transferred to the same weight of gold, silver, iron, or copper, it would raise them to a red heat, and perhaps convert them into flame, or incandescent luminous vapour.

That the particles of all bodies are surrounded by an elastic medium, which prevents their actual contact, is evident from their compressibility. And that this medium is caloric is proved by the facts already stated, that it augments the volume of solids, liquids, and gases, which are again reduced to their former dimensions by abstracting what was before added; and by the large amount of heat that is disengaged by friction, which is transitive pressure, or by percussion, which is sudden pressure; both of which cause condensation. It was estimated by Sir Isaac Newton, that the pores of gold occupy about the same space as 
its solid atoms; and that in water, the pores are about forty times greater than its solid particles. (Optics, Book ii. p. 242.) If then it be true, that all bodies are full of caloric,-that it occupies 827 parts by volume of the atmosphere, and 1719 parts of steam, it must be obvious that it constitutes by far the greater proportion by bulk, of the solid globe we inhabit. And if when intimately combined with the particles of ponderable matter, its thermal properties are disguised or hidden from the senses, the same thing is true of water and the strong acids, the individual properties of which are concealed while they are in a state of chemical union with rocks, salts, \&c.*

Having thus proved that caloric is a material agent, I now proceed to show that it is a selfactive principle, capable of moving itself, and of generating motion in all other bodies. The cardinal facts which connect its agency with the general theory of physics, may be reduced to the following propositions :-

1. That the activity or moving power of all

* The above facts will enable us, in some measure, to comprehend the theory of opacity and transparency, the cause of which, Sir John Herschel thinks, has never yet been satisfactorily explained. For as it is well ascertained that the particles of the atmosphere, steam, gases, water, saline and metallic solutions, like glass, and a great variety of crystalline solids, are arranged in regular series, at considerable distances from one another, the rays of light pass through them with slight interruption, giving rise to the phenomena of transmission and what is called transparency. But when the regular arrange- 
bodies, is directly in proportion to the amount of caloric around their particles:-

2. That all molecular motions, whether centrifugal or centripetal, may be resolved into the law by which caloric repels its oun particles, and attracts those of ponderable matter, with forces that vary inversely as the squares of the distance:-

3. That the quantity of motion in the world, whether mechanical, chemical, or vital, is in proportion to the mean temperature of different latitudes, ceteris paribus, and diminishes from the equator to the poles:-

4. That the centrifugal force by which planets are impelled through their orbits, is directly in proportion to the heating power of the sun; and like gravitation, is inversely as the squares of the distance:-

5. That the aggregate vital energy of animals, and the developement of their organization, are ex-

ment of the particles of ice, glass, quartz, and other crystals, is disturbed by unequal pressure, or unequal expansion by caloric, the rays of light are transmitted imperfectly : and if their symmetrical structure be broken down or deranged, as when they are reduced to powder, their power of transmitting light is so far destroyed, that they are rendered opaque. Sir Isaac Newton supposed that opacity was owing to the largeness, and transparency to the smallness of the particles and intervening pores of bodies. (Optics, B. ii. p. 235.) But many salts, rocks, and metals, are transparent when dissolved in water and the strong acids, although their particles are much larger than those of common ink and many other bodies which are black and opaque. 
actly in proportion to the amount of caloric obtained by respiration, and combined with their tissues:-

6. That every variety of electricity is convertible into caloric, and the latter again into electricity; consequently, that they are modifications of one and the same principle:-

7. That the directive power of the compass needle diminishes from the isothermal equator to the points of lowest mean temperature, which are the magnetic poles; and that all its variations correspond with the variations of terrestrial temperature:-

8. That caloric is the active principle in light, whether radiated from the sun, or generated by ordinary combustion, friction, percussion, phosphorescence, or the electric discharge.

That caloric is a self-active principle, might naturally be inferred from the fact, that every change in the temperature of bodies is attended with motion among their particles. It has also the power of moving from one place to another, and even through the vacuum of an air pump, without any projectile impulse from the particles of ponderable matter; as when it radiates from hot bodies. And that it has the faculty of generating motion among the particles of other matter, would appear from all the phenomena of nature with which we are best acquainted.

For example, under the ordinary pressure of the atmosphere, and at, or a little below the temperature of $32^{\circ}$, the particles of water exist in the 
solid and apparently fixed state. But if $140^{\circ}$ of caloric be added, their mobility is so far increased that they glide freely over one another, and assume the fluid form. If more be added, their activity is still further augmented by every degree of temperature, up to the boiling point, when the whole is found to be in a state of rapid intestine motion. And if at this stage of the experiment, the water be kept over a furnace, until it has received about $1000^{\circ}$ more of caloric, the boiling liquid is converted into steam, the moving force of which is exalted by every addition of this active principle, which has the power of converting all other bodies from solids into liquids, vapours, gases, and flame, or luminous incandescent particles.

If then it be true, that caloric alone gives to the quiescent particles of ponderable matter powers of motion which they do not possess without it; and that their mobility is augmented by every addition, and diminished by every abstraction of the igneous principle-it follows with all the clearness of absolute demonstration, that in the total absence of caloric, if such a condition were possible, the universal system of nature would be a motionless mass of inert and chaotic matter. It also follows, that every thing in nature is composed of two descriptions of matter, the one essentially active, and the other passive; as maintained by many of the most distinguished 
philosophers of ancient Greece. Here is the foundation of all physical logic, and a key to the whole mechanism of nature. For as it is certain that all the changes and transformations of matter are the immediate effects of motion, it follows that a complete knowledge of the prime mover would lead to a perfect theory of physics.

Since the time of Sir Isaac Newton, attraction and repulsion have been generally regarded as ultimate principles of action, for which no reason can be assigned.* But if it be a fact, that the elastic force of bodies is augmented by every addition, and diminished by every abstraction of caloric, it is obvious that the entire privation of

- After referring to his theory of planetary motion, Newton observes in his Preface to the Principia,- "many things induce me to suspect, that all the rest of the phenomena of nature may depend upon certain forces, by which the particles of bodies, by some causes hitherto unknown, are mutually impelled towards each other in regular figures, or are repelled and recede from one another; which forces being unknown, philosophers have hitherto attempted the investigation of nature in vain." Sir H. Davy also observes, that " the various forms of matter, and the changes of these forms, depend upon active powers, such as gravitation, cohesion, calorific repulsion or heat, chemical attraction, and electrical attraction." (Chemical Philosophy, p. 67.) Dr. Arnott further states, that " attraction and repulsion are ultimate facts, which admit of no explanation in the present state of science." (Elements of Physics.) And Sir John Herschel adds, that "we have no means of further analyzing the phenomena of cohesion and elasticity, but must regard them, until we see reasons to the contrary, as ultimate phenomena, referable to the direct agency of an attractive and repulsive force." (Introduction to the Study of Nat. Philosophy, s. 80.) 
it, would destroy the repulsive power of their particles. And as we have seen, that without caloric, they could have no power of motion, it is evident that they could neither approximate nor recede from one another; consequently, that both attraction and repulsion are modified effects of one and the same agent. Moreover, if it can be proved that this agent is every where present-in the pores of bodies, as in the stellary spaces-and cannot be traced to any more comprehensive principle-it must be allowed to possess all the attributes of a primary efficient cause. For, nothing can merit the title of a vera causa, unless it be something which has the power of moving itself, and of generating motion in other bodies.

It is equally evident, that whatever the cause of attraction and repulsion may be, it must determine all the phenomena of cohesion, chemical affinity, crystallization, elasticity, ${ }^{*}$ decomposition,

* If the particles of the atmosphere and other bodies were not surrounded by caloric, there could be no vibrations, (in which heat has been supposed to consist,) therefore no sound. And here it is worthy of notice, that the velocity with which sound is propagated through different media, is directly in proportion to their elasticity, ceteris paribus. For example, it travels through the atmosphere when at the temperature of $32^{\circ}$, at the rate of 1090 feet per second; but when at $62^{\circ}$, it travels 1125 feet per second. It also moves at the rate of 3375 feet per second through hydrogen gas, which contains a much larger amount of caloric around its particles, than the same weight of atmospheric air, or any other gas, as will be shewn hereafter. In accordance with the above facts, it is well known that sound is transmitted more 
and recombination. When I come to treat of the mode in which caloric produces opposite effects, it will be found that in certain proportions it causes the particles of ponderable matter to separate, while in other proportions it forces them to unite:-that the aggregate force of attraction by which it tends to unite with the particles of gross matter, holds them together, and maintains the earth in the globular form :-in short, that all the phenomena of nature may be referred to the law by which caloric repels its own particles, and attracts those of ponderable matter.

That the quantity of evaporation and rain throughout the earth is in proportion to the heating power of the sun, ceteris paribus, would seem to be a self-evident proposition. And it will be shewn hereafter from numerous scientific observations, that the annual average amount

distinctly, and rapidly, through light and resinous, or the more combustible species of wood, than through such as are dense, less elastic, and thercfore contain less of the elastic æther termed caloric. It also moves with greater velocity through water than glass, and more swiftly through either than through rocks and metals, if we make allowance for the greater density of the latter. For it was found by MM. Biot and Colladon, that it was transmitted through water at $46^{\circ}$, at the rate of 4704 feet per second; and through cast iron at $61^{\circ}$, at the rate of 11,090 feet per second. But the specific gravity of cast iron is nearly eight times that of water. And we shall find that it contains a far greater amount of caloric around its particles than the same weight of iron, although less than an equal bulk of iron. 
of rain within the tropics, except in desert places, is about 100 inches, or three times greater than in the middle latitudes; and about nine times greater than in the polar regions. Hence the enormous size of the tropical rivers, compared with those of the higher latitudes. For example, it has been found that the Orinoco, which drains only 400,000 square miles of territory, discharges more water into the sea than the Mississippi, which drains $1,350,000$ square miles.* It will also be shewn, that the quantity of lightning throughout the earth, diminishes from the torrid zone; where during the rainy season, it occurs almost every day, for nearly half the

* It has been estimated by geographers, that about thirty-three cubic miles of water are discharged daily into the sea by all the rivers of the earth. So that if this calculation be correct, or even an approximation to the truth; and if the same proportion of rain falls into the sea as on a given area of dry land, it follows that nearly 140 cubic miles of water must be carried into the atmosphere every twenty-four hours, and again precipitated in the form of rain and snow. Such are the vast forces which caloric is continually exerting in the phenomena of meteorology, without any reference to those violent commotions of the atmosphere termed hurricanes, tornadoes, and other less impetuous winds. Nor is it unworthy of passing notice; that as the quantity of water diffused through the atmosphere is in proportion to the heating power of the sun, the barometer stands higher, on an average, within the tropics than in the middle or polar latitudes; as proved by the observations of Erman, laid before the French Academy of Sciences, - after my chapter on the barometer had been printed. More water is also converted into steam during the heat of the day, and more steam is condensed into water during the coldness of night, which is the most convenient period for rain, as it does not then impede the labours of husbandry. 
year,--on to the polar regions, where it scarcely ever lightens.

But were it not for the union of caloric with the particles of ponderable matter, there could be no fluidity of the ocean, which would be stationary as the solid frame-work of the mountains. Were it not for the heating power of the sun, there could be no contractions and expansions of the atmosphere, therefore no winds, nor fluctuations of the barometer. But in the present order of things, not an atom of the great aerial ocean is wholly quiescent for a single moment of time. Its tropical portions being constantly expanded by the influence of a vertical sun, rise and give place to the denser air of colder latitudes; by which a perpetual circulation is kept up, as described in the 1st chapter of Ecclesiastes, v. 6. "The wind goeth toward the south, and turneth about unto the north: it whirleth about continually, and returneth again according to its circuits."

If the earth were of uniform surface and elevation, there would be a gradual diminution of temperature from the equator to the poles, and the winds would be as regular as the movements of the heavenly bodies. But owing to the present distribution of land and sea, mountains and valleys, plains and woods; the temperature of the globe is infinitely diversified, even in the same latitudes; by which the phenomena are rendered proportionally complex. And as the changes of 
weather depend chiefly on the direction of winds, they cannot be predicted with invariable accuracy, without knowing all the circumstances which modify the temperature of different and distant places. It is not therefore surprising that meteorology has never been reduced to the certainty of an exact science.

Were it possible to compute the aggregate forces of caloric in all the mechanical, chemical, and vital transformations which are for the most part unobserved, we should be astonished at the result.* But men are so accustomed to the regular course of nature, that they are less aroused by the grandeur of the sun, rising in pomp and might, filling the world with beautiful creations, and diffusing everywhere the spirit of gladness, than by a passing meteor of the night.

That the whole theory of geological dynamics is in some way immediately connected with the agency of caloric, is now generally admitted by

* It is in the torrid zone that nature exults in the plenitude of her powers in modifying the surface of the earth,- where the forces of the volcano, the earthquake, and of universal chemistry, are surpassed only by those which wheel the planets through their orbits. For example, we are informed by Captain Burnes, that during the Cutch earthquake of 1819 , the Delta of the Indus was elevated about ten feet, over an area of fifty miles in length, and sixteen in breadth, in some places. We also learn from Mr. Lyell's excellent work on Geology, that during the shocks of 1822 in South America, the coast of Chili was raised about four feet, over an area of 100,000 square miles. And it is well known that similar movements are constantly taking place in different parts of the earth, or beneath the ocean. 
philosophers. But the general fact to which I would here invite attention is, that the number of volcanos and the forces they exert are in proportion to the heating power of the sun.* For example, among the 200 volcanos now in action in different parts of the earth, about one half are confined to the tropical regions. In the island of Java alone, Mr. Lyell says there are thirty-eight : and there is about the same number in other tropical portions of the old world. Between latitudes $10^{\circ}$ and $15^{\circ}$, in the Provinces of Guatimala and Nicaragua in South America, there are twenty-one; while in Peru, between latitudes $14^{\circ}$ and $20^{\circ}$, there are sixteen; and $I$ know not how many in the West Indies.

Again; that the subterranean forces by which the dry land has been elevated from beneath the ocean, have in all past ages been in proportion to the heating power of the sun, would appear from the relative heights of the earth in different latitudes. Nearly the whole of tropical America

* In every point of view, a complete theory of volcanos is of fundamental importance: for they regulate the distribution of land and sea, the magnitude and elevation of continents, the diversities of temperature in given latitudes, the character of rivers, and modify the direction of winds, which are impeded or deflected by mountain ranges. They are also the great terrestrial laboratories in which most of the precious gems are formed,-in which carbon is liquified, and by slowly cooling under an immense pressure, assumes the crystalline form of that beautiful ornament the diamond, which has been aptly designated as " a lump of light." Nor is it unworthy of notice, that all the richest gems and metals have been found in greatest abundance in the tropical mountains, or among the materials washed down from them by rains, rivers, and springs. 
for 3,000 miles in length, and several hundred in width, is one great system of mountains, separated by plains, which, within the tropics, are from twelve to fifteen thousand feet above the sea. Near the equator, Sorato and Illimani tower to elevations of 25,400 , and 24,350 feet, according to the measurements of General Pentland. As we proceed northwards towards Mexico, the loftiest peaks are those of Chuquibamba, Gualatiere, Sahama, Cotopaxi, Sierra, Antissana, and others, which vary from 19,000 to 22,000 feet, until we arrive at the table lands of Mexico, which, between latitudes $19^{\circ}$ and $24^{\circ} \mathrm{N}$. are from six to 8,000 feet above the sea.

As we advance through the middle latitudes of North America, the rocky mountains average about 10,000 feet. And if we except St. Elias and Mount Hooker, they never exceed 12;000 feet. Nor do the table lands which slope from their base exceed from three to 5,000 : while it is well known that from latitude $60^{\circ}$, the elevations diminish on to the polar sea. On the other side of the equator, the highest mountains of Chili are the Acongagua and Descabezado, which, between latitude $32 \cdot 28^{\circ}$ and $35^{\circ} \mathrm{S}$. rise to elevations of 23,200, and 21,100 feet,-from which they all diminish on to Patagonia, and thence to Cape Horn.*

* It is said that Captain C. Ross has recently discovered in S. lat. $80^{\circ}$ a mountain 12,400 feet high. But a few such exceptions are too slight to invalidate the general law. 
If we turn to the old world, we shall find that there is not a single mountain chain of the first magnitude throughout the middle latitudes of Asia, Europe, New Holland, nor the islands of the sea:-that, as in South America, the highest plains of India, between latitude $24^{\circ}$ and $32^{\circ}$, are from twelve to 15,000 feet; while the Himalayas rise to elevations of from twenty-three to 26,862 feet :- that the long chains of the Altai, which extend across Europe and Asia, in about the latitude of $50^{\circ}$, are generally from six to 8,000 , and rarely exceed 15,000 feet:- that the mountains of western Europe also diminish in height from the Alps, the Appennines, and the Pyrenees of the south, to the Carpathians, the Dofrines, and Urals of the north; which rarely exceed 6,000 feet:- that the vast plains of central Asia, between the Altai and Himalaya mountains, are from three to 5,000 feet above the level of the sea; while the plains of Siberia decline gradually on to the polar ocean:-that in Greenland and Spitzbergen the average height of the mountains is about 5,000 feet; while Hecla in Iceland is only 4,980 feet.

If the mountains of Africa are less elevated than those of southern Asia and tropical America, they are far more numerous, and the amount of high table lands is much greater than in any other quarter of the globe. Extending from the equator to $34^{\circ} \mathrm{S}$. and $37 \frac{1}{2}^{\circ} \mathrm{N}$. its central plateaus are supported by an immense chain that crosses 
the continent from west to east; between which and its southern extremity, there are three other parallel ranges that diminish in height on to the Cape of Good Hope. The vast plains of Abyssinia and Nubia are also several thousand feet above the ocean, and supported by innumerable mountains of still greater magnitude than those of Atlas in the west; while the eastern coast is flanked by a chain which extends, with few interruptions, from north latitude $10^{\circ}$ to $32^{\circ} \mathrm{S}$. But it is evident that the elevation and extent of table lands, (which are in fact widely extended mountains,) afford a far more accurate measure of geological forces, than the height of a few isolated peaks.

From the foregoing brief outline we perceive, that all the highest mountains of the earth are found within $32^{\circ}$ of the equator : and, what is still more important to observe-that the average elevation of the table lands is about equal to that of the mountains in the middle latitudes, where again, the table lands are of nervly the same height as that of the polar mountains. The conclusion is therefore irresistible, that the aggregate force by which mountains, islands, and continents, have been raised, from beneath the ocean, like all the chemical transformations on the surface of our planet, is in proportion to the heating power of the sun, ceteris paribus.

And that the same law prevails throughout the planetary system, would appear not only from 
analogy, but from a series of telescopic observations continued for ten years on the surface of Venus, by the celebrated Schröeter, who has estimated the height of its principal mountains as varying from $10 \cdot 84$ to 22.05 . miles. So that after making due allowance for the uncertainty of such observations, it is probable that he has arrived at an approximation to the truth. For, as Venus is 1.40 times nearer to the sun than the earth, and as the heating power of the sun is inversely as the squares of the distance, Venus must receive more caloric than a given area of the earth, in the ratio of $1 \cdot 96$, or nearly as 2 to 1 , because the square of 1.40 is 1.96 . For the same reason, as the heating power of the sun is 6.959 times greater at Mercury than on the earth, which is 2.638 times farther from the sun, the mountains of Mercury ought to be of corresponding magnitude. And as Mars is 1.494 times farther from the sun than the earth, he must receive $\mathbf{2 \cdot 2 3 2}$ times less caloric; which must proportionally modify all the conditions of his surface. In like manner, as Jupiter is $5 \cdot 157$ times farther from the sun than the earth, he must receive 26.594 times less caloric. And so on to the extremity of the solar system.

But in estimating the changes which the surface of our planet has undergone during long geological epochs, we must not overlook the influence of variations in the inclination of the 
earth's axis, in modifying the mean temperature of different latitudes. It is generally supposed to have been demonstrated theoretically by Laplace, that the total variation of the planetary inclinations must be comprised within the narrow limits of $3^{\circ}$. That in so vast and complicated a problem as that of perturbation, geometers may have overlooked some important elements in their calculations, would seem highly probable from the limited period since which accurate observations have been made; for they admit that the disturbing influence of all the planets and their satellites upon each other is such, that millions of years are required to bring about one cycle.

But if it were wholly impossible to determine the exact amount of variation in the planetary inclinations, during the countless ages that have past, geology affords the most conclusive evidence, that at some remote period of the earth's existence, the inclination of its axis must have been far less than at present; or the equator and poles must have been reversed. For it has been discovered that the secondary formations at Melville Island, and other parts of the polar regions, are filled with the fossil remains of plants and animals, which could have been produced only in a warm climate; and that the newest tertiary deposits in Siberia, abound with bones of the Mastodon or mammoth, which seems to have been as common in the higher 
latitudes of Asia and America, as elephants are now within the tropics. The conclusion is therefore undeniable, that a warm climate once prevailed in the arctic regions, and, perhaps, at several distant periods of time. Nor is it possible to account for such a state of things without supposing that in the progress of long geological epochs, the inclination of the earth's axis has undergone very great changes.

That this inclination is now actually diminishing at the rate of one minute in $126 \frac{1}{4}$ years, is admitted by all astronomers. It therefore follows, that if it should go on decreasing in the same ratio, without any oscillations or retrogradations, it would wholly vanish in about 177,760 years, when the sun would shine upon every part of the earth with nearly the same force, and produce a grand physical millenium, * or what may betermed

* In the tenth book of the sublimest song in our language, Milton represents the earth as enjoying this happy exemption from winter, before the fall of man : after which, the Creator

" Bid his angels turn askance

The poles of earth twice ten degrees and more:

* * * * to bring in change

Of seasons to each clime; else had the spring

Perpetual smiled on earth with verdant flowers.

These changes in the heavens, though slow, produced

Like change on sea and land.

Beast now with beast 'gan war, and fowl with fowl, And fish with fish; to graze the herb all leaving,

Devoured each other." 
a vernal period of the great year. For although there would be perpetual summer at the equator, and a gradual diminution of temperature on to the highest latitudes, there would be no winter. In short, the days and nights would be every where of the same length, except immediately around the poles, which would be always illuminated, and there would be no variety of seasons, but an unceasing verdure would everywhere prevail. And that the earth may have frequently passed through such a state, is highly probable from the fact, that at the present moment, the axis of Jupiter has very little if any inclination. And that this inclination has an extensive range of variation, would further appear from the fact, that in the case of Saturn it is now $28^{\circ} 40^{\prime}$, while in that of Mars it is $30^{\circ} 18^{\prime}$, according to Sir John Herschel. There is therefore no obvious reason why the inclination of the earth's axis should not go on augmenting until it arrives at the same angle.*

* In reality, it is more in accordance with analogy to suppose that this variation may pass through an entire revolution, than that it is confined within the narrow limits of $2^{\circ}$ or $3^{\circ}$. Should such a revolution go on uniformly at the rate of $48^{\prime \prime}$ in a century, its completion would require a period of $2,700,000$ years,- unless interrupted by a conjunction of all the planets; an event which the ancients regarded with dread, as the cause of deluges, or some other signal catastrophe. We are informed by Mr. Samuel Davis, that, according to the Surya Siddhanta, the oldest Hindoo work on Astronomy, the obliquity of the ecliptic was $24^{\circ}$, when it was written; which must therefore have been 4000 years before the 19 th century. (Asiatic Researches, vol. ii.) 
But are we not further authorized to conclude, that the equator may have gradually shifted to the middle and even the polar latitudes? This hypothesis would enable us to explain the high and uniform temperature which prevailed throughout the northern hemisphere when the higher latitudes abounded with tropical plants and animals, a great physical fact which cannot be satisfactorily accounted for in accordance with the theory of Laplace. The truth is, that his mathematical reasonings were founded on the supposition that all the planets move in nearly the same plane; whereas it is now admitted by astronomers, that the orbit of Pallas is inclined to the ecliptic at an angle of $34 \frac{1}{2}^{\circ}$, and that of two satellites of Uranus at an angle of $78^{\circ} 58^{\prime}$. But these cosmical bodies had not been discovered when the Mecanique Celeste was written; nor had Geology then taken its legitimate rank among the Sciences.

This brings us to the general theory of planetary motion. The leading facts of the solar system which connect the movements of the heavenly bodies with the agency and laws of caloric, may be reduced to the following propositions.

1. That the sun is 882,000 miles in diameter, and revolves on his axis from west to east, in about twenty-five days.

2. That planets revolve around the sun, satellites around planets, and all of them upon their 
axes, in the same direction that the sun moves upon his axis.

3. That the heating power of the sun diminishes in proportion as the squares of the distance increase.*

4. That the centrifugal force by which planets and their satellites are impelled through their orbits diminishes in proportion as the squares of the distance from the centres of power increase.

5. That the centripetal force by which planets are impelled towards the sun, and satellites

* For example, as Mercury is 1.888 times nearer to the sun than Venus, he receives more caloric than Venus, in the ratio of 3.564 to one; because the square of 1.888 is 3.564 . And as Mercury is 2.638 times nearer to the sun than the earth, he receives 6.959 times more caloric, or the square of 2.638 . For the same reason, as Mercury is 3.944 times nearer to the sun than Mars, the latter receives 15.555 times less caloric: Ceres 25.157 times less; Jupiter, 185.259 times less on a given area; Saturn 625 times less; and Uranus 2500 times less. Or, if we take our own planet as the standard of measure, the heating power of the sun is 2.232 times greater at the earth than at Mars, because he is 1.494 times farther from the sun; $7 \cdot 371$ times greater than at Ceres; 26.594 times than at Jupiter; 89.737 times than at Saturn; and 358.988 times greater than at Uranus. But as the planets are impelled through their orbits by two equal and opposite forces that unite in support of each other, the velocities do not diminish at the same rate as their mean distances from the sun: for while Jupiter is $5 \cdot 157$ times farther from the sun than the earth, his velocity is only about $2 \cdot 30$ times less. In like manner, although Saturn is nearly $9 \frac{1}{2}$ times farther from the sun than the earth, his velocity is only about three times less; and so of all the other planets, as may be readily ascertained by comparing the times and distances in the following Tables, constructed from data furnished by Sir J. Herschel. (Treatise on Astronomy.) 
towards their primaries, diminishes in the same ratio.

6. That by the joint operation of two forces, each of which varies inversely as the squares of the distance, the celestial bodies are impelled through their orbits with velocities which vary in accordance with Kepler's third law, as shown in the following tables:

\section{TABLE 1.}

\begin{tabular}{|c|c|c|c|c|c|}
\hline & $M e$ & & nes. & es & \\
\hline & fro & $d$. & $m$. & & \\
\hline & 36 & 88 & 0 & $0 \ldots 10$ & 3 \\
\hline & & 224 &.. & & \\
\hline$\ldots$ & & 365 & $6 \ldots 0$ & & \\
\hline 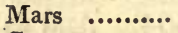 & 142 & 687 & 0 & & 4,18 \\
\hline & 260 & 1681 & $\ldots$ & $0 \ldots 4$ & \\
\hline$r$ & 490 & 4332 & $\ldots 14$ & $0 \ldots 2$ & \\
\hline & 90 & 10759 & ... 5 & $0 \ldots 2$ & 00 \\
\hline us & 1800 & & ... 20 & $0 \ldots 15$ & \\
\hline 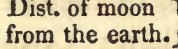 & th & 27 & $7 \ldots 43$ & 2,20 & 2,160 \\
\hline
\end{tabular}

TABLE II.

SATELLITES OF JUPITER.

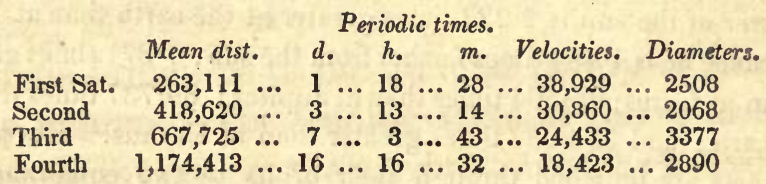

TABLE III.

SATELLITES OF SATURN.

Mean dist. d. Periodic times. Velocities.

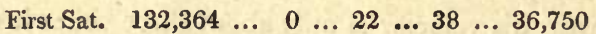

$\begin{array}{llllllllll}\text { Second } & 169,850 & \ldots & 1 & \ldots & 8 & \ldots & 53 & \ldots & 32,503\end{array}$

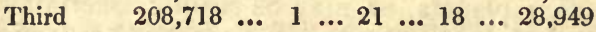

$\begin{array}{lllllllllll}\text { Fourth } \quad 269,350 & \ldots & 2 & \ldots & 17 & \ldots & 45 & \ldots & 25,739\end{array}$

$\begin{array}{llllllllll}\text { Fifth } \quad 376,198 & \ldots & 4 & \ldots & 12 & \ldots & 25 & \ldots & 21,802\end{array}$

$\begin{array}{llllllllllll}\text { Sixth } \quad 872,199 & \ldots & 15 & \ldots & 22 & \ldots & 41 & \ldots & 14,320\end{array}$

$\begin{array}{llllllllll}\text { Seventh } & 2,542,180 & \ldots & 79 & \ldots & 7 & \ldots & 55 & \ldots & 8,389 \cdot 5\end{array}$ 
Three of the asteroids, and the satellites of Uranus, have been omitted, because their elements have not yet been fully ascertained. The third column in the tables was obtained by multiplying the distances by 2 ; which gives the diameter of the orbits. On multiplying this by $3 \cdot 1416$, and dividing the product by the periodic times, we get the velocities with a sufficiently near approximation to the truth for our present purpose.

After the establishment of the true solar system by Copernicus,* the invention of the telescope, and the discovery of Jupiter's satellites by Galileo, the most important advance ever made in Astronomy was that of the immortal Kepler, announced in a work entitled "Harmonice Mun$d i$," published in 1619. In that work, he demon-

* We are informed by Aristotle and Plutarch, that the sun was recognized as the centre of our system by Pythagoras, who learned it in Egypt. There is also reason to believe that some of the early Chaldean astronomers were acquainted with the same theory. But as it was unknown to all the Greek philosophers, except Pythagoras, or was rejected by them, the knowledge of it must have been always confined to a very small number of the ancients. It is stated by Josephus, that an imitation of the sun, moon, and five planets, was represented in the Jewish Tabernacle; and the general system of nature, on the robes of the high priest: that his mitre was a symbol of heaven; (as it was of the sun among the Egyptians;) his breast-plate of the earth in the centre of the universe; the twelve stones set in it, of the twelve zodiacal signs; and the ephod of the four elements. (Jewish Antiquities, Book iii. Sect. 7.) 
strated that " the squares of the periodic times of any two planets are to each other, in the same proportion as the cubes of their mean distances from the sun,-a law which has been found equally true of satellites and their primaries,-if we except the mutual influence they exert upon each other, termed perturbation. It also led to the important discovery of Newton, that every particle of matter in the universe attracts every other, according to the law of the inverse square of the distance;-a law which, independent of all hypotheses in regard to the cause of motion, was one of the highest generalizations ever made in the science of Nature.

In regard to what is called Newton's first law of motion, various and opposite opinions have been entertained. By Leibnitz and other philosophers of the last century, it was rejected as hypothetical. According to this law, as announced in the first book of the Principia, " every body perseveres in its state of rest or of motion, unless compelled to change that state by forces impressed thereon." On this law was founded his theory of planetary motion, as developed in the third book, in which he maintains, that when first created, the earth and heavenly bodies were projected into empty space, by the agency of a primitive impulse, communicated at various distances from their centres of gravity; by which their annual and diurnal revolutions have been 
ever since maintained, without any renewal of the cause.*

But in all the operations of nature with which we are best acquainted, force is always expended in producing motion; and if not as constantly renewed, is very soon exhausted. Nor have we the slightest proof, that motion is ever generated without the immediate agency of some active principle. The power of steam is created by the immediate agency of caloric, and ceases whenever the acting principle is withdrawn. The force with which a horse shoe magnet of soft iron holds on to the armature, is generated by the passage of an electric current through the wires which are coiled around it; but ceases the moment the current is arrested. The metallic wire that connects the extremities of a voltaic battery, attracts iron filings, and deflects a magnetic needle in its vicinity, so long as the electric fluid is disengaged by chemical action, but ceases whenever that action is at an end. The powers of digestion, secretion, nutrition, and muscular motion, are generated by means of an active principle which is obtained from the atmosphere by respiration ;

* Newton observes, "that the motions of the planets may subsist an exceeding long time, it is necessary that the heavens should be void of all resisting matter." And he adds in another place,- " by the vis insita of bodies, I mean nothing but their vis inertia." (Princip. book iii.), 
but cease whenever that important function is arrested; as will be shown in subsequent parts of this work.*

But if it be true that caloric is perpetually radiated from the sun and fixed stars into the boundless regions of space, it must constitute an infinite ocean of æthereal essence ; consequently, there can be no such thing as a vacuum, which, as Aristotle rightly observed, would destroy all motion. Nor is it less obvious, that if caloric be a self-active principle, and is every where present, there can be no such condition of matter as vis inertia, which literally means the power of not acting. And that a single impulse is not competent to maintain the unceasing motion of planets and satellites, is evident from Newton's

* Such facts have created very strong doubt in the minds of philosophers in regard to the truth of Newton's first law of motion. For example, it is observed by Sir John Herschel that, " to say matter has inertia, is only to say that the cause is expended in producing its effect, and that the same cause cannot continue to produce its effect without renewal." (Nat. Philosophy, sect. 234.) And it was humorously argued by the author of Knickerbocker, that " as the projectile force has long since ceased to operate, while its antagonist remains in undiminished potency, the world ought, in strict propriety, to tumble into the sun." Nor would it be difficult to demonstrate, that this catastrophe would occur before it performed one fourth part of its annual revolution, if the force of gravity were counteracted only by a single impulse of equal force. Mr. Whewell also observes in his Bridgewater Treatise on Astronomy, that " to say motion must, continue the same from one instant to another, because there is nothing to stop it, seems to be taking refuge in words." But there is no one force 
own hypothesis, that they are impelled or drawn with an equal force at right angles to the direction of the original projection. Moreover, when Newton referred the centrifugal force to the immediate agency of the Deity, and that of gravity to an inherent property of matter, he departed from that uniformity of nature and of causation, on which all true science is founded. To be consistent, he ought to have referred all physical power to the immediate agency of the Deity, or to the inherent properties of matter.

That the illustrious author of the Principia was not ultimately satisfied with the data on which his theory of planetary motion was founded, viz. the projectile impulse, the vacuum of space, and the vis insita of matter, ${ }^{*}$ is plain enough from what has

in nature which is not counteracted by another force. It is therefore evident that Newton's first law of motion does not apply, as he originally intended, to the planetary revolutions. Mr. Whewell is equally explicit in renouncing the vacuum of space: for when treating of the luminiferous æther, he says, " it must not be merely like a material fluid poured into the vacant spaces of the material world; it must affect the physical, chemical, and vital properties of whatever it touches, and be the means of communication between planets and systems." (Book i. ch. xvii. and book ii. ch. xi.) Yet he observes in another chapter, that " in the machinery of the universe there is, so far as we know, no material connection between the parts which act on each other." (Book ii. ch. i.)

* It might as well be said that " opium causes sleep by means of a dormitive property," as that the particles of bodies are held together by means of an inherent power of attraction termed cohesion; or that planets are maintained in their orbits by an in- 
been already said in the early part of this chapter, concerning his views of the æther. But here again he was unfortunate in his explanation of the mode in which it produces the phenomena of cohesion, capillary attraction, gravitation, \&c. For he supposed that " the æther was more rare within the bodies of the sun and planets, than in the celestial spaces between them; and that its density increases perpetually in proportion as the distances increase from them, thereby causing the gravity of those great bodies towards one another, and of their parts towards each other, every body endeavouring to go from the denser parts of the medium towards the rarer." (Optics, Queries 20, 21.)

The failure of this hypothesis has been already exposed by Mr. Whewell, who justly observes that all elastic fluids tend to an equilibrium; so that if the density of the æther increased with the distance, the force of gravity would diminish until the equilibrium was restored, when it would cease; while it is now generally understood, that the density of all radiant matter diminishes with every increase of distance from

herent power of gravity, without the agency of an intermediate impelling principle. And if we admit that each of the eleven planets and their fourteen satellites was projected into space by a primitive impulse, is it not remarkable that the continuous force of that impulse should precisely correspond with the heating power of the sun, and be just equal to the power of gravity? 
any given centre. And it will be proved hereafter, that the rether is more dense within the pores and around the particles of dense than of light bodies, in which it is more dense than in free space. On the whole, it is not very surprising that Newton's views of the æther have been generally regarded as chimerical, and insufficient to explain the leading phenomena of nature; especially as he never identified it with any known principle. And when he referred the centripetal forces of matter to its agency, he assigned no physical cause of the centrifugal force. But if the centrifugal force of planets be directly in proportion to the radiating power of the solar orb, caloric must be the cause of this force : for the essential character of a vera causa is, that the effects it produces are a measure of its intensity.*

Nor is it less certain, that if the caloric which is perpetually radiated from the sun be not anni-

* Moreover, as the mean temperature of the earth has remained the same for long periods of time, it follows that the planets must give off by radiation the same amount of caloric they receive from the sun. This amount must depend on their superficial area, and on their distance from the sun. It therefore becomes an important question, how far it may operate in producing the centrifugal force of their satellites, just as the radiating power of the sun generates the centrifugal force of the planets themselves. At the same time it must be observed, that the motions of the satellites are subject to the direct influence of the sun; which, however, is greatly diminished by his immense distance, compared to the nearness of their primaries. For as Sir John Herschel observes, 
hilated, it must either accumulate in the planetary spaces, and thus raise their mean temperature; or it must return to the great fountain from which it emanates. It also follows, that if the vast æthereal tide flow perpetually toward the sun, with the same force which it exerts in maintaining the centrifugal power of planets, there is no good reason why it should not be the cause of the centripetal force which maintains them in their orbits ; consequently, that the projectile and gravitating forces of Sir Isaac Newton are owing to one and the same principle which produces all the contractions and expansions, separations and combinations of the particles of ponderable matter; as will be proved in the third chapter of this, and the whole of the second book. Nor can there be a rational doubt, that in the total absence of solar radiation, all the mechanical, chemical, and vital operations of the planets would be arrested; and that if the interstellary spaces were reduced

" the greatest part of the sun's attraction, which is common to both, is exerted in retaining both primary and secondary in their common orbit about himself, and in preventing them from parting company ; the small excess of force acting only as a disturbing power." And he states that, according to the calculations of Newton, the mean value of this excess, in the case of the moon's disturbance by the sun, does not exceed ${ }_{r}^{\frac{x}{7 g}}$ of the principal force which retains the moon in its orbit. (Astronomy, sect. 493). It must also diminish, relatively, as the magnitude and distance of planets increase. Yet it is sufficient to give the orbits of their satellites the character of somewhat zigzag circles. 
to absolute zero, there could be no motion of the heavenly bodies.

Moreover if it be true that there is an unceasing circulation of æthereal matter throughout the solar system, it will account for the revolution of the sun on his axis; a phenomenon which has never yet been explained in accordance with the Newtonian theory; and the knowledge of which is of fundamental importance to a right understanding of physical astronomy; as it is in the laws which regulate the actions of the sun, that we must seek for the origin of planetary motion. For example, it will be shewn hereafter, that the tendency of caloric to unite with other bodies, is in proportion to the quantity of matter they contain, ceteris paribus. Hence it is that two pounds of water will condense just twice as much steam as one pound; and that a small fire is quenched by a large quantity of coal, with which the caloric unites, and thus arrests the process of combustion. We are therefore authorised to infer, that the aggregate force by which the æther of space tends to unite with the different bodies of the solar system, is in proportion to their mass, and inversely as the squares of the distance.*

* By glancing over the Tables, p. 32, it will be observed that the velocity of planets round the sun does not depend upon their magnitudes, but on their distance from him, and that the same law applies to their satellites; which accords with the discovery 
If the sun were a perfect sphere, and not surrounded with planets, the æther would press with equal force upon all parts of his surface, and thus maintain him in a perfectly fixed state. But as he is not a perfect sphere, and as the pressure of the æther upon him from every part of the solar system, is modified by all the surrounding planets and satellites, it is obvious that the centripetal force of the æther must vary on different parts of his surface, so as to give him a rotary motion on his axis, - a result which may be owing in part to certain actions going on with-

of Galileo, that the velocity with which bodies fall to the earth is the same, whether they be large or small, dense or light, when the resistance of the atmosphere is removed. But if the distance of planets from the sun were equal, the velocity of their satellites would be in proportion to the magnitude of their primaries, and inversely as the cubes of the distance. At the present distance of the earth from the sun, the moon revolves around us at the rate of 2,168 miles an hour, at the distance of 237,000 miles from the earth. But if the earth were at the place of Jupiter, and if the velocity of satellites diminish in the same ratio as that of their primaries, on receding from the sun, the velocity of the moon would be 2.303 times slower than at present, and only 941 miles an hour. It must, however, be observed, that as the volume of Jupiter is about 1,300 times that of the earth, his first satellite, which is 263,111 miles from his centre, moves at the rate of 37,140 miles an hour. And if his first satellite were only 237,000 miles from his centre, (the distance of the moon from the earth,) it would move at the rate of 41,200 miles an hour, and faster than the moon, (if the earth were at the place of Jupiter,) in the ratio of nearly forty-four to one,-a difference which must therefore be owing to the difference between the magnitude of Jupiter and that of the earth. 


\section{in the sun himself, and on which his radiating power depends.*}

* The above views will also enable us to explain the diurnal revolution of planets, the elliptical form of their orbits, the inclination of their axes, and all the phenomena of the tides. In the first place, if the planets were perfectly round, and not influenced by each other, both the radiating power of the sun, and the centripetal pressure of the æther, would be the same on all parts of their surface, and they could have no rotary motion. Nor could there be any elongations of their orbits, which would be perfect circles, if the centrifugal and centripetal forces by which they are impelled were always equal and the same. But as none of the heavenly bodies are perfectly spherical, the solar radiation, like the returning pressure of the æther, must operate with unequal force on different parts of their surface, and tend to give them a rotary motion; the rapidity of which may depend upon the extent of their deviation from the perfectly spherical form, and, perhaps, on the inclination of their axes: which, again arises from their mutually disturbing influence upon each other, modified by the difference between their equatorial and polar diameters. In the case of Jupiter, this difference is as 107 to 100 ; whereas in the earth, it is as 299 to 298.

There is another circumstance which may have an equally important influence on the elliptical form of the planetary orbits. For example, we learn from the telescopic observations of Sir William Herschel, that all parts of the sun are not equally luminous; that at times, there may be seen on his surface spots, some of which are so large as to measure 45,000 miles in linear diameter, exhibiting the appearance of a dark, opaque, and solid ground. It therefore follows, that different quantities of caloric are radiated from different parts of his surface, so as to augment and diminish within certain limits, the centrifugal force of the planets, causing them to approximate the sun in certain parts of their orbits, and to recede from him in other parts, with corresponding accelerations and retardations in their annual motions, and, perhaps, variations in their mean annual temperature. On the other hand, as the centripetal pressure of the æether on 
When I come to treat of the physiological and pathological laws of caloric, it will be found that the aggregate amount of life on our planet is in proportion to the heating power of the sun, ceteris paribus:-that no seed ever germinates, and no

each of them is modified by the disturbing influence of all those beyond, this also tends to alter the circular form of the orbits, and render them more or less elliptical. Nor is it less obvious, that the interference of the moon must cause a successive diminution of gravity or æthereal pressure upon the earth, so as to cause a corresponding elevation of the tides, which are still further elevated by the influence of the sun when in conjunction with the moon. Thus we perceive that as the mean temperature of planets, (at least of the earth,) and of the spaces between them, is uniformly the same, there must be a perpetual circulation of caloric from and to the centre of the solar system, as from and to the planets. We have also found that the heating power of the sun is just equal to the centrifugal force of planets, and an accurate equation of the gravitating force: from which it follows, that whatever is true of the laws established by Kepler and Newton, must be equally true of the foregoing induction; while it has the additional advantage of assigning a well known principle as the physical cause of the phenomena, and of thus affording a resting place for the mind.

From all the foregoing facts and observations we are authorized to conclude, that caloric is a self active principle which is perpetually circulating throughout the universe,-from suns to planets, and back again to the great fountains from which it emanates : in short, that it is what Homer called

"The golden everlasting chain,

Whose strong embrace holds heaven, and earth, and main."

That the movements of the heavenly bodies are in some way immediately dependent on the heating power of the sun, appears to me almost a self-evident proposition, and was so regarded by many of the ancient sages of the east. It was also vaguely re- 
egg is ever hatched, without a due supply of warmth:- that as the thermometer rises in spring, so does the sap of plants; and as the mercury mounts up in summer, the forces of life augment, but decline in autumn, and are wholly arrested during winter:-that as the annual rings of trees correspond in thickness with the mean temperature of the growing season in the higher latitudes, and are always thickest on the side exposed to the sun,- the germination, growth, and

cognized by Milton, who represents the sun as both eye and soul of this great world,-

"Toward which the planets

Turn swift their various motions, or are turn'd

By his magnetic beam, that gently warms

The universe, and to each inward part,

With gentle penetration, though unseen,

Shoots invisible virtue, e'en to the deep."

(Paradise Lost, b. iii.)

When rightly understood, caloric is capable of explaining all the phenomena of attraction, repulsion, and planetary motion; but these will not explain the operations of chemistry, geology, meteorology, vegetation, and animal life; nor the generation of steam, which has become so important an agent in spinning and weaving our fabrics, propelling boats, ships, and carriages, working mines, and in nearly all the most useful arts. But we cannot expect to comprehend fully the modus operandi of caloric in any one class of phenomena, until we rise high enough to survey the whole field of knowledge, and to perceive the intimate connexion between all its various branches. It was truly observed by Mr. Hume, that " the only expedient from which we can hope for success in our philosophical researches, is to march up directly to the capital or centre of the sciences, which being once mastered, we may everywhere else hope for an easy victory." 
decay of vegetation, constitute a natural thermometer on a grand scale. It will also be found, that organized bodies are composed chiefly of those elements which contain the largest amount of caloric around their particles; by which they are rendered proportionally active, and endowed with the faculty of entering into vital combinations, so as to form highly complex tissues: that the vital energy of animals, the activity of their functions, and the developement of their organs, are in proportion to the amount of caloric which circulates through, and is employed in combining arterial blood with the solids. A right understanding of these laws is of vastly greater importance than those of Geology, Astronomy, or even Chemistry. For until we comprehend the operations of life, health, disease, the modus operandi of medicines and morbific agents, the healing art can never take its appropriate rank among the exact sciences; nor be rescued from the charge of mysticism, quackery, and ignorance of what is essential to the character of a philosophical physician. But as "the strength of a science is, like that of the old man's fagot, in the bond," the candid seeker after truth is requested to suspend his judgment, until he shall have carefully examined the whole of the evidence adduced in support of the author's peculiar views. 


\section{CHAPTER II.}

\section{Atomic Constitution of Matter.}

" Omnia in mensura, et numero, et pondere disposuisti."

Liber Sapientiæ, xi. 21.

BEFore treating of the relative quantities of caloric in different bodies, and of the law by which it produces the opposite forces of attraction and repulsion, combination and separation, contraction and expansion; I shall present a brief outline of what is known in regard to the ultimate constitution of ponderable matter. The doctrine that everything in nature is governed by measure, number, and weight, seems to have been recognized by Moschus of Sidon, and other oriental sages, long before the time of Pythagoras and Democritus, who maintained that all matter is composed of exceedingly small, hard, and unchangeable atoms, that vary in magnitude; so arranged and combined as to produce an endless diversity of mineral, vegetable, and animal bodies.

The same theory was adopted by Bacon, Boyle, Newton, and many other distinguished modern philosophers, who very justly conceived that if matter were infinitely divisible, all species would be confounded. And it is obvious that if the elements did not unite in definite proportions, the laws of chemistry could not be understood, 
nor its results be predicted with certainty. In opposition to this simple and rational view of the subject, it was maintained by Boscovich, that the minutest portions of matter consist of mere mathematical points, without extension or solidity, surrounded by alternate immaterial spheres of attraction, and repulsion,-by one of which, the said mathematical points are drawn together, and by the other kept asunder, so as to be prevented from touching.

We are indebted to the researches of Wenzel, Bergman, and Richter, for the discovery that definite proportions of acids and alkalies are required for mutual saturation; and that many other chemical combinations take place only in fixed ratios. It was further maintained by William Higgins of Dublin, (in a work entitled "A Comparative View of the Phlogistic and Antiphlogistic Theories," published in 1789,) that all compounds are formed by the union of exceedingly minute atoms, which are surrounded by atmospheres of caloric; and that oxygen unites with nitrogen in proportions which are even multiples of the lowest. But to Dr. John Dalton of Manchester, was reserved the distinguished honour of reducing the atomic theory to a systematic form, in a work entitled "Chemical Philosophy," published in 1808-10,-aided by the subsequent analyses of Thomson, Berzelius, Prout, GayLussac, Dulong, and many others.

The most general law of chemical affinity as 
announced by Dalton is, that the constituents of ponderable matter, whether simple or compound, are capable of combining with each other only in fixed or definite proportions by weight.

In a practical point of view, this law has been of the highest importance to the manufacturing chemist, independent of its connexion with the whole theory of physical science.

Passing over the early and imperfect analyses of Dalton, it has been established by the united labours of the most accurate experimenters of modern times, that water is always composed of 8 parts by weight of oxygen to 1 of hydrogen ; that common salt is always composed of 36 parts by weight, (in round numbers) of chlorine to 24 of sodium; that carbonate of lime, whether in the form of marble, chalk, or stalactites, is invariably composed of $\mathbf{2 2}$ parts by weight of carbonic acid, to 28 of lime, \&c.

It was by thus ascertaining the relative proportions in which bodies combine chemically by weight, that Dr. Dalton was lead to a perfectly simple method of deducing the relative weights of their ultimate chemical atoms. The theory assumes, that in all cases, the lowest combining proportion of bodies, whether simple or compound, represents the weight of its particles; and that whenever a body combines with another in two or more proportions, the larger is an even multiple by some whole number of the smaller, 
as 2 to 1,3 to 1,4 to 1 , \&c.; fractional parts seldom occurring in well ascertained cases.

By inspecting the following Table, it will be seen that the smallest combining ratio of oxygen is 8 , compared with hydrogen as unity; and that when it combines with other elements in larger proportions, they are $16,24,32,40$, or some multiple of 8 . Chlorine combines with mercury in the ratio of 36 , as in chloride of mercury, (calomel), or of 72 , as in the bi-chloride of mercury, (corrosive sublimate) and so of carbon, hydrogen, and other elements.

I have adopted the atomic numbers employed by the majority of British chemists in preference to those of Berzelius, chiefly with a view of avoiding the inconvenience of fractions. I have also chosen hydrogen as a standard of comparison for the same reason. Berzelius has selected oxygen 100.00 as a standard, on account of its great abundance, and the vast variety of combinations which it forms; while Thomson and Ure have employed oxygen as unity, by which hydrogen is rendered 8 times less; or 0.125 , carbon 0.75 , sulphur 2 , mercury 25 or $12 \frac{1}{2}$, chlorine 4.5 , and so on; both of which are unavoidably attended with fractions that are difficult to remember.

Dr. Wollaston employed the terms chemical equivalent, and Sir Humphrey Davy combining proportion, to denote the atom of Dalton. I shall generally use the term atom, or particle, as indi- 
cating the smallest chemical divisions of bodies; and molecule, as a small assemblage of atoms.

Berzelius represents the different elementary bodies by the initial letters of their Latin names. Thus, $\mathrm{O}$. denotes oxygen, $\mathbf{H}$. hydrogen, $\mathbf{N}$. nitrogen, S. sulphur, P. phosphorus, Cl. chlorine, Br. bromine, I. iodine, F. fluorine, C. carbon, Au. gold, Hg. mercury, Ag. silver, Cu. copper, Pl. platina, St. tin, Pb. lead, Zn. zinc, Si. silicium, Se. selenium, As. arsenic, Fe. iron, M. manganese, Al. aluminum, Mg. magnesium, Ca. calcium, Ba. barium, L. lithium, Na. sodium, K. potassium, (or kalium), which are the most important.

The number of atoms in each element of a compound is indicated by figures, as in the following formula. N. $\mathrm{O}^{5}$, represent 1 atom of nitrogen and 5 of oxygen, as in nitric acid: while sulphuric acid, which is composed of 3 atoms of oxygen and 1 of sulphur, is denoted by $\mathrm{S} \mathrm{O}^{3}$. He has in many cases introduced symbols of still more remarkable brevity and convenience. For example, the number of oxygen atoms in a compound is designated by dots placed over the letter, which indicates the element with which it combines. Thus, the composition of water is represented by the symbol, $\dot{\mathrm{H}}$; carbonic oxide by $\dot{\mathbf{C}}$; carbonic acid by $\ddot{\mathrm{C}}$; protoxide of nitrogen by $\dot{\mathbf{N}}$; binoxide of nitrogen by $\ddot{\mathrm{N}}$; nitrous acid 
by $\ddot{\mathrm{N}}$; and nitric acid by $\dddot{\mathrm{N}}$. This is a most important improvement of chemical symbols, when we reflect that oxygen enters into the composition of nearly all compound bodies.

Berzelius represents the number of sulphur atoms by commas. Thus $\mathbf{H}$ indicates sulphuretted hydrogen; and $\ddot{\mathbf{H}}$, bisulphuretted hydrogen, \&c. He also denotes various compounds by the initial letters of their names. Aq. represents water : Cy. Cyanogen; Ni. nitrate of potass ; Am. ammonia, \&c. It is sometimes convenient to denote 2 atoms of an element by a dash under

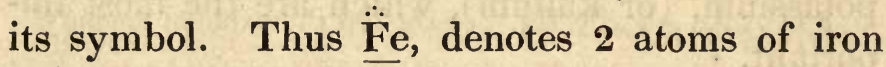
and 3 of oxygen, as in the peroxide of iron.

\section{TABLE OF ATOMIC WEIGHTS,}

AND OF THE SYMBOLS BY WHICH THEY ARE REPRESENTED.

Parts by weight.

Parts by weight.

80 xyg. combine with $1 \mathrm{H}$. to form $\dot{\mathrm{H}} 9$ parts by weight of water.

$16 \mathrm{O}^{2} \ldots \ldots \ldots 1 \mathrm{H} . \ldots . \ddot{\mathrm{H}} 17$ Binoxide of hydrogen.

$80 \ldots \ldots 6$ C. $\ldots . . \dot{C} 14$ Carbonic oxide.

$16 \mathrm{O}^{2} \ldots \ldots \ldots 6 \mathrm{C} . \ldots \ddot{\mathrm{C}} 22$ Carbonic acid.

$16 \mathrm{O}^{2} \ldots \ldots 16 \mathrm{~s} . \ldots \ddot{\mathrm{S}} 32$ Sulphurous acid.

$24 \mathrm{O}^{3} \ldots \ldots \ldots 16 \mathrm{~S} . \ldots . \dot{\check{\mathrm{S}}} 40$ Sulphuric acid.

$80 \ldots \ldots 14 \mathrm{~N} . \ldots \dot{\mathrm{N}} 22$ Protoxide of nitrogen.

$16 \mathrm{O}^{2} \ldots \ldots 14 \mathrm{~N} . \ldots \ddot{\mathrm{N}} 30$ Binoxide of do.

$24 \mathrm{O}^{3} \ldots \ldots \ldots 14 \mathrm{~N}$. .... $\ddot{\dot{\mathrm{N}}} 38$ Hyponitrous acid. 
$32 \mathrm{O}^{4}$ combine wlth $14 \mathrm{~N}$. to form $\stackrel{\mathrm{N}}{\mathrm{N}} 46$ Nitrous acid.

$40 \mathrm{O}^{5} \ldots \ldots \ldots 14 \mathrm{~N} . \ldots . \ddot{\mathrm{N}} 54$ Nitric do.

$8 \mathrm{O} \ldots \ldots .36 \mathrm{Cl} . \ldots . \mathrm{Cl} 44$ Protoxide of chlorine.

. $32 \mathrm{O}^{4} \ldots \ldots . .36 \mathrm{Cl} . \ldots . \quad$ Cl 68 Peroxide of do.

$40 \mathrm{O}^{5} \ldots \ldots \ldots 36 \mathrm{Cl} . \ldots \quad$ Ci 76 Chloric acid.

$8 \mathrm{O} \ldots \ldots .440 \mathrm{~K} . \ldots . \dot{\mathrm{K}} 48$ Potass.

$8 \mathrm{O} \ldots \ldots .24 \mathrm{Na} . \ldots \mathrm{Na} 32$ Soda.

$80 \ldots \ldots 20 \mathrm{Ca}$. .. Ċa 28 Lime.

$80 \ldots \ldots .8 \mathrm{Si} . \quad \ldots$. Si 16 Silex, silicic acid.

$8 \mathrm{O} \ldots \ldots .64 \mathrm{Cu} . \ldots \dot{\mathrm{Cu}} 72$ Protoxide of copper.

$16 \mathrm{O} \ldots \ldots .64 \mathrm{Cu} . \ldots \ddot{\mathrm{Cu}} 80$ Binoxide of do.

$80 \ldots \ldots 200 \mathrm{Hg} . \ldots . \dot{\mathrm{Hg}} 208$ Protoxide of mercury.

$16 \mathrm{O}^{2} \ldots \ldots .200 \mathrm{Hg} . \ldots \ddot{\mathrm{Hg}} 216$ Binoxide of do.

$80 \ldots \ldots \ldots 110 \mathrm{Ag} . \ldots \mathrm{Ag} 118$ Protoxide of silver.

$24 \mathrm{O}^{3} \ldots \ldots \ldots 16 \mathrm{P} . \ldots . \quad \dot{\ddot{\mathrm{P}}} 40$ Phosphoric acid.

$80 \ldots \ldots .28$ M.... $\dot{M} 36$ Protoxide of manganese.

$8 \mathrm{O} \ldots \ldots .28 \mathrm{Fe} . . . . \mathrm{Fe} 36$ Protoxide of iron.

$24 \mathrm{O}^{3} \ldots \ldots \ldots 56^{2} \mathrm{Fe} \ldots . . . \dot{\mathrm{Fe}} 80$ Peroxide of iron.

$80 \ldots \ldots .12 \mathrm{Mg} . . . \quad \dot{\mathrm{Mg}} 20$ Oxide of magnesia.

$80 \ldots \ldots .10 \mathrm{Al}$... Al 18 Alumina.

$24 \mathrm{O}^{3} \ldots \ldots 12 \mathrm{C} . \ldots \dot{\mathrm{C}^{2}} 36$ Oxalic acid.

$36 \mathrm{Cl} . \ldots . .1 \mathrm{H} . . . \mathrm{Cl} \mathrm{H} 37$ Hydro chloric acid.

126 I. ....... $1 \mathrm{H} . \ldots 1 \mathrm{H} 127$ Hydriodic acid.

$16 \mathrm{~S} . . . . \ldots 1 \mathrm{H} . . .$. H 17 Sulphuretted hydrogen.

$32 \mathrm{~S}^{2} \ldots . \ldots \quad 1 \mathrm{H} . \ldots . . \mathrm{H}^{\prime} 33$ Bisulphuretted hydrogen.

$6 \mathrm{C} \ldots \ldots \ldots 2 \mathrm{H}^{2} \ldots \mathrm{CH}^{2} \quad 8$ Light carburetted hyd.

$12 \mathrm{C}^{2} \ldots \ldots \ldots 2 \mathrm{H}^{2} \ldots \mathrm{C}^{2} \mathrm{H}^{2} 14$ Olefiant gas.

$12 \mathrm{C}^{2} \ldots \ldots \ldots 14 \mathrm{~N} . \ldots \mathrm{C}^{2} \mathrm{~N} 26$ Cyanogen. 
Parts by weight.

Parts by weight.

$36 \mathrm{Cl}$. combine with $24 \mathrm{Na}$... Cl Na 60 Chloride of Sodium.

$24 \mathrm{C}^{4} \ldots \ldots .4 \mathrm{H} . \ldots . \mathrm{C}^{4} \mathrm{H}^{4} \quad 28$ Ftherine (En)

$36 \mathrm{C}^{6} \ldots \ldots .3 \mathrm{H} . \ldots \mathrm{C}^{6} \mathrm{H}^{3} \quad 39$ Bicarburet of hyd.

$36 \mathrm{C}^{6} \ldots \ldots .5 \mathrm{H} \ldots . \mathrm{C}^{6} \mathrm{H}^{5} 41$ Naphtha.

$60 \mathrm{C}^{10} \ldots . .4 \quad 4 \mathrm{H} \ldots \mathrm{C}^{10} \mathrm{H}^{4} \quad 64$ Naphthalin.

$90 \mathrm{C}^{15} \ldots \ldots .4 \mathrm{H} . \ldots \mathrm{C}^{15} \mathrm{H}^{4} 94$ Paranapthalin.

$14 \mathrm{~N} \ldots \ldots .3 \mathrm{H} \ldots . . \mathrm{N} \mathrm{H}^{3} \cdot 17$ Ammonia.

$80 \ldots . .200 \mathrm{Au}$... O Au 208 Protoxide of gold.

$80 \ldots \ldots 104 \mathrm{~Pb} \ldots . . .0 \mathrm{~Pb} 112$ Protoxide of lead.

$80 \ldots . .96 \mathrm{pl} \ldots . .0 \mathrm{pl} 104$ Protoxide of platina.

$80 \ldots . .72 \mathrm{Bi} \ldots . . \mathrm{O} . \mathrm{Bi} .80$ Oxide of bismuth.

$26 \mathrm{Cy} . . . .1$ 1 H. ... Сy H 27 Hydro-cyanic acid. $26 \mathrm{Cy} \ldots \ldots .80 . \quad \ldots \dot{C} \mathbf{C y} \quad 34$ Cyanic acid.

$26 \mathrm{Cy} \ldots \ldots .40 \dot{\mathrm{S}} . \ldots$ Cy $\ddot{\mathrm{S}} 66$ Sulpho-cyanic acid.

$26 \mathrm{Cy}$..... $36 \mathrm{Cl}$.. Cy Cl 72 Chloro-cyanic acid.

$14 \mathrm{C}^{2} \mathrm{H}^{2} \ldots .99 \mathrm{Aq} . \mathrm{C}^{2} \mathrm{H}^{2} \dot{\mathrm{H}} 23$ Alcohol.

$28 \mathrm{C}^{4} \mathrm{H}^{4} \ldots .99 \mathrm{Aq} . \mathrm{C}^{4} \mathrm{H}^{4} \dot{\mathrm{H}} \quad 37$ Ether.

$22 \ddot{\mathrm{C}} \ldots \ldots \ldots \quad 17 \mathrm{~N} \mathrm{H}^{3} \ddot{\mathrm{C}} \mathrm{N} \mathrm{H}^{3} \quad 39$ Carbonate of ammonia.

$44 \ddot{\mathrm{C}}^{2} \ldots \ldots 48 \dot{\mathrm{K}} \ldots . . \ddot{\mathrm{C}}^{2} \dot{\mathrm{K}} 92$ Bicarb. of potass.

$54 \ddot{\ddot{N}} \ldots \ldots 48 \dot{\mathrm{K}} \ldots \ldots \ddot{\ddot{\mathrm{N}}} \dot{\mathrm{K}} 102$ Nitrate of potass.

$37 \mathrm{Cl} \mathrm{H} \ldots 17 \mathrm{~N} \mathrm{H}^{3} \cdot \mathrm{ClH} \mathrm{N} \mathrm{H}^{3} 54$ Muriate of ammonia.

$37 \mathrm{Cl} \mathrm{H} \ldots 28 \mathrm{En} .$. Cl H En 65 Muriatic æther.

$40 \ddot{\mathrm{S}}$...... $32 \dot{\mathrm{Na}} \ldots . . . \dot{\mathrm{S}} \dot{\mathrm{Na}} 72$ Sulphate of soda.

$40 \ddot{\mathrm{S}} \ldots \ldots 20 \mathrm{Mg} \ldots . . \dot{\mathrm{S}} \dot{\mathrm{Mg}} 60$ Sulphate of magnesia.

The lowest numbers in the two first columns of the above Table down to oxide of bismuth 
represent the atomic weights of simple bodies, or multiples of them; while the numbers of the 3rd column, including all those from hydrocyanic acid in the 1st and 2nd columns, denote the weights of compound particles or molecules. Thus it will be found, that the atomic weight of oxygen is 8 times that of hydrogen, carbon 6 , sulphur 16 , nitrogen 14 , chlorine 36 , \&c.-that the atomic weight of water is 9 , of carbonic oxide 14, protoxide of nitrogen 22 , which are binary compounds; whereas carbonic acid, sulphurous acid, and all other bodies that are formed of 2 atoms of one element, and one of another, were called ternary compounds by Dr. Dalton. For the same reason, olefiant gas is a quaternary compound-nitrous acid a quinquenary compound-alcohol sexanary, being composed of $\mathrm{C}^{2} \mathrm{H}^{3}$ O.- carbonate of ammonia septenary; while nitrate of potass, æther, and many other bodies, are still more complex, being formed of larger numbers of simple atoms, united into compound particles or molecules, which retain their individuality and specific relations to caloric, until decomposed and again reduced to their constituent particles.

Berzelius regards all organic bodies as composed of definite ratios of their constituent elements-an hypothesis which is rendered more and more probable by the recent progress of organic chemistry. It has been ascertained by the 
analysis of Gay-Lussac, Dr. Prout, and others, that perfectly dried wood is composed of about 50 parts by weight of carbon, to 50 of oxygen and hydrogen in the proportions that form water. M. M. Petersen and Schödler have also found recently, by an important series of experiments on 24 different species of wood, that they are composed of carbon, oxygen, and hydrogen, in very nearly the same proportions by weight : and it is certain that definite ratios of oxygen combine with their carbon and hydrogen during combustion. They found that $100 \mathrm{lbs}$. of lime-wood absorb and combine with $140 \cdot 523 \mathrm{lbs}$. of oxygenand that $100 \mathrm{lbs}$. of beech, which required less oxygen than any of the 24 species, combined with 130.834 lbs. of oxygen. (Journal of Prac. Science, Nov., 1836.) It was formerly maintained by Gay-Lussac and Thenard, that vegetable substances are acid when they contain a larger proportion of oxygen than is required to form water-resinous, oily, or alcolıolic, when the quantity of hydrogen predominates-and saccharine, mucilaginous, \&c., when there is no excess of either oxygen or hydrogen. Though exceptions have been found to their results, they are true in so many cases, that it is well to bear them in mind.

The recent progress of chemical science has led to the discovery of some apparent excepthus to the law of multiples. The following examples have been indicated by Dr. Turner. The 
peroxide of iron is composed of 12 parts oxygen to 28 of iron. Oxygen combines with manganese in the same ratio, forming a sesquioxide, from the latin word sesqui, one and a lialf. It also unites with arsenic in the ratio of 12 to 38 of the metal, as in arsenious acid; and of 20 to 38 , as in the composition of arsenic acid. With phosphorus, it unites in the ratio of 4,12 , and 20 , as in hypophosphorous acid, phosphorous, and phosphoric acids; which would seem to indicate, that oxygen is capable of combining with the above substances in the ratios of $\frac{1}{2}, 1 \frac{1}{2}$, or $2 \frac{1}{2}$ atoms.

This difficulty has been evaded by supposing that 2 equivalents or atoms of one substance unite with 3,5 , or more atoms of another-that if 2 atoms of phosphorus unite with 3 , and 5 atoms of oxygen, we obtain the ratios of $1 \frac{1}{2}$ and $2 \frac{1}{2}$; or if one atom of iron unite with 1 of oxygen, and another compound be formed of 2 atoms of iron to 3 of oxygen, the latter would be in the proportions of 1 , and $1 \frac{1}{2}$, and so of other like cases.

When 1 atom of oxygen unites with 2 of lead, they form a ternary atom of what is termed a dinoxide, or a suboxide. Dr. Turner lays it down as a general rule, that when a metal forms two oxides, the oxygen of which is in the ratio of 1 to $1 \frac{1}{2}$, the first is usually the protoxide, and the second a compound of two atoms or equivalents of the metal to 3 of oxygen, as in the oxides of iron nickel, and chromium.

It is highly probable, that a more accurate and 
refined mode of analysis, will prove hereafter that several of the present atomic numbers do not represent the true weights of the atoms. But it is also probable, that in nearly all cases where this is not so, they represent either multiples, or sub-multiples of them.

There are other exceptions to the law, that all bodies combine chemically in fixed or definite proportions by weight. Many of the metals unite with each other in all proportions when converted into the liquid state by heat, or electricity, forming alloys.

Water combines with alcohol, and with the strong acids in unlimited proportions; and it will be shown further.on, that the ratios in which sugar, numerous salts, oily, resinous, and gelatinous substances, unite with water by chemical solution, are determined by the temperature of the water, solubility of the bolies, \&c. But in all such cases, the affinity is comparatively weak, and the changes of properties consequent on combination inconsiderable.

\section{Theory of Volumes.}

In the year 1805, Gay-Lussac and Humboldt proved by numerous experiments, that water is always composed of 2 measures by volume of hyrirogen to 1 of oxygen, as had been previously shewn by Higgins. By following up the investigation, Gay-Lussac found, that many other 
gases, both simple and compound, unite with each other in very simple ratios by volume-that 1 volume of $A$ unites with $1,2,3$, or more volumes of $\mathbf{B}$; and that the bulk of the resulting compounds, always bears a very simple and definite ratio to that of its constituents, or to that of one of them.*

This law has been extended by Dr. Prout and others, to vapours, and even to the supposed vapours of bodies which do not exist in the elastic form, except when united with the permanent gases. For example, if carbon be burnt in 100 cubic inches of oxygen gas, (the weight of which is 34.60 grains,) an equal volume of carbonic acid is formed; (which weighs $47 \cdot 26$ grains,) showing that 12.66 grains of carbon have been dissolved and chemically united with 100 cubic inches of oxygen, which are thus converted into the elastic state; and that 2 atoms of oxygen have united chemically with 1 of carbon. In this way it was found, that the specific gravity of carbon vapour is 416 , compared with oxygen $1 \cdot 111$, as determined experimentally by Dr.

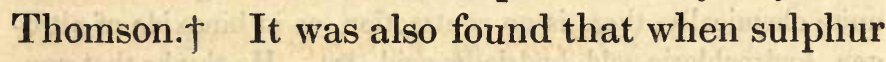
is chemically combined with oxygen by combustion, an equal volume of sulphurous acid is formed, the specific gravity of which is $2 \cdot 222$, or

* Mémoires D’Arcuiel, 1809, Tom. II.

+ Mitscherlich has maintained recently, that the specific gravity of carbon vapour is double the estimate of Prout. He observes, that as it cannot be determined by direct experiment, it 
just double that of oxygen : therefore it is evident, that 100 cubic inches of sulphur vapour, as it exists in sulphurous acid, are of the same weight as 100 cubic inches of oxygen. Such facts led to a new mode of ascertaining the atomic weights of bodies, and threw much additional light on the ultimate constitution of matter. For example, if sulphurous acid be composed of 2 atoms of oxygen to 1 of sulphur, it follows, that the atom of sulphur must be just 16 times that of hydrogen, and double that of oxygen.

By pursuing this method of investigation, Dr. Thomson arrived at the conclusion, that carbon, oxygen, and sulphur, are even multiples of hydrogen without fractions-(Records of Science, March, 1836); whereas Berzelius makes the atomic weight of carbon $0 \cdot 76438$; that of sulphur 2.01165; and sulphurous acid 4.01165, compared with oxygen 100 .

ought to be deduced from analogy-for example, if carbonic acid consisted of equal volumes of carbon vapour and oxygen, he maintains that they ought to combine without any condensation, because in all other cases, when equal volumes of gaseous bodies unite chemically, there is no contraction, as in binoxide of nitrogen, hydrochloric acid, hydriodic acid, \&c. He thinks that condensation never takes place, unless the combining volumes are unequal; therefore, that carbonic acid is composed of one volume of oxygen to half a volume of carbon vapour, (the specific gravity of which would be $\cdot 832$, instead of 4116 , or 12 times that of hydrogen.) But it is not very material whether we regard the specific gravity of carbon vapour as 6 or 12 times that of hydrogen, as either number is in accordance with the law of multiple ratios. 
Without pretending to decide which of these illustrious experimenters has approximated most nearly to the truth, it would appear from all the lights of modern analysis, that when the atomic numbers shall have been ascertained with perfect accuracy, they will be found to constitute very simple ratios. It is obvious, that if the atomic weight of carbon is 6 times that of hydrogen, oxygen 8 , and sulphur 16 , the above and many other equivalent numbers of Berzelius cannot be correct; which is also the case with those of Dr. Turner, who has adopted most of them. Whether this be true or not, the simplicity of the atomic theory, as adopted by the majority of British chemists, has been greatly diminished by the number of decimals which Berzelius has affixed to his atomic weights. I concur most fully with Professor Forbes, in the hope that philosophers may dismiss that superfluity of decimal places which has been recently introduced into several branches of physical science. They have already tended to shake the confidence of some, as to the soundness of the atomic theory.

The important discovery of Gay-Lussac has been so far extended and verified by the united researches of modern chemists, that it may be regarded as an established law; that all gaseous bodies combine with each other in definite proportions by volume, and in accordance with the law of multiples. 
The following Table will show the connexion between the specific gravity of gaseous bodies and their atomic weights. The first column of figures represents their specific gravities, compared with common air as a standard, as deduced from the experiments of Thomson, Prout, Berzelius, Dulong, Gay-Lussac, Ure, Dumas, and Mitscherlich, under the ordinary pressure of the atmosphere, and at the temperature of $60 \cdot \mathrm{F}$. with the exception of phosphorus, sulphur, arsenic, and such other bodies as require higher temperatures to convert them into the gaseous state. The second column exhibits the number of grains in 100 cubic inches; while the third column gives the relation of their specific gravity to that of hydrogen as unity; and is obtained by dividing the numbers in the first column, by the specific gravity of hydrogen.

$$
\begin{array}{lll}
\text { Gases and vapours. Specific gravities. } \quad \text { No. of grains in } & \begin{array}{c}
\text { Sp. gr. com- } \\
\text { pared with } \\
\text { hydrogen. }
\end{array}
\end{array}
$$

Atmospheric air..... 1.000...... $31.01 \ldots . .15$

Chlorine ......... 2.500 Cl. ... 76.20 .... 36

Iodine vapour......8 8.716 I..... $265 \cdot 76 \ldots \ldots 126$

Bromine do. ....... 5.555 Br. ... 169.29 .... 80

Carbon vapour ..... 416 C..... $12.68 \ldots \ldots \quad 6$

Carburetted hydrogen $\quad .555 \mathrm{C} \mathrm{H}^{2}{ }^{2} . \quad 17 \cdot 30 \ldots \ldots \quad 8$

Olefiant gas ....... $981 \mathrm{C}^{2} \mathrm{H}^{2} . \quad 29.90 \ldots \ldots \quad 14$

Ætherine vapour . ... $1.963 \mathrm{C}^{4} \mathrm{H}^{4} \ldots \quad 61 \cdot 13 \ldots \ldots 28$

Carbonic oxide ....... 972 C O or C $29 \cdot 62 \ldots . \quad 14$

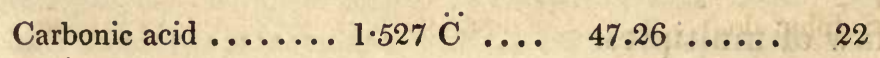


$\begin{array}{lll}\text { Gases and vapours. } \quad \text { Specific gravities. } & \text { No. of grains in } \\ 100 \text { cubic inches. } & \begin{array}{c}\text { Sp. gr. com- } \\ \text { pared with } \\ \text { hydrogen. }\end{array}\end{array}$ Aqueous vapour ..... $625 \dot{\mathrm{H}} \ldots . .19 .05 \ldots \ldots .9$ Alcohol vapour $\ldots \ldots . .1 \cdot 620 \mathrm{C}^{2} \mathrm{H}^{3}$. $49.37 \ldots \ldots 23$ Ether do.......2. 2.570 $\mathrm{C}^{4} \mathrm{H}^{5} \mathrm{O} \quad 79.67 \ldots \ldots 37$ Cyanogen ........ 1.815 C $\mathrm{C}^{2} \mathrm{~N} \ldots \quad 56.47 \ldots \ldots 26$

Sulphurous acid ..... $2 \cdot 222 \quad \ddot{\mathrm{S}} \ldots \quad 67 \cdot 72 \ldots \ldots \quad 32$

Sulphuric acid...... $2777 \quad \ddot{\mathrm{S}} \ldots \quad 84 \cdot 72 \ldots \ldots \quad 40$

Protoxide of nitrogen .. $1.527 \quad \dot{\mathrm{N}} \ldots \quad 47.26 \ldots \ldots 22$

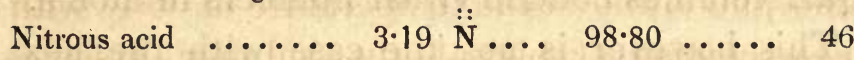

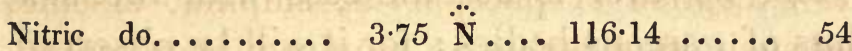

Hydrogen gas ....... 0.0690 H... $2.13 \ldots \ldots \quad 1$

Phosphuretted hydrogen $1 \cdot 185$ P H .. $36 \cdot 74 \ldots \ldots .17$

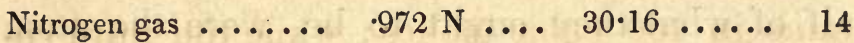

Ammonia......... $590 \mathrm{~N} \mathrm{H}^{3} \quad$. $18.19 \ldots \ldots .8 .5$

Hydrochloric acid ... $1270 \mathrm{Cl} . \mathrm{H}$. $39 \cdot 36 \quad \ldots \ldots .18 .5$

Hydrocyanic do...... $942 \mathrm{C}^{2} \mathrm{~N} \mathrm{H} \quad 29.30 \ldots \ldots .13 .5$

Binoxide of nitrogen .. $1 \cdot 041 \ddot{\mathrm{N}} \ldots \quad . .32 \cdot 13 \quad \ldots \ldots \quad 15$

Hydriodic acid ..... 4.409 I H ......... 63.5

Hydrobromic do. .... $2.812 \mathrm{Br} . \mathrm{H} \quad \ldots \ldots \ldots \ldots . .40 .5$

Mercury vapour ..... 6.944 Hg... ........ 100

Protochloride of mercury $8 \cdot 204 \mathrm{Cl} . \mathrm{Hg}$. ........ 118.5

Bichloride of ditto ... $9.431 \mathrm{Cl}^{2} \mathrm{Hg}$. ....... 136

Bromide of do. ..... 9.665 Br. Hg. ....... 140

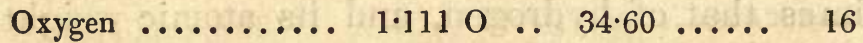

Phosphorus vapour. .. 4.444 P... ........ 64

Arsenic vapour ..... 10.625 As. .. ......... 152

Sulphur do. ...... 6.666 S ... ........ 96 
By comparing the numbers in the 3rd column of the Table, down to nitrogen, with the atomic weights in the preceding table, page 50, it will be found that they are identical - or, that the specific gravity of the gases and vapours in the upper department of the Table, corresponds with their atomic weights, as deduced from the analysis of compound bodies. From which it follows, that equal volumes contain equal numbers of atoms.

This however is not the case with the next class of gaseous bodies ; for it will be observed, that from ammonia down to bromide of mercury, the atomic weights in the 3 rd column are just half of what they ought to be, were the atom and the volume the same-that is, allowing the atomic weights in the first Table to be the true ones.

It will also be observed, that the specific gravity of oxygen is 16 times that of hydrogen, while its atomic weight is only 8 -showing that its specific gravity is double its atomic weight as exhibited in the first Table. The difference is still greater between the specific gravity of phosphorous vapour and its atomic weight, in the ratio of 4 to 1 -or of 64 to 16 . The same is true of arsenic vapour, its specific gravity being 152 times that of hydrogen, and its atomic weight only $38-$ while the specific gravity of sulphur vapour is 6 times its atomic weight, the former being 96 , and the latter 16 . 
The following Table will show at once the nature and importance of the facts on which the theory of volumes is founded, and their connexion with the atomic constitution of matter.

Vols. or cubic inches. Cubic inches: Vols.

$200 \mathrm{H}$. combine $100 \mathrm{O}$. to form Aq. 200 of Aqueous vapour $300 \mathrm{H} .$. do. .. $100 \mathrm{~N}$. to form Am. 200 Ammonia. 200 H. . do. .. 100 C. vapour $\mathrm{CH}^{2} 100$ Light Carbur. hyd. $200 \mathrm{H}$. .. do. . $200 \mathrm{C} .$. do... $\mathrm{C}^{2} \mathrm{H}^{2} 100$ Olefiant gas 400 H. . . do. . 400 C.. do .. En. 100 Etherine vapour $300 \mathrm{H}$. . do . . $600 \mathrm{C}$. . do... $\mathrm{C}^{6} \mathrm{H}^{3} 100$ Bicarburet of hydr. $500 \mathrm{H}$. . do. .. $600 \mathrm{C}$. . do... $\mathrm{C}^{6} \mathrm{H}^{5} 100$ Naptha vapour $1000 \mathrm{Car}$. vapour $400 \mathrm{H} \ldots$.... $\mathrm{C}^{10} \mathrm{H}^{4} 100$ Napthalin vapour 1500 C. .. do... $400 \mathrm{H}$...... $\mathrm{C}^{15} \mathrm{H}^{4} 100$ Paranapthalin do. 200 Nitrogen do. 100 Oxygen.. N O 200 Protoxide of Nitr. 200 N. .... do. 300 O....... $\dot{\mathrm{N}} 200$ Hyponitrous acid 200 N. ... do. 4000 ...... $\quad 200$ Nitrous acid $200 \mathrm{~N} . .$. do. 5000 ..... $\ddot{\mathrm{N}} 200$ Nitric acid 100 C. vapour do. 2000 ..... $\ddot{\mathrm{C}} 200$ Carbonic acid 200 C. do. do. $100 \mathrm{~N}$...... C $\mathrm{C}^{2} \mathrm{~N} 200$ Cyanogen 400 Car. oxide.. $400 \mathrm{H}$..... C $^{4} \mathrm{H}^{4}$ Hydrous acetic acid 100 Olefiant gas $100 \mathrm{Aq}$.vap. $\mathrm{C}^{2} \mathrm{H}^{3} \mathrm{O} 100 \mathrm{Alcohol}$ vapour 200 .. do. ... $100 \mathrm{Aq}$. do. $\mathrm{C}^{4} \mathrm{H}^{5} \mathrm{O} 100$ Ethereal vapour

100 Chlorine do. $100 \mathrm{H}$.... Cl. H. 200 Hydrochloric acid 100 C. vapour $1000 \ldots$. C 200 Carbonic oxide $100 \mathrm{I}$ do. $100 \mathrm{H} \ldots$. . I H 200 Hydriodic acid 
Vols. or cubic inches. Cubic inches.

Vols.

$100 \mathrm{Cy}$. combine $100 \mathrm{H}$ to form Cy. H $200 \mathrm{Hydrocyanic}$ acid $100 \mathrm{Cy} . \ldots . .100 \mathrm{Cl}$..... Cy. Cl. 200 Cyanuret of chlorine 100 Cy. ..... 100 I....... Cy. I 200 Cyanuret of iodine 200 N. ..... $2000 \ldots . . . \dot{N} \quad 400$ Binoxide of nitr.

25 P. ..... 100 H..... P H 100 Phosphuretted hyd. 16 Sulphur vap. 100 H..... S H 100 Sulphuretted do.

16 S..... do. 200 O.... $\ddot{\mathrm{S}} 200$ Sulphurous acid

16 S. . . do. 300 O..... $\dot{\mathrm{S}} 200$ Sulphuric acid

By glancing over the above Table, we perceive that the aggregate volume of the 18 first gases and vapours, down to æther, is reduced during chemical combination from 3 to 2,4 to 2,3 to 1,4 to 1 , (as in olefiant gas) - from 8 to 1 , as in ætherinefrom 9 to 1, in Faraday's bicarburet of hydrogen-from 11 to 1 , in naptha vapour-and from 14 and 19 to 1 , as in napthalin and paranapthlinin all of which, the specific gravity and atomic weight are the same.

The next class of gases and vapours in the 2nd department of the Table, unite chemically without any change of volume, such as chlorine and hydrogen, to form hydrochloric acid gas, the specific gravity of which is a mean of its constituents, - and so of the other six gases and vapours, including binoxide of nitrogen-in all of which the specific gravity represents only one half of their atomic weights. 
It will also be observed, that the volume of phosphorus vapour is augmented from 25 to 100 , on uniting with hydrogen, and that of sulphur from 16 to 100 , as in sulphuretted hydrogen, sulphurous acid, \&c.

Here is a most important series of phenomena that have never been explained.-1. Why the specific gravity of gaseous bodies does not always correspond with their atomic weights, except in accordance with the law of multiple or submultiple ratios:-2. Why many gases unite chemically with contraction of volume and diminution of elastic force:-3. others without contraction:4. and some with expansion of volume, as the vapours of sulphur, phosphorus, \&c.

It will be shewn in the next chapter, that all the phenomena of contraction, expansion, and the elastic force of gaseous bodies, depend on their relations to caloric, which surrounds every atom of ponderable matter, and, by its transition from one body to another, determines all the chemical or physical changes which they undergo; that the elastic force of hydrogen, oxygen, and nitrogen, (which depends on the relative proportions of caloric and ponderable matter of which they are composed,) is so great, that no degree of force, except that of chemical attraction, has been adequate to condense them perfectly into the liquid form : but that on uniting chemically with each other, and with carbon, 
phosphorus, sulphur, and various other bodies, they are deprived of their elastic force, and in many cases without any disengagement of caloric.

The following observations will shew at once how chemical affinity modifies the specific gravity and elastic force of gases. It has been seen that the specific gravity of chlorine is 36 times that of hydrogen. Its elastic force is also small, as it may be condensed by a pressure equal to 4 atmospheres, or even by cold without pressure. But when 100 cubic inches of chlorine unite chemically with 100 cubic inches of hydrogen, (the elastic force of which is immense), they form 200 cubic inches of hydrochloric acid gas, the elastic force of which is equal to the pressure of 40 atmospheres, at the temperature of $50^{\circ}$. During this combination, the larger atoms of chlorine take from those of hydrogen a definite ratio of caloric, by which the elasticity of the hydrogen is diminished, and that of the chlorine increased. At the same time, the atoms of chlorine are removed farther from each other, causing an alteration of specific gravity in the resulting compound. In like manner, when one volume of iodine vapour, the specific gravity of which is 8.75 , unites chemically with an equal volume of hydrogen, the specific gravity of the resulting compound is diminished to $4 \cdot 385$ - and so of the rest, together with many other like combinations not set down in the Table. 
The volume of phosphorus, arsenic, and sulphur vapours is still further augmented on uniting with hydrogen and other permanent gases. The specific gravity of these vapours, as deduced from the experiments of Dumas and Mitscherlich, (who converted them into the gaseous state by heat,) are $4 \cdot 444,10 \cdot 625$, and $6 \cdot 666$ (see table, page 61 ); but when phosphorus vapour unites with hydrogen, its volume is augmented fourfold-that is, from 25 to 100 , as in phosphuretted hydrogen. Sulphur vapour is expanded still more on uniting with hydrogen, viz. from 16 to 100 , as in sulphuretted hydrogen, as before stated. Now it must be remembered that the vapours of phosphorus, sulphur, mercury, and arsenic, have little or no elasticity, unless at high temperatures; from which it follows, that their volume and elastic force are augmented on uniting with hydrogen, by acquiring from it a sufficient amount of caloric to produce the effect. These views will be more fully expanded when I come to treat of the natural forces of caloric.

When thus investigated in connection with the cause which moves atoms, and the law by which they are united and separated, the atomic theory embraces the whole science of nature. But until the mutual relations of rthereal and ponderable matter shall be better understood, the theory of atoms, and consequently that of chemistry, must remain involved in profound obscurity - a lifeless 
mass of phenomena, for which no satisfactory reason can be assigned.

In regard to several bodies termed elementary, chemists have not yet been able to determine whether we have obtained their true atomic weights, or only multiples or submultiples of them. At one time, it was supposed by Ampère and Dumas, that equal volumes of all gases and vapours, simple or compound, contain exactly the same number of atoms. In order to sustain this hypothesis, so beautiful from its simplicity, Dumas imagined that when chlorine unites chemically with hydrogen to form hydrochloric acid gas, their atoms undergo a division, by which 2 atoms of the acid are formed out of one of each of its elements. It is needless to insist, that these hypotheses have not been found in accordance with established facts.

That equal volumes of all gases contain equal numbers of atoms was inferred, first, from the circumstance that all gaseous bodies are equally expanded by the same additions of caloric, the pressure being equal: and secondly, from the supposed fact, (which has been termed the law of Mariotte), that the volume of any gas whatsoever, diminishes in proportion to the pressure exerted upon it, the temperature being equal. It was maintained, that if the number of atoms in each gas were not the same, the diminution of volume under the same pressure ought also to vary. 
Recent experiments performed by Erstedt and Despretz, have proved that this is actually the case- that the volume of sulphurous acid, cyanogen, ammonia, and sulphuretted hydrogen, diminishes much more rapidly under an equally increasing pressure, than oxygen and nitrogen, as in common air-consequently, that the law of Mariotte is not true when applied to gases indiscriminately; but only to such as have the same degree of elastic force. Despretz regards the above deviation from the law of Mariotte, as referable to some unknown law which regulates the constitution of gases.

When I come to treat of the causes which modify the elastic force of gases, it will be shewn that their volume and compressibility are determined by their relations to caloric, and not by the number of atoms in a given volume.

Berzelius maintains in a recent work, entitled Des Proportions Chimiques, that all gaseous bodies in the simple state, contain the same numbers of atoms, or that the atomic weights of simple bodies are represented by their specific gravity in the gaseous state: from which it would follow, that the atomic weight of hydrogen is $\frac{\mathrm{T}}{\mathrm{x}} \mathrm{t}$ that of oxygen, (instead of $\frac{1}{8}$ ), corresponding with the difference between their specific gravities. And as it was found that water is always composed of 2 volumes of hydrogen to 1 of oxygen, it was inferred by Davy, Berzelius, Prout, and others, that 
water is a ternary compound, of two atoms hydrogen to 1 of oxygen.

In like manner, when it was found that the protoxide of nitrogen is composed of two volumes nitrogen and one of oxygen, it was inferred that it is a ternary compound of two atoms nitrogen to one of oxygen. In accordance with this view, Berzelius and many of the continental chemists regard the hydrogen atom of Dalton, and the nitrogen atom of Thomson, Turner, Brande, and other British authors, as double atoms, or multiples of their real weights. But if it be true, that the only combining proportions on which we can depend, are such as the most accurate experimenters have found them to enter by weight into the composition of compound bodies, we are not authorized to adopt the numbers of Berzelius, until verified by new and more accurate methods of analysis. At the same time, I am free to confess, that the great degree of elastic force in nitrogen, favours the opinion of Berzelius, that its atomic weight is 7 , compared with hydrogen, instead of 14. It cannot, however, be supported on the ground that equal volumes of gases and vapours contain the same numbers of atoms; for it is manifest, that while the atomic weight of ammonia is 17 times that of hydrogen, its specific gravity is only 8.5 ; that the atomic weight of hydrochloric acid is 37 , but its specific gravity only $18 \cdot 5$, and so of various other gases. It is 
also evident, that whenever the specific gravity of gases does not correspond with their atomic weights, they vary according to the law of multiples or submultiples, which renders the theory of volumes nearly as simple as if the atom and the volume were always the same.

It is exceedingly difficult, if not wholly impossible, to explain the foregoing phenomena of chemical combination, without adopting the theory of Newton, Higgins, and Dalton, that the elements of ponderable matter are composed of ultimate atoms, which, however minute they may be, must have both extension and weight. If they were mere mathematical points, or mere centres of force, without extension, as maintained by Boscovich and Exley, they could not possibly form extended and massy aggregates. That ponderable matter consists of incalculably small particles or atoms, is evident from all the phenomena of solution, the diffusion of odours, and the minuteness of organized animalcules. According to the observations of Ehrenberg, the monas, which has a complicated stomach and other organs, is not more than a 20-thousandth part of an inch in diameter; while other species have been discovered, so minute, that a million of them have been supposed not to exceed the magnitude of a single grain of sand.

The phenomena of crystallization are not less astonishing. When a drop of muriate of ammo- 
nia is magnified by an oxy-hydrogen microscope, it is seen to shoot into many hundred thousand small crystals, (each of which must contain at least as many ultimate atoms, ) which coalesce into one symmetrical solid crystal; yet are they all governed and arranged by number, measure, and weight. An ultimate particle of lead, which is 104 times larger than an atom of hydrogen, is estimated by Dr. Thomson as only $\frac{1}{310,000,000,000}$ th of a grain. Yet, if the igneous ather which surrounds these molecules be a material agent, its particles must be inconceivably smaller. We can no more measure the ultimate minuteness of this spiritual and fiery essence than we can comprehend the infinitude of space and duration. We are less amazed on contemplating the vast cycles of geology and astronomy, than by attempting to follow nature in her smallest proportions. We know not the absolute weights of gravitating atoms, but we know from the preceding facts, especially those on which the law of multiples is founded, that they vary in size. We know not the forms of ultimate atoms, nor whether they are all of the same density; but as all bodies in the liquid state are disposed to assume a round form, we may conclude that they are spherical, and that the various forms of crystalline bodies are determined by the modes in which their particles are grouped and arranged.

Dr. Prout has recently maintained that the 
chemical molecules of oxygen, hydrogen, carbon, \&c. do not exist in a state of ultimate division; but that they are composed of many sub-molecules, which he conceives are analogous in subtilty and refinement to imponderable matter.* It will be shewn hereafter, that the electric spark, and the spark from the collision of flint with iron, steel, and other hard bodies, is imponderable while in that state. It will be inquired further on, whether ponderable matter in such a state may not be more subtile than in the elementary gaseous form; and whether the different colours of electric light, and of the flames of combustion, may not depend on the different primitive colours of ultimate atoms.

Relative Quantities of Caloric in Different Bodies.

This is one of the most difficult problems in Physical Science, the very elements of which have yet to be unfolded. If it be true, that the whole material world is composed of gravitating atoms which vary in size, and that they are surrounded by an active, igneous, and æthereal principle, which is immediately connected with all their properties and changes, it is obviously an object of primary importance to ascertain the

* Bridgewater Treatise, p. 90. 
relative proportions of each, and the laws of their operation upon each other. Without hoping fully to develope a subject which has hitherto baffled all the efforts of preceding philosophers, I shall endeavour to shew, that the methods which have been employed for the purpose of estimating the constituent caloric of bodies are fallacious; the application of which, to the phenomena of combustion, respiration, evaporation, and solution, has been a constant source of error.

It has been known ever since the time of Dr. Black, that different quantities of caloric are required to produce the same temperature, in equal weights or volumes of different bodies - that $1 \mathrm{lb}$. of water requires about double the quantity of caloric to raise its temperature 50 or $100^{\circ}$, that $1 \mathrm{lb}$. of oil does-and that, on cooling an equal number of degrees, water gives out twice as much caloric as an equal weight of oil: from which it was inferred, that the same difference existed between the latent caloric of oil and water at all temperatures, down to their absolute zeros-in other words, that the whole amount of caloric in water is double that of oil.

This difference of capacity for caloric, as it was termed by Dr. Black and his disciples, which was found to exist between all other bodies, has been regarded by Crawford, Kirwin, Lavoisier and Laplace, Leslie and Dalton, as a measure of the relative quantities of caloric which is chemically 
combined with them, and has been generally termed specific heat. But it is now universally conceded, that the whole subject is involved in profound obscurity, and that nearly all the experiments connected with specific heat, are at variance with each other; which alone is a sufficient proof that the truth has not yet been fully ascertained.

According to the above mode of deducing the amount of caloric in bodies, water should contain more caloric than an equal weight of any other known liquid or solid, as it gives out a larger quantity on cooling an equal number of degrees. If capacity or specific heat were a true criterion of what they contain, the latent caloric of æther, alcohol, oils, wood, coal, and all those bodies which are known to be the most combustible, would be comparatively low; which is refuted by all the phenomena of combustion. This ought to have been inferred from the large proportions of hydrogen that enter into the composition of such substances, and from the well-known fact, that a given weight of hydrogen gives out far more caloric during combustion than any other known body. Ever since the first discovery of hydrogen, it has been regarded as an exceedingly igneous substance. The older chemists termed it inflammable air. At one time, Kirwin maintained that it was identical with the phlogiston of Stahl, which was in reality the undiscovered latent heat of Black. 
These vague hypotheses have been superseded by the more definite views of the celebrated Lavoisier, who proved that hydrogen is composed of a ponderable base, united with an igneous fluid, which he termed caloric ; and which may be separated from each other by chemical action.

According to the experiments of Dr. Dalton, caloric enough is decomposed and given out during the combustion of $1 \mathrm{lb}$. of hydrogen gas, to melt $320 \mathrm{lbs}$. of ice. According to Crawford, $480 \mathrm{lbs}$. of ice are melted by the heat given out during the combustion of $1 \mathrm{lb}$. of hydrogen; which Dr. Thomson thinks is about as far beyond the truth, as Dalton's estimate falls short: consequently, that $400 \mathrm{lbs}$. may be regarded as the mean quantity of ice that will be melted during the combustion of $1 \mathrm{lb}$. of hydrogen. If then we admit with Dr. Black, that $140^{\circ}$ of caloric are required to melt $1 \mathrm{lb}$. of ice, $56,000^{\circ}$ of heat must be given out during the combustion of $1 \mathrm{lb}$. of hydrogen.

It must however be observed, that during the process, 2 volumes of hydrogen combine chemically with 1 of oxygen - or that 1 atom of oxygen combines with 1 of hydrogen; and as the atomic weight of oxygen is 8 times that of hydrogen, $8 \mathrm{lbs}$. of oxygen must unite with 1 of hydrogen, making $9 \mathrm{lbs}$. of water. From which it is evident, that a certain proportion of the caloric disengaged, is afforded by the oxygen; for we find 
that the volume and elastic force of both gases are destroyed on assuming the liquid form.

If equal volumes of all gases contained the same quantities of caloric, as conjectured by Dr. Dalton, we should have $37,334^{\circ}$, as the amount of heat disengaged from $1 \mathrm{lb}$. of hydrogen, and $18,666^{\circ}$ from the oxygen, or $\frac{1}{3}$ of $56,000^{\circ}$, corresponding with the difference between the specific gravity of oxygen and hydrogen, which is as 16 to 1 -(that is, the volume of $1 \mathrm{lb}$. of hydrogen is twice that of $8 \mathrm{lbs}$. of oxygen). In accordance with this hypothesis, $1 \mathrm{lb}$. of hydrogen should give out 16 times more caloric than an equal weight of oxygen, coinciding with the difference between their volumes.

But as it will be shewn hereafter, that equal volumes. of the compound gases, which have a greater density than that of hydrogen, contain more caloric, I shall assume for the present, that $1 \mathrm{lb}$. of hydrogen contains 8 times more caloric than $1 \mathrm{lb}$. of oxygen, corresponding with the difference between their atomic weights; for it would be contrary to all analogy to suppose, that an atom of hydrogen, which is only $\frac{1}{8}$ the size of an oxygen atom, should contain double, or any other greater quantity of caloric.*

* It is therefore probable, that $1 \mathrm{lb}$. of hydrogen evolves $28,000^{\circ}$ of caloric during combustion, which would melt $200 \mathrm{lbs}$. of ice at $32^{\circ}$-and that $8 \mathrm{lbs}$. of oxygen afford the same quantity. From the large amount of caloric combined with hydrogen, we are en- 
This view of the subject is in accordance with the hypothesis of Dulong and Petit, to be noticed further on, who inferred from their experiments that the atoms of all bodies contain equal quantities of caloric.

Still, we are left in the dark in regard to the amount of caloric which is retained around the atoms of oxygen and hydrogen, after their condensation into the liquid form - the knowledge of which would constitute a valuable addition to the present stock of physical science.*

When we consider the vast abundance and importance of oxygen and hydrogen in the economy of nature, it becomes obvious, that a correct mode of ascertaining the relative quantities of caloric which they contain, would throw new light on all

abled to comprehend why those bodies which contain much of it, are so highly volatile and combustible, as, the different æthers, alcohol, volatile oils, tallow, wax, turpentine, bituminous coal, and nearly all other light bodies.

* If the volume of water were diminished in the same ratio at all temperatures, by the abstraction of caloric, we might arrive at a proximate estimate of the absolute quantity of caloric which it contains. For example, it is known that water is diminished about $\frac{\mathrm{r}}{22}$ of its volume on reducing its temperature $180^{\circ}$, viz. from $212^{\circ}$ to $32^{\circ}$. If then it be assumed that the pores of water are 20 times greater than its solid atoms, (and Newton supposed that they were double this estimate,) it would require the abstraction of $3,600^{\circ}$, to deprive it of all its caloric, provided the volume continued to diminish in the same ratio. But as it has been found that below the freezing point of mercury, its volume contracts in a greater ratio than at higher temperatures, it is probable that the same thing may be true of other bodies. 
the relations of æthereal and ponderable matter. All the waters of the earth are composed of oxygen and hydrogen, in the proportions of 8 to 1 by weight. When converted into vapour by solar caloric, and diffused through the atmosphere, water is connected with all the phenomena of metereology. As a mechanical agent, running water is perpetually wearing down mountains, hills, and elevated plains, and transporting them to valleys, lakes, and seas.

As a chemical agent, water is slowly but constantly dissolving rocks, salts, and metals, which are again precipitated in the crystalline or solid state. It forms a large proportion of all animal and vegetable bodies; also, of many salts and rocks. As a constituent of the atmosphere, oxygen is indispensable to all the phenomena of vitality. It enters largely into the composition of nearly all acids, alkalies, native ores, or metallic bases ; and constitutes about $\frac{1}{4}$ of the earth's crust.

The importance of carbon is not less manifest; forming, as it does, the basis of all organic matter. In combination with hydrogen, it constitutes the principal portion of the food by which we are nourished, and of the fuel by which we are warmed, and kept alive during winter. According to the analysis of Gay-Lussac, and of Dr. Prout, it forms about one half of lignin, or perfectly dried woody fibre. It is the chief ingredient in those immense subterranean forests of 
ancient vegetation, termed fossil coal ; and which, perhaps, exceed in quantity a hundred fold, all the trees and plants that now cover the surface of our planet.

Still greater is the quantity of carbon which is locked up in a latent state of combination with lime and other rocks; for it constitutes about $\frac{1}{8}$ of the widely diffused strata of carbonate of lime, which forms the basis of extensive territories in every quarter of the world. Although it is now fully established, that all the varieties of fossil coal are of vegetable origin, geologists seem not to have ascertained, or even inquired, why the chemical constitution of coal is so various in different regions. In Wales, and in several mountainous portions of the United States, there are extensive deposits of hard coal, termed anthracite, consisting almost entirely of carbon, which burns slowly, and without flame; while all the other varieties of fossil coal are composed of carbon, united with various proportions of hydrogen, oxygen, and in some cases of nitrogen, with the exception of Cannel coal, which is without oxygen. The following facts may tend to throw some light on this obscure subject.

1. So far as the knowledge of the writer extends, anthracite is confined to regions that have been elevated by subterranean fire, and at Carbondale in Pensylvania presents every appearance of having undergone the action of intense heat. 
2. It has been found by geologists, that where beds of bituminous coal have been perforated by mineral veins, (which were originally the conduit pipes for the escape of volcanic heat,) it has been changed into coke, or nearly pure carbon.

3. That beds of anthracite are confined chiefly to mountainous regions; whereas inflammable coal belonging to the same geological epoch, is found in vast quantities between horizontal strata of sandstone and shale. But I must return from this digression to the immediate subject of inquiry.

After all attempts to ascertain the specific heat of bodies had proved discordant and fallacious, a series of experiments was undertaken by MM. Dulong and Petit, the object of which was to discover what relation existed between the atomic weights of various bodies and their capacities for caloric. The result of their researches was, that the specific heat of water was nearly three times that of sulphur and several of the metals, in which it was about one half less than in some other elements, four times less than in others again, such as phosphorus and iodine, while in carbon it was nearly six times less than in water, or as $0 \cdot 169$ to $1 \cdot 000$. They also found that there was no uniform relation between the quantities of caloric evolved during the combustion of different bodies, and the specific heat of their resulting products, the capacity of which was often the same before as after the process. Yet they maintained that 
the atoms of all simple bodies have the same specific heat; because when they vary, it is in multiple or submultiple ratios, or nearly so; and that the atomic equivalents of all bodies which do not accord with this assumed law, ought to be altered and made to agree with it. (Ann. de Chim. et de Phys. tom. x.)

The recent efforts of Dr. Thomson to verify the hypothesis of Dulong and Petit, have not been more successful; as will appear from the following table, representing the atomic weight of twenty-six simple substances, (compared with oxygen as unity,) their specific heat, and the resulting product. He observes, that " if the specific heat of bodies multiplied into their atomic weights be a constant quantity, it will follow that every simple atom is surrounded with the same quantity of heat." (Records of Science, April, 1836.)

Atomic weight. Specific heat. Product.

\begin{tabular}{|c|c|c|c|}
\hline & 5 & $0 \cdot 2$ & \\
\hline Silicon ...... & 1 . & $\ldots .0 \cdot 187$ & $0 \cdot 187$ \\
\hline Aluminum.... & $1 \cdot 25$ & $0 \cdot 150$ & $0 \cdot 187$ \\
\hline Oxygen....... & 1 & $0 \cdot 236$ & $0 \cdot 236$ \\
\hline Chlorine .... & $4 \cdot 5$ & 0.827 & 0.372 \\
\hline Bromine ...... & 10 & $0 \cdot 472$ & $0 \cdot 437$ \\
\hline Hydrogen. & $0 \cdot 125$ & $3 \cdot 293$ & $.0 \cdot 412$ \\
\hline Nitrogen & 1.75 & $0 \cdot 269$ & $0 \cdot 472$ \\
\hline Sulphur...... & 2 & $0 \cdot 188$ & $0 \cdot 37$ \\
\hline Arsenic ....... & $4 \cdot 75$ & 0.081 & $0 \cdot 385$ \\
\hline 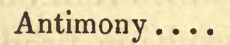 & 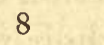 & & $9 \cdot 376$ \\
\hline Tellurium & 4 & $0 \cdot 091$ & 0.36 \\
\hline Iron $\ldots$ & $3 \cdot 5$ & $0 \cdot 110$ & 0.38 \\
\hline i & & & - \\
\hline
\end{tabular}


Atomic weight. Specific heat. Product.

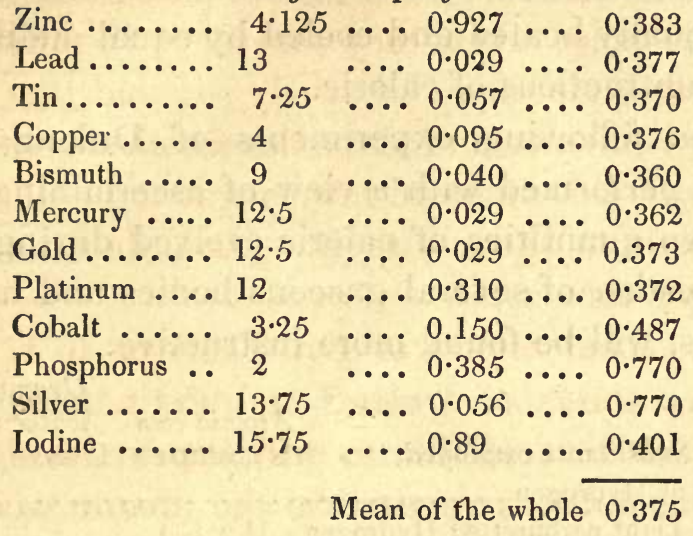

Dr. Thomson maintains, that if the atoms of carbon, silicon, and aluminum were doubled, and those of phosphorus and silver reduced one half, their specific heat would be about the same as the mean of the whole; and that the other deviations from this average, ought to be referred to inaccurate experiments. But if for the sake of argument we admit his assertion, it would follow that an equivalent of water contains $5 \cdot 85$ times more caloric than one of carbon, silicon, or aluminum; 4.76 times more than an atom of oxygen; above two and a half times more than one of hydrogen, nitrogen, iodine, or cobalt; and about 40 per cent. more than one of phosphorus or silver; for the specific heat of water is $1 \cdot 125$ when multiplied by its atomic weight. And that capacity is no measure of the relative quantities of caloric in different bodies, would appear from the experiments of Haycraft, Delarive, and 
Marcet, who found that equal volumes of all gases are equally heated and cooled by equal additions and subtractions of caloric.

The following experiments of Dulong and Hess, performed with a view of ascertaining the relative quantities of caloric evolved during the combustion of several gaseous bodies and a few metals, will be found more instructive.

Grammes of Atomic com- water raised

Substances employed position $1^{\circ}$ centigrade.

1 Litre of Hydrogen ................... 3,102

1 L Light carburetted Hydrogen. H 2 C $1 \ldots \ldots 9,587$

1 _- Olefiant gas.............. H $2 \mathrm{C}_{2} \ldots \ldots .15,338$

1 - Carbonic oxide ........... O 1 C C $1 \ldots \ldots .3,130$

1 - Cyanogen .............. C $2 \mathrm{~N}_{2} \ldots \ldots .12,269$

1 - Alcohol vapour........... C 2 H 3 O $\mathrm{O}_{1} \ldots 14,375$

1 — Ether vapour .......... C 4 H 5 O O 1 . 32,254

1 - Turpentine vapour ....... C 10 H 8 ... 70,607

Carbon vapour equal to 1 litre in the gaseous state ... 7,858

1 Litre of Oxygen gas with iron ............. 6,216

$1 \longrightarrow$ Tin .............. 6,508

$1 \longrightarrow$ Antimony .......... 5,552

$1 \longrightarrow$ Zinc ............ 7,577

$1 \longrightarrow$ Cobalt $\ldots \ldots \ldots \ldots \ldots \ldots, 5,721$

$1 \longrightarrow$ Nickel ........... 5,333

Mean of the six metals 6,151

To these may be added the results of M. Despretz, who found, that during the combustion of $1 \mathrm{lb}$. of different substances, caloric enough was evolved to raise the following quantities of water from $32^{\circ}$ to $212^{\circ}$.

Substances employed. Quantities of water. $1 \mathrm{lb}$. of Hydrogen .............. 236.4 lbs.

- Charcoal from wood......... 75 
Substances employed. Quantities of water. $1 \mathrm{lb}$. of Olive oil .............. 90

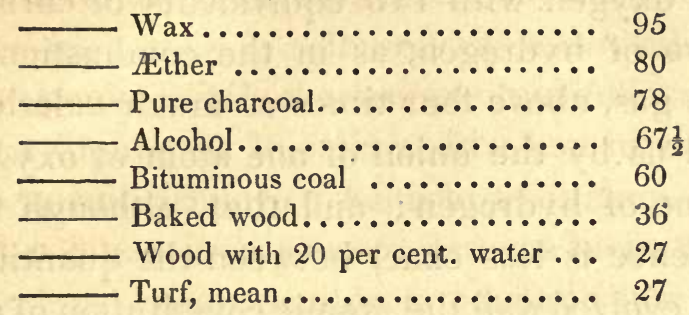

From the table of Dulong and Hess we perceive, that during the combination of one atom of oxygen with two of hydrogen and one of carbon, as in light carburetted hydrogen, about three times more caloric is evolved, than by the combustion of the same volume of pure hydrogen; and that one atom of carbon vapour, as it exists in carbonic oxide, gives out almost precisely the same amount of heat as an equal volume of hydrogen. It would also appear from the same table, that during the chemical union of oxygen with the above metals, and its conversion into the state of solid oxides, about twice as much caloric is evolved as by the same bulk of hydrogen. So that if nearly the whole is afforded by the oxygen, it would be about eight times less than is given out by the same weight of hydrogen, corresponding with the difference between their atomic weights; for hydrogen is sixteen times lighter than oxygen: from which it would follow, that during the combination of oxygen with carbon and hydrogen, the atom of each gives out the same quantity of heat. 
We further perceive, that during the combination of oxygen with two equivalents of carbon, and two of hydrogen, as in the combustion of olefiant gas, above four times as much caloric is evolved as by the union of one atom of oxygen with one of hydrogen; and that, although the coincidence is less exact between the quantities of heat evolved and the atomic constitution of the remaining compound gases, it is sufficiently so to prove that hydrogen and carbon contain more caloric around their atoms than an equal weight of oxygen; and that equal volumes of the gases do not afford the same quantities of caloric. It must, however, be admitted, that the results of Despretz are at variance with those of Dulong and Hess, as he found that hydrogen evolves only $3 \cdot 15$ instead of 6 times more caloric than the same weight of carbon.

Let us next inquire whether the power of bodies to refract light may not afford a measure of the relative quantities of caloric around their particles. It was suggested by Newton at the close of both the Optics and Principia, that the power of bodies to reflect, refract, and inflect light, is in proportion to the quantity of æther that covers their surface, and surrounds their particles; which æther he also regarded as the cause of cohesion, elasticity, solution, capillary attraction, and gravitation. For example, he found that in spirit of wine, spirit of turpentine, olive oil, linseed oil, camphor, and amber, which are highly 
A MEASURE OF THEIR CONSTITUENT CALORIC. 87

inflammable bodies, the power of refracting light is two or three times greater, in respect to their densities, than in salts, rocks, or any other stony concretes, which are less combustible: and as it was higher in the diamond than in any other body which he tried, he arrived at the conclusion that it was a sulphureous or unctuous body coagulated, and would be found inflammable. (Optics, Book ii. 240-50.)

That there is at least a nucleus of truth in this hypothesis of Newton, would appear from the numerous experiments of Brewster, Wollaston, Biot, Arago, and Dulong, who have found that in phosphorus and sulphur, as in all those bodies which are composed chiefly of hydrogen and carbon, with various proportions of oxygen and nitrogen, the power of refracting light is much greater in proportion to their specific gravities, than.in any other bodies; and we have the most decisive proof that they contain proportionally more caloric around their particles, as might naturally have been inferred from all the phenomena of their combustion, volatility, and tendency to assume the gaseous state. But, so far as I am informed, no one has attempted to ascertain what relation exists between the latent caloric of bodies and their refractive powers, except my friend Mr. Dyer, whose views on the subject, if ever carried out, have not been published.

The most important experiments on the re- fractive power of gaseous substances with which 
I am acquainted, are those of M. Dulong, published in the Annales de Chimie et de Physique, xxxi. 154 ; as in the following table, which represents their refractive power and specific gravity, at the same temperature and pressure of the atmosphere,-to which I have added their atomic composition.

\section{TABLE I.}

Refractive Power.

Atmospheric air.........

Oxygen .......

Nitrogen...... $1 \cdot 020$

Deutoxide of Nitrogen .. $\quad 1.030$

$\begin{array}{lll}\text { Protoxide of Nitrogen ... } & 1.710\end{array}$

Carbonic Oxide........ 1:157

Carbonic Acid ........ 1.526

Marsh Gas.......... 1.504

Olefiant Gas ......... 2.302

Hydrocyanic Acid...... 1.531

Hydrochloric Acid...... 1.527

Ammonia ........... $1 \cdot 309$

Chlorine............ 2.623

Cyanogen ........... 2.832

Sulphuretted Hydrogen.. 2 2 187

Sulphurous Acid ....... 2:260

Hydrochloric झther .... 3.720

Phosgene Gas......... 3.936

Sulphuret of Carbon .... 5.110

Sulphuric Æther ...... 5.197
Specific Gravity. $1 \cdot 000$ $1 \cdot 026$ 685 976

$\begin{array}{lllll}\mathrm{O}_{2} & \mathrm{~N} & 1 & \ldots \ldots & \ldots\end{array}$

$\begin{array}{llllll}0 & \mathrm{~N} & 1 & \ldots . \ldots . . & 1.527\end{array}$

$\mathrm{O}_{1} \mathrm{C}_{1} \ldots \ldots \ldots .972$

$\begin{array}{llllll}\mathrm{O}_{2} & \mathrm{C}_{1} & \ldots \ldots & \ldots & 1.524\end{array}$

$\mathrm{H} 2 \mathrm{C} 1 \ldots \ldots . .555$

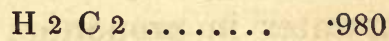

$\begin{array}{lllllll}\mathrm{C}_{2} & \mathrm{~N} & 1 & \mathrm{H} & 1 & \ldots & \ldots\end{array}$

Cl. $1 \mathrm{H} 1$

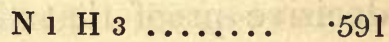

$2 \cdot 470$

$\begin{array}{lllll}\mathrm{C}_{2} & \mathrm{~N} & 1 & \ldots \ldots & \ldots\end{array}$

$\begin{array}{llllll}\mathrm{S}_{1} & \mathrm{H} & 1 & \ldots \ldots & \ldots . & 1 \cdot 178\end{array}$

$\begin{array}{llllll}\mathrm{S} & \mathrm{O}_{2} & \ldots \ldots \ldots & 2 \cdot 247\end{array}$

C 4 H 5 Cl. 1 .... $2 \cdot 234$

$3 \cdot 442$

$2 \cdot 644$ $2 \cdot 580$

From the above table we perceive, that there is no uniform relation between the refractive power of gases and what is called their specific heat, as admitted by M. Dulong; while it is 
equally obvious, that it is not in proportion to their specific gravity, nor to the size of their particles. It will be observed, however, that the refractive power of oxygen is nearly double that of hydrogen, which is sixteen times lighter: it therefore follows, that if their refractive powers be a measure of their latent caloric, hydrogen must contain $8 \cdot 14$ times more than an equal weight of oxygen; corresponding with the difference between their atomic weights, and the relative quantities of caloric they evolve during the process of combustion. It is much to be regretted that we have no means of ascertaining the refractive power of carbon, separately, in the gaseous state. But as it is about three times higher in marsh gas, and four times greater in olefiant gas than in simple hydrogen, we are authorized to conclude, that a pound of hydrogen contains six times more caloric than the same weight of carbon; or that the particles of each are associated with the same quantities of caloric.

And as the refractive power of nitrogen is $\mathbf{2} \cdot 17$ times that of hydrogen, (the specific gravity of which is fourteen times less than that of nitrogen) it follows that hydrogen must contain 6.45 times more caloric around its particles than the same weight of nitrogen. Nor can there be a rational doubt, that if the experiments were rigidly accurate, the refractive power of hydrogen would be just eight times that of oxygen, and seven times 
that of nitrogen; consequently, that the true atomic weight of nitrogen is 7 compared with hydrogen, (as maintained by Dalton and Berzelius,) instead of 14, as supposed by the majority of chemists. And if such be the fact, it follows, that hydrogen, carbon, nitrogen, and oxygen, (which are by far the most important of all the elements, because the most active, and because they are the principal constituents of organized bodies,) contain the same amount of caloric around their chemical atoms.*

\section{A still more direct and cogent proof that the} refractive power of bodies is in proportion to the

* There is, therefore, reason to believe, that when the refractive power of all bodies shall be rightly ascertained, we shall have a more certain method of determining their atomic equivalents, many of which are acknowledged to be doubtful; and that we shall be able to correct errors in regard to the chemical composition of bodies, that have arisen from imperfect analyses. It must, however, be admitted, that in the present state of science, the refractive power of compound gases, liquids, and solids, does not always correspond with that of their constituents in the separate state; a circumstance which may be owing in part to imperfect experiments, and partly to the fact, that during nearly all chemical combinations and decompositions, caloric is either absorbed or given out, as will be shewn hereafter. But as we have found that in hydrogen, carbon, and oxygen, it coincides so nearly with the quantities of caloric they give out during combustion; and is nearly the same in several compound gases, when deduced from the refractive power of their elements, the subject is one that merits the most careful investigation. For if there be no uniform ratio between the refractive power of bodies and their specific gravities, while in the best ascertained cases, it accords with the quantities of caloric they afford by combustion, it is difficult to resist the conclusion that caloric is the cause of refraction, as it is of attraction and repulsion. 
amount of caloric around their particles is, that it is higher in water than in ice, higher in fluid than in solid sulphur, as it is in all those bodies which are composed chiefly of carbon and hydrogen, such as alcohol, æther, the volatile and fixed oils, than in water, the specific gravity of which is greater, as will be seen from the following table, taken chiefly from the experiments of Sir David Brewster. It will also be seen, that it is higher in the diamond, which consists of pure carbon (condensed by an immense pressure, than in any other solid body, if we except phosphorus and sulphur, both of which are highly inflammable, and afford very large quantities of caloric by combustion.

\section{TABLE II.}

Representing the Refractive power and Specific gravity of different classes of bodies in the liquid and solid states.

Refractive Power.

Water ........... 1.335

Ice............ $1 \cdot 307$

Alcohol ........... $1 \cdot 372$

Æther........... 1.358

Melted Bees Wax .... 1.450

- Spermaceti .... 1.470

Oil of Lavender ..... $1 \cdot 457$

- Caraway ....... 1.491

- Turpentine...... 1.475

- Camphor ...... 1.487

- Lemon ........ $1 \cdot 481$

- Olives......... 1.470

Castor Oil ......... 1.490

Melted Sugar ....... 1.555

Gum .......... 1.554
Specific Gravity.

...... $1 \cdot 000$

..... 980

.... $\cdot 794$

.700

.960

940

877

940

890

988

847

910

969

$1 \cdot 500$

$1 \cdot 400$ 
Refractive power.

Acetic Acid ........ 1.396

Malic Acid ........ 1.395

Nitrous Acid ....... 1.396

Nitric Acid ......... 1.406

Sulphuric Acid ..... 1.440

Phosphoric Acid..... 1.544

Rock Salt ....... 1.557

Quartz .......... 1.548

Garnet........... 1.515

Calc Spar.......... 1.665

Aragonite .......... 1.693

Sapphire, blue ....... 1.794

Arsenic............ 1.811

Calomel .......... 1.970

Carbonate of Lead .... $\quad 2 \cdot 084$

Sulphur, native ..... 2.038

- melted ..... 2. $2 \cdot 148$

Phosphorus......... 2.224

Diamond .......... $2 \cdot 470$

Chromate of Lead .... 2.926

Mercury .......... 5.000*
Specific gravity.

$1 \cdot 062$

$1 \cdot 090$

$1 \cdot 450$

$1 \cdot 480$

$1 \cdot 840$

$2 \cdot 687$

$2 \cdot 600$

$2 \cdot 600$

$4 \cdot 000$

$2 \cdot 700$

$2 \cdot 900$

$4 \cdot 200$

$5 \cdot 800$

$7 \cdot 200$

6.400

$2 \cdot 033$

1.990

$1 \cdot 770$

3.591

6.000

13.500

* The refractive power of mercury was determined by $\mathbf{M}$. Arago from its power of reflecting light, in accordance with the hypothesis of Newton that both are owing to the same cause, and that the one is a measure of the other. Should this hypothesis be well founded, we have an easy method of ascertaining the refractive power of solid and opaque bodies. That M. Arago has very closely approximated the truth in regard to mercury, would appear from the high refractive power of calomel, as determined by Brewster. And that it is nearly the same in lead as in mercury, would appear from the high refractive power of its compounds, as in the carbonate and chromate of lead; while it is well known that gold, platinum, silver, iron, tin, zinc, and other dense metals, reflect a much larger proportion of light, (when smoothly polished,) than the same surface of rocks, gems, glass, or the lighter metals ; and the latter more than water, alcohol, æther, or the oils. It would, therefore, appear that the denser metals contain from two to four times more caloric around their particles than an equal bulk of water, but very much less 
It has been recently discovered by the researches of chemists, that many bodies composed of different elements, the atoms or particles of which vary in size, exhibit the same crystalline form, as in the phenomena of isomorphism, from

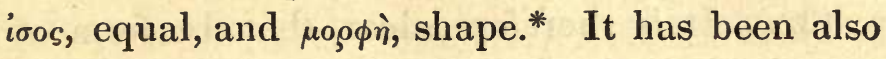
ascertained that other bodies composed of the same elements of ponderable matter in the same proportions, assume totally different crystalline forms, as in the phenomena of dimorphism.

For example, it was found by Scoresby, that in the arctic regions water congeals in an almost endless variety of geometrical figures, of which he enumerates five classes; the lamellar, the stelliform, (which is the most general, and occurs chiefly when the temperature is near $32^{\circ}$ );

than an equal weight of water, sulphur, phosphorous, or any of the compounds of oxygen, carbon, hydrogen, and nitrogen.

* In regard to the rationale of isomorphism, Mitscherlich laid it down as a law, that "the same number of atoms combined in the same way, produce the same crystalline form, which is determined by the number and position of the atoms, independent of their chemical nature." According to this view, the arseniate and phosphate of soda, the protoxides of iron, zinc, copper, nickel, manganese, and some other salts, are of the same form, because composed of the same number of particles arranged in the same manner. But the atomic weight of arsenic acid is thirtyeight, and that of phosphoric acid, forty. The seleniate of soda is also identical in form with the sulphate of soda, although the atomic weight of selenic acid is sixty-four, and that of sulphuric acid, forty. It is therefore not easy to comprehend why they produce the same form on uniting with soda, without supposing that sulphuric acid contains a larger amount of caloric around its particles, the volume of which would be thus increased, so as to approximate the magnitude of those of the selenic acid. 
the regular hexagon, which becomes thin, and diminishes in size as the cold increases; aggregations of hexagons, which occur chiefly at low temperatures; and lastly, combinations of hexagons with spines or radii. (Arctic Regions, vol. i. p. 432.) It is therefore clear, that the form of crystals depends on the arrangement of their particles, and not on their essential nature. But if it be a fact that caloric is the agent which regulates the distance of atoms or particles from one another, and causes all their movements, whether of union or separation, it must obviously determine the various modes of their arrangement, whether in the solid, liquid, or gaseous states. And as the atomic composition of water in every state is the same, it is impossible to comprehend why it should assume various crystalline forms, as observed by Kepler, Cassini, and Scoresby, without admitting that its particles are surrounded with different quantities of caloric, on assuming these different forms.*

* The various crystalline forms are now generally arranged in six divisions or systems, as in the following classification by Gustav Rose: 1. The cubic or tessular. 2. The square prismatic, (in which the lateral edges, like the terminal planes, are parallel.) 3. The rhombohedric. 4. The right prismatic. 5. The oblique prismatic. 6 . The doubly oblique prismatic.

In all crystalline bodies the form is angular, and the arrangement of their particles rectilinear. In those of which all the sides and angles are alike, the expansion by caloric is equal in all directions, as in the cube, the regular octohedron, and the rhomboidal dodecahedron; and the refraction of light is single, when they are of uniform temperature and density, as it in the transparent gases, 
It has been also discovered by Rose, that at the temperature of $50^{\circ}$, carbonate of lime assumes the form of rhombohedric crystals, as in calc spar; whereas, at the temperature of $150^{\circ}$, it takes the cubic form, as in Aragonite, the composition of which is the same. And when rhombic crystals of calc spar are heated to $212^{\circ}$, they are changed to the cubic form, without any change in its chemical composition,-if we except the addition of caloric, which is the cause of all molecular aggregations, and therefore the creator of forms. Corresponding with the foregoing facts,

vapours, liquids, and glass. But in the square prismatic and rhombohedric classes, the expansion by caloric is dissimilar in two directions; while in the right prismatic, the oblique prismatic, and the doubly oblique prismatic, it is dissimilar in three directions. And when a ray of light is made to pass through any of these bodies, or through glass unequally cooled, and solids of unequal density, whether from unequal temperature or pressure, it is refracted in two different pencils, more or less inclined to one another, according to the molecular arrangement of the body, and the direction in which the pencil is incident; thus producing all the phenomena of double refraction, which also occurs when it passes through resins, gums, jellies, horn, shells, bones, elastic integuments, and animal lenses. Whenever a ray of light is thus divided, both the transmitted rays are said to be polarized; that is, its properties are so far changed that it is incapable of undergoing reflexion or refraction, except at certain angles; or of transmission through transparent bodies, except in particular positions. For example, a plate of tourmalin permits the rays to be transmitted in one position, but in a position perpendicular to this it arrests and stifles them, because in these two rectangular directions its particles are differently arranged. It is therefore manifest that all the phenomena of crystallization, the reflexion, refraction, double refraction, polarization, and doubtless the diffraction of light, are immediately connected with the theory of caloric. 
Mitscherlich has shewn that the mutual inclination of the crystalline planes in calc spar is altered eight and a half minutes of a degree between the temperature of $32^{\circ}$ and $212^{\circ}$; while in other cases it varies nearly $1^{\circ}$ in different specimens of the same salt. For a full account of his discoveries, see Ann. de Chym. et de Phys. tom. xiv. 172 ; xix. 350 ; xxiv. $264,355$.

In accordance with the above facts, it has been discovered that on crystallizing from solution in the bisulphuret of carbon, or in oil of turpentine, at temperatures below $100^{\circ}$, sulphur assumes the octohedric form, with rhombic bases; but that when melted by itself and allowed to cool slowly, it takes the form of an oblique rhombic prism on solidifying at $230^{\circ}$. (Graham's Elements of Chemistry, p. 189.) It has also been ascertained that pure carbon occurs in the form of regular octohedrons, as in the diamond, but in six sided plates in Graphite. And Professor Johnston has recently shown that there is a large class of bodies composed of the same elements in the same proportions, which crystallize in two, if not more primitive forms. But since the time of Dr. Black, chemists have attended so little to the agency of caloric in the varions transformations of matter, that they have scarcely ranked it among their elements, although it constitutes by far the largest proportion by volume of solid bodies.

The phenomena of isomerism are no less remarkable, as illustrating the influence of caloric 
in changing the chemical properties of bodies. For example, if phosphoric acid be obtained dry by evaporating its solution, and then fused, it becomes what is called pyro-phosphoric acid. In these two states, although composed of phosphorus and oxygen in the same proportions, it produces totally different salts, on uniting with equal proportions of the same base. It has also been found, that crystals of tartaric and racemic acids, in their ordinary class of salts, are both composed of oxygen, hydrogen, and carbon, in the same proportions, and are so modified by heat as to form different salts on uniting with the same proportions of the same base : and so of many other acids.

Among the most civilized nations of antiquity, it was supposed that everything in nature is composed of four primitive elements, which they termed earth, water, air and fire, to which Aristotle added a fifth. But the tendency of modern science has been to increase the number, until it has extended to fifty-four, all of which are regarded as simple, because chemists have not yet been able to resolve them into fewer elements. There is reason, however, to believe that none of our chemical atoms and elements are perfectly simple, if we except caloric, which also exists in a great variety of states, as will be shown hereafter; and that it is only in the subtilized form of light that we can hope to discover the ultimate constitution of ponderable matter.*

* For example, if it be true that all the reputed elements are 


\section{In accordance with the hypothesis advanced} by Newton in one of his Optical Queries, that light and common matter are mutually convertible into each other, it has been recently maintained

convertible into light, and that light is decomposable into seven primitive rays by prismatic refraction, as maintained by Newton, or into only three fundamental colours, when analyzed by absorbent transparent media, as maintained by Brewster, it will follow that what we call simple bodies are composed of one, two, three, or more of the primitive elements which constitute white light. Now it is worthy of remark, that hydrogen is the most elastic of all gaseous bodies, and affords during combustion an almost perfectly blue light; while according to the experiments of Newton, the blue rays are more refrangible than any others except the violet, which is not a simple colour according to Brewster, but composed chiefly of blue, with small proportions of yellow and red; which he regards as the three primitive rays, and the elements of all compound colours. It is therefore probable that the blue and violet rays are more refrangible than the others, for the same reason that hydrogen, of which they are formed, is the most elastic of all known bodies; viz. because it contains more caloric around its particles in proportion to their size. And it was supposed by Newton that the atoms of light diminish in size from the red to the violet extremity of the spectrum. Again, as sulphur burns with a blue, and iodine with a violet light, (which contains small proportions of the other rays,) they may be composed chiefly of hydrogen, with some other base or bases; and cannot be otherwise decomposed than by expanding them into the subtile form of light. On the other hand, during the combustion and ignition of potassium, strontium, barium, lithium, sodium, and magnesium, they afford chiefly red light, with small proportions of the other coloured rays; therefore must all be composed principally of one element, the primitive atoms of which are red, while those of hydrogen (which is the basis of sulphur, iodine, and perhaps some other bodies) are blue. Hydrochlorate of calcined soda also affords an orange coloured light; while in that of chlorine, silver, copper, and some other bodies, there is a predominance of greenish rays; so that if green light be composed chiefly of yellow and blue, as maintained by Brewster, 
by Sir David Brewster, that " the particles of light are identical with the ultimate atoms of bodies, and that there is a specific affinity between definite atoms and definite rays, though we do not understand its nature." (Transactions of the Brit. Association, vol. i. p. 231.) He also observes in another work, that "when a portion of light enters a body, and is never again seen, we are entitled to say that it is detained by some power exerted over it by the particles of the body; that it enters into chemical combination with them, and produces the various chemical effects by which their colours are changed, and the juices of plants elaborated," - to which he adds, "It is not easy to allow that such effects are produced by undulations of an æthereal medium." (Optics, chap. xxxiv.)

That every description of ponderable matter is actually convertible into light by a sufficiently intense heat, or by electricity, will appear from the following undeniable facts:-

1. That the quantity of light generated by ordinary combustion, friction, or percussion, is always in proportion to the rapidity with which ponderable matter is ignited and volatilized.

2. That the colour of light thus produced always depends on the species of matter employed.

all bodies that burn with a green light must be compounds of two or more primitive elements; while others, again, which afford different proportions of all the coloured rays of the spectrum are still more complex. 
3. That the electric spark (like that produced by the collision of flint and steel) consists of exceedingly minute portions of ponderable matter in a state of incandescence, as will be shown hereafter by the decisive and beautiful experiments of Fusinieri.

4. That when the electric fluid is transmitted through the vacuum of an air pump, little or no light is produced, as proved by the experiments of De Luc, and afterwards by those of Sir $\mathbf{H}$. Davy.

5. That the most intense heat of a voltaic battery never produces any light, except when acting on ponderable matter; consequently, that light and heat are not identical,* as maintained by some modern theorists; and that neither of them is generated by the mere vibrations of an æethereal medium.

* That caloric is a constituent of light, (as it is of all other bodies,) and is the active principle in its generation, is evident from the fact, that the most refractory gems and metals are transformed into luminous incandescent particles by a sufficiently intense heat, definite measures of which are required to produce the effect on different species of matter. It has also been proved by the experiments of Hulme, Dessaignes, Macartney, and others, that every species of phosphorescence is promoted (for a time) by moderate heat, and always extinguished by the coldness of freezing mixtures; while others have found that the light of luminiferous insects is much greater in vessels of oxygen gas than in common air. But that caloric is a distinct essence, and may exist independent of light, is manifest from the fact, that it converts solids into liquids, vapours, and gases, in the midst of perfect darkness; while it radiates from the earth during night, as it does from boiling liquids and other hot bodies, without being attended with any light. 
In accordance with the foregoing facts, it has been found that each of the primitive rays produces specific changes of colour in different bodies; that the blue and violet rays of the spectrum change the white chloride of silver to a dark violet hue; whereas the red rays change it to a rose colour; and that the same change of colour is produced on the protochloride of lead and the oxide of mercury, when moistened and exposed to the red rays of the spectrum, as in the experiments of Scheele, Sennebier, Davy, and Seebeck: - that a piece of white paper stained yellow with a solution of guiacum in alcohol, was turned green in five minutes by exposure to sunshine, but remained unaltered for several months in the dark; and that when the yellow paper was made green by exposure to the violet rays, its original colour was restored by exposure to the red rays of the spectrum, as shown by the experiments of Wollaston.

The chemical agency of light is still more strikingly illustrated in the production of those accurate pictorial delineations of objects termed Daguerreotypes, which are formed by the immediate influence of the regal sun. Moreover, that there is "a specific affinity between definite atoms and definite rays," is evident from the fact, that bodies repel and reflect certain rays, while they attract and absorb others. For example, it was found by Sir David Brewster, that red transparent solutions and glasses per- 
mitted the red rays of the spectrum to pass freely through them, but absorbed and obliterated the other rays; ${ }^{*}$ that blue media permitted rays of the same colour to pass through them, but absorbed the other rays; and that green media absorbed the rays at both extremities of the spectrum, but the red most where it verges to blue, and the violet most where it verges to yellow. Nor is it more remarkable, that bodies should absorb one or more primitive rays, and reflect or transmit others, than that certain elements of ponderable matter should have an elective affinity for some, and an antipathy for other elements; the rationale of which is doubtless the same in both cases, and must be sought in the fact, that as the different rays of light are of different temperatures, so are the elements of ponderable matter associated with different quantities of caloric. And it will be found hereafter, that no chemical union of bodies ever takes place without the transition of

* If in our cathedrals, colleges, and other public buildings, were judiciously placed a few windows composed of perfectly red, yellow, and blue glasses, (to which might be added combinations of these colours,) the mind would be elevated, refined, and instructed, on beholding such a vivid display of all that is most beautiful in light when thus decomposed, and reduced to its primitive elements. Never shall the author forget the emotions of delight and admiration he experienced on first looking at the sky through a fine ruby glass,-when it presented the appearance of a vast dome of lurid flame; and the whole face of the earth, as if by enchantment, was suddenly dyed of a gorgeous crimson hue. We little think how cheaply some of the highest pleasures of existence may be purchased. 
caloric from one to the other, attended in most cases, with a change of temperature.

But if the ultimate atoms of ponderable matter be identical with those of light, and the latter consist of seven primitive rays, as supposed by Newton, it follows that the fifty-four elements enumerated by chemists are not simple bodies, but compounds of two or more primitive elements, as before suggested; or, that if light consist of only three primitive rays, united with caloric, everything in nature must be composed of four elements. Nor is it possible to admit with Newton, that the blue and indigo are distinct primitive rays ; while it is certain that all the known varieties of colour may be produced by combinations of red, yellow, and blue; which, as Brewster has shewn, overlap each other, and extend quite across the spectrum.

What then becomes of the enormous quantities of light perpetually radiated throughout the solar system? This is doubtless one of the most curious, important, and comprehensive problems in the whole range of physics, and deserves the profoundest attention of philosophers. Thus much is certain, that if light be matter, it cannot be annihilated, any more than the great fountains from which it emanates; that whatever falls upon the earth, and is not reflected or radiated from it into surrounding space, must combine with, and become a constituent portion of, its surface ; that certain rays produce specific chemical and vital 
effects; while the various powers of different bodies to decompose white light by absorption, transmission, reflexion, refraction, and polarization, cause an endless diversity of colours. Light then is not only a revelation of all that is grand and beautiful in the outward universe, but the agent by which all its operations are carried on. It is therefore probable, that when fully understood, it will enable us to explain whatever is now mysterious in the ultimate mechanism and laws of nature.

And if " the particles of light be indentical with the ultimate atoms of ponderable matter," (the $\pi \rho \omega^{\prime} \tau \dot{v} \lambda \dot{\eta}$ of the ancients,) the question naturally arises, whether all the planets and satellites of our system may not be so many masses of embodied light, which is first aggregated into nebulæ, and then into comets, that go on gradually augmenting in size, by constant additions of light, until after enormous periods of time, (compared with which our geological epochs are mere fractions,) they arrive at maturity; or until, by the expenditure of his substance, the sun is so far reduced in magnitude, that the centrifugal power of his rays becomes inferior to the centripetal pressure of the surrounding ætherwhen they would gradually approach, and finally in succession fall into the sun ?-In short, whether the ponderable matter of the sun and fixed stars is not perpetually expanded by caloric into the subtile form of light, which is as constantly re- 
converted into the matter of planets and satellites?

This theory enables us to answer the important question, "What becomes of light?" while it affords a more intelligible explanation of the manner in which cosmical bodies are generated and finally destroyed, than any merely metaphysical hypothesis - unless by metaphysics we understand the universal Science of Ontology, or of whatever exists. ${ }^{*}$ It also enables us to comprehend why the distances of the planets from each other augment in nearly definite ratios, from Mercury to Uranus; why they increase in magnitude (if we except Mars and the asteroids) from Mercury to Jupiter; and why their equatorial exceeds their polar diameters. For ex-

* Nor is this altogether a new hypothesis : for it was maintained by the early Hindoo Cosmogonists, that there is a creation and destruction of innumerable worlds in eternal succession; that they all emanate from the Divine Being, and after long periods of time are resorbed into the primitive fountain of their existence; a doctrine which certainly had its origin in the general belief of the ancients, that the sun was the Supreme Being. And we are informed by Brucker, that the oriental theory of emanations was adopted by some of the older Greek philosophers. Hence the doctrine of Heraclitus, that all things were originally formed from fire, (which is light or flame,) and must again return to the same state. (Diogenes, lib. ix. s. 8, p. 552.) We are also told in the first chapter of Genesis, that light was created before the earth, or even the sun, moon, and stars. Nor is it more difficult to comprehend the generation of worlds from the matter of light, than that they should have been created out of nothing; or from a gradual contraction of the sun's atmosphere, as maintained by Laplace. 
ample, it is obvious that if light obey the same laws as other projectile bodies, a much larger proportion of what is radiated from the sun would lose its original force and velocity at the distance of Jupiter, Saturn, and Uranus, than at that of any one of the planets nearer to the sun; so that a corresponding amount of luminous matter would be aggregated into comets, which may successively fall into those great masses and their satellites, in the same way that many thousand meteoric stones, and showers of stones, have fallen from unknown heights upon our planet, since the historical era,-a fact which clearly demonstrates that the earth has been augmenting in size, independently of the constant additions of matter it receives from the sun in the form of light. And as it is equally evident that the tropical portion of planets receives much greater quantities of light from the sun than the middle and polar latitudes, this fact affords a more satisfactory reason for their equatorial protuberances than the prevalent theory, which refers them to the rapid diurnal motion of their equatorial zones.

If the foregoing views be well founded, it follows that light, in connexion with caloric, which is the active principle in its generation, and always forms a constituent portion of it, is the primitive basis of all material existence,-or the physical Ens entium-consequently cannot be resolved into the mere vibrations of an ætherial 


\section{medium, as maintained by many distinguished mathematicians of the present age.*}

* That the vibratory theory of light is not a true representation of nature, would further appear from the following considerations :

1. That it does not explain what the æther is, nor what causes it to vibrate.

2. That light is propagated in straight lines, and will not pass through a bent tube; whereas vibrations move around interposing bodies, which obstruct the passage of light, as maintained by Newton.

3. That the wave theory does not explain the generation of light by combustion, ignition, friction, and percussion; how it is connected with caloric and electricity; nor why ponderable matter is essential to its production.

4. That it does not explain the decomposition of light by prismatic refraction, absorption, and transmission; nor how it modifies the chemical and vital properties of ponderable matter; while " it leaves the whole subject of colours, both in opaque and transparent bodies, involved in profound obscurity." (Whewell.)

5. That in adopting the theory of undulations, "we are called on for acts of faith, and certain admissions must be made at every step," as acknowledged by Sir John Herschel, who is certainly one of its ablest advocates.

6. That as the different colours of light depend on the species of ponderable matter employed in its generation, they cannot be resolved into different numbers of ætherial vibrations.

7. That the radical defects of the wave theory have been disguised by an imposing array of algebraical formulæ; while the most important facts connected with its history have been overlooked, or intentionally neglected; and that it is exceedingly difficult to understand, as admitted by Mr. Whewell. And it might as well be said that the first mover in the steam engine is motion, as that light consists merely in the vibratory motions of an æther. 


\section{CHAPTER III.}

On the Law by which Caloric produces the opposite Forces of Attraction and Repulsion, Contraction and Expansion.

"That alone is true philosophy which repeats the words of the universe with fidelity, and is written, as it were, by dictation of the universe."

BACON.

THE doctrine that every thing in nature is composed of two descriptions of matter, the one essentially active and æthereal, the other passive and motionless, was recognized by the most acute and profound sages of antiquity in every quarter of the civilized world. But notwithstanding they all regarded elementary caloric as the prime mover, they seem to have overlooked the law by which it repels its own particles, and tends to combine with those of ponderable matter; with forces that vary inversely as the squares of the distance, so as to produce all the centrifugal and centripetal forces of nature. The same observation applies equally to Bacon, Descartes, Newton, and other modern philosophers, who, although they referred all the operations of nature to what they called a spirit or pneumatical body, a materia subtilis, a subtile ather, \&c. they never identified it with any known principle, nor explained how it causes both attraction and repulsion, union and separation. 
Why then does caloric repel its own particles, and attract those of ponderable matter, with forces that vary inversely as the squares of the distance? To this primary and leading question $I$ answer, that caloric repels its own particles because they are of the same nature, and attracts those of ponderable matter because they are of a totally different nature; that in every variety of state caloric is an essentially active principle, and incomparably more refined than any description of ponderable matter, even when expanded into the subtile form of light; for it permeates the most dense and opaque bodies, which are wholly impervious to light. And that the forces of caloric diminish in proportion as the squares of the distance augment, is obvious from the fact, that all æthereal emanations are necessarily diffused in the same ratio, on radiating from any given centre.*

That caloric is a self-active principle has been already shewn by its power of moving itsëlf, and of giving motion to other bodies, the activity of which is augmented by every addition, and diminished by every abstraction of heat; proving,

* It would therefore seem to follow, that there must be a limit to the diffusion of caloric; that it is not infinitely subtile and divisible; but that there must be a definite number of particles in any given quantity of it. It is only by its extension throughout illimitable space that it can be regarded as infinite; for we shall find that, while it governs all the operations of the material universe, it is itself governed by invariable and necessarily fixed laws. Yet there is reason to believe that its great activity depends on its extreme subtilty and refinement. 
that if the particles of ponderable matter could be wholly deprived of caloric, they would be passive and motionless. At the same time it is highly probable, that if universal space were filled with caloric alone, (without any ponderable matter,) it would also be inactive, and constitute a boundless ocean of powerless or quiescent æther, because it would then have nothing on which to act. And we shall find that, however inactive of itself, ponderable matter has certain properties by which it modifies and controls the actions of caloric, both of which are governed by immutable laws that have their origin in the mutual relations and specific properties of each.

That atoms of the same nature repel one another, and attract those of a different nature, would appear from the best known phenomena of chemistry and physical optics. For example, it has been long known that similarity of properties among the elements of ponderable matter causes them to repel each other, as if by a mutual antipathy ; but that diversity of properties is favourable to chemical combination. We have also found that transparent media transmit rays of light of their own colour, but attract and absorb those of different colours.

I now proceed to shew, that all the expansions and contractions of gaseous bodies depend on the relative proportions of caloric and ponderable matter of which they are composed; and that the force by which caloric tends to unite with the particles 
of ponderable matter is in proportion to their size, ceteris paribus. For example, the atoms of hydrogen are smaller, and contain a larger amount of caloric around them, than those of any other gas ; the consequence of which is that its elastic force is such, that no mechanical pressure hitherto employed has been sufficient to condense it into the liquid form.* And it was found by Perkins, that atmospheric air (which is composed of oxygen and nitrogen in a state of mechanical mixture) may be submitted to a pressure equal to 1200 atmospheres, without being perfectly condensed into the liquid form. (Philosophical Transactions, 1826.)

But when 3 volumes of hydrogen unite chemically with 1 of nitrogen, they contract into 2

* Under the pressure of the atmosphere, and at the temperature of $60^{\circ}$, hydrogen is 15,480 times lighter than water, the pores of which are 40 times larger than its solid particles, according to Newton. It is therefore evident, that the pores of hydrogen exceed the diameters of its particles several thousand times, and, perhaps, to the same extent, that the spaces between the different planets exceed their mean diameters. What, then, is the cause of the stupendous force by which the particles of hydrogen are kept at such comparatively great distances from one another? Is it some virtue, property, or condition termed polarity? Or is it owing to the existence of certain hypothetical immaterial spheres of repulsion around its particles? Is it possible that masses, and the atoms of which they are composed, are capable of acting upon each other at comparatively great distances without an intervening medium? That the polume of gaseous bodies is augmented by every addition of caloric, has been proved by the experiments of Gay-Lussac, who found that 1000 cubic inches of common air were expanded to 1375 cubic inches by raising its temperature from $32^{\circ}$ to $212^{\circ}$. It was further ascertained by Dulong and Petit, that 
volumes of ammonia, the elastic force of which is so far diminished that it may be condensed into the liquid state by a pressure equal to 6.5 atmospheres, or by cold alone at the temperature of $46^{\circ}$ below $0^{\circ} \mathrm{F}$. And when 2 volumes of nitrogen combine with 1 of oxygen, the elastic force of the resulting compound gas is so far diminished, that it may be liquified by a pressure equal to 44 atmospheres at the temperature of $32^{\circ}$, as first shewn by the experiments of Sir $\mathbf{H}$. Davy ; or by a pressure equal to 50 atmospheres at the temperature of $45^{\circ}$, according to Faraday. What then is the rationale of these curious phenomena? Is the sphere of repulsion in the elementary gases exchanged for one of attraction as they unite chemically, with contraction of volume and diminution of elasticity? Or how many immaterial and imaginary spheres of attraction and repulsion are required to explain the phenomena of solidity, liquidity, and gasefaction? The summary answer to these queries is, that "the self repulsive power of caloric is

the same law of expansion is true of atmospheric air and hydrogen, up to the temperature of $680^{\circ}$; from which they concluded, that it was true of all gases, and at all temperatures. (Ann. de Chim. et Phys. vii. 120.) Dr. Dalton also found that the elastic force of steam was equal to the weight of the atmosphere at $212^{\circ}$, but was equal to the pressure of 135 atmospheres when raised to 320 . And we learn from the experiments of Perkins, that when water is confined in very strong vessels it expands with a force equal to the pressure of 1050 atmospheres when raised to the temperature of $419^{\circ}$. 
counteracted and diminished by its affinity for ponderable matter, by which the athereal atmospheres are drawn into a smaller compass. The reduction of volume and elastic force are referable wholly to this one cause.

Perhaps the principle cannot be better illustrated than by a consideration of the statical and dynamical changes that are produced on hydrogen and chlorine, by their mutual action upon each other.

We have seen, that the specific gravity and atomic weight of chlorine are 36 , compared with hydrogen as 1; and that the elastic force of hydrogen is immense. It has been also shown by Faraday; that the elastic force of chlorine is low -that it may be liquefied by a pressure equal to 4 atmospheres at the temperature of $60^{\circ} \mathrm{F}$.*

But when 1 volume of chlorine is made to unite with 1 of hydrogen, they form 2 volumes of hydrochloric acid gas, the specific gravity of which is 18.5 ; or a mean between that of its constituents. During this combination, the hydrogen loses the greater part of its elastic force, while that of the chlorine is greatly augmented. That is, a definite proportion of caloric is attracted by the heavier atoms of chlorine from the lighter atoms of hydrogen, by which its particles are removed farther

* When combined with aqueous vapour it may be liquefied, and even'solidified, at the temperature of $32^{\circ} \mathrm{F}$. 
from each other, and its elasticity increased at the expense of the hydrogen. Nay more, it is by virtue of this very attraction that the atoms of hydrogen are forced into chemical union with those of chlovine, and their separate individuality destroyed. In other words, all the above changes, including that by which the gases are united and identified, are referable wholly to the transition of caloric from the one to the other.

It will be shown hereafter, that no chemical combination of any one body with another ever takes place, without a simultaneous passage of caloric or electricity from one to the other; that if water and other liquids could exist as such without caloric, (which is impossible, ) they could not combine with salts, metals, and rocks; and that the diminution of bulk which attends the combination of liquids with solids, is owing to the same law which determines the reduction of volume and elastic force of gases and vapours. The most simple illustration of combination effected by the attraction of ponderable matter for caloric, is that by which steam is condensed by water or ice, and intimately combined with their particles. When a certain proportion of steam is mixed with cold water, its volume and elastic force are destroyed by the same attraction of ponderable matter for caloric which causes liquids to combine with, and dissolve solids, or which causes gases to combine chemically, with contraction of volume and diminution of elastic force. 
There is no limit to the application of this doctrine in the phenomena of chemistry.

If a piece of ice be introduced into a vessel full of ammoniacal gas, the latter disappears rapidly, and the ice is melted, forming a chemical solution of ammonia (spirit of hartshorn). Now it is obvious on a moment's reflection, that the volume and elasticity of the ammoniacal gas are destroyed by the attraction of ice for its caloric. It is equally true, that the ammonia is chemically combined with the ice by the same attraction, as will be proved when I come to treat of chemical solutions. Again, if one volume of hydrochloric acid be mixed with one volume of ammoniacal gas, they combine rapidly with evolution of much heat, when they lose the gaseous or elastic state, making a solid crystalline salt (sal ammoniac) of a cubical or octohedral form. The atomic weight of the acid is 37 , and that of the alkali 17. (See Table of Atomic Weights, p. 51.)

In this case, there is an attraction of caloric by the larger particles of the acid, by which those of the ammonia are forced into chemical combination with them, forming compound particles of still larger size, the weight of which is 54, compared with hydrogen as unity.

Thus it is evident that the repulsive power of caloric, on which the volume and elastic force of gases depend, is counteracted and diminished by an affinity of ponderable atoms for caloric; and that this attraction augments in a certain ratio as 
the size of the particles increases, until it wholly predominates over the repulsive force. The atoms of hydrogen, nitrogen, oxygen, and light carburetted hydrogen, retain a large amount of caloric around them in proportion to their size; the consequence of which is, that the thermo-repulsive force greatly predominates. But when they are made to combine with each other chemically, or with carbon, phosphorus, sulphur, chlorine, \&c. making gases of greater specific gravity and atomic weight, their elastic force is diminished, even in cases where little or no caloric is given out, as in the combinations of nitrogen and hydrogen, nitrogen and oxygen, nitrogen and carbon, with numerous others, formed of these and of sulphur, phosphorus, \&c.

It has long been a matter of controversy whether the oxygen and nitrogen of the atmosphere exist in a state of mechanical mixture, as maintained by Dr. Dalton, or in a state of chemical combination. Dr. Thomson has recently maintained that it is composed of 80 parts nitrogen to 20 of oxygen, constituting definite proportions by volume; therefore, that it is a chemical compound. (Records of Science, vol. iii. page 184.) This hypothesis does not accord with the best established facts connected with the theory of volumes. For example, in all the combinations of oxygen and nitrogen that are known to be chemical, there is a reduction of volume and elasti- 
city, except in the case of the binoxide, which is composed of equal volumes of each. Besides, it would seem to be a general law, that, whenever unequal volumes of gases unite chemically, there is a diminution of their aggregate volume. This view is supported by the facts presented in Table III. page 63 ; while it is evident from the foregoing details, that all such chemical combinations are attended with a reduction of elasticity. But the volume and elastic force of oxygen and nitrogen, as they exist in atmospheric air, are the same as when in a separate state, which would seem to demonstrate, that air is a mechanical mixture, and not a chemical combination.

The elastic force of light carburetted hydrogen is less than that of simple hydrogen. When Mr. Perkins submitted it to mechanical pressure, he found that it began to liquefy under a force equal to the weight of 40 atmospheres; and that under a pressure of 1200 atmospheres it was perfectly condensed into the liquid form. Being composed of 2 atoms hydrogen to 1 of carbon, its specific gravity and atomic weight are to hydrogen in the ratio of 8 to 1 .

When 2 atoms or volumes of carbon unite with 2 of hydrogen, they form bicarburetted hydrogen (olefiant gas), a compound, the specific gravity and atomic weight of which are 14, compared with hydrogen as unity. During this combination, the 4 volumes of hydrogen and carbon contract into 1 volume, the elastic force of which 
has not been ascertained; but from the foregoing facts, there cannot be a doubt, that it is very low, compared with that of carburetted hydrogen.

It cannot be maintained that there is less caloric in 100 cubic inches of carburetted hydrogen, or olefiant gas, than in an equal volume of hydrogen. On the contrary, it appears from the results of their combustion, that they contain much more. According to the experiments of Dr. Dalton, caloric enough is evolved during the combustion of $1 \mathrm{lb}$. of carburetted hydrogen to melt $85 \mathrm{lbs}$. of ice; while the same weight of olefiant gas afforded heat enough to melt $88 \mathrm{lbs}$. of ice. Now, when it is remembered that the volume of hydrogen is 8 times that of carburetted hydrogen, and 14 times that of olefiant gas, weight for weight, it becomes self-evident, that equal volumes of these compound gases contain more caloric than hydrogen.

The proportions of caloric in equal volumes of alcohol vapour, æthereal vapour, nitrous acid, cyanogen, \&c., are still greater than in carburetted hydrogen or in olefiant gas. Why then, I repeat, is their elastic force so much less at the same temperature? The obvious answer to this question is, that the larger compound particles of such gaseous bodies exert a stronger affinity for caloric, by which it is drawn into a smaller space, and chemically united, producing definite contractions of volume, and consequently an increase of specific gravity. 
If the self-repulsive force of caloric in these compound gases were not counteracted by an attraction between their particles and thermal æther, their elastic force would be greater than that of hydrogen in proportion to the greater amount of their latent caloric.

This conclusion is rigorous; and it is so important in its bearing upon the whole science of chemistry and physics, that I have dwelt upon it even at the hazard of repetition, with a hope that by presenting the operation of the same principle in different points of view, it might be rendered clear and intelligible to the most ordinary capacity. It explains why the expansive force of steam is greater, other things being equal, in proportion as the quantity of water employed in its generation is less; a thorough comprehension of which is destined to effect an immense saving of fuel.

The law by which the elastic force of æthereal matter is counteracted by the mutual affinity between it and ponderable matter, is still more strikingly illustrated by the changes which are produced in the statical and dynamical properties of hydrogen and sulphur, oxygen and nitrogen, chlorine and nitrogen, with some others.

It was before noticed that the specific gravity of sulphur vapour as determined by the experiments of Mitscherlich, is 6.666, which is about 96 times the specific gravity of hydrogen gas : and it re- 
quires a temperature of about $640^{\circ} \mathrm{F}$. to maintain it in the gaseous form, when not united with other bodies. But if brought into contact with hydrogen gas, or if sulphur be volatilized in contact with hydrogen, they both undergo remarkable changes.

1. In the first place, 16 parts by weight of sulphur combine chemically with 1 of hydrogen, forming hydrosulphuric acid (sulphuretted hydrogen), the specific gravity of which is 17 times that of hydrogen, and its elastic force comparatively low. The particles of sulphur, which are 16 times larger than those of hydrogen, attract from the latter gas a portion of the æther which encompassed its atoms, by which they are intimately united.

2. During this process, the particles of sulphur acquire a much greater repulsive force, and are removed so much farther from each other, that they occupy 6 times the volume which they $\mathrm{did}$ in the form of vapour, before combining with the hydrogen.

3. The elastic force of the hydrogen is so far diminished by uniting with sulphur, atom to atom, that sulphuretted hydrogen may be liquefied by a pressure equal to 17 atmospheres at the temperature of $50^{\circ}$, according to the experiments of Faraday. It was afterwards discovered by Davy that when reduced to the temperature of $3^{\circ} \mathbf{F}$., the elastic force of its vapour was equal to the pressure of only 14 atmospheres. 
When 2 atoms of sulphur 32, combine with 1 atom of hydrogen, the resulting compound is a brownish yellow, and dense liquid, (specific gravity 1.769), somewhat acid, of an oily and tenacious consistence. If it be submitted to very low temperatures, its specific gravity and cohesion are still farther augmented, when it becomes an exceedingly firm solid, like butter, tallow, and innumerable other fluids and semifluids under the same circumstances. When an atom of sulphur 16 , combines with 2 atoms of oxygen 16 ; or when sulphur vapour combines with oxygen, the elasticity of the latter is nearly destroyed; while the atoms of sulphur are removed farther from each other, and acquire a degree of elasticity at the expense of the oxygen : for the specific gravity of the sulphurous acid thus formed is only $\mathbf{2 \cdot 2 2 2}$, which is just $\frac{1}{3}$ of $6 \cdot 666$, that of the sulphur vapour, in agreement with the law of multiples, which may be traced in all the contractions and expansions that gaseous bodies undergo during combination and decomposition.

According to the experiments of Faraday, sulphurous acid may be liquefied by a pressure equal to 2 atmospheres, at the temperature of $45^{\circ}$; and by cold without pressure, according to the experiments of Bussy and others. It must be observed, however, that during the combinations of oxygen and sulphur, a portion of caloric is given out, as in the union of oxygen and hydrogen to 
form aqueous vapour; which is one cause of the diminished elasticity in sulphurous and sulphuric acids.

A thousand examples might be adduced equally calculated to illustrate the chemical force with which æthereal matter is attracted by the atoms of gravitating matter, and its idio-repulsive force thus diminished or destroyed.

The same order of phenomena which marks the union of sulphur and hydrogen, is exhibited during the combination of phosphorus, iodine, bromine, selenium, tellurium, \&c. in the state of vapour with hydrogen and other permanent gases. The volume and elasticity of these dense vapours are augmented by receiving from the lighter gases a portion of the principle on which their volume, \&c. depend, during the very act of combining.

The specific gravity of phosphorous vapour is $4 \cdot 444$ at the temperature of $550^{\circ} \mathrm{F}$.-or about 64 times the specific gravity of hydrogen. But when it combines with hydrogen, atom to atom, it becomes highly elastic, and its particles occupy 4 times their former space, as in phosphuretted hydrogen, the specific gravity of which is only 17 times tha of hydrogen.

The specific gravity of iodine vapour is $\mathbf{8 . 7 5}$ at the temperature of $347^{\circ} \mathrm{F}$. When it unites with hydrogen, atom to atom, (that is, in the ratio of 126 by weight to 1 of hydrogen,) hydriodic acid is formed, the specific gravity of which is $4 \cdot 386$, or about one-half that of iodine 
vapour, in accordance with the law of multiples as shown in hydrochloric acid, ammonia, \&c.

The same principle applies to the various combinations of hydrogen with the vapours of bromine, cyanogen, arsenic and mercury, as in its combinations with the vapours of sulphur, iodine, \&c. (See Table III. of the preceding Chapter.)

When 3,4 , or 5 volumes of oxygen combine with 2 of nitrogen, the aggregate bulk and elastic force of the resulting compounds diminish with every additional dose of oxygen. Nitrous and nitric acid may be liquefied by moderate degrees of cold without pressure. Yet they contain nearly, if not quite as much caloric as the oxygen and nitrogen of which they are composed, when in a separate state. It was long ago observed by Higgins, that during those combinations no caloric is given out-and that during the union of nitric acid with potass, very little heat is disengaged.*

That this is really true, would appear from the immense quantity and intensity of the heat evolved by the deflagration of nitrate of potass with charcoal and sulphur, as in gunpowder and other deflagrating mixtures formed of nitre, phosphorus, naphtha, turpentine, and various combustibles. It is generally known, that during their combustion with nitre, nearly as much caloric is given out,

* It is also known that when nitrous acid is passed through a red hot iron tube, it is decomposed into its constituent elements, which resume their original volumes and elastic force. 
even in vacuo, as when burnt in atmospheric oxygen; which proves that a large amount of caloric is concentrated around the particles of the nitric acid of the saltpetre, and set at liberty during its decomposition.

\section{Philosophy of Explosion or Detonation.}

Immediately connected with the foregoing theory, is the rationale of explosion,-a phenomenon which has never been explained, and has been often adduced as an argument against the materiality of caloric. It has been supposed that the quantity of heat given out during explosion, and that which is requisite to convert gunpowder into the gaseous state, could not have existed in a state of combination with its particles.

This has arisen from not attending to the law by which caloric is concentrated around the atoms of ponderable matter, with a force that increases in proportion to the augmentation of their size, other things being equal; and by which its selfrepulsive force is counteracted. I have shown that the elastic force of nitrogen is equal to a pressure of 1200 atmospheres; but that when 5 volumes of oxygen are combined with 2 of nitrogen, they contract into 2 volumes of nitric acid, without any material loss of caloric, and yet that the elastic force of nitric acid is very small ;--that when 5 atoms of oxygen 40 , unite with an atom 
of nitrogen 14, they form compound molecules of nitric acid, the weight of which is 54 , compared with hydrogen 1 : from which, and the foregoing facts, we are bound to infer, that the repulsive force of the æther which surrounded the atoms of oxygen and nitrogen, is counteracted and nearly vanquished by the attraction of the larger particles of the compound for caloric.*

By referring to Table I. page 51, we perceive that the atomic weight of potass is 48 , compared with hydrogen as unity. One atom of nitric acid 54 , combines with 1 of potass 48 , making compound molecules of nitrate of potass, the weight of which is 102 ; and the attraction of which for caloric has so far overcome its idio-repulsive force, that they are aggregated into a crystalline solid of a cubical form. Let us then examine the composition of gunpowder. It consists of 1 atom of nitre 102,1 of sulphur 16 , and 3 of charcoal 18 ,

* It was before shown that when 2 volumes of hydrogen combine with one of oxygen to form water, an immense quantity of caloric is disengaged, and that the aeriform state is merged in that of the liquid state. But as the combinations of oxygen and nitrogen retain nearly the same amount of caloric as their constituents, they also retain the gaseous form at ordinary temperatures, though their aggregate bulk and elasticity are greatly diminished. This fact is very remarkable; for the particles of nitric acid are larger than those of water in the ratio of 54 to 9 ; or 6 to 1. It is difficult to conceive why they retain the elastic state, unless they retain around them a large amount of the same æthereal matter which belongs to their elementary constituents : whereas oxygen and hydrogen give out a large proportion of it on combining to form water. 
in a state of intimate mixture. When perfectly dry, and heat is applied, the nitre is decomposed into its original constituents, with a tremendous force of explosion, which is owing principally to the elastic force of the nitrogen, on being released from its combination with the oxygen and potass of the nitre. During this rapid process, 2 atoms of oxygen combine with 1 of sulphur, making sulphurous acid gas; while the other 3 atoms of oxygen that existed in the nitric acid, combine with 3 atoms of charcoal, forming carbonic oxide and carbonic acid. But as the elastic force of these gases is comparatively low, the explosive action must depend chiefly on the sudden expansion of nitrogen on assuming the gaseous state. The whole is nothing but an instantaneous combustion of sulphur and charcoal, accompanied by the disengagement of heat and light, as in ordinary combustion, and by the sudden liberation of nitrogen, which, in the separate state, exerts an elastic force equal to a pressure of $16800 \mathrm{lbs}$. to the square inch. The force is also greatly increased by the caloric given out during the formation of carbonic oxide and carbonic acid, the quantity of which is by no means inconsiderable.

This is a most instructive exemplification of the law by which caloric exerts two opposite forces, -the one or the other prevailing according to circumstances. At ordinary temperatures, the particles of nitre, sulphur, and charcoal, retain 
caloric around them with a greater force than that by which it repels its own particles; but when they are decomposed and subdivided into smaller particles, the repulsive force of their æthereal constituent acquires the ascendency.

The same principle applies to all fulminating compounds, whether solid, liquid, or aeriform, as chlorate of potass, fulminating mercury, gold, silver, platina, \&c. ; iodide and chloride of nitrogen, protoxide and peroxide of chlorine, and some other detonating compounds, all of which are attended with expansion of volume and disengagement of heat, during their decomposition.

Chlorate of potass is composed of chloric acid and potass. When triturated with sulphur, phosphorus, and charcoal, it forms a deflagrating compound. In the ratio of 3 parts of the chlorate to 1 of sulphur, it explodes violently when gently heated, or struck with a hammer. If 2 grains of the chlorate be mixed with 1 of phosphorus, in a bit of paper, and struck with a hammer upon an anvil, there is a violent explosion. The chloric acid is decomposed in all such cases; the chlorine unites with the combustible; and the oxygen being liberated expands with a force proportional to its elasticity in the gaseous state, for the same reason that nitrogen expands when separated from the nitre of gunpowder,

Fulminating mercury is composed of oxygen and cyanogen, combined with the protoxide of mercury, in the proportions of 1 atom of each. 
When exposed to a temperature of $300^{\circ} \mathrm{F}$, it is suddenly decomposed; from which it is evident that the self-repulsive force of the caloric is restrained by its affinity for the particles of the compound, until a further supply of thermal æther is added, when the elastic force prevails, and the compound is resolved into its constituents with a violence sufficient to indent or lacerate iron. During the process, oxygen combines with the carbon of cyanogen, forming carbonic acid, while the nitrogen of the cyanogen, being released from its confinement, expands, causing the explosion. The same effect is produced on bringing concentrated nitric or sulphuric acid in contact with it, the oxygen of which combines with the carbon of the cyanogen, leaving the nitrogen at liberty to exert its expansive force.*

* It is only by contemplating the elastic force of caloric in oxygen and nitrogen, while in the state of simple gases, that we are enabled to appreciate the stupendous force of attraction by which it is concentrated around the molecules of ponderable matter. If we take the experimental result of Rumford, that 15 grains of gunpowder expand when ignited, with a force equal to the pressure of $400,000 \mathrm{lbs}$. or 200 tons weight, it follows from a simple calculation, that the elastic force of caloric in $1 \mathrm{lb}$. of gungunpowder, is equal to the pressure of 102,400 tons weight. This enormous force is restrained by the attraction of caloric for the molecules of gunpowder and all detonating compounds that contain nitrogen, until decomposed, when it expands with an energy far surpassing the most elastic steam, for the same reason that the oxygen of chlorates expands with irresistible violence when decomposed. It is therefore certain, that a more perfect knowledge of the application of gunpowder and other fulminating compounds, must lead to a far more effectual and rapid mode of destroying life than the steam gur. 
Fulminating silver is composed of oxygen and cyanogen, united with its protoxide. When gently heated, it is decomposed and resolved into its constituents. At the same moment, oxygen combines with the carbon of the cyanogen, forming carbonic acid, leaving the nitrogen at liberty to expand with explosive violence. And so of fulminating gold and platina, which are composed of ammonia, combined with the oxides of these metals. When decomposed by heat, the electric spark, or by percussion, their oxygen unites with hydrogen of the ammonia to form water, when the nitrogen expands as before.

Of all the detonating compounds, chloride of nitrogen affords the most simple and striking example of the opposite effects exerted by caloric under different circumstances. It is composed of 3 atoms or volumes of chlorine to 1 of nitrogen, which, on uniting, condense into a heavy and oily liquid, the specific gravity of which is $1 \cdot 6$. While its elements are united, the elastic force of the caloric in nitrogen is restrained by the greater force with which it is attracted around the atoms of chlorine. These two opposite forces are so nearly balanced, that by adding a small amount of caloric to the chloride it is decomposed, the nitrogen expanding with its accustomed force, when reduced to the separate state. The chlorine also assumes the gaseous state, with evolution of heat and light. The chloride may be decomposed 
by the volatile oils, naphtha, phosphorus, and various other combustibles, which unite with chlorine, when it explodes as when heated to $212^{\circ} \mathrm{F}$.

Euchlorine, peroxide of chlorine, and deutoxide of hydrogen, also expand with explosion and evolution of heat and light on being decomposed, because the affinity of their particles for caloric is diminished by reducing their size. The more completely ponderable matter is divided, the less power it has of concentrating, or retaining æthereal matter around its particles. Hence, the quantity of caloric given out during ordinary combustion, other things being equal, is in proportion as the decomposition is complete. When coal or wood is but partially decomposed, gross vapours are formed, constituting smoke, the particles of which are much larger than those of flame, and which retain and carry off a considerable amount of the caloric that is given out by radiation when the combustion is perfect.

The whole theory of combustion is founded on the various degrees of force with which ponderable matter attracts thermo cethereal matter, under different circumstances. Caloric is more concentrated around the atoms of dense, than of light gases and vapours; and greatly more so around the larger compound particles of liquids and solids. In short, all the absorptions of caloric by which it combines with and becomes latent in 
ponderable matter, result from their mutual affinity: while the escape of caloric during combustion, or deflagration, results from the diminution of that affinity, for the same reason that the volume and elastic force of hydrogen and nitrogen greatly augment on the decomposition of ammonia.

There is nothing more clearly demonstrable in science, than that all the caloric evolved during the decomposition of ponderable matter, whether solid, liquid, or gaseous, is only a liberation of what was previously concentrated around the atoms of the materials employed. When the particles of solids are separated and subdivided by friction, or collision, a portion of their concentrated caloric is disengaged, producing incandescent sparks, or streams of fire.

A machine is exhibited at the Hall of Practical Science in London, which illustrates the enormous quantity of caloric in steel, and its evolution by decomposition, in the most beautiful and striking manner. A circular plate of soft iron is made to revolve at the rate of 5000 times per minute, when the hardest steel on being applied to its edge is cut through rapidly, and reduced to inconceivably small particles, which are still farther expanded by the caloric thus liberated, into a shower of metallic flame and sparks. This kind of ignition proceeds equally well in vacuo, as in the atmosphere. 
Mr. Brande observes, in the last edition of his Manual of Chemistry, page 390, that the existence of nitrogen in nearly all the powerfully detonating bodies, is a singular fact; and that explosion must remain unexplained until we ascertain the cause of the detonating power of such compounds. He also adds, that at present the phenomena are at variance with the usual explanation of the evolution of heat and light during combustion, which have been supposed to be the result of union and condensation, instead of expansion and decomposition.

The truth is, that in a large majority of cases, combustion, as well as explosion, is attended with expansion of the materials employed. Lavoisier, who maintained that gaseous oxygen was the source of heat and light in all cases of combustion, supposed that it was always condensed on combining with combustibles. This partial view of the subject has been incorporated with so many works on Chemistry and Natural Philosophy, that it has become a very general opinion, that oxygen is the only supporter of combustion, and the source of heat and light, instead of the bodies with which it unites.

We have already seen, that during the combination of oxygen with hydrogen, they are both condensed into the liquid state; which condensation is attended with the evolution of caloric and light. But a large proportion of the caloric 
thus given out is disengaged from the hydrogen, which is therefore as much a supporter of combustion as the oxygen.

Oxygen is also condensed, and even solidified on combining with metals during their combustion in it, by which they are converted into oxides. In such cases, it is doubtless the principal source of caloric. It is however not the only supporter of metallic combustion; for cyanogen, chlorine, bromine, iodine, sulphur, phosphorus, and some other solid bodies unite rapidly with metals when they are heated together, with evolution of heat and flame.

The combustion of carbon, sulphur, and phosphorus in oxygen gas, is attended with intense heat; yet they are greatly expanded without any condensation of the oxygen : for the carbonic, sulphuric, and phosphoric acids produced, have the same volume as that of the oxygen.

During the combustion of æther, alcohol, oils, resins, wood, coal, and other inflammable bodies in oxygen, the volume of the gaseous products exceeds that of the oxygen; yet the process is attended with the production of immense quantities of heat and light.

There is a mixture prepared at the Military Academy of Woolwich, called the Carcass composition, that burns with great violence, somewhat like the detonating compounds, which cannot be quenched with water, and has been supposed to resemble the Greek fire. 
I am indebted to Dr. Faraday for the following mode of preparing it.

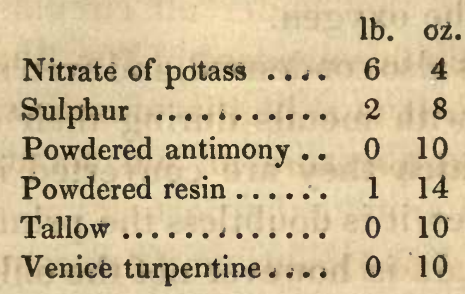

The resin, tallow, and turpentine, are melted together. The sulphur and nitre are then added, being kept hot all the time and well stirred about. The powdered antimony is then added and worked well in it, when it may be formed into the shape required.

The combustion of this mixture is truly terrific, and the quantity of heat evolved enormous. It also goes on in vacuo as well as in the air, which is true of all deflagrating and detonating compounds. All such combustions are attended throughout with expansion of the burning bodies instead of condensation.

The explosive power of gunpowder may be lessened by augmenting the proportions of charcoal and sulphur. Fuses, which burn with a gradual, or continuous deflagration, are composed in the ratio of

$$
\text { Ib. oz. }
$$

Nitre................... $4 \quad 4$

Sulphur.................. 1

$\begin{array}{lll}\text { Common gunpowder ground into meal.. } & 1 & 12\end{array}$ 
From the foregoing facts and observations, we perceive how partial and erroneous is the prevalent notion, that under all circumstances caloric is a repulsive agent. We find that the caloric of explosion, like that of ordinary combustion, is only a liberation of what was previously concentrated around the particles of ponderable matter, and diffused during its dissolution.

Such is the beautiful simplicity of nature, that a clear comprehension of the law by which the molecules of a salt are aggregated and dissolved, affords a miniature representation of the mechanism by which the universe is kept in motion, from the law of gravitation to the no less important transformations of chemistry.

It has been shown, that cold, or the abstraction of caloric, produces the same effect on gases as mechanical pressure-that is, it diminishes their volumes and condenses them into liquids or solids; which is effected by lessening the ratio of æthereal or elastic matter, while the quantity of ponderable matter remains the same. If we suppose that the repulsive force of this æther in hydrogen is equal to the weight of 2000 atmospheres, it must be attracted with a still greater aggregate force, by the atoms of sulphur and other bodies : for we have seen that when 1 atom of sulphur combines with 1 of hydrogen, the resulting compound, sulphuretted hydrogen, may be liquefied by a pressure equal to 17 atmos- 
pheres at $60^{\circ} \mathrm{F}$. while the bisulphuretted hydrogen becomes liquid, or semi solid, without any pressure.

By the affinity of ponderable matter for caloric, its atoms are approximated and held together: by its elastic or self-repelling property, it separates them from each other, as in gasefaction, explosion, and all decompositions. The fact that Philosophers have overlooked this affinity by which caloric is concentrated around the particles of liquids and solids, resolves the problem of contradictions by which the theory of caloric has been so long perplexed, and explains why many have doubted its materiality - why the phenomena of combustion, explosion, cohesion, and chemical affinity have not been understood.

I have shown, that caloric is the cause of repulsion in steam and all gases; in vaporization, combustion, and the expansive force of detonating compounds: and that this elastic force is counteracted and diminished, or vanquished by its affinity for gravitating matter.

The ancient philosophers of Greece often referred to an agency, by which they supposed that all nature was perpetually tending to a general dissolution: but being restrained by the overpowering concord of things, (by which they meant attraction,) the result of the conflict was the beautiful order and harmony of the world.

This doctrine throws a clear and full light on 
all the powers, motions, combinations and decompositions of the elements by which we are surrounded and sustained; and, when perfectly unfolded in all its relations, will be found to furnish a simple and rational interpretation of the book of nature.

\section{Constitution of Liquids.}

It has been shown in the preceding chapter, that there is an intimate relation between the elastic force of gases, and the proportions of igneous ather which surrounds their atoms - that hydrogen contains a larger amount of caloric, in proportion to the quantity of ponderable matter, than any other known body, and possesses a corresponding degree of expansive force: but that when it unites chemically with oxygen, it gives out a large proportion of caloric, by which its volume and elasticity are diminished.

It has also been shown, that other things being equal, the elastic force of other gaseous bodies is in proportion to the amount of igneous matter which is combined with any given quantity of ponderable matter.

I shall now proceed to show, that the lightest and most volatile liquids are composed of elements which contain a large proportion of caloric around their atoms. I am not aware that any one, since the time of Boyle and Newton, 
has attempted to explain why liquids differ so greatly in their volatility. Boyle supposed that their tenacity was owing to the grossness of their particles, while Newton referred their volatility to the smallness of their particles. Neither of these hypotheses, which are nearly the same, is in accordance with the present state of science. The proximate atoms of water are less than those of alcohol, æther, and various other liquids that are more elastic and volatile at the same temperatures. The atoms of nitrous and nitric acids, of sulphuretted and phosphuretted hydrogen, of chlorine, hydrochloric acid, and many other gaseous bodies, are larger than those of carbon, sulphur, phosphorus, silicium, calcium, \&c. Yet the former are much more volatile and elastic than the latter. The atoms of ætherine, sulphurous acid, muriatic æther, (which is composed of atherine and hydrochloric acid) protoxide of chlorine, \&c. are larger than those of water or hydrocyanic acid, the elasticity of which is much inferior.*

Such facts prove conclusively, that the elastic force of gases and liquids is not determined alone

* Lucretius observes that light passes through scraped horn, which wine and water will not do, because the particles of the latter are too large; but that water and wine percolate strainers more readily than oils, because the latter are composed of larger particles, or of particles that are hooked. (De Natura Rerum, Book II.) 
by the size of their proximate atoms, but by their relations to a self-repelling fluid.

There is a class of liquids which are composed chiefly of hydrogen and carbon, that seem to form a connecting link between gases and more fixed bodies. They are generally much lighter than water, and exceedingly volatile. Such are Faraday's ætherine and bicarburet of hydrogen, spirit of gum elastic,paraffine, and naphtha. Fther, alcohol, pyro-acetic spirit, acetic æther, and most of the essential oils, which are composed of carbon and hydrogen, united with small proportions of oxygen, are lighter than water, and some of them highly volatile. There are also a few combinations of hydrogen and carbon with nitrogen, chlorine, and even iodine, that are very volatile, as nitrous æther, hydrocyanic acid, muriatic, and hydriodic æthers. There cannot be a doubt that all such liquids owe their volatility to the same cause which determines the elastic force of gases. Accordingly, we find, that ætherine, the lightest of them all, boils or expands rapidly into the gaseous state, under the pressure of the atmosphere below $32^{\circ}$. Common æther boils at $96^{\circ}$, muriatic æther at $60^{\circ}$, nitrous æther at $60^{\circ}$, and acetic æther at $105^{\circ}$, while alcohol boils at $173^{\circ} .^{*}$ But when the pressure of the atmosphere is removed, as under an ex-

- With a view of ascertaining how far the rationale of such phenomena had occupied the attention of philosophers, I took an opportunity of asking a distinguished professor and author in 
hausted receiver, the elastic force of the caloric which surrounds their particles, expands them rapidly into vapour at $145^{\circ}$ below their boiling points under the pressure of the atmosphere. In all such cases, liquids are expanded into the gaseous state by the elastic force of their latent constituent caloric, which is thus diffused and carried off, by which intense cold is produced. In vacuo, pure æther is rapidly expanded into vapour at $-46^{\circ}$, alcohol at $28^{\circ}$, and water at $67^{\circ}-$ from which it follows, that they are all elastic fluids like gases, but in a less degree; and that if their elasticity were not restrained by the pressure of the atmosphere, they would boil at ordinary temperatures, until the process were checked by the pressure of their own atmospheres.

By reference to a subsequent Table, it will be seen that æther is composed of 5 atoms of hydrogen, 4 of carbon, and 1 of oxygen; or 2 atoms of olefiant gas to one of water; and that

London, why æther, alcohol, \&c. were more volatile than water, and the latter than sulphuric acid: after pausing a few moments, he replied, that " he supposed it was owing to the smallness of their cohesion," the reason of which remained in statu quo.

I have thought proper to relate this circumstance, because the present systems of chemistry and physics are full of such definitions and explanations, the fundamental reason of things being overlooked. When a teacher is asked by his pupil why men can see through water, glass, and many other hard dense bodies, he answers with the utmost self-complacency, because they are transparent, and there is an end of the matter. 
alcohol is composed of 3 atoms hydrogen, 2 of carbon, and 1 of oxygen-while water is composed of 1 atom hydrogen to 1 of oxygen. Hence the difference between their specific gravities and boiling points - the specific gravity of pure æether being about $\cdot 700$, and that of alcohol $\cdot 794$, compared with water 1000 , which congeals at $32^{\circ} \mathrm{F}$.while æther and alcohol are exceedingly difficult to congeal.*

That light and volatile liquids contain more caloric than water and some others which are more dense and tenacious, might be inferred from the large amount of hydrogen which they contain, and from their highly combustible property. So highly inflammable is ætherine, that it takes fire on the first approach of a lighted taper.

It has been often stated gravely by chemical writers, that cold results from evaporation, because vapours have a greater capacity for caloric than the liquids from which they are formed,-but this is mere verbiage, and does not explain how liquids

- It was said that alcohol had been frozen by Hutton; and Fourcroy supposed that he had frozen æther at $-46^{\circ}$. But neither Thenard nor Bussy were able to congeal it: from which it is probable, as observed by Mr. Brande, that the æther employed by Fourcroy was not pure. It is now certain however from the experiments of Thilorier, that both may be congealed.

When alcohol and water are mixed, they combine chemically, with diminution of their aggregate volume and disengagement of heat. Proof spirit is composed of about equal weights of each, the specific gravity of which should be $\cdot 916$. 
are expanded into vapour. The coldness results from the elastic force of their latent caloric, by which it is expanded over a larger space; yet without being separated from their particles and radiated as during combustion.

When an open vessel of water is placed over a fire, its temperature never rises above $212^{\circ} \mathrm{F}$. however hot the fire may be,--because at $212^{\circ}$, the elastice force of caloric in water overcomes the pressure of the atmosphere, and expands it into steam, the bulk of which is 1720 times that of water. But when water is enclosed in a strong vessel like Papin's Digester, and prevented from expanding into steam, its temperature rises to 4 or $500^{\circ}$. If a vessel could be obtained strong enough, water might be made red hot,-and if again permitted to expand, its temperature would immediately fall in proportion to the diffusion; and so of all other vapours.

The production of cold during the exhaustion of a receiver, as reported by Leslie and Dalton, is referable to the same cause, and not to an increase of capacity for caloric in rarefied air, as they supposed. That is, a large proportion of caloric is carried off in combination with the air which is pumped out; so that what remains is greatly diffused by virtue of its elasticity, producing a corresponding reduction of temperature. When carbonic acid, ammonia, cyanogen, chlorine, and other elastic fluids are converted into the liquid 
or solid state by pressure, a still greater reduction of temperature results from their sudden expansion on removing the pressure.

M. Thilorier has recently invented an apparatus by which he can form large lumps of solid carbonic acid, the rapid expansion of which, causes a reduction of temperature $-132^{\circ}$. When alcohol was poured upon them, it was immediately converted into a hard, brittle ice; while æther was congealed to the consistence of sodden snow. M. Bussy has also congealed alcohol, (sp. gr. $\cdot 850$ ) by the evaporation of liquid sulphurous acid in vacuo. (Ann. de Chim. for May, 1824.)

When wether is dropped upon the hand, the caloric of the living body expands it into vapour, and is carried off in an invisible form, causing great coldness. In the same way, the caloric of the solar rays is continually expanding the water of the earth into vapour, and diffusing it through the atmosphere, (to be given out in colder regions) by which the sultry heats of summer are diminished.

That all odoriferous emanations consist of extremely minute particles of bodies diffused through the atmosphere by caloric, need scarcely be mentioned,--being obvious from the fact, that at very low temperatures, they are not produced. Excessive cold puts a stop to all volatilization and decomposition of matter.

That the numerous facts connected with the 
constitution of different liquids may be the more readily understood, I have presented them in a tabular form.

The second column of the first table exhibits the number of carbon atoms in the various compound liquids, with the letter $\mathbf{C}$ annexed,- the second column, the number of hydrogen atomsthe third, of oxygen, and the fourth, of nitrogen ; while the fifth column represents their united equivalents, or proximate atomic weights, compared with hydrogen as unity. The sixth column gives the specific gravity of the liquids, compared with water $1000,-$ and the seventh, their boiling points. The remaining numbers give the relative proportions of their constituents in the 100 parts by weight, as derived from the best analyses of modern chemists. By inspecting the first table, it appears that all the most spirituous and volatile liquids contain large proportions of hydrogen and carbon-that most of them are lighter than water, and boil at lower temperatures.

Naphtha is composed of 5 atoms hydrogen and 6 of carbon, or of 87.75 parts by weight of carbon, to $\mathbf{1 2 . 2 5}$ of hydrogen in the 100 . It is also more dense than ætherine, and less volatile. Hence it would seem, that the elasticity of æetherine exceeds that of naphtha, for the same reason that the elastic force of olefiant gas is greater than that of ætherine; or that the elasticity of hydrogen exceeds that of olefiant gas. 
TABLE I.

Representing the Atomic Constitution, Specific Gravity, and Boiling Points of various Volatile Liquids, \&.c.

\begin{tabular}{|c|c|c|c|c|c|c|c|c|c|c|c|c|}
\hline & हूँ & 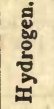 & 总 & $z$ & 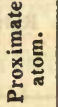 & हैं & 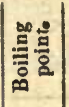 & \multicolumn{5}{|c|}{$\begin{array}{l}\text { Relative Proportions by Weight in } \\
100 \text { Parts. }\end{array}$} \\
\hline Atherine, & $C^{4}$ & $\mathrm{H}^{4}$ & •• & $\cdots$ & 28 & $\cdot 627$ & $32^{0}$ & C. & $\begin{array}{r}H \\
14 \cdot 25\end{array}$ & $\begin{array}{l}0 . \\
\ldots\end{array}$ & $\begin{array}{l}\mathbf{N} . \\
\cdots\end{array}$ & $\begin{array}{c}\text { Parts. } \\
100\end{array}$ \\
\hline Sp.of caoutch. & C & $\mathrm{H}$ & & $\ldots$ & $\ldots$ & $\cdot 640$ & & $\ldots$ & $\because$ & ... & $\ldots$ & $\ldots$ \\
\hline Mur. æther & $C^{4}$ & $\mathrm{H}^{3}$ & $\mathrm{Cl}$ & $\ldots$ & 65 & $\cdot 874$ & $60^{\circ}$ & $36 \cdot 9$ & $7 \cdot 7$ & $55.4 \mathrm{Cl}$ & $\ddot{0}$ & \\
\hline Nitrous æther & $C^{4}$ & $\mathrm{H}^{3}$ & $\mathrm{O}^{4}$ & $\mathbf{N}$ & 75 & $\cdot 880$ & $70^{\circ}$ & $32 \cdot 00$ & $6 \cdot 67$ & $42 \cdot 67$ & $18 \cdot 66$ & 100 \\
\hline Acetic æther & $C^{8}$ & $\mathrm{H}^{8}$ & $0^{4}$ & $\ldots$ & 88 & ‥ & $105^{\circ}$ & 54.55 & $9 \cdot 09$ & $36 \cdot 36$ & $\ldots$ & 100 \\
\hline Ess. of lemon & $C^{5}$ & $\mathrm{H}^{4}$ & $\ldots$ & & 34 & $• 847$ & & $88 \cdot 1$ & $11 \cdot 9$ & ... & & 100 \\
\hline Hydrocy. acid & $\mathrm{C}^{2}$ & H & $\ldots$ & $\mathbf{N}$ & 27 & $\cdot 705$ & $80^{\circ}$ & $44 \cdot 4$ & $3 \cdot 7$ & & $51 \cdot 8$ & 100 \\
\hline Comn. æther & $\mathrm{C}^{4}$ & $\mathrm{H}^{5}$ & 0 & $\ldots$ & 37 & $\cdot 700$ & $96^{\circ}$ & $64 \cdot 87$ & 13.51 & $21 \cdot 62$ & $\cdots$ & 100 \\
\hline Naphtha & $C^{5}$ & $\mathrm{H}^{6}$ & $\ldots$ & ... & 36 & $\cdot 750$ & $160^{\circ}$ & $87 \cdot 75$ & $12 \cdot 25$ & $\cdots$ & $\cdots$ & 100 \\
\hline Bicarb. of hyd. & $\mathrm{C}^{6}$ & $\mathrm{H}^{3}$ & $\ldots$ & ... & 39 & $\cdot 850$ & $186^{\circ}$ & $\because \cdots$ & … & ... & $\cdots$ & $\cdots$ \\
\hline Paraffine & C & $\mathrm{H}$ & $\ldots$ & $\cdots$ & ํ. & $\cdot 870$ & $120^{\circ}$ & $85 \cdot 02$ & $14 \cdot 98$ & * & $\cdots$ & $\cdots$ \\
\hline Pyro acetic sp: & $\mathrm{C}^{3}$ & $\mathrm{H}^{2}$ & 0 & $\cdots$ & 28 & $\cdot 792$ & $132^{0}$ & $\cdots$ & $\cdots$ & $\cdots$ & $\cdots$ & $\cdots$ \\
\hline Pyroxilic spirit & $C^{4}$ & $\mathrm{H}^{5}$ & $\mathrm{O}^{2}$ & $\cdots$ & 45 & $\cdot 804$ & $150^{\circ}$ & 17.60 & $3 \ddot{15}$ & $81 \ddot{25}$ & $\ldots$ & $\dddot{100}$ \\
\hline Hydriod. æther & $\begin{array}{l}C^{4} \\
C^{6}\end{array}$ & $\begin{array}{l}\mathrm{H}^{3} \\
\mathrm{H}^{5}\end{array}$ & I. & $\ddot{\mathrm{N}}$ & $\begin{array}{r}154 \\
55\end{array}$ & 1.92 & $148^{\circ}$ & $\mid \begin{array}{l}15 \cdot 60 \\
65 \cdot 5\end{array}$ & $\begin{array}{l}3 \cdot 15 \\
9 \cdot 1\end{array}$ & $\begin{array}{c}81.251 \\
\ldots\end{array}$ & $\ddot{25 \cdot 4}$ & 100 \\
\hline Alcohol & $C^{2}$ & $\mathrm{H}^{3}$ & $\ddot{0}$ & N & $\begin{array}{l}55 \\
23\end{array}$ & $\begin{array}{l}.700 \\
.794\end{array}$ & $\begin{array}{l}180^{\circ} \\
173^{\circ}\end{array}$ & $\begin{array}{l}00.5 \\
52 \cdot 17\end{array}$ & $13 \cdot 51$ & $21 \cdot 62$ & $\ldots$ & 100 \\
\hline Bisul. of carb. & C & $\mathrm{S}^{2}$ & ... & $\ldots$ & 38 & $1 \cdot 272$ & $102^{\circ}$ & $15 \cdot 79$ & $84 \cdot 21 \mathrm{~S}$ & $\ldots$ & $\cdots$ & 100 \\
\hline Chl. of sulphur & $\mathrm{S}^{2}$ & Cl. & $\ldots$ & $\ldots$ & 68 & $1 \cdot 6$ & $200^{\circ}$ & .. & $\cdots$ & ... & $\cdots$ & \\
\hline Chl. of nitr. & N. & $\mathrm{Cl}^{3}$ & $\ldots$ & ... & 122 & $1 \cdot 6$ & $212^{\circ}$ & $11.5 \mathrm{n}$ & $88.5 \mathrm{Cl}$ & $\cdots$ & $\cdots$ & 100 \\
\hline Iodide of nitr. & N. & $\mathbf{I}^{3}$ & $\ldots$ & $\ldots$ & 392 & ... & $\theta$ & $3.6 \mathrm{n}$ & $94.4 \mathrm{I}$. & ... & $\cdots$ & 100 \\
\hline N.acid,concen. & $\mathbf{N}$ & $\mathrm{Aq}^{2}$ & - & $\cdots$ & 72 & $1 \cdot 5$ & $210^{\circ}$ & $75 \cdot \ddot{N}$ & $25 \mathrm{Aq}$. & ... & ... & $\cdots$ \\
\hline Mu. acid,conc. & Cl.H & $\mathrm{Aq}^{6}$ & & $\cdots$ & 91 & $1 \cdot 6$ & $112^{\circ}$ & ... & $\cdots$ & ... & $\cdots$ & ... \\
\hline Tartaric acid & $\mathrm{C}^{4}$ & $\mathrm{H}^{2}$ & $\mathrm{O}^{5}$ & ... & ... & $\cdots$ & ... & ... & $\cdots$ & $\cdots$ & $\cdots$ & ... \\
\hline Citric acid & $\mathrm{C}^{4}$ & $\mathrm{H}^{2}$ & $0^{4}$ & $\cdots$ & ... & 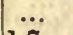 & & ... & .. & ... & $\cdots$ & $\cdots$ \\
\hline Hydriodic acid & I & $\mathrm{H}$ & $\ldots$ & ... & 127 & $1 \cdot 7$ & $260^{\circ}$ & $\cdots$ & $\cdots$ & .. & $\cdots$ & $\cdots$ \\
\hline Acetic acid & Ac. & Aq. & 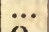 & $\cdots$ & 60 & $1 \cdot 062$ & ... & & (4), & & & \\
\hline Cyanic acid & Cy. & $\ddot{c i}$ & 0 & 1 & $\begin{array}{l}34 \\
50\end{array}$ & 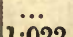 & $\ddot{2 i 7^{0}}$ & $\left|\begin{array}{l}35 \cdot 2 \\
45 \cdot 8 \mathrm{Cy}\end{array}\right|$ & $\begin{array}{l}41 \cdot 10 \\
54 \cdot 2 \mathrm{~S}\end{array}$ & $23.7 \mathrm{n}$. & $\cdots$ & \\
\hline $\begin{array}{l}\text { Sul. cyan. acid } \\
\text { Perchloric acid }\end{array}$ & Cy. & $\mathrm{O}^{7}$ & $\because \cdots$ & $\begin{array}{l}\cdots \\
\cdots\end{array} \mid$ & $\begin{array}{l}59 \\
92\end{array}$ & $1 \cdot 6$ & $392^{\circ}$ & $\ldots$ & ... & … & $\ldots$ & $\cdots$ \\
\hline Sul. & $\because s$ & $\mathbf{A q}^{2}$ & 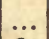 & $\cdots$ & 58 & $1 \cdot 84$ & $620^{\circ}$ & $81 \cdot 63 \mathrm{~S}$ & $18.37 \mathrm{Aq}$ & & .. & 100 \\
\hline Water & & & 10 & $\ldots 1$ & 9 & 1.000 & $\left|212^{\circ}\right|$ & $\ldots$ & $11 \cdot 9$ & $88 \cdot 1$ & $\ldots$ & 100 \\
\hline
\end{tabular}




\section{TABLE II.}

Representing the ultimate Constitution of the Volatile and Fixed Oils, with some other Compounds,-their Specific Gravity, Boiling Point, \&.c.

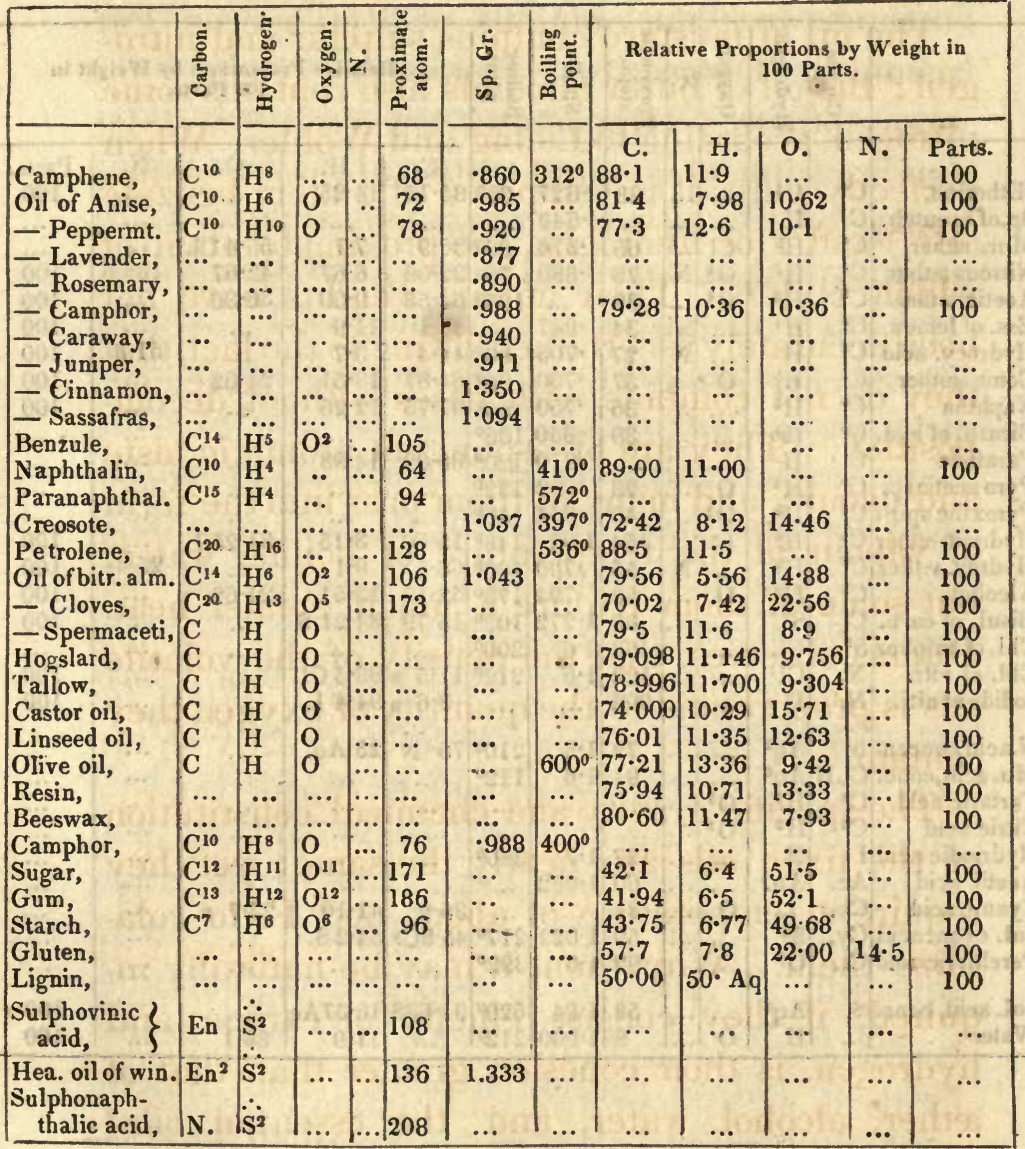


It has been found, that several of the essential oils are hydrocarbons, as the essence of turpentine, lemons, copaiva, burgamot, and camphene, or camphogen ; but that most of them are composed of hydrogen and carbon, united with oxygen; or that they are oxides of hydrocarbons, as they have been termed by Dumas.

The oil of mustard contains sulphur and nitrogen; the oil of bitter almonds also contains some nitrogen, according to Liebig and Wöhler. When perfectly pure, it is composed of 1 atom benzule (Bz.) and 1 of hydrogen, the proximate atom of which is 106. Their atomic weights have not been accurately ascertained, owing to the fact, that they do not combine with bases without decomposition. They are of a pungent aromatic taste and odour; and many of them pass into the form of vapour at the temperature of boiling water; but some of them require a much greater heat. Dumas observes, that the density of the volatile oils is proportional to the quantity of oxygen they contain.

The specific gravity and chemical constitution of the fixed oils are nearly the same; yet they require a temperature of about $600^{\circ} \mathrm{F}$. to volatilize them. Why then, it may be naturally inquired, if they consist chiefly of carbon and hydrogen, is their cohesion greater than that of æther, alcohol, water, and the essential oils? The following facts may tend to throw some degree of light on this question. 
By adverting to the second table, it will be found that camphene, or camphogen, is composed of $10 \mathrm{c}$. to $8 \mathrm{~h}$. united into 1 compound atom, the weight of which is 68 , compared with hydrogen : whereas, the essence of lemon is composed of $5 \mathrm{c}$. to $4 \mathrm{~h}$. making a proximate atom equal to 34 , or one-half that of camphene. The consequence of which is, that the latter is much more volatile than the former, though their specific gravities are nearly the same. Camphene requires a temperature of $312^{\circ} \mathrm{F}$. to make it boil, while the essence of lemon is highly volatile like naphtha. Camphene is the principal ingredient in oil of turpentine and camphor, both of which are oxides of camphene. Common camphor is composed of 1 atom camphene to 1 of oxygen. There is also an artificial camphor, composed of hydrochloric acid 1 atom, united with 1 of camphene. While 3 atoms of water and 1 of camphene make the hydrate of camphene; and 5 atoms oxygen to 1 of camphene, camphoric acid. Petrolene, which is obtained from petroleum by distillation, according to Boussingault, is composed of carbon and hydrogen in the same proportions as camphene; but its proximate atom being just double that of camphene, corresponding with the difference between the specific gravity of their vapours, it possesses the consistence of a fixed oil, requiring a temperature of $536^{\circ} \mathrm{F}$. to convert it into vapour, The product (asphaltine), which 
remains after the distillation, is still more tenacious.

Naphthalin is composed of 10c. $4 \mathrm{~h}$. united into 1 atom 64. It is a highly tenacious liquid, requiring a temperature of $400^{\circ}$ for its volatilization.

According to Dumas and Laurent, there is a combination of carbon and hydrogen in the ratio of 15c. 4h. (equivalent 94) which has been called paranaphthalin. It is one of the last products from the distillation of coal tar, and is less volatile than naphthalin. The atomic weight of sulphuric acid is 40, and that of naphthalin 64 . When 2 equivalents of the former unite with 2 of the latter, the compound equivalent is 208 of sulpho naphthalic acid, (according to Faraday) forming a hard and brittle solid, that is soluble in water, alcohol, and oils.

Naphthalin also forms a dense and tenacious compound with chlorine. With cyanogen, sulphur, iodine, bromine, \&c. it forms dense semiliquids, the cohesion of which augments in proportion to the increased magnitude of their compound equivalents.

From the atomic constitution of camphene, oil of turpentine, cloves, peppermint, anise, naphthalin, \&c. there can scarcely be a doubt that their cohesion, and that of the fixed oils, is greatly modified, if not wholly determined by the number and relative proportions of elementary atoms 
which combine into complex atoms or particles of larger size. Hence, ætherine is more volatile than naphtha, and the latter than camphene. Camphene is more volatile than naphthalin, and the latter than paranaphthlin, although they are all composed of carbon and hydrogen. The atomic equivalent of camphene exceeds that of naphthalin, while the latter is less volatile: but this is owing to the fact, that camphene contains just double the ratio of hydrogen.

By looking over the preceding tables, we perceive that the most volatile liquids are composed largely of hydrogen, and of other elastic gases, such as hydrochloric æther, nitrous æther, acetic æther, hydro-cyanic and hydriodic æthers, chloride of nitrogen, nitric acid (anhydrous,) pyroacetic spirit, \&c.-all of which expand into the gaseous state at temperatures below $212^{\circ} \mathrm{F}$, notwithstanding their proximate equivalents are large: but it was also shown, that carbon, phosphorus, sulphur, iodine, bromine, and even arsenic, may be converted into permanent gases by combining chemically with hydrogen - that they attract from it a portion of caloric by which their elastic force is increased, and that of the hydrogen diminished -that their volume and elasticity decrease in proportion to the size of their proximate atoms, until they assume the liquid or solid form. The most embarrassing circumstance connected with this subject is, that carbon should not be elastic at all 
temperatures, like oxygen, nitrogen, hydrogen, and their combinations. Considering the large amount of caloric which it contains, there is something very mysterious about the fixedness of charcoal at high temperatures.

The whole theory of distillation and sublimation is founded on the different degrees of volatility in the various ingredients of solid and liquid bodies, from the rectification of the æthers, alcohol, and the volatile oils, to the distillation of coal, by which its carbon, hydrogen, and oxygen are volatilized in a state of carburetted hydrogen, olefiant gas, carbonic oxide, \&c. as in coal gas.

That the proximate atoms of the fixed oils, (such as olive oil, castor oil, spermaceti, lard, tallow, and other bodies which are difficult to volatilize, as tar, resin, beeswax, petroleum, \&c.) are larger than those of the volatile oils, would appear from a variety of considerations.

1. They are generally opaque, and many of them obtained by expression from the seeds of plants - from which it is probable that they contain a mixture of gross particles, united with more volatile particles-and that they differ from essential oils in a manner somewhat analogous to the difference between smoke, which is composed of gross vapours, and the pure gases, which are transparent and invisible.

2. In its ordinary state of impurity, oil of turpentine volatilizes slowly at $300^{\circ} \mathrm{F}$, when a limpid 
oil passes over. At $360^{\circ}$ it boils-but on losing its essential oil, it becomes more tenacious, and requires a temperature of $500^{\circ} \mathrm{F}$. to make it boil -thus, passing from the state of a volatile to that of a fixed oil.

The oil of anise is composed of 10 atoms carbon, 6 of hydrogen, and 1 of oxygen, making its proximate atom equal to 74 -while the oil of peppermint consists of $\mathrm{C}^{10} \mathrm{H}^{10} \mathrm{O}$, making its compound equivalent 78: so that in their atomic constitution they resemble naphthalin, forming a medium between the more volatile oil of lemons, and those termed fixed.

According to Dumas, the oil of cloves is composed of 20 atoms carbon, to 13 of hydrogen, and 5 of oxygen, making its proximate atom 173. It is accordingly very difficult to volatilize, like the fixed oils-from which it is probable, that their atomic constitution is similar, and determines their tenacity.

When the volatile oils are exposed to the atmosphere, they absorb oxygen, by which they become resinous and concrete. The oil of turpentine is thus converted into rosin. By absorbing oxygen, the fixed oils become rancid,- and much more rapidly in warm than cold weather-during which process, carbonic acid is produced, and heat evolved, as in fermentation. Hence, the spontaneous combustion of cotton goods which have imbibed oily matter. They all give out great 
quantities of caloric during combustion, and are very bad conductors of heat and electricity.

Query. May not the mild and unirritating properties of the fixed oils depend chiefly on the size of their proximate atoms, by which they retain around them their latent caloric, so that when taken into the stomach, they produce no burning sensation or inflammation? And may not their refusal to combine with cold water be owing to the same cause? for it will be seen hereafter that no chemical combination ever takes place without a transition of caloric from one body to another.

It would be a matter of the highest interest and importance to ascertain the cause which determines the specific agencies of the rthers, alcohol, and its combinations with water, as brandy, gin, \&c. on the living body, - what gives them their tonic and exhilarating properties-why the volatile oils are pungent and aromatic, while the fixed oils are bland, producing no sensation of heat when taken into the stomach. The modus operandi of hydro-cyanic, oxalic, nitric, and sulphuric acids, together with all active medicines, which are poisons, is still involved in profound darkness. A thorough investigation of this whole subject, physiologically and pathologically, under the guidance of broad and fundamental principles, would create a new era in medical science, and rescue it from the opprobrium of mysticism and uncertainty which have long rendered its utility 
more than doubtful among men of the soundest views.

That nitric, sulphuric, and phosphoric acids, owe their active properties to the igneous principle with which they are associated, cannot be doubted; as their action is attended with an intense heat, as when mixed with oils, sugar, and alcohol; and is accompanied by the formation of new chemical compounds. It is the prevalent opinion of medical men, that hydro-cyanic acid destroys life by a sedative influence; but I have satisfied myself by inspecting the stomachs of individuals who have been destroyed by it, that it produces a high degree of active inflammation. There never was a stomach more injected with blood, than one exhibited in Guy's Hospital, produced by swallowing a large dose of prussic acid. - It has been discovered by the recent researches of chemists, that there are several combinations of carbon and hydrogen, the relative proportions of which are the same, while they differ greatly in their physical properties: for example, olefiant gas is composed of 2 atoms carbon, united with 2 of hydrogen, forming a bicarburet of hydrogen, which is permanently elastic at all temperatures; while ætherine is a quadri-hydro-carbon, consisting of 4 atoms carbon, to 4 of hydrogen, united into 1 compound atom, the weight of which is 28 , compared with hydrogen as unity; or just double the atomic weight of olefiant gas. Accordingly, 
we have seen, that although ætherine is a highly volatile liquid, it is far less elastic than olefiant gas.

Such bodies have been termed isomeric, by Berzilius, (from ıбos equal, and $\mu$ soos part.) Dr. Turner explains the difference between the properties of these bodies by supposing that their particles are differently grouped together. (Page 238, Chem. 5th edit.) This is no doubt true, but does not explain why their particles contract into a smaller space, and why the specific gravity and elastic force of ætherine and olefiant gas are different. I have already proved that the repulsive force of caloric in hydrogen is counteracted and diminished in proportion to the quantity of carbon united with it, and that the igneous æther is concentrated around the larger atoms of etherine by virtue of their mutual affinity. May not the arrangement of their particles, and the variation in their chemical properties result from the same cause? Such queries open a wide field of speculation to the philosophical chemist, and their solution is of fundamental importance to a right understanding of chemical philosophy. 


\section{BOOK II.}

\section{CHAPTER I.}

On the Cause of the Forces which regulate the Constitution of Solids.

IT was long since observed by Lord Bacon, that the most important facts connected with the fundamental constitution of nature, had been quite overlooked; such as "the cause of heat and light, weight and density, hardness and softness, solidity and fluidity, fermentation and putrefaction, germination and organization."-Novum Organum.

Although more than two centuries have elapsed since Bacon pointed out the radical defects of science, and the true mode of its regeneration, with profound sagacity, and a soul-stirring eloquence never surpassed, scarcely one of the above problems have been resolved in a satisfactory manner. Philosophers are still as much divided in regard to the cause of heat and light as they were in the time of Bacon, Galileo, and Boyle; or the still more remote period of Plato and Aristotle. 
Sir Isaac Newton devoted many years to the investigation of light, and really accomplished much towards an elucidation of its physical properties; but without ever having inquired into its connexion with heat, or its wonderful agency in the work of the universe.

The same illustrious author resolved the cohesion of solids and the tendency of heavy bodies towards the centre of the earth, into the same law which determines the aggregation of planets, and their revolutions around the sun: but he did not identify the cause of universal attraction with any known agent. In short, he did not distinctly unfold the fundamental principle of action in nature - of expansion and contraction, density and lightness, hardness and softness, solidity and fluidity, chemical union and decomposition. There is nothing more remarkable in the history of science, than that the phenomena of attraction should have been so far unfolded and generalized, without any definite knowledge of its cause. It would seem that one of the first inquiries of the philosopher ought to be, what is the agent or cause of force, by which the atoms of matter are held together? and that the most natural answer would be, that which surrounds and fills the spaces between them.

It can no longer be disguised, that in regard to the cause of cohesion, capillary attraction, and gravitation, Sir Isaac Newton has expressed himself with so much ambiguity as to leave his fol- 
lowers in great doubt whether he had any settled opinion on the subject. In the first edition of the Principia, he maintained that universal space is a vacuum; or that it was void of all sensible matter, and that the ultimate particles of bodies are endowed with inherent forces, or powers of attraction and repulsion.

That he afterwards renounced the vacutm of space and the self motive pover of atoms, is evident from the scholium which he added to the second edition of the Principia, his letter to Boyle, and from the whole tenor of the Opticks-in each of which, he maintains the existence of an exceedingly subtile, active, and elastic æther as pervading universal space and the pores of all bodiesthat it was the cause of cohesion, capillary attraction, and of the force by which menstruums dissolve solids-in fine, that it was the moving power of nature.

It is also universally known, that he regarded light as a material substance, capable of being attracted and repelled by gravitating matter; which alone is sufficient to prove, that he had abandoned the hypothetical vacuum of space. He further supposed that light and common matter were convertible into each other-an hypothesis which I shall endeavour to show hereafter by an appeal to nature, and the most decisive experiments, is susceptible of positive demonstration.

Considering the almost unbounded influence 
of Newton's authority on nearly all subjects connected with the science of nature, it is important that his real opinions should be distinctly understood. I shall, therefore, proceed to prove, by his own words, that he did not regard attraction as an ultimate law of nature, resulting from the inherent properties of atoms. In addition to the passages before quoted, in page 26 of this work, he observes, in the advertisement to the second edition of the Opticks, " to show that I do not take gravity for an essential property of bodies, I have added one question concerning its cause, choosing to propose it by way of question, because I am not satisfied about it for want of experiments." *

The same view is still further expanded in the third book of the Opticks, page 365. After observing that "all matter, even light, seems to be composed of exceedingly small, hard, and unchangeable atoms, which in the densest bodies touch only in a few points," he adds, "how they can stick together so firmly as they do without the assistance of something which causes them to be attracted or pressed towards one another, is very difficult to conceive." He remarks, in another passage, page 369 , " there are agents in nature capable of causing the particles of matter to stick together by very strong attractions, and

* The above sentence refers to the ather, which, in the second edition of the Principia, he proposed hypothetically as the cause of universal attraction. 
that it is the business of experimental philosophy to find them out." Yet it is an undoubted fact, that nearly all the most distinguished followers of Newton have represented him as teaching the vacuum of space-that the sun operates upon the planets without any intervening mechanical medium - and that the gravitating matter of which planets is composed, is held together by virtue of inherent powers, or innate forces, which Newton expressly says that he could not conceive.

It was truly observed by Bacon, that "the doctrines of great and original minds are often degenerated and embased by time - that while the lighter parts of their labours float down the stream of time, the weightier and more valuable, frequently sink into oblivion." * This remark applies with great force to the misconception and perversion of the ancient systems of philosophy, the most important features of which are but vaguely and imperfectly comprehended by the moderns. When Greece was the centre of light and civilization to the whole world, nearly all her most distinguished sages maintained the existence of an igneous principle, which extended throughout the universe. This powerful and omnipresent agent was regarded by them as the life of nature, and the cause of all concord and discord, (by which they evidently meant attraction and 
repulsion,) by virtue of which the celestial bodies were preserved in their respective courses, and connected as by an invisible everlasting chain; and without which there could be no generation or dissolution of bodies.

Such were the opinions of Pythagoras, Parmenides, Democritus, Heraclitus, Plato, and many others. Hippocrates termed it "a strong but invisible fire which rules all things without noise, and is never in repose; which actuates and animates the whole system of nature." Here is a definition of heat in accordance with the discoveries of Dr. Black, but still more comprehensive and important.

Like the ancient Greek philosophers, Bacon reduced all matter to two classes, active and passive; the first of which he describes as rare, invisible, and without weight, though a real and quantitative substance, pervading and filling the pores of all gross bodies. I have already shown that this active spirit, to which Bacon referred all the motions and transformations of matter, is only another name for caloric. (See page 24.) But if this pneumatical power be the cause of all the changes of living and dead matter, it must be the cause of attraction, as well as repulsion; of decomposition and recombination.

In his treatise on the Wisdom of the Ancients, Bacon further maintains that the attraction of matter was typified among the early Greek phi- 
losophers and poets, by the elder Cupid, or principle of love; that it was the primitive cause of force, or the moving power of elementary atoms, which formed and organized the universe of things out of chaos. He adds, by way of commentary on this ancient allegory, that " there is doubtless a primary and universal law of nature, which regulates the circular revolutions of the celestial bodies, and to which are owing all contraction and expansion of matter."

In the third book of his treatise on the Advancement of Learning, he says, that whoever shall attentively observe the appetences of matter, shall receive clear information concerning celestial objects from things which are constantly seen around us; and that it is the object of science not only to ascertain the number, situations, and periodic motions of the heavenly bodies, but the physical cause of their mutual action upon each other, which he terms living astronomy, to distinguish it from that which is vulgar and empirical.

It was also maintained by Newton, that all the phenomena of nature are resolvable into attraction and repulsion, which he referred to the agency of an all pervading ethereal substance, capable of contraction and dilatation,-that this ather preserves the particles of the atmosphere and all gaseous bodies at a distance from each other. But, as it is now demonstrable, that caloric alone is the cause of expansion and the elastic force of 
gases, vapours, and volatile liquids, there can no longer be the shadow of a doubt that it is identical with the æther of Newton, the pneumatical power of Lord Bacon, and the universal igneous principle of the ancient Greek philosophers. Nor is it possible to doubt that Newton regarded this principle as the proximate cause of cohesion, capillary attraction, chemical affinity, and of universal gravitation; all of which he viewed as modified effects of one and the same agent.* It was owing to the vague and imperfect account which he gave of its modus operandi, that philosophers have even doubted the reality of its existence, and treated it as a chimera of the author's imagination, invented for the purpose of sustaining his theory of nature; the consequence of which has been, that the law of gravitation has been regarded as a comprehensive generalization of àggregate movements, for which no definite reason can be assigned: while the great and noble science of chemistry, which, in a practical point of view, is far more important than astronomy, consists of an immense collection of facts and experiments, the connection of which with the phenomena of heat, light, electricity,

* It is now universally admitted, that the force with which menstruums dissolve, and combine with solid bodies, is an exertion of chemical attraction; a force which Newton referred to the æther, as I before stated, page 26 ; and I shall demonstrate hereafter, that caloric is not only the universal solvent of nature, but that it is the only agent by which liquids are enabled to combine chemically with solids. 
cohesion, capillary attraction, and gravitation, has never been distinctly understood, or reduced to fundamental laws.

Had Newton discovered the simple law by which the æther produces the opposite effects of contraction and expansion, he would probably have traced its agency in the plienomena of combustion, solution, vaporization, and all the molecular changes of matter : or had Dr. Black, and his successors, fully comprehended that universal law of caloric by which it attracts ponderable matter with a force that augments in proportion as bodies are deprived of it, they would have found that it is as capable, under such circumstances, of becoming a powerful bond of cohesion, as it is, under other circumstances, of dissolving their union, and of converting them into elastic fluids. But they have all overlooked the force of attraction, by which this subtile fluid is concentrated around the particles of gravitating matter, and thus rendered latent; and by which its self-repulsive force is counteracted or destroyed.

So imperfectly has Sir Isaac Newton's theory of attraction been understood, that while some of his followers have considered gravitation as a distinct and primary agent, others have regarded it as a fundamental and universal property of matter, by which all bodies tend to a common centre: but I have shewn that Newton referred 
attraction, repulsion, and heat, to the agency of an ather. Not being able to comprehend how one and the same agent could produce such opposite effects, Buffon maintained that the powers of nature, which are known to us, may be reduced to two: that which causes weight, and that which causes heat, -that to the power of attraction, joined to the cause of heat, may be referred all the phenomena of living and dead matter. Still the cause of attraction remained unexplained. Had Buffon advanced but one step further, he would have resolved all the forces of nature into one and the same cause.

Since the discovery of latent heat by Dr. Black, nearly all philosophers have viewed it as the antagonist of that universal force by which all things are held together. When treating of liquids, Dr. Dalton observes, that they must be considered as bodies under the control of two most powerful agents, attraction and repulsion, the last of which he refers to caloric. Sir $\mathbf{H}$. Davy also observes, that heat, or the power of repulsion, may be considered as the antagonist of cohesion; the one tending to separate, and the other to unite the particles of bodies. (Chemical Philosophy, page 30.) Still the important question recurs, what is the cause of attraction? Newton says, it is an effect of some unknown æthereal agent, and that it is the business of philosophy to find it out. 
What then is the internal constitution of matter? Are the pores of bodies void of all substance? or are they pervaded by subtile and active matter? If so, what is it, and what are the laws by which it operates? It is quite certain, that until these important queries are resolved, the science of nature can never be established on the solid rock of first principles; but must remain, as heretofore, imperfect and vacillating.*

It requires no extended series of argument to prove, that whatever the cause may be which moves atoms, must also be the cause which moves the largest bodies, for the simple and obvious

"It was supposed by Epicurus and his followers, that " the atoms of fluids were smooth and spherical, by which they were enabled to glide freely over each other; but that the atoms of solids were hooked," as if their forms could change on passing from the liquid to the solid state. He also maintained that the pores of bodies were void of all matter. (De Natura Rerum, book ii.) Others have supposed that the particles of bodies are glued together by an immaterial cement, as bricks are held together by mortar. (Baxter on the Immateriality of the Soul.) The Rev. W. Jones referred cohesion to the pressure of a cold ather, from the fact that liquids are converted into solids by cold. This he thought was demonstrated by the expansion of water during the process of freezing; an effect which is obviously owing to the arrangement of its particles in the crystalline form. Ampere, Berzelius, and some other modern philosophers have maintained that the atoms of bodies are endowed with electric polarity, or that their opposite sides are in different states of electricity; while the great body of chemists regard the whole subject as involved in profound obscurity. 
reason that they are made up of atoms. If it be true, that cohesion, capillary attraction, and chemical affinity, be only modifications of gravity, as maintained by Newton, Laplace, Buffon, Guyton, Morveau, and other philosophers, it follows, that the whole theory of nature, whether mechanical, chemical, or physiological, is resolvable into that of atoms, and the cause by which they are surrounded, attracted and repelled, united and separated. If we are capable of discovering the cause which holds together the particles of a pebble, or crystal of ice, and can demonstrate that it is a universal constituent of ponderable matter, we are also capable of comprehending the cause which binds all things together by gravity. Newton expressly affirms, that " the drops of fluids affect a round form by the mutual attraction of their parts, as the earth affects a round form by the mutual attraction of its parts by gravity." (Opticks, book iii. page 370.)

It is self-evident, that if the particles of bodies be not endowed with inherent powers of motion, they must be impelled by some other agent;that is, they must act upon each other at a distance, without the agency of any physical tie, or by something intimately connected with them. Thus it will be found, that the primary object of science is to ascertain the cause which moves atoms, and the mode in which it produces so 
many and diversified effects; that chemistry and natural philosophy are only different branches of one great science, which cannot be studied apart from each other, without departing from the unity and simplicity of nature, every operation of which is governed by the same code of physical laws, from the aggregation of a crystal to that of suns, planets, and their satellites.

It is still a problem with philosophers, whether the particles of bodies are drawn together, or pressed together. Newton supposed, that the æther, which I have shewn to be identical with the cause of heat, was more rare within the substance of dense than light bodies; and more dense in the spaces beyond them, than around their particles, by which they are pressed together. (See page 28, chap. 1.) But I have shewn the reverse of this to be the fact; - that a cubic inch of carburetted hydrogen, which is eight times the specific gravity of simple hydrogen, contains a greater amount of æthereal matter around its particles, because they are larger, and have a stronger attraction for it. For the same reason, equal volumes of olefiant gas contain more of the igneous æther around its atoms than light carburetted hydrogen, while the vapours of alcohol, æther, naphthalin, ætherine, and many other gaseous bodies, attract and retain around their particles still larger quantities, corresponding with their greater size. 
I have proved, that when chlorine, or the vapours of carbon, sulphur, phosphorus, \&c, are brought into contact with hydrogen, they diminish its elastic force by withdrawing from it a portion of its caloric; and that all gaseous bodies are combined chemically, with contraction of volume, by virtue of their attraction for caloric, for the same reason that steam, ammoniacal gas, and the vapours of alcohol, æther, nitrous acid, hydrocyanic acid, \&c. are condensed by contact with cold water, and chemically united with the water.

I have shewn, in the foregoing chapters, that the atoms of all bodies are surrounded with subtile and active matter, without which they could neither approximate nor recede from each other; consequently, would be passive and motionless ; that the various forces, movements, and changes of form which bodies undergo, are determined by the relative proportions of rthereal and ponderable matter of which they are composed; that when the active principle predominates, they are decomposed, or expanded into gases, vapours, or even flame, which is luminous æther; but that when the ratio of gravitating matter predominates, its attraction for caloric counteracts its self-repulsive force, by which gases are chemically united into vapours, with contraction of volume and diminution of elasticity, or condensed into liquids and solids. 
It still remains to prove that the colesion of metals, rocks, and all other solid bodies, is determined by the various degrees of force with which they attract caloric; and that it is resolvable into the same cause which produces the contraction and chemical combination of gases, or reduces them to the form of liquids. If it can be established as a general law, that the particles of all bodies are held together, with forces which vary according to the different degrees of their affinity for caloric, and that this affinity varies with every change in the relative proportions of caloric and ponderable matter, the problem of attractions will be greatly simplified; for it will be evident that cohesion is not the result of pressure, as conjectured by Newton, but that contraction and expansion, density and lightness, solidity and fluidity, are modified effects of one and the same agent; in fine, that all the operations of nature depend on the relations of æthereal and ponderable matter.

A thorough comprehension of the law by which caloric is chained down in a state of intimate combination with the ponderable matter of the earth, and thus prevented from expanding throughout the universe, would banish from the science of Physics all those vague and absurd speculations, which have been founded on hypothetical data, such as innate forces, immaterial properties, occult qualities, inertia of atoms, \&c. 
Surely there are mysteries enough in science, without our going beyond the range of experience and observation. Perhaps the most fruitful source of error in physics, has been owing to partial and limited views of nature; and the confounding of phenomena or effects with the cause which produces them. Some modern writers on natural philosophy, speak of gravitation as though it were " the animating principle of nature." In the fifth volume of the Cabinet Cyclopedia, we are told that, "all the great changes and revolutions of the bodies which compose our system, can be traced to, or derived from this principle." But if gravitation were a universal principle of action in nature, it ought to explain the phenomena of solution, repulsion, evaporation, the expansive force of gases and fulminating compounds; in short, it ought to account for all the operations of chemistry, geology, and meteorology, which is not the fact. It therefore follows, that there must be a principle of action in nature ulterior to that of gravitation, as admitted by Newton.

It might as well be said that repulsion is the animating principle of nature, as the general attraction termed gravitation. The true state of the case is, that both attraction and repulsion are subordinate, though universal effects of an allpervading principle that surrounds every particle of matter in the universe, to which may be 
referred the phenomena of heat, electricity, light, evaporation, and combustion, together with all the diversified transformations of matter.

If the atoms of ponderable matter were wholly deprived of this principle, they would no longer be capable of attracting and repelling each other; consequently, there could be no cohesion,--and if cohesion be only a modification of universal attraction, it is idle to regard gravitation as the first of secondary causes, from which all the phenomena of motion may be deduced; while it is only an expression of the general fact, that bodies tend towards each other with forces which vary inversely as the distance. When the vacuum of space, and the projectile force of planets, on which the Newtonian theory was originally founded, shall have sunk into oblivion; the above fact will remain a monument of lofty generalization until time shall be no more.

It was by confounding the external world with the impressions which it produces on the senses, that Berkeley was led to resolve the universe of matter into mind or spirit. The mathematical theory of Boscovich before noticed, is equally beyond the power of human comprehension. In the same spirit of metaphysical subtlety, the celebrated Kant denied the existence of ultimate atoms, by assuming that they were without extension or solidity: while he resolved heat, light, electricity, and magnetism, into the power 
of attraction and repulsion, as if such powers could exist without substance. Not less obscure is the modern doctrine which resolves light, heat, and electricity, into vibrations of some unknown hypothetical æther. Who can grapple with such shadowy and unsubstantial data?

It has been already shewn, that caloric is not an effect, condition, or property of other matter, but an all-pervading and independent active principle, without which there could be no vibrations. Had Bacon, Boyle, Newton, and Hooke, been aware of the law by which æthereal and active matter is attracted and concentrated around the particles of ponderable matter, and thus disguised from the senses, as shewn by Dr. Black, they could never have confounded the cause of heat with motion and vibration; or had Count Rumford recognised the vast force of attraction by which caloric is concentrated around the particles of iron and other metals, he would not have been at a loss to account for the heat evolved by the friction of boring a cannon.

It is an exceedingly partial and superficial view of caloric to regard it merely as the cause of temperature, fluidity, vaporization, decomposition, \&c.; for it is self-evident that if the attraction of caloric for metals, ice, and other bodies, augments in proportion as they are deprived of it, it must be an attractive as well as a 
repulsive agent-an æthereal bond of cohesion, the force of which varies according to the relative proportions of caloric and ponderable matter. Every alteration in these proportions produces a change in the physical, chemical, and even vital properties of all bodies.

That the force with which caloric combines with, and is concentrated around the particles of ponderable matter, augments in proportion as they are deprived of it, may be regarded as a fundamental axiom, derived from the general experience of mankind; and is founded on a law of nature which connects all the phenomena of molecular attractions with the theory of latent caloric. Without the recognition of this important truth, it is impossible to comprehend the most familiar phenomena of every day life: why, for example, the atmosphere abstracts from animal bodies their vital heat, with a rapidity proportional to the reduction of its temperature; or why caloric is rendered a latent constituent of all matter. The attraction of ice for caloric exceeds that of water, because it contains less of it than water ; the consequence of which is, that the particles of water are drawn closer together, and maintained in the solid form with a corresponding force of cohesion. If it be objected that water expands during congelation, it may be answered that its particles are arranged in series, forming angles of $60^{\circ}$ and $120^{\circ}$, making large pores or 
cavities. Were it not for this, the volume of ice and other crystalline bodies, would diminish on assuming the solid form. That the volume of ice is actually reduced, and its cohesion greatly augmented by the abstraction of caloric, is evident from the large fissures found in bodies of ice after an excessive freeze in rigorous climates, and from the rocky firmness which it exhibits. Were it possible to reduce the temperature of ice $1000^{\circ}$, its attraction for caloric would be immense, with a corresponding augmentation of its density and cohesion.

If the atoms of gold, silver, copper, iron, lead, tin, and other metals, be surrounded with caloric alone, and if it have a definite degree of attraction for each, it must hold them together with a corresponding force of cohesion, for the obvious reason, that " nothing can act where nothing is." Or if the atoms of oxygen, hydrogen, and carbon, of vegetable matter be surrounded with caloric, and nothing else, it must be the cause of their contraction and expansion, of their chemical union and decomposition, unless the atoms be endowed with inherent powers of attraction and repulsion-which is hypothetical and contrary to all analogy.

If it be maintained, that electricity is a constituent of all bodies, I answer, that latent electricity, as it exists in a state of combination with the particles of ponderable matter is identical 
with caloric. For the proofs of this identity, the reader is referred to the next book, where it will be demonstrated that solar caloric is the basis of lightning; and that under all circumstances, however various the phenomena of electricity, they are only modified effects of the same agent which produces evaporation and solution.

The general recognition of this important truth will banish from the science of nature an immense mass of obscure and metaphysical jargon, by divesting it of that complexity which has hitherto baffled every attempt to explain in a satisfactory manner, the connexion of heat and electricity with cohesion and chemical affinity. The absurdity of supposing that the atoms of bodies are surrounded with two distinct æthereal agents, one of which draws them together, while the other repels them asunder, is too obvious to require a serious refutation.

By the attraction of caloric for ponderable matter, it unites and holds together all things; by its self repulsive agency, it separates and expands all things.

To whatever portion of nature's wide domain we turn our attention, we recognize the operation of this universal law. Hence it is, to use the significant language of Bacon, that " heat and cold are nature's two hands ;" which is a general though vague enunciation of the above law : for 
it is certain that in a philosophical sense, the words heat and cold are only relative terms, which indicate different proportions of the same æthereal agent.

It is because the attraction of caloric for solids exceeds that of liquids, that their cohesion is greater than that of liquids. It is because the attraction of mercury for caloric exceeds that of water, that its particles are held together with a greater force of cohesion. When reduced to the temperature of $-39^{\circ}$, the attraction of mercury for caloric is so far augmented that it assumes the solid form : but the most important fact connected with this change is, that it acquires a corresponding power of attracting other bodies, the temperature of which is higher. It was before stated, (page 106,) that when the hand is applied to frozen mercury, its caloric is rapidly withdrawn. They are also held together with great force, as iron is attracted by a powerful magnet when charged with electro-caloric by a voltaic battery. It is therefore highly probable, that if the temperature of mercury were reduced $-100^{\circ}$, it would abstract from animal bodies their vital heat with a force and rapidity resembling an electric shock; and that if it were possible to reduce its temperature two thousand degrees below zero, the force of its attraction for caloric would surpass all means of computation; while 
its cohesion and density would be proportionally augmented.*

It is owing to the attraction of caloric for gravitating matter, that when the hand is applied to iron, copper, gold, silver, and other dense metals at very low temperatures, it adheres fast, and cannot be disengaged without lacerating the skin; or that when a portion of melted zinc is poured upon a solid plate of the same metal, there is a rush of caloric from the liquid to the solid, by which their particles are drawn together; or that when water is poured upon a block of ice $15^{\circ}$ or $20^{\circ}$ below zero, it is imme-

* It is because iron, copper, gold, silver, platinum, and other dense metals, have a stronger attraction for caloric than silks, furs, down, woollens, resins, bitumens, sulphur, coal, iodine, bromine, dry wood, potassium, sodium, with innumerable other light bodies, that they abstract it more rapidly from warm-blooded animals, and consequently feel colder to the touch. It is because the dense metals exert a powerful attraction for caloric, that it is concentrated and held around their particles with immense force, and cannot be disengaged from them, even in small proportions, without the application of great mechanical pressure. Accordingly, we find that they are good conductors of caloric, and cohere together with a corresponding force of aggregation. Their cohesion and conducting power are also augmented in proportion to their condensation by pressure, as in wire drawing; from which it follows, cateris paribus, that their affinity for caloric, on which their cohesion and conducting power depend, increases with their density and loss of caloric. It is equally true of all other bodies, without a single exception, that their cohesion and conducting power are determined by the relative degrees of their attraction for caloric, which augments in proportion as they are deprived of it. 
diately converted into the solid state, and incorporated with the ice by virtue of the same force which causes universal attraction.

It is by the attraction of caloric for ponderable matter that it combines with different bodies and produces their liquidity; it is also by virtue of the same attraction, that liquids are enabled to dissolve and combine with other bodies. Philosophers have generally assumed, that cohesion is the antagonist of chemical affinity, and that they are produced by different causes : but the most obvious phenomena of nature demonstrate that they are produced by one and the same cause, and that all molecular combinations result from the attraction of caloric for ponderable matter. The only difference between cohesion and chemical attraction is, that the one is exerted between homogeneous atoms, and the other between heterogeneous atoms, which vary in size, and in the degrees of their affinity for caloric. It is owing to the attraction of caloric for ponderable matter, that when a piece of tin is laid on a portion of melted lead, the tin is dissolved, and its particles intimately blended with those of the lead. In all such cases, it is undeniable that the atoms of the liquid are forced to combine with those of the solid, by the agency of caloric alone; for the obvious reason, that no other agent has been employed to produce the effect. 
It is in this way that all metallic alloys are formed. If six drachms of solid zinc be brought in contact with an ounce of melted copper, there is a transition of caloric from the one to the other, by which the particles of zinc are transported from their original place, and intimately combined with those of the copper, by the same power which unites the atoms of individual metals. The simple matter of fact is, that all the elements of nature may be united by fusing them together, and again separated by larger proportions of the same agent. If a mass of granite, or basalt, were plunged into a cauldron of burning lava, they would be intimately incorporated throughout by the transition of caloric from the lava to the solid rock. It is scarcely necessary to add, that the various materials of which all volcanic rocks are formed, are thus united and held together, by the same power which maintains the solidity and cohesion of the earth.

The internal constitution of metals is so far modified by their different degrees of purity, that no two series of experiments hitherto performed for the purpose of ascertaining their respective degrees of cohesion and conducting power have presented the same results. According to Emmerson, the cohesion of gold wire, one-tenth of an inch in diameter, supports 500 pounds weight, and iron wire of the same size, 4.50 pounds; whereas other experimenters have 
found the tenacity of iron to exceed that of gold and all other metals.

That the cohesion of metals is determined by the relative degrees of their affinity for caloric, would appear from a variety of considerations. It was ascertained by Buffon, that when equal quantities of tin, lead, silver, copper, gold, and iron were heated to an equally high temperature, the tin and lead cooled in the shortest time; silver next, then gold, copper, and lastly iron; corresponding very nearly with the relative degrees of their cohesion, as determined by $\mathrm{Mr}$. George Rennie. (Phil. Transactions for 1818.) But, as observed before, the cohesive force of different metals has been so variously stated by different individuals, that little reliance can be placed in any of them. It will be seen hereafter, that the radiating power of different bodies, cateris paribus, is inversely as their attraction for caloric; from which it will follow, that if iron require a longer time to cool a given number of degrees than copper, gold, silver, tin, and lead, it must have a stronger attraction for caloric. It is for the same reason, that when these metals are reduced to a very low temperature, iron and copper abstract caloric from the living body more rapidly than mercury, lead, tin, arsenic, potassium, sodium, and all other bodies, the cohesion and conducting power of which are small, and the radiating power of which is proportionally great. 
The art of plating bars of iron, copper, \&c. with gold, silver, zinc, tin, and other metals, is founded wholly on the cementing power of caloric, which forces them together, by what may be termed chemical cohesion, to distinguish it from the aggregation of simple bodies. Plates of gold are made to unite with bars of iron, and other metals, by being pressed together, and placed in a stove or furnace.

When bars or plates of iron are thoroughly cleaned and polished until quite bright, and immersed in melted tin, they are soon covered over with a thin white coat; or if a slip of copper be perfectly cleaned and polished, then heated, and rubbed over with a piece of tin, a portion of the latter metal combines with the copper, giving it a silvery coat, which adheres to it for the same reason that the hand adheres to frozen mercury, or other metals, when reduced to very low temperatures.

The common mode of tinning copper vessels, is to make the surface bright by scraping and washing them with a solution of muriate of ammonia. They are then warmed, when the tin is melted and poured into them, by which it incorporates with every part of their surfaces, and when cold remains firmly united. In the same way, iron vessels are coated with zinc. It is well known that silex cannot be made to combine with potass or soda to form glass without the agency of heat, which is equally essential to 
the welding of iron, and to the soldering of all other metals. The adhesive property of wax, gum, sugar, \&c. when in a state of fusion by caloric is equally familiar to every one.

The truth is, that all the internal and external properties of bodies, whether mechanical or chemical, such as hardness and softness, density and lightness, tenacity and firmness, volatility and combustibility, are determined by their relations to caloric.

It is well known to spinners and weavers, that the fibres of cotton, wool, flos-silk, and flax, are brittle during cold weather, and that if their rooms are not kept at a proper temperature, their threads often break. On the other hand, some of the most brittle substances in nature, such as glass, may be spun into thread almost as fine as that of the silk-worm, when in a state of fusion by heat; while butter, lard, and many other substances that are soft and tenacious when warm, become hard and brittle at very low temperatures. The same is true of iron and some other metals, which become brittle like glass or ice during excessively cold weather. The rationale of this will appear from the general fact already established, that the attraction of caloric for bodies augments in proportion as they are deprived of it ; the consequence of which is, that it is more concentrated around their particles, which cohere with a corresponding force, producing great hardness; but when by a blow, 
or any sudden force, they are removed in the slightest degree from their place, the cohesion is broken, and they fly asunder. In the state of liquids, their particles glide freely over each other, without losing their hold, as one magnet glides over another. This is the case with all the maleable metals, and with the tenacious oils, gums, glue, \&c. until reduced to very low temperatures, when they all become more or less brittle like ice. It is owing to the augmented cohesion and hardness of very cold iron that it will not bend, but snaps asunder,-that is, its particles refuse to glide over each other; while, at higher temperatures, the greater extent of the igneous atmospheres that surround them, holds on to them at greaterdistances, though with less force, causing toughness or tenacity.

When two pieces of lead, tin, zinc, or any other soft metal, are pressed together with sufficient firmness, their atoms are brought within the range of this attractive medium. The same is true of the hardest substances, when softened by heat. Even polished plates of glass, marble, wood, and many other bodies, when brought into close apposition, cohere, but still better when fused together by heat.

It was before stated that the æthers, alcohol, and many other liquids, have no cohesion whatever at ordinary temperatures ; and when released from the pressure of the atmosphere, are ex- 
panded into vapours by the repulsive power of their latent caloric. They are accordingly very bad conductors, like silks, woollens, furs, and other light bodies, that are full of caloric. Yet by a sufficient reduction of temperature, their attraction for the igneous principle is so far augmented, that their particles are drawn closer towards each other, and bound together in the solid form; and if their temperature could be reduced $2000^{\circ} \mathrm{F}$. there is every reason to believe that their cohesion would equal that of salts, rocks, or even the denser metals.

From all the foregoing facts and arguments it is evident, that hardness and softness, solidity and liquidity, are not essential conditions of bodies, but depend on the relative proportions of æthereal and ponderable matter of which they are composed; that the most elastic gas may be reduced to the liquid form by the abstraction of caloric, and again converted into a firm solid, the particles of which would cling together with a force proportional to their augmented affinity for caloric. On the other hand, it is equally evident, that by adding a sufficient quantity of the same principle to the densest metals, their attraction for it is diminished, when they are expanded into the gaseous state, and their cohesion destroyed.

As the author has met with a few individuals who cannot readily conceive how a self-repulsive 
agent can operate as a bond of cohesion between the particles of ponderable matter, it may be proper to shew by a few familiar examples, that the force with which liquids hold together the particles of solid bodies, is not in proportion to the attraction of their own particles for each other, but in proportion to their affinity for the solids.

It is well known that at ordinary temperatures of the atmosphere, the particles of water cohere with very slight force. It is also known, that when granite, lime, clay, and marle, together with all other rocky and earthy bodies, are reduced to the condition of a perfectly dry and impalpable powder, their particles glide freely over one another, having little or no attraction for each other. On adding to this powder a due proportion of water, they are found to unite together by a very strong attraction, forming dense and highly tenacious mortar. The less water such ingredients contain, the stronger is their attraction for it. Hence it is, that the cohesion of mortar augments in proportion as it is deprived of water by drying; or that when the earth has been parched by a long drought, it attracts and absorbs more rapidly a shower of rain, than when in a moist state, in the same way that all bodies attract and absorb caloric with a force and rapidity in proportion as they are deprived of it. In like manner, the cohesion 
of mortar is diminished by adding to it larger proportions of water, in the same manner that the cohesion of ice, metals, and other bodies, is lessened by increasing their temperatures - that is, by altering the relative proportions of caloric and ponderable matter.

Innumerable liquids might be mentioned, the atoms of which have no cohesion among themselves, which, nevertheless, operate as a bond of union among the particles of various other solids when in the state of powder. It is by virtue of the affinity between wheat flour and water, that they form a cohesive dough; and so of a thousand other bodies, the particles of which have little attraction for each other, without the medium of a liquid; but if caloric be indispensable to fluidity, it must be the ultimate and efficient cause of attraction between fluids and solids. It is the caloric of melted wax, glue, paste, gum, melasses, \&c. by which they are enabled to combine with and hold together the particles of solid bodies, for the same reason that the caloric of melted metals, rocks, \&c. enables them to combine with solids, and to hold them together. If sulphate of lime be reduced to the state of powder, its particles have scarcely any cohesion for each other; but if eonverted into mortar by the admixture of water, they cohere into a rocky cement, the firmness of which is in proportion to the force of attraction between the water and the lime. 
In fine, the more profoundly we scrutinize the operations of nature, the more evident it becomes, that all the modifications of force by which the particles of bodies are united, depend on the various degrees of their attraction for a self-repulsive æther; and that they cohere with a force proportional to their affinity for caloric. It is therefore ridiculous to maintain, that an agent which repels its own particles, cannot hold together the particles of other bodies.

\section{T'heory of Conduction and Radiation.}

The most general and well established fact connected with conduction is, that all the lightest bodies in nature are bad conductors of caloric and electricity; such as furs, eider down, silks, woollens, cottons, resins, lac, bitumins, phosphorus, dry wood, \&c. among solids; and æther, alcohol, oils, and water, among liquids; while gases are still worse conductors-whereas, the densest known bodies are good conductors, such as gold, silver, platina, mercury, copper, \&c. Next to the pure metals in conducting power, are rocks, gems, flint glass, porcelain, and the denser liquids, as solutions of the acids and alkalies. Owing to their extreme fusibility, it is difficult to determine the conducting power of potassium and sodium; but it is certain that 
they are bad conductors of caloric, and probably worse than water, in proportion to the difference between their specific gravities.

It has also been proved in the preceding chapter, that all the lightest known bodies are composed of large proportions of caloric, (which repels its own particles,) compared with the quantity of ponderable matter-that all vegetable and animal compounds are composed chiefly of oxygen, hydrogen, carbon, and nitrogen, in various ratios.

It has been further shewn, that the attraction of all bodies for caloric, increases in proportion as they are deprived of it. If then it be true, that the conducting power of bodies is only a modification of their attraction for caloric, (a proposition that cannot be doubted,) it becomes obvious that the conducting power of bodies is intimately connected with the relative proportions of æthereal and ponderable matter of which they are composed. Other things being equal, it is attracted most strongly by those bodies which contain the least of it, and repelled by those which are full of it. The atoms of gases being surrounded by extensive atmospheres of caloric, (that repels its own particles,) have very little affinity for caloric, and are therefore bad conductors. The same thing is true, though in a less degree, of all the lighter liquids and solids.

On the other hand, the atoms of the metals 
which contain less caloric around them in proportion to their size, and being closer together, attract and conduct it from one to the other, with different degrees of rapidity; modified by the arrangement of their atoms, and perhaps by other circumstances not yet fully understood. It is, doubtless, owing to the crystalline structure of ice, that it is a worse conductor of electricity than water. May it not be owing to the same cause that glass, resins, sulphur, and some other bodies, are better conductors of electricity in the liquid, than in the solid state?

That the conducting power of all bodies augments in proportion as they are deprived of caloric, may be regarded as a self-evident proposition.

The conducting power of metals is increased in proportion to their condensation by pressure, for the same reason that it is augmented by a reduction of temperature,-that is, owing to the loss of a portion of their latent caloric. Caloric has a stronger attraction for pure metals than for their oxides, chlorides, fluorides, bromides and iodides; their specific gravity, cohesion, and conducting power are also greater.*

* Lord Bacon observes, in the Second Book of the Novum Organum, that it should be inquired why metals and stones, feel colder to the living body than the fur of animals, silks, woollens, feathers, wood, \&c.; whether the latter contain more inherent heat than the former; and if so, whether it be owing to their 
The connexion of this subject with the philosophy of radiation is exceedingly important, and seems never to have been rightly understood. It was ascertained by Leslie as a very general fact, that the radiating power of bodies was inversely as their conducting power. This result was supported by a great variety of experiments performed by Dr. Wells, with a view of explaining the production of dew; and still farther confirmed by the recent researches of Melloni. It was found by Dr. Wells, that eider down, wool, cotton, grass, the leaves of trees, and all vegetable substances, parted with their caloric more rapidly by radiation, than rocks and metalsthat while dew collected in large quantities on the former, during clear nights, there was generally little or none on the latter. But no one seems to have suspected, that the radiating power of bodies was determined by their latent

oily nature, or to the air which they contain. Dr. Thomson thinks that it is owing to the air within their pores; while the great mass of writers on Chemistry and Physics, resolve the whole mystery by telling us, that they are bad conductors of caloric, which is the very thing to be explained. The hypothesis of Dr. Thomson is so far from affording a solution of the difficulty, that he does not explain why air is a bad conductor. The simple matter of fact is, that all those articles of clothing which retain the caloric of the body most effectually, contain a large amount of the igneous principle, and are therefore bad conductors. For the same reason, they are highly combustible; and, when submitted to friction, afford abundance of the electric æther-on which account, they have been called electrics. 
caloric, or that it was even modified by their attraction for it.

It was supposed by Prevost, whose opinion has been adopted by a majority of writers on Chemistry and Natural Philosophy, that the tendency of all bodies to an equilibrium of temperature, is owing to a perpetual exchange of caloric from one to the other by radiation: but it is evident from the foregoing facts, that the motions of caloric by which it passes out of one body into another, are owing to its attraction for ponderable matter, as well as to its selfrepulsive or radiating power. When a hot body is placed in vacuo, and at a distance from other bodies, it parts with caloric by radiation alone, with a rapidity proportional to temperature. When placed in atmospheric air, it loses the same quantity of caloric by radiation, while an additional portion is abstracted by the contiguous particles of air.

It is generally stated, that bodies cool about twice as fast in air as in vacuo. Count Rumford found that a thermometer cooled from $212^{\circ} \mathrm{F}$. to $32^{\circ}$, in vacuo, in ... $10 \mathrm{~m}$. $5 \mathrm{sec}$.

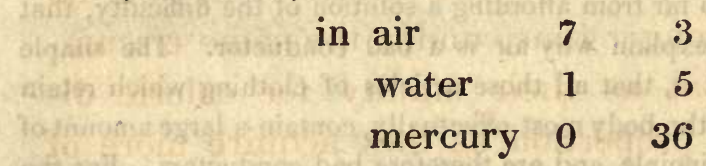

But if it be true that all bodies attract and absorb caloric, with a force and rapidity in proportion as they are deprived of it, it is obvious that in 
air, $-50^{\circ}$, the thermometer would sink much more rapidly. It is equally obvious, that when placed in water, mercury, and other dense liquids, the effect is produced wholly by their attraction for caloric, and without radiation.

It was before stated, that the metallic oxides have but little attraction for caloric, compared with the pure metals; and that their cohesion, specific gravity, and conducting power, are accordingly small. The experiments of Leslie prove that their radiating power is much greater. He found that while the radiating power of clean lead was only 19 , it rose to 45 when tarnished by oxidation; that the radiating power of plumbago was 75, and deutoxide of lead (red lead) 80 . He also discovered, that while the radiating power of gold, silver, copper, and polished tin, was only 12 , that of crown glass was 90 , sealingwax 95 , resin 96 , writing-paper 98 , and lampblack 100 .

In short, all light bodies, which are full of latent æthereal fire, and therefore bad conductors, are proportionally good radiators; while the denser metals, which contain less of it, hold on to it for a longer time, under the same circumstances. But as their affinity for caloric diminishes in proportion as they acquire more of it, they also radiate freely at very high temperatures. On the other hand, if the dense metals could be reduced $1000^{\circ}$ below zero, they would 
attract and conduct it with a force and velocity like lightning.

Whatever may be the influence of colour on the radiating power of bodies, it is trifling compared with the relative proportions of æthereal and ponderable matter of which they are composed.

It has been long known that metallic vessels, such as tea-urns, retain their temperature much longer than vessels of stone, earthenware, wood, \&c. which have less affinity for caloric than metals; and that the same metallic vessels retain their temperature longer when highly polished than when rough. The latter effect would seem to be owing to the closer proximity of the particles composing a smoother surface; for it has been found, that when wood is reduced to sawdust, it radiates more rapidly than in the solid state; that locks of wool, cotton, flos-silk, \&c. radiate better than the same materials when spun and woven, by which their fibres are brought closer together. So when the particles of a metallic surface are brought near to each other, they exert a stronger affinity for caloric than when more distant, and thus prevent it from flying off, for the same reason that the cohesion and conducting power of metals are augmented by condensation as in wire drawing. Is it not owing to the same cause, that electricity escapes more rapidly from rough surfaces which consist 
of innumerable points, than from such as are smooth and highly polished?

Connected with this subject, is another fact that has never been explained, and which may appear at variance with the above theory of radiation, until duly considered. It has been ascertained by Leslie and other experimenters, that the reflecting power of bodies is inversely as their radiating power; and that their power of absorbing caloric is proportional to their radiating power.

It was discovered by Newton, that the surfaces of glass and polished marble are covered over by an invisible and repulsive medium, which prevents their actual contact, even when pressed together with great force. It is doubtless owing to this elastic and repulsive æther, which adheres to polished metals by a still stronger attraction, that when water is poured upon them, it glides over, without wetting or touching them; and that steel needles are enabled to float on the surface of water, notwithstanding their greater specific gravity. It is this thermo-electric æther which prevents polished metals from absorbing caloric, and causes it to rebound from their surfaces by reflection; while light bodies, and metals that are rough or uneven, which contain less of the repulsive medium over their surfaces, absorb more, and reflect less caloric. 


\section{CHAPTER II.}

\section{Chemical Attraction.}

"Of the great and comprehensive laws, which rule over the widest provinces of natural phenomena, few have yet been disclosed to us."

WHEWELL.

A complete history of Chemistry would embrace an account of all the molecular transformations perpetually going on throughout nature, by which matter is maintained in a state of unceasing motion, as if pervaded by a principle of universal life. Every process of combustion, solution, fermentation, putrefaction, and recombination, are only modified exertions of chemical action, by which the face of the earth is perpetually renovated,-and without which, the great frame of nature would fall into an eternal sleep or death.

Whether in a practical or philosophical point of view, a perfect theory of chemistry would be of far higher importance than that of universal gravitation; for it would lead to a knowledge of all the properties of the elements by which we are surrounded, and of their application to the extension of human happiness. Yet there never was a period in the history of science, when 
greater uncertainty prevailed in regard to the primary cause of chemical action, than at the present time. The celebrated Erstedt regards : the science of chemistry as in the same condition now, that mechanical philosophy was in the age of Galileo, Descartes, Huygens, and Newton; and maintains that no general principle has been discovered which governs all affinities. (Sur l'Identité des Forces Chimiques et Electriques.)

Notwithstanding the recent progress of atomic chemistry, Dr. Prout observes, that this great science " is founded solely on experience, for the phenomena of which we can assign no reason." (Bridgewater Treatise, p. 29.) On the same subject, the language of Professor Whewell is still more emphatic and precise. In the concluding chapter of his Treatise on Astronomy, he states, that " no one lias pointed out any common feature between chemical affinity and the attractions of which we know the exact effects; and that we are still more profoundly ignorant of the vital principle." Alas! if this be a true representation of the actual state of human knowledge, is it not high time that men should awake from their lethargy, and observe more attentively all the circumstances connected with chemical action? It was profoundly observed by Bacon, that " in all generation and transformation of bodies, we should inquire what is added, what remains, and what is lost,-what is united, and what is sepa- 
rated,-what hinders, what commands, and what gives the motion." (Novum Organum.)

This is the true foundation of the inductive philosophy; careful observation, rigid analysis, the rejection of all hypotheses, and the undue authority of distinguished names, must ultimately lead to the discovery of all causes. It is doubtless an object of great practical importance to know the proportions in which the elements of ponderable matter unite to form water, alcohol, æther, acids, alkalies, salts, rocks, \&c.; but it is still more important to know what the agent is, by which they are brought together and maintained in a state of intimate combination.

It is already well known, that all chemical action is resolvable into attraction and repulsion, or combination and decomposition. I have also shewn, that every particle of ponderable matter is surrounded by an active, subtile and igneous fluid, which in one proportion exerts a prodigious force of attraction for them, and thus holds them together; while in larger proportions, it separates them by a counteracting and idio-repulsive force-that every change in the dimensions, powers, and aptitudes of different bodies, is attended by an addition or subtraction of this æthereal principle ; that all liquids, vapours, and gases are solutions of ponderable matter in caloric, with which they are intimately united by a mutual affinity. 
The proximate agency of caloric in chemical affinity would have been long since recognised, but for the difficulty of comprehending how a self-repulsive agent could become a cause of attraction. But it is self-evident, that if a globule of ice be composed of oxygen, hydrogen, and caloric ; and if there be an attraction between the particles of ice and caloric, they must be held together with a force equal to that attraction; and so of all other bodies. Besides, if it were demonstrated, that some other æthereal fluid, such as electricity, surrounds the particles of ice, it must have an attraction for them like caloric, or it could not become a bond of union. It therefore follows, that in either case, the effect results from one and the same fundamental law, which involves an identity, or unity of causation. In addition to what was before stated, page 186, the following facts will further illustrate the manner in which a self-repulsive fluid becomes a bond of union between the particles of ponderable matter, which have no inherent affinity for each other.

It is well known, that the particles of æther, alcohol, and many other volatile liquids, repel each other with such force, that when the pressure of the atmosphere is removed, they fly asunder, and assume the form of elastic vapours, thus presenting the character of an idio-repulsive agent. It is also known that when the particles 
of resin, charcoal, and hundreds of other bodies, are reduced to the state of an impalpable powder, like the dust of our roads after a long drought, they have little or no attraction for each other: but if they be brought into contact with the above volatile liquids, they cohere with considerable force. Why? Undoubtedly because there is a mutual attraction between the liquids and powders, which counteracts the repulsive force of the liquids, and prevents them from flying off in the form of vapour.

If the particles of dust had no cohesion for each other whatever, they would represent the condition of ultimate atoms wholly deprived of caloric, which could neither approximate nor recede from each other. At the temperature of $67^{\circ} \mathrm{F}$. water is an elastic fluid in vacuo; but if a thin film of water be placed between two plates of glass in an exhausted receiver, they cohere together, because the water is more strongly attracted by the glass, than repelled by its own particles. However imperfect such illustrations may be, they are sufficient to prove that a selfrepulsive agent may become a bond of attraction to other bodies. But the fact which must for ever set this question at rest is, that the attraction of all bodies for caloric augments, cateris paribus, in proportion as they are deprived of it, and that their cohesion augments in the same ratio.

To those philosophers who have regarded elec- 
tricity as the proximate cause of molecular attraction, it may be somewhat surprising that I have proceeded so far without an examination of the facts on which the electro-chemical theory was founded.

To this I answer, that no general law of electric action has ever yet been pointed out capable of explaining all the phenomena of molecular forces-in short, that nearly all the leading facts, connected with the theory of electricity, are involved in the utmost obscurity and uncertainty.

I have shown that caloric is a universal and independent agent, which may be everywhere recognized as a source of power and motionof contraction and expansion-of solution and recombination - that it is an essential principle of action in all the proceedings of nature.

But, in regard to electricity, we are not informed by those who assign it as the cause of chemical action, whether it be a material agent which may be added to, and subtracted from ponderable matter, or a mere effect resulting from the inherent properties of common matter. The electro-chemical theory of Sir Humphrey Davy was founded on the well known fact, that when bodies are in different states of electricity, they attract each other. Starting from this point, he assumed, first, the existence of two electric fluids, each of which has an attraction 
for the other, and repulsion of its own particles ; secondly, that all bodies which combine chemically, are in opposite states of electricity. Finding that the atoms of oxygen, chlorine, fluorine, iodine, and bromine, were attracted by the positive pole of the voltaic battery, he inferred that they were combined with negative electricity: while all those bodies that were attracted to the negative extremity of the battery, were supposed to be electro-positive; and that in consequence of the attraction existing between such bodies, they rushed into a state of chemical combination, when the two electricities assumed the form of light, or fire. (Phil. Transactions for 1806.)

It would be an irksome and endless task to detail all the objections that might be urged against this ingenious hypothesis. That it was not understood by Sir H. Davy himself, is manifest from the fact, that, in the same Lecture, he asks the question, "May not the remote cause of electrical energy be identical with chemical affinity, and an essential property of matter?" He also observes, in the Chemical Philosophy, that " electricity seems to result from the general powers and agencies of matter." How is it possible to reconcile or comprehend such vague and contradictory views?

Had not this distinguished chemist attached himself in early life to the hypothesis, that " ca- 
loric was a mere effect," instead of being an allpervading and sufficient cause of motion, his own experiments would have led him to perceive that caloric and electricity are mutually convertible into each other; for he was among the first to demonstrate that electricity is capable of producing the same effects which are usually ascribed to caloric. By means of a wire, connected with the poles of a battery, he caused water and other liquids to boil.

1. Let us examine briefly some of the consequences which flow from the hypothesis that caloric results from the combination of two electric fluids, admitting for the present, (what has never been established,) that electricity consists of two mutually attractive fluids.

The hypothesis assumes in the first place, that all the elements of ponderable matter are reducible to two classes, one of which is united with positive, and the other with negative electricity, the mutual attraction and combination of which, produce the phenomena of heat, and the chemical union of bodies. But it is selfevident, that if heat result from the union of two electric fluids, all simple bodies must be without caloric, until they unite chemically, which is contrary to matter of fact; for it has been demonstrated in the preceding part of this work, that all bodies are composed of caloric and ponderable matter-ra fact which cannot be pre- 
dicated of electricity, unless we admit, that, in its latent or combined state, it is identical with the omnipresent igneous fluid. It is impossible to imagine any thing more at variance with common sense and the universal experience of mankind, than the supposition that caloric is the offspring of electricity-or that a universal agent should be the effect of any other power which is not universal. It would be quite as rational to maintain that the ocean, from which all the waters of the earth are derived, is produced by the perpetual influx of rivers from the dry land.

2. Another objection to the electro-chemical theory arises from the fact, that bodies which are assumed to be in the same electric state, unite chemically.

For example, oxygen combines with chlorine, fluorine, iodine, and bromine, making chloric, fluoric, iodic, and bromic acids; while sulphur, phosphorus, carbon, hydrogen, and the metals, which are considered to be in an opposite state of electricity from the above elements, combine chemically with each other as well as with oxygen, chlorine, \&c. Besides, it is not true that oxygen, chlorine, iodine, and bromine, are uniformly in the same electric state; for it is very well known that when chloric acid is decomposed, its elements are conveyed to different poles of the battery - that when sulphurous and 
sulphuric acids are decomposed by the pile, sulphur goes to the negative pole; but that when sulphuretted hydrogen is decomposed, sulphur goes to the opposite pole-that when carbon, selenium, arsenic, and tellurium are united with oxygen, they are positive, but negative with hydrogen-proving that bodies are neither essentially positive nor negative, and that they vary in this respect according to circumstances-consequently, that all classifications of bodies founded on their electric polarities are fallacious.

Dr. Thomson observes, that " if chemical affinity were merely the result of different states of electricity, bodies could not remain united unless these different electrical states were permanent. But if the positive and negative electricities combine and fly off in the form of fire, there must be an end of the different electrical states which caused them to unite, and of course the union must cease, which is contrary to matter of fact. (Thomson on Heat and Electricity, p. 335.)

3. A still more fatal objection to the electrochemical theory is, that it affords no explanation whatever of cohesion or simple aggregation; whereas I have demonstrated that the particles of homogeneous bodies are held together by the same cause which maintains the chemical union of heterogeneous elements-that 
the particles of copper are held together by the same agent that causes it to combine with zinc and other metals : but who has ever maintained that the atoms of homogeneous bodies are in different states of electricity?

It is not surprising that M. Becquerel, who follows Davy and Berzelius in referring chemical attraction to electricity, should have admitted that cohesion is a stumbling block, (la pierre d'achoppement), in the way of every attempt hitherto made to connect the theory of chemistry with that of electricity. (Traité de L'ectricité et du Magnétisme, vol. iii. p. 369.)

4. Those who regard caloric and electricity as distinct agents, and the latter as the cause of chemical affinity, make caloric the cause of repulsion. Nothing could be more absurd than such partial and contradictory views of nature. Has it not been known, ever since electricity was first studied as a science, that it possesses the power of repulsion as well as caloric? I have also proved that the effects of caloric are not limited to its self-repulsive agency-that it has a universal attraction for ponderable matter, and repulsion of its own particles, by virtue of which it binds bodies together, or tears them asunder, according as it pervades them in greater or less proportions-and it will be shewn hereafter, that all the motive powers of electricity, whether of high or low tension, are 
governed by the same fundamental law; that all the most powerful displays of electric action are only modified effects of that all-pervading spirit of matter which warms in the life-giving solar beams, and preserves the universe in a state of unceasing motion.

It is because philosophers have not sufficiently examined the relations of heat and electricity, and the law by which they are connected with ponderable matter, that almost every department of Physics has become involved in profound obscurity. It is self-evident, that if electricity be a bond of union between the particles of bodies, it must have an attraction for them-a circumstance which has been overlooked by Davy, Berzelius, Ampère, and their followers. Dr. Thomson observes, that "with respect to the unknown link which unites electricity to atoms, and keeps it united with them, we are quite in the dark." (Inorganic Chemistry, yol. i. p. 40.)

Never can the science of chemistry be reduced to the simplicity of established principles, until men shall recognize the relations of caloric and electricity, and the universal law by which they are connected with ponderable matter.

When a bar of iron is charged with the electric æther, it attracts iron filings, which collect around it in large bunches, each particle clinging to the others, like bees suspended from the 
branch of a tree. But if electricity be a selfrepulsive agent, it must have a still stronger attraction for the particles of iron, or it could not become a temporary bond of union between them-and that it is the true cause of magnetic attraction in soft iron, is obvious from the fact, that when it is withdrawn the attraction is destroyed, and they fall asunder.

At the same time, it is equally evident that electricity is not the generic principle of action in nature. If so, it ought to be everywhere present under all circumstances; but so far is this from being the fact, that in its most copious and concentrated form, (that of lightning,) its manifestations are only occasional and momentary. Besides, if electricity were the primary moving power of matter, it ought to be the cause of fluidity, evaporation, gasefaction, and those expansions of the atmosphere on which all its circulations depend. It is true that when sufficiently concentrated, it produces the same phenomena which are universally ascribed to caloric - that is, it raises the temperature of bodies, converts solids into liquids, vapours, and gases,-ignites combustibles, and produces the chemical union of bodies.

If then there be any truth in the great fundamental axiom, that the same effects must be referred to the same cause, it is clear that electricity is only a modification of the omnipresent 
igneous principle. This identity is indicater by the fact, that when a current of the electric fluid is made to combine with metals, until they are melted or ignited, its properties are so far changed, that it no longer produces a shock, but in all respects exhibits the same phenomena which result from the heat of combustion. Dr. Hare attributes the explosive power of gunpowder and other fulminating mixtures to electricity; which is wholely unintelligible on the supposition that caloric and the electric fluid are distinct agents; for it is demonstrable that the expansive force of all such compounds is owing to their sudden conversion into gases, and that gases are expanded by caloric as certainly as that the elastic force of steam is due to the same power.

A thousand facts might be adduced to prove that without caloric there could be no electricity. Those light and highly combustible bodies which afford the largest amount of caloric by friction, such as furs, silks, woollens, resins, sulphur, \&c. also afford the largest proportions of electricity during the same process, and therefore have been termed electrics. Moreover, the strong acids, which give out the most heat during chemical action, afford the largest supply of electricity when acting on the metallic plates of a voltaic battery.

Again, those bodies which have the strongest 
attraction for caloric, such as metals, conduct it most freely. The same is true of electricity. Hence it is that both caloric and electricity disappear most rapidly when in the vicinity of good conductors, being attracted by them and incorporated with their substance. It is thus that flashes of lightning are absorbed by the earth and rendered latent. Or if a light feather be charged with electricity, and suspended in the still air of a room, at equal distances from sticks of resin, sulphur, glass, and metals, it will approach the latter in preference to the former, cateris paribus, with a force and rapidity that varies inversely as the squares of the distance.

If it be true that caloric and electricity be only modifications of the same agent, the electro-chemical theory becomes intelligible, and may be reconciled with the chemical agency of caloric. For example, those bodies which have the strongest tendency to unite chemically with each other, are said to be in opposite states of electricity. It is also certain, that the same bodies which contain different quantities of caloric, are most disposed to unite chemically; while those which have nearly the same relations to caloric have little attraction for each other, such as sulphur and phosphorus, potassium and sodium-the reason of which is, that a transition of caloric from one body to another is indispensable to all chemical combinations. 
Every chemist knows, that he cannot carry on his distillations, separations, and recombinations without the agency of heat. But regarding this as an incidental circumstance, he resorts to the agency of electricity for a solution of the problem, without inquiring into the source of this mysterious power, or whether it could have any existence independent of the igneous principle.

The controlling agency of caloric in the phenomena of chemistry, may be traced in all the decompositions and recombinations that are perpetually going on throughout nature. The truth of this proposition is attested by the vast amount of chemical action within the torrid zone, and within the temperate latitudes during summer; while in the regions of perpetual congelation there is no chemical transformātion. It is well known, that animal and vegetable matter may be preserved without alteration for unlimited periods of time, in conservatories of ice or snow.*

* Nothing could more clearly illustrate this fact, than the account of a huge elephant (or mammoth,) discovered in the midst of a large mass of ice on the shore of the frozen ocean, near the mouth of the river Lena in Siberia; where it must have remained for thousands of years, as it belonged to an extinct species. When first discovered, in 1799 , by a Tonguiese fisherman, the carcass was perfectly fresh and entire, parts of which were given by the neighbouring Jackouts to their dogs; while the remainder was devoured by wild beasts, after its disengagement from the ice, when its skin, bones, and teeth were removed 
It is therefore obvious, that if the earth could be wholly deprived of solar heat, all its chemical motions and changes would cease. It was admitted by Dr. Black, that "heat is indispensable to chemical action, by overcoming the cohesion of bodies, and thus enabling them to exert their attractive powers." But I have demonstrated that the agency of caloric is not confined to the mere separation of bodies; that the same agent which expands them into vapours and gases, enables them to unite chemically with each other, to form new compounds, in obedience to the same law by which liquids are enabled to dissolve and unite chemically with solids; that is, by the attraction of caloric for ponderable matter.

The most extraordinary fact connected with the history of modern science is, that while caloric is constantly employed in all the operations of chemistry, and the arts of everyday use, several distinguished modern philosophers have refused it a separate numerical station among the elements; treating it as an incidental or subordinate effect of those powers and changes of which it is the primary and efficient cause.

to Petersburgh. Its neck was covered with a long main, and the rest of its body with black hairs and a reddish fur or wool. The tusks were nine feet long, and weighed 350 pounds. For further particulars in regard to this curious discovery, see $\mathrm{Cu}$ vier's account, extracted from the Memoirs of the Petersburg Academy, and quoted by Bertrand in his Revolutions of the Globe. 
When Count Rumford and Sir H. Davy supposed that heat was motion, they mistook the effect for the cause; for $I$ have shewn that all the contractions and expansions of bodies, whether solid, liquid, or gaseous, result from their various relations to caloric. If a portion of alcohol or water be put into a Florence flask, their particles remain comparatively tranquil; but when placed over a burning lamp, a rapid intestine motion begins, and augments in proportion to the increase of temperature, until they are driven off in the form of steam. Nothing, however, could be more absurd, than to confound the motion of ebullition with its cause, which is evidently something derived from the lamp; for when the source of heat is removed, the ebullition and vaporization cease.

When Lavoisier pointed out the extensive agency of oxygen in combustion and fermentation, he overlooked the still more important fact, that the chemical power of all bodies is augmented by every addition of caloric; and when Davy observed, that combustion was the solution of bodies in oxygen gas, he overlooked the fact, that all gaseous bodies are solutions of ponderable matter in caloric, without which they could not dissolve and combine chemically with other bodies.

It was maintained by Beccher and Stahl, that all bodies contained within them an exceedingly 
subtile, elastic, and active principle, which they termed phlogiston, and which was disengaged during the process of combustion, producing the phenomena of heat and light, or fire. Many and long were the disputes of philosophers concerning the nature of phlogiston. While many maintained that it was a material substance, Lavoisier is supposed to have demonstrated that it was only an imaginary something, invented for the purpose of explaining the mystery of combustion. That Stahl regarded phlogiston as the cause of heat and inflammation, is evident from the name he gave it, which in the Greek language signifies heat or fire.

From what is reported of Dr. Black's unpublished Lectures on Respiration, it would seem that he confounded phlogiston with the carbon secreted from the lungs; for he maintained, that a portion of atmospheric air unites with phlogiston in the lungs, and that animal heat was disengaged during the process. (Leslie on Animal Heat.)

The celebrated Scheele supposed that heat was composed of phlogiston and empyreal air, (oxygen,) and that light was composed of phlogiston and heat: while Kirwin supposed that phlogiston was identical with inflammable air (hydrogen). Such were the vague and contradictory opinions of philosophers in regard to the nature of heat, light, 
and pllogiston, during a great part of the preceding century.

After the discovery of latent heat by Dr. Black, and of oxygen by Priestley, the theory of Stahl was gradually superseded by that of Lavoisier. This celebrated chemist maintained that oxygen consisted of caloric and light, united with a ponderable base, and that during every case of combustion this base combined with the burning body, by which its volume was diminished; while the caloric and light of the oxygen were given out in the form of fire.

It is scarcely necessary to add, that this theory was also found to be exceedingly defective and erroneous in nearly all its essential conditions; that atmospheric oxygen is not indispensable to the process of combustion, nor the exclusive source of caloric and light ; that all bodies contain definite quantities of caloric in a latent or combined state, and may be expanded into flame or light by a sufficient quantity of the same principle.* He was equally mistaken in supposing

* When carbon, sulphur, phosphorus, boron, and the metals are heated in vacuo, they become luminous without the agency of oxygen. Another decisive proof that oxygen is not the only source of light is, that its colour varies according to the nature of the combustible. Hydrogen affords a bluish light; potassium, and many other bodies, burn with a red light. Hence it is, that bituminous coal burns with a bluish light when only partially ignited, because the hydrogen alone is volatilized, while its carbon 


\section{LAVOISIER'S THEORY OF COMBUSTION.}

that the condensation of oxygen was always necessary to combustion.

It is doubtless true, that during the chemical union of gaseous oxygen with metals, its volume is greatly diminished, and a large amount of heat disengaged, by which the metals are expanded into the luminous state when the process is rapid. But it is equally certain, that the combustion of wood, coal, naphtha, alcohol, æther, and a thousand other bodies, is attended with expansion instead of contraction of the combining materials, as illustrated in the third chapter, when treating of explosion and deflagration. It is here worthy of special attention, that while Lavoisier pointed out the vast abundance and importance of oxygen in combustion, respiration, acidification, and fermentation, he did not explain the cause of oxidation, which is indispensable to a theory of combustion.

The most direct and compendious method of

remains fixed. Hence also it is, that around the bottom of a candle flame, where the heat is not sufficient to ignite the carbon, there is always a circle of bluish light, which proceeds from the combustion of hydrogen. When potassium is thrown upon water, it enters into a state of vivid combustion; the water is decomposed, and the metal expanded into red light. At the same time, a portion of the hydrogen thus decomposed, unites with the potassium, producing a beautiful purple and rose coloured flame; that is, the blue and red colours on combining produce a reddish purple. Query,-May not all the diversities in the colours of heterogeneous light resulting from combustion be thus accounted for in a very simple manner? 
arriving at the proximate physical cause of chemical action, would be a careful history of all the circumstances which accompany the generation and dissolution of compound bodiesthat is, to "observe what is added, what remains, and what is separated, what commands, and what gives the motion," as recommended by Bacon.

It is obviously impossible to make any important progress in the science of nature, without ascertaining the cause of motion. But I have already demonstrated that the particles of ponderable matter, per se, have no inherent powers of motion-a doctrine which was clearly admitted by Sir Isaac Newton-consequently, that all attempts to explain the phenomena of expansion and contraction by the innate forces of atoms must be given up as hypothetical and untenable.

I have also proved, that cohesion and the chemical union of atoms do not result from the external pressure of an æther, as supposed by Newton; but from the mutual attraction of æthereal and ponderable matter-that the particles of gross matter are surrounded by an active and igneous fluid, which holds them together, or repels them asunder, according as it pervades them in greater or less proportions-without which there could be no expansions and contractions of the atmosphere, therefore no winds -no evaporation and condensation, conse- 
quently, no rain, snow, hail, dew, or frost; and no lakes, rivers, and springs, therefore, no animal or vegetable growth-no earthquakes and volcanoes, therefore no mountains.

It is impossible to realize the absence of caloric, while it is perpetually emanating from the great fountain of physical existence throughout the solar system; and intimately combined with all matter, whether organic or inorganic. The greatest cold of the polar regions, or of the planetary spaces, is only a diminution of the igneous principle, which is for ever changing the forms, properties, and powers of all things.

Every change and movement of the atmosphere is immediately connected with changes of temperature, from the gentlest breeze to the most desolating tempests of lightning, thunder, and rain. In like manner, all the chemical changes that mark the course of nature, are attended with changes of temperature, from the slowest process of fermentation to the most rapid combustion-that is, all the decompositions and recombinations of matter are attended by the addition or subtraction of caloric. Without the continual agency of the solar fluid, the vital air, the ocean, and the solid ground, would become a motionless mass of inert and chaotic matter. Without the reception of caloric from the atmosphere by respiration, the wonderful mechanism of animal motion, sensation, and 
life, could not go on. Nay, more, all the phenomena of health and disease are immediately connected with temperature, from the slightest invasion of a chill, the coldness of cholera or the black death, to the most scorching fever.

Nearly all the phenomena of Chemistry may be referred to combustion and solution. Every process of fermentation, respiration, and putrefaction, are slow combustions, to which caloric is equally essential, as to every case of solution, vaporization, and gasefaction. It is well known to every practical chemist, that water is generated by combustion - that nitrogen, carbon, sulphur, phosphorus, selenium, chlorine, iodine, boron, arsenic, and some other bodies, have no affinity for oxygen at very low temperatures; but that when caloric is added in sufficient quantities, a rapid oxidation takes place, as in ordinary combustion, by which acids are generated-that when potassium, sodium, barium, lithium, calcium, magnesium, and strontium, are heated in atmospheric air, they combine rapidly with its oxygen, forming alkalies-that when aluminum, glucinum, yttrium, thorinum, and zirconium, are heated with oxygen gas, new compounds are generated, termed earthy basesand that when the other metals are exposed to a high temperature, they are converted into acids and metallic oxides.

At the temperature of $32^{\circ} \mathrm{F}$. iron has no per- 
ceptible attraction for atmospheric oxygen; hence it is that in the polar regions, and during excessive winters in the middle latitudes, metals are not corroded by oxidation, but speedily acquire a coating of rust in tropical climates.* The process of oxidation augments with every addition of caloric up to the fusing point. It is therefore preposterous to maintain, that the attraction of metals for oxygen is owing to some inherent property of their particles, or that caloric operates merely by overcoming their cohesion, and thus enabling their chemical forces to come into play. So powerful is the attraction of iron for oxygen when raised to a white heat, that it takes it from potassium, which, at ordinary temperatures, is the most oxidable of all the metals. As the attraction of potassium for oxygen is known to be augmented by every increase of temperature, there is every reason to believe that its latent caloric is the primary and efficient cause of the chemical force by which it is enabled to decompose water, and even ice-and that if its temperature could be

* If a piece of cold polished iron be inserted into fluid mercury, there is little or no attraction exerted between them; but if the iron be made red hot before immersion, it acquires a coating of mercury, which adheres firmly. Even gold, which adheres to mercury at common temperatures, attracts it still more powerfully when heated, and so of other metals. 
sufficiently reduced, its affinity for oxygen would be destroyed.

In accordance with this view of the subject, it is well known that phosphorus, sulphur, and the most combustible compounds of hydrogen and carbon have no affinity for oxygen at very reduced temperatures, but attract it rapidly when assisted by heat. It would therefore be a waste of time to multiply proofs that caloric is the cause of oxidation. There is not a substance in nature with which it may not be made to unite under the influence of heat.

Finding it impossible to overlook the agency of caloric in chemical affinities, Sir H. Davy maintained that "it gave freedom of motion to the particles of bodies, and exalted their electrical energies." (Phil. Transactions, Nov. 1806.)

It is also observed by Berzelius, that " a great number of bodies seem to possess but feeble affinities at ordinary temperatures of the atmosphere, which acquire very active powers of attraction when raised to high temperatures." (Des Proportions Chimiques, p. 57.)

This illustrious chemist might have added, that the chemical power of all bodies is exalted by every addition of caloric and diminished by its abstraction. All the destructions and regenerations of matter may be referred to, or derived from that law of caloric by which it repels 
its own particles, and is attracted by ponderable matter. By its self-repulsive property, caloric dissolves, expands, and decomposes all things: by its affinity for ponderable matter it contracts, unites, and holds together all things - thus causing the centrifugal and centripetal forces of nature. By the agency of heat, chlorine, fluorine, iodine, and bromine, are made to combine with sulphur, phosphorus, metals, \&c. by which new compounds are generated, termed chlorides, fluorides, iodides, and bromides. When carbon, sulphur, phosphorus, and other bodies are heated with metals, they are converted into carburets, sulphurets, and phosphurets. By the agency of solar heat the oxygen of the atmosphere is made to combine with the elements of dead animal and vegetable matter, which are thus constantly undergoing a. slow combustion or dissolution during summer, termed putrefaction; and by which new combinations are formed.

It has been said, that iron and other metals may be kept in a state of ignition for unlimited periods of time without any loss of their substance. Nothing could be more unfounded. The truth is, that the incandescence or luminosity of all bodies, cateris paribus, is in proportion to temperature; while they are volatilized and dissipated in the same ratio. Ignition is only a modification of combustion. When 
iron is raised to a red heat, the oxygen of the air combines with it, as in cases of ordinary combustion, by which the process is kept up; but if they are heated in vacuo, the ignition ceases when the heat is withdrawn.

It is necessary to distinguish the quantity of light produced by combustion from its intensity. When carbonate of lime and many other fixed bodies are submitted to the high temperature of an oxy-hydrogen blow-pipe, they are slowly dissipated, with the disengagement of a most dazzling and intense light, but in small quantity; whereas, if æther, alcohol, naphtha, wax, tallow, oils, resins, phosphorus, sulphur, cotton, paper, silk, and many other inflammable compounds, are submitted to one third of the above temperature, a far greater quantity of light is produced, but of much less intensity: yet we are informed by Dr. Lardner, " there is reason to believe that all bodies begin to be luminous when heated, at the same temperature." (Treatise on Heat, p. 24.) On the other hand, when charcoal is exposed to the concentrated heat of a large voltaic battery, it is expanded into light that in splendour almost rivals that of the solar beams; yet not in great quantity, as during the combustion of more volatile bodies. The concentrated heat of a forge while acting upon iron and other metals that are difficult to volatilize, creates a light so intense, that it strikes upon the eye-balls like 
finely comminuted sand. But the same degree of heat acting upon an equal weight of oil, wood, or bituminous coal, would produce one hundred times the quantity of light, though of much less intensity.

That modification of light termed phosphorescence, is generally the result of a slow combustion. Being produced at very low temperatures, it is both small in quantity, and of low intensity.

From all the preceding facts and observations it would appear,

1. That the heat of combustion results from the disengagement of that principle which holds the particles of bodies together.

2. That the attraction of ponderable matter for caloric is modified by every chemical change which it undergoes, whether of combination or decomposition, contraction or expansion. (See Chapter III.)

3. That the light of combustion, or flame, results from the ultimate division of ponderable matter by caloric, which is diffused in all directions by radiation with extreme velocity; and that without the volatilization of combustible matter, there could be no artificial light. 


\section{5}

\section{CHAPTER III.}

\section{Chemical Solution.}

“ Veniet tempus quo posteri nostri apperta nos nescisse mirenter."

Seneca.

The vast importance of chemical solution is sufficiently obvious when we reflect, that it is immediately connected with all the most important operations of nature. Could we take in at one view the whole system of nature, we should behold throughout, one vast theatre of solution and crystallization, of decomposition and recombination.

We should perceive that the atmosphere always contains an immense quantity of water diffused through it in a state of invisible transparent solution, until it meets with colder currents of air, when it is condensed and precipitated in the form of rain, snow, or hail, by the abstraction of its solvent principle; that all lakes, rivers, and springs, contain greater or less proportions of the rocks, salts, and metals that compose the crust of the earth through which they pass, in a state of chemical solution; that are carried down by running water and depo- 
sited on different parts of the great " ocean floor."

We should observe many thousand hot springs, issuing from the sides of mountains, and from the bottom of the sea, charged with enormous quantities of earthy and metallic bodies in solution; which are precipitated as they cool down, forming new strata of rocks and earthy deposits.

Could we look through the earth as through a great crystal, and behold all its molecular motions and changes, as we do the formation of a salt by the aid of an oxy-hydrogen microscope, we should be transported with admiration of a scene at once so grand, simple, and beautiful. The exquisite mechanism by which crystals are generated, is carried on by the regular arrangement of atoms in series and aggregates, the forms of which are determined by the most exact mathematical laws, by the adjustment of atoms by far too small to be discerned with the most powerful microscope. During the crystallization of a drop of muriate of ammonia, magnified three million times, and reflected on a large white ground, many thousand small crystals are seen shooting in every direction as the solution evaporates, which coalesce and form one solid crystal. Still more admirable is the process of organization by which the particles of dead matter are converted into plants and animals, endowed with irritability, sensibility, and the power of attracting nourishment for their sup- 


\section{port; while solution or fluidity is essential to every vital process.*}

* A complete history of the Mississippi river, would afford an instructive example of the power of water in slowly dissolving rocks, and transporting them to distant regions. Receiving as it does, many large tributaries, that are fed by a thousand smaller streams, which drain more than a million square miles of territory, they pass through every variety of rocky strata. Some of its largest tributaries, such as the Ohio, Missouri, Kentucky, Cumberland, and Tennessee rivers, meander through extensive regions, based on secondary limestone, which extends with occasional interruptions, from Alabama to the falls of Niagara; and varying from 500 to 2000 feet in depth. Through these immense beds of ancient limestone, they have furrowed channels from 200 to 400 feet deep. By their chemical solvent power, hundreds of subterranean caverns have been gradually formed in the long lapse of ages, with all those beautiful calcareous crystals termed stalactites, with which many of them are so gorgeously decorated. All valleys and river beds are slowly formed by the chemical and mechanical agency of running water. Many springs also contain in solution large quantities of carbonate of iron, which, as well as lime, make a cement that binds into solid masses the beds of loose sand through which they pass, forming sand stone. Were we to follow out this subject in a geological point of view, we should find that a great portion of the solid materials that have been thus removed from the numerous valleys drained by the Mississippi, have been transported to the gulf of Mexico, which it is slowly filling up; while the rest is conveyed by the gulf stream into the wide Atlantic to form new rocks, after having travelled thousands of miles in a state of invisible solution. The amount of soil, gravel, and sand, which are washed down from mountains, hills, and plains, into the valleys during floods of rain is enormous. The greater part of Louisiana, which contains about 48,000 square miles, is composed of vegetable mould, pebbles, gravel, sand, and clay, that have been conveyed by this great river into the gulf of Mexico. Immense masses of floating trees are also deposited on its banks and islands, and at its mouth, which are covered by sand and clay, where they will be gradually converted into beds of coal. Thus it is that every thing in nature is in a state of perpetual transition and revolution. 
That caloric is the universal solvent of nature is evident from the fact, that all solid bodies are convertible into liquids and gases or vapours, by a sufficiently high temperalure, and reconverted into solids by its abstraction. It is equally clear, that if caloric be the cause of all liquidity, vaporization and gasefaction, it must be the menstruum by which liquids and elastic fluids are enabled to dissolve other bodies.

The most remarkable facts connected with solution, may be reduced to the following propositions :-

1. That all fluids are chemical combinations of caloric with ponderable matter. Water is composed of oxygen, hydrogen, and caloric; sulphuric acid of oxygen, sulphur, and caloric, and so of other liquids, the elements of which are chemically combined with it in definite proportions :

2. That no solution of a solid in a fluid ever takes place, without a transition of caloric from the solvent to the solvend :

3. That the solvent power of water and other menstruums is exalted by caloric, and diminished by its abstraction :

4. That the solutions of animal, vegetable, and mineral substances in water and other fluids, are strictly chemical combinations.

It therefore follows according to the most rigid principles of logic, that if caloric be the cause of solution, it must also be the physical 
cause of chemical attraction, by which salts, rocks, and metals, are held in a state of intimate combination with fluid menstruums.

It may be objected, that caloric is not the universal solvent of nature, because lime and magnesia are more soluble in water at $60^{\circ} \mathrm{F}$. than at $212^{\circ}$. But if it be true that lime and magnesia, like all other bodies, are dissolved in unlimited proportions by hot springs, such exceptions disappear, and therefore cannot invalidate the general fact.

It is stated by Mr. Lyell, to whom the science of Geology is so largely indebted, that the warm springs which supply the baths of San Filippo, near Rome, contain in solution so large a quantity of calcareous and magnesian rocks, that they have been known to deposit in a pond, a mass thirty feet thick in twenty years.-(Principles of Geology, vol. i. p. 204.)

Mr. Lyell seems to suppose that the carbonic acid contained in hot springs, is the chief cause of their solvent power. But it is well known that sulphate of lime, and many other rocks, are dissolved by hot springs without the aid of carbonic acid. It is therefore evident, that the solubility of lime and magnesia is augmented by heat, as certainly as that the fusibility of all other rocks and metals is augmented by it. It is highly probable, that the carbonic acid found in hot springs, has been driven off from a state of combination with lime, during the process of 
solution, by the agency of intense heat. Few geologists are aware how large a proportion of the calcareous, magnesian, and silicious rocks distributed over our planet, have been deposited from hot springs. Mr. Lyell has shewn, that various parts of Italy and Sicily are covered over by strata of limestone thus formed, several hundred feet deep in many places.

It is impossible to have enlarged views of chemical science, if we confine our observations to the petty operations of an artificial laboratory. Those who do so might conclude, that silex is insoluble, or nearly so, in water. But those who look to the great laboratory of subterranean chemical action, where the heat is far more intense than man can produce, will find that silex is there dissolved as copiously as sugar in boiling water; and that it is deposited in vast quantities by hot springs, such as the geysers of Iceland, the valle das furnas of St. Michael, and innumerable others that issue from volcanic regions, forming opal, chalcedony, and various silicious gems.

The flinty deposits found in the chalk beds of Europe, have doubtless been derived from submarine hot springs. Many of the marine fossils found in the chalk, are composed of silica, a fact which cannot be otherwise accounted for.*

* It is related by Mr. Barrow, in his Visit to Iceland in 1834 , that the streams which proceed from the geysers of Iceland, deposit a white silicious rock, of a close compact texture, resemb- 
It was discovered by Gay Lussac, that the solubility of sulphate of soda in water, is augling white marble. This is an exceedingly interesting and important fact to the geologist. The author was once greatly embarrassed on finding beautiful strata of perfectly white silicious rocks, which had been obviously deposited from water, inclosed between masses of basalt, greenstone, and other volcanic rocks in the mountains of North Carolina, more than 4000 feet above the ocean level. As all the other portions of those mountains consisted of granite, gneiss, porphyry, and other igneous rocks which had been elevated by subterranean heat, the existence of the white sedimentary rocks remained a mystery, until the agency of hot springs was investigated.

The geysers rise up through volcanic rocks, in an island where the eruptions of lava are so enormous, as to fill up gorges many hundred feet deep, and two hundred feet wide. When not confined in narrow valleys, they expand into broad lakes of melted rocks that vary in thickness. Were such eruptions to cover the white silicious strata deposited by the geysers, (as they undoubtedly have done, and will do again,) they would be inclosed between igneous rocks, like the snow-white flinty strata in the mountains of North Carolina. All animal and vegetable petrifactions composed of silex, have been doubtless formed in waters holding this mineral in solution, from the most minute animalcules and delicate moss agates, to the largest fragments of silicified wood. Mr. Barrow states, that on the margins of the numerous little streams in the neighbourhood of the great Geyser, every description of wood, bones, the horns of animals, and even paper, worsted stockings, handkerchiefs, \&c. were found in a silicified state.

The steam emitted from volcanos is charged with a great variety of rocks, salts, and metals, in a state of solution, which are deposited in the crystalline form as the solutions cool down. When melted silex cools under the pressure of a mass of lava, making rock crystal, a portion of steam is sometimes inclosed within its centre, and condensed into water, where it remains for unlimited periods of time. All geodes are probably formed by the cooling down of lava, that contained steam or other gaseous fluids within their interior, that escape by percolation, if the rocks be porous, leaving their centres hollow. 
mented by every addition of temperature from $32^{\circ}$, to about $70^{\circ}$, and then diminishes up to $212^{\circ}$ F.-(Ann. de Chim. et de Phys. xi. 296.)

It is also generally known, that chloride of sodium (common salt) is not more soluble in water at $212^{\circ}$ than at $60^{\circ}$. Whatever may be the cause of such anomalies, they do not afford the slightest proof that caloric is not the solvent, for this plain reason, that when a solution of common salt is exposed to great cold, it is precipitated, and the water becomes nearly freshthat is, when the agent which held it in a state of chemical combination with the water is withdrawn, it falls down-which clearly proves that the chemical attraction of water for the salt is owing to its caloric. Hence it is, that sea water is deprived of nearly all its salt by congelation, as demonstrated experimentally by Danes Barrington,- a fact which the author has seen verified on a large scale. In the month of January, 1834, when the Bay of New York was frozen over, the ice that covered it was found to be but slightly brackish. It is therefore evident, that if the ocean could be frozen throughout, it would not be capable of holding its salt in a state of chemical combination, but that it would fall to the bottom, constituting a solid stratum, varying in thickness with the depth of the ocean. Dr. Turner states, that common salt dissolves in twice and a half its own weight of water at 
$60^{\circ}$-from which, and the preceding facts, it follows, that if the ocean were saturated with salt and afterwards frozen, it would deposit a stratum more than one-third its depth.

It is likewise obvious, that the tropical ocean must contain more salt in suspension than the Polar seas, especially during winter, and in the vicinity of icebergs, or other frozen masses.*

If it be maintained that caloric is not the solvent of sulphate of soda, lime, and magnesia, because they are more soluble in water at $60^{\circ}$ than at $212^{\circ}$, the same mode of reasoning would prove that caloric is not the solvent of sulphur, which is well known to be perfectly liquid at $230^{\circ}$ F., but becomes viscid at $300^{\circ}$, and continues so up to $400^{\circ}$. In reply to such objections, it may be stated in the first place, that no chemical union ever takes place until one at least of the combining bodies is reduced to the fluid state, and that caloric is essential to all fluidity: secondly, that the chemical force by which water is enabled to dissolve and combine with animal, vegetable, and mineral substances, is exalted by every addition of tem-

* It can hardly be denied, that sugar is chemically combined with cyder by the agency of caloric; for it is well known that during the congelation of sweet cyder, its sugar falls down, and may be found at the bottom of the vessel which contains it, in the state of a highly concentrated syrup. But if afterwards exposed to warmth, it is again taken up and recombined with its watery solvent, which thus acquires its original properties. 
perature, in a thousand cases for one exception -and I have shown that the above examples afford no real exceptions to the principle, but confirm it-that sulphate of soda and common salt are far more soluble in water at $60^{\circ}$ than at $32^{\circ}$-that lime and magnesia are perfectly soluble in hot springs, which owe their solvent power to intense subterranean heat.

Berzelius supposes that the greater solubility of lime and magnesia in cold than boiling water, is owing to a portion of carbonic acid that is almost always found combined with cold water; but which is driven off at a high temperature. Whether this be regarded as a true explanation of the fact or not, it is generally admitted by chemists, that carbonic acid augments their solubility in water. This however does not fully resolve the problem, since the solubility of sulphate of soda increases with the temperature from $32^{\circ}$ to $70^{\circ} \mathrm{F}$. and then diminishes slightly, up to $212^{\circ}$.

Dr. Arnott admits, that the solution of a solid in any gas or fluid menstruum is merely another mode of melting it by heat - that the menstruum itself is fluid only because of the heat which it contains. (Elements of Physics, vol. ii. p. 47.)

This is a true statement as far as it goes; and it is highly probable, that if this philosopher had renounced the inherent attractive properties of atoms, as Newton did on second 
thoughts, he would not have added the following sentence. "A menstruum dissolves other bodies, merely because its attraction for them brings their particles into union with the heat which already exists in it." Why then should water at $212^{\circ}$ exert a stronger attraction for salts than water at $32^{\circ}$ ? Why should hot water ascend through porous solids, and capillary tubes more rapidly than cold water? Why should boiling water dissolve 18 times more nitrate of potass than ice-cold water? and 20 times more chlorate of potass? Why should boiling water attract and dissolve, or combine chemically with the aromatic constituents of tea, coffee, and a thousand other vegetable products more rapidly than cold water, if caloric be not an attractive agent? or why are the chemical affinities of all bodies modified by every addition and subtraction of caloric, if it be not the ruling principle of action in all solutions?

That caloric is the medium by which water is enabled to combine chemically with salts, will appear from another view of the subject. For example, those salts which have the greatest affinity for caloric, have also the strongest attraction for water. The consequence of which is, that they absorb it from the atmosphere, producing what is termed their deliquescence-and when dissolved in water they absorb its caloric, by which cold is produced. 
It is likewise owing to the powerful attraction of such salts for caloric, that when dissolved in water they are so difficult to congeal-that is, they require an intense degree of cold to abstract from them that portion of caloric which maintains them in a state of chemical combination with water. When I come to treat of freezing mixtures, it will be seen that solutions of potass and chloride of lime, formed by mixing them with snow, remain liquid at 82 and $83^{\circ}$ below the freezing point of water.

The same thing is true of many other salts, though to a less extent. It is owing to the attraction of common salt for caloric, that sea water will not freeze at $32^{\circ}$, but requires a farther reduction of temperature to produce the effect, when it gives up a portion of its heat and the salt falls down. When 30 per cent. of - common salt is dissolved in water, its freezing point is reduced to $0^{\circ}$. Moreover, the cohesion of the solution is so far augmented, that its boiling point is raised to $224^{\circ} \mathrm{F}$.

In like manner, all those salts which have a strong attraction for caloric, and therefore produce cold during their solution, lower the congealing point of water, and elevate its boiling point ; such as nitrate of potass, nitrate of soda, acetate of soda, tartrate of potass, muriate of ammonia, and many others.*

- It is owing to the affinity of sulphate of soda for caloric, 
Dr. Lardner states, that the solution of a salt in water diminishes the cohesive force of the liquid, and therefore lowers its freezing point. (Treatise on Heat, p. 194.)

The fact however is just the reverse, for a saturated solution of chloride of calcium in water requires $42^{\circ}$ more caloric to overcome its cohesion than pure water-that is, it requires a temperature of $264^{\circ} \mathrm{F}$. to make it boil. In other words, the particles of water, which are held in a state of chemical union with the salt by caloric, have a stronger attraction for the particles of chloride of calcium, than for each other; therefore cannot be separated and driven off in the form of vapour without an augmentation of temperature.

From the preceding facts and observations we are brought to the general conclusion, that the deliquescence of salts, the production of cold

that when dissolved in hot water, and tightly corked up in a phial, it cools down without crystallizing, if kept perfectly still. But if shaken, a portion of the caloric which held it in a state of combination with the water is disengaged, when the phial becomes warm, and the solution crystallizes. If the cork be withdrawn, the same effect is produced, owing to the mechanical pressure of the atmosphere, which forces out of the solution a portion of its caloric. By inserting into it a piece of ice, or any salt that has an affinity for caloric, crystallization is produced for the same reason that all other fluids are congealed by the abstraction of their caloric. It has been said that a film of oil retards the crystallization, which is no doubt the fact, because a bad conductor of caloric, and therefore prevents its ready escape. 
during their solution in water, the low temperatures at which they congeal, and the high temperatures at which they boil, are all determined by their affinity for caloric, which holds them in a state of chemical combination with water.

\section{Theory of Freezing Mixtures.}

It was before stated that no solution of a solid in a liquid ever takes place without a transition of caloric from the solvent to the solvend. The truth of this proposition is strikingly illustrated by the phenomena of freezing mixtures.

When water is congealed into snow or ice, it has a stronger affinity for caloric than in the liquid state. Hence it is that when a lb. of water, at the temperature of $172^{\circ} \mathrm{F}$. is mixed with a lb. of ice or snow, the latter is dissolved, and the mixture brought to the temperature of $32^{\circ}$-proving that $140^{\circ}$ of caloric have been attracted from the water by the snow, and intimately combined with it in a latent state during the process of liquefaction.

But there are many salts which abstract caloric from snow, by which they are dissolved, or chemically combined with the snow. Such is the affinity of common salt for caloric, that when mixed with its own weight of snow, both at the temperature of $32^{\circ}$, there 
is a transition of caloric from the snow to the salt, by which they are intimately united, and the temperature of the mixture reduced $-9^{\circ}$, or $41^{\circ}$. Again, so powerful is the attraction of chloride of calcium for caloric that when 3 parts of it are pulverized and mixed with 2 of snow, both at $32^{\circ}$, the temperature and congealing point of the mixture are reduced $-50^{\circ}$ : and if 4 parts potass be mixed with 3 of snow, the temperature falls $-51^{\circ}$ or $83^{\circ}$ in all. But if 2 parts chloride of calcium and 1 of snow be reduced $-9^{\circ}$, and put into the solution of snow and salt, the temperature and freezing point of this new mixture are reduced $-74^{\circ}$.

That such salts attract caloric from snow is evident from the fact, that if the chloride of sodium and snow be cooled to $-9^{\circ}$, and then mixed together, no solution or farther reduction of temperature takes place - and that if chloride of calcium and snow be cooled from 32 to $-50^{\circ}$ before they are mixed, no chemical solution, nor change of temperature occurs, because there is no transition of caloric from one to the other.

Many other salts have the power of absorbing caloric from water, acids, and from snow, such as nitrate of potass, nitrate of soda, muriate of ammonia, muriate of zinc, sulphate of soda, \&c. If nitrate of ammonia be pulverized and mixed with its own weight of water, at $50^{\circ} \mathrm{F}$. the temperature is reduced $46^{\circ}$, that is down to $4^{\circ}$, which 
is $28^{\circ}$ below the freezing point of water-and if the same quantity of carbonate of soda be added, the temperature is reduced $-7^{\circ}$, or $39^{\circ}$ below $32^{\circ}$. If then such salts can abstract caloric from water at $4^{\circ}$, and even below zero, it follows $\dot{a}$ fortiori, that they can take it from snow at $32^{\circ}$.

Dr. Turner observes, that when salt and snow are mixed, the salt causes the snow to melt by reason of its affinity for water. But if the snow and salt be cooled down $-9^{\circ}$ there is no attraction between them, and therefore no solution nor reduction of temperature. The truth is, that all freezing mixtures are dissolved by caloric as certainly as that snow is dissolved by boiling water; for the simple and sufficient reason, that caloric is indispensable to all fluidity, without which there can be no chemical combination. "Corpora non agunt, nisi sint soluta." When snow is dissolved in the strong acids, there is a rapid transition of caloric from the acids to the snow, by which they are chemically combined, with a reduction of temperature, as in the solutions of ice or salts in water. If 8 parts of snow be dissolved in 5 of muriatic acid, there is a reduction of temperature from $32^{\circ}$ to $-27^{\circ}$ : or if 7 parts of snow be dissolved in 4 parts of diluted nitric acid, the mixture falls $-30^{\circ}$. The same effects are produced by mixing pulverized salts with the strong acids.

After having demonstrated that caloric is the 
universal solvent of nature, and that solution is strictly a chemical process, it would be needless to insist that the strong acids owe all their chemical properties to the heat which is combined with their atoms. Like all other liquids, they are solidified by the abstraction of caloric, and when frozen, their burning caustic properties are greatly impaired, together with their powers of combining with other bodies.*

It may be regarded as a fundamental axiom in science, that the laws of nature are uniform throughout her boundless dominions, and through all her diversified changes and revolutions; and that the same effects must be ascribed to the same cause.

Whatever hypothesis is opposed to this great principle, should be at once rejected as unsound:

Some modern philosophers, of high reputa-

* When this subject shall have been more fully investigated, it will be found that the melting point of tin, bismuth, and lead, when united into an alloy, is reduced for the same reason that the melting point of chloride of sodium, chloride of calcium, potass, and other salts, is lowered on mixing them with snow. This would appear from the fact, that when 217 grains of lead, 118 of tin, and 284 of bismuth, are finely powdered and mixed with 1617 grains of mercury, the temperature of the mass falls from 64 to $18^{\circ} \mathrm{F}$,-proving that there is a transition of caloric from one to the other-which is true, in fact, of all chemical changes. Besides, when 3 parts lead, 2 of tin, and 5 of bismuth are pulverized and mixed together, they melt at $197 \% \mathrm{~F}$.

R. 
tion, have taken a different view of this important subject. In his late Bridgewater Treatise, Dr. Prout observes, that "the world itself before arriving at its present condition, has not only undergone a progressive series of different states; but in these different states, different laws of nature have prevailed." (Book I. Section 4.)

It is also maintained by the Rev. Mr. Lloyd, that " the forces by which the world was brought into its present form, were originally far more energetic, before the appetences of matter for matter had been so extensively satisfied. Shall we expect (he adds, ) to find the same activity in a neutral salt, as in its separate elements before chemical combination?" (Transactions of the British Association for 1835.)

In answer to such hypotheses, it may be stated, that they are not only unsupported by the slightest evidence, but are contradicted by all analogy. The truth is, that unless the laws of nature were uniform throughout all her changes and transformations, there could be no established principles of science. Old things pass away, and all things become new, but the properties and laws of the primitive elements never change. Memphis and Thebes, Nineveh and Babylon, Balbec and Jerusalem, with their gorgeous palaces and solemn temples, have passed into other forms of existence- 
yea, the "everlasting mountains" have silently mouldered into ruins, and been transported to other regions; but nature remains for ever fresh and vigorous, as in the morning of creation.

The "sun himself may waste away, grow dim with age," and pass into other modes of existence-still, there is not the slightest evidence that the primitive constituents of matter ever change. Mr. Lyell has done a most important service to the science of geology by proving, that all the revolutions of the earth have been brought about by existing causes.

If then it be true that caloric is indispensable to the existence of gaseous oxygen, and to its combination with other bodies, as in combustion, fermentation, and putrefaction - to the generation of water, and its power of uniting with salts, it is equally essential to the generation of acids, and to their chemical combination with the alkaline, earthy, and metallic oxides, as in the formation of salts and rocks.

It is quite evident, that all solid bodies have been formed from a state of chemical solution. Volcanic rocks have been formed from a state of fusion by subterranean caloric; while sedimentary rocks have been formed from a state of solution in water; and $I$ have proved that the solvent power of water is owing wholly to caloric-that those bodies which are insoluble in 
cold or even boiling water, become so at still higher temperatures.*

It was observed by Lord Bacon, that "we should inquire how far infusions may be made, by the help of attractions." The truth is, that all infusions, like the solutions of salts in water, are obtained by the attractive power of caloric. Cold water has no attraction for tallow, butter, and other oily substances; but the cook understands practically, that when water is raised to a boiling temperature, it will extract and combine with the gelatinous and oleaginous ingredients of animal bodies, making soups and gravies - consequently, that the combining power is not in the water, but results from the agency of heat.

The chemical power of water is so far exalted by caloric, that, when raised to the temperature $400^{\circ}$, as in Papin's Digester, it dissolves nearly all animal matters, except the bony phosphate

* The familiar process of drawing teas depends simply on the attractive power of heat, to which we owe all our infusions, medicinal extracts, emulsions, \&c. The superior cleansing property of hot over cold water, is owing to its power of combining chemically with the various impurities that adhere to clothing, \&c. It is also known that metals are deprived of their drossy combinations, and thus purified by the agency of heat. Hence, among the nations of antiquity, it was regarded as the type of purity - a term derived from the Greek word $\pi v \rho$, signifying heat or fire. 
of lime, together with the oily and resinous portions of wood, which are but slightly soluble in boiling water.

Caloric enables water to combine with salts and the various ingredients of organic compounds, for the same reason that it enables wood, coal, and all other combustibles, including the metals, to attract oxygen from the atmosphere-or for the same reason that it enables melted metals to dissolve and unite with solid metals.

All solutions of salts in water, or metals in acids, are the results of an attraction between the solvent and the solvend. But if this attraction augments with every addition of caloric, it cannot be an inherent property of the menstruum.*

* Nothing could more strikingly illustrate the immense aggregate force of chemical attraction than the phenomena of solution. For example, it is well known that when sugar or salts are dissolved in water, and metals in acids, the liquids undergo very little augmentation of volume-consequently, their density must be greatly increased. But it is evident from the experiments of Perkins, that a mechanical pressure equal to 2000 atmospheres, is not capable of reducing the volume of water more than $\frac{1}{12}$ th, if so much. What then must be the force of attraction by which salts and metals are united during the process of chemical solution? By attracting from the liquids a portion of their caloric, the solids are dissolved, or chemically united, with diminution of volume, for the same reason that the bulk and elastic force of gases are lessened on combining chemically. 
It was before shewn, that when tin, lead, copper, silver, and other metals, are converted into the liquid state by heat, their power of combining with each other is greatly augmented; and that whenever a melted metal unites with a solid metal, there is a transition of caloric from the one to the other.

In like manner, when mercury, gold, silver, \&c. are converted into vapour, under plates of copper, iron, and other solid bodies, there is a transition of caloric from the former to the latter, by which the particles of metallic vapour are transported to, and intimately combined with the solids, for the same reason that melted tin unites chemically with copper and iron vessels when poured into them, as in the process of tinning; or for the same reason that aqueous vapour is attracted by cold bodies, and combined with them in the form of dew or frost; that is, by virtue of an attraction of their caloric for bodies that contain less of it.

But if the attractive power of all bodies be modified by every change in their relations to caloric, it is unphilosophical to refer the effect to electricity, unless it be a modification of caloric ;

The force of chemical attraction is equally evident from the manner in which it overcomes the cohesion of solid bodies. The attraction of nitric acid for the atoms of silver, copper, and iron, must exceed that of their cohesion; for it tears them asunder, but in an almost imperceptible manner, and atom by atom. 
and still more absurd to confound attraction with the innate properties of ponderable matter.

That the strong acids owe their activity and chemical properties to caloric, is evident from the following facts :

1. They all become solid by the abstraction of caloric, when their burning caustic properties are greatly diminished, together with their power of dissolving other solid bodies.

2. Their power of dissolving metals is greatly augmented by raising their temperature.

Concentrated sulphuric acid acts very feebly. on iron, until made boiling hot. Copper is dissolved rapidly by sulphuric acid when raised to the boiling point. Lead, which is not affected by sulphuric acid when cold, is readily dissolved by it at $212^{\circ} \mathrm{F}$. Its solution in nitric and acetic acids is also greatly augmented by raising their temperature. But it would not be philosophical to maintain that an agent which is indispensable to all fluidity, and which increases the solvent power of acids, is different from the primary and efficient cause of solution.*

3. When the earthy, alkaline, and metallic

* The first part of the process by which metals are dissolved in the strong acids, is decidedly one of combustion. For example, when nitric acid is poured upon plates of iron, copper, \&c. a portion of its oxygen unites chemically with them, by which they are converted into oxides, with disengagement of heat, (as when poured on volatile oils, and other inflammable bodies,) after which, they are dissolved like salts in water. 
oxides are dissolved in the acids, they are chemically united with them, and thus maintained in a state of transparent solution, like salts in water, in opposition to their specific gravity; and may be crystallized by evaporation or by cold.*

Could we clearly explain why sugar, gums,

* Philosophers have never yet determined fully, why innumerable bodies arrange themselves in the crystalline form, on passing from the fluid to the solid state. But it is known, that when salts, rocks, and many metals, are converted into the liquid form, whether by the direct agency of caloric alone, or by means of a chemical menstruum, their particles arrange themselves in regular series, at various angles, forming symmetrical aggregates, that cohere in definite forms as they cool down. When sulphur, iodine, camphor, benzoic acid, with many other simple and compound bodies, are converted into the gaseous state, they also crystallize in regular forms on cooling down, like solutions of salts in water, or metals in acids.

From some recent experiments performed by M. Bequerel and Mr. Cross, it has been supposed that electricity is the agent by which crystals are aggregated. But if electricity be regarded as a distinct power sui generis, and the only cause of crystallization, why does water and a thousand other liquids assume the solid and symmetrical form on merely reducing their temperatures? There can be no doubt, that when a current of voltaic electricity is directed for days, weeks, and months, upon salts and rocks, as in the experiments of Mr. Cross, it decomposes and transports their elements to the extremities of the battery, where they will assume the crystalline form : but it is equally certain, that crystallization is constantly going on in the laboratory of nature, where no electric action can be detected by the most delicate tests.

The whole of this problem is resolvable into one of still higher importance and generality; that is, whether electricity be only 
starch, gelatine, albumen, and some salts, are more soluble in water than in alcohol; why sulphur, phosphorus, resins, \&c. are more soluble in alcohol than in water; and why some bodies are soluble in oils that are insoluble in other liquids; why one acid dissolves metals which another will not; and why some metals are more

a modification of that universal principle of action, which $I$ have endeavoured to shew, is capable of producing all the contractions and expansions of matter.

As yet, philosophers are but partially acquainted with the circumstances which determine the numerous diversities in the forms of the same substance : why, for example, there should be several hundred varieties in the crystalline arrangement of carbonate of lime. But it has been ascertained by the recent researches of Mitscherlich and Haidinger, that various proportions of water unite with many substances at different temperatures, during the process of crystallization, producing a corresponding diversity of forms; that seleniate of zinc unites with three different portions of water, and assumes three different forms, according as its temperature is cold, lukewarm, or hot; and so of other solutions. They also found that moderate degrees of temperature, such as that of the solar rays, produced a decided change in the molecular arrangement of solid crystals.

Not less remarkable and unexpected was the discovery of Mitscherlich, that many bodies differing in chemical composition, assume the same crystalline forms, which are determined by the relative number and position of their atoms; in other words, that the same number of atoms, united in the same way, produce the same crystalline form; that the protoxides of iron, copper, zinc, nickel, and manganese, crystallize in the same form; which is also true of the neutral phosphate of soda, arseniate of soda, and many other compounds that vary in chemical composition. Such bodies have been therefore termed isomorphous, meaning identity of form. 
soluble in diluted than in concentrated acids; the obscurities of Chemical Science would rapidly disappear.

If, however, it be true, that caloric is the universal solvent, without which liquids could not combine chemically with solids, we must endeavour to resolve the remaining difficulties, by carefully investigating the circumstances which determine the relative attractions of caloric for different bodies, and its transition from one to another.

Between water in the state of ice, and tallow, or oils, there is no affinity whatever. But when water is raised to the boiling point, it unites readily with all oleaginous substances; and at still higher temperatures dissolves resins, and various other bodies. The solubility of sulphur and phosphorus in alcohol is also augmented by temperature.

All solutions and precipitations are owing to the transition of caloric from one body to another. What is termed elective affinity is owing to the stronger attraction of one body for caloric than another. By the solvent power of caloric in nitric acid, it is enabled to combine chemically with silver, the particles of which are diffused equally throughout the menstruum, making a transparent solution of nitrate of silver. But if a portion of mercury be poured into the solution, the silver is precipitated as the mercury dissolves. 
It therefore follows, that if the caloric of nitric acid enabled it to dissolve and combine with the silver, it must have a still stronger attraction for the particles of mercury, or it would not desert the atoms of silver for them; in short, that the silver is separated from its combination with the acid by an abstraction of caloric, for the same reason that salts dissolved in water are precipitated by a reduction of temperature.

The same principle must apply to all other elections and precipitations, modified, however, by circumstances not yet fully understood.

Lead precipitates mercury, and copper lead, which is again thrown down from a state of combination with nitric acid by iron; all of which changes are attended with transitions of caloric from the solvent to the solvend.

The art of coating metals with other metals by precipitation, is founded on the above law, such as gilding, silvering, tinning, \&c. If a plate of copper or iron be immersed in a solution of nitrate of mercury, a coating of the latter metal is precipitated on them, for the same reason that aqueous vapour is precipitated on cold bodies, and coheres to them in the form of frost or ice. If nitrate of silver be dissolved in water, and a plate of clean copper be inserted into the solution, a beautiful coating of silver is precipitated on the copper; or, if a polished iron rod be immersed in a solution of nitro-muriate 
of gold, the latter is precipitated on it in the metallic form; for the same reason- that melted tin, zinc, bismuth, silver, \&c. are attracted by solid metals, and thus chemically united with them, as in the process of plating. Hence it follows, that if caloric be indispensable to the solution of metals in acids, their precipitation must be owing to its abstraction by the solid metals.

From a general view of the preceding facts and observations, it is evident, that caloric is the cause of all oxidation; that water and the strong acids are generated by its agency, and chemically united with the earthy, alkaline, and metallic oxides, forming salts and rocks : in short, that combustion, fermentation, and solution, are modified effects of the same cause. Vinous fermentation begins at about $59^{\circ} \mathrm{F}$. and increases up to $77^{\circ}$, at which point acetous fermentation begins, and ceases at $88^{\circ}$. The difference between putrefaction and combustion is only in degree. The former requires a temperature of about $80^{\circ}$, and augments up to $135^{\circ} \mathrm{F}$.; while phosphorus enters into a slow combustion at $43^{\circ}$, and potassium at still lower temperatures. 


\section{CHAPTER IV.}

\section{Capillary Attraction.}

That very law which moulds a tear, And bids it trickle from its source, That law preserves the earth a sphere, And guides the planets in their course. ROGERS.

Considered in all its relations and bearings, capillary attraction is one of the most important processes in nature, and is immediately connected with all the changes and modifications of both living and dead matter. It is the force by which solids and liquids are drawn and held together; which causes plates of glass, wood, metal, \&c. to adhere with some force to the surface of water and other liquids, when laid flat upon them. It is by the force of capillary attraction, that the waters of the earth are conveyed through its crust in opposition to that of gravity ; for water is much lighter than the earthy and rocky strata through which it descends; and has been found at the greatest depths to which miners have penetrated, forming subterraneous streams, which greatly augment after heavy rains. During this transudation of water through 
the earth, it dissolves and combines chemically with a portion of its mineral ingredients; after which, it is forced to the surface by hydrostatic pressure, (on meeting with an obstruction to its horizontal progress,) forming innumerable springs and fountains of delicious water.

It is owing to the attraction of liquids for solids that the dust of our roads, which, when dry, has little or no cohesion, becomes so tenacious after rain; or that a rope when moistened with water, contracts with great force. The combination of tannin with leather, and colouring matter with clothing, are due to a modification of the same power that enables water to combine with salts, or to permeate porous rocks.

Several distinguished philosophers have recently conjectured, that a discovery of the cause which determines the rise of liquids through porous solids and capillary tubes, would unfold the latent principle of action in all molecular changes, whether chemical or vital. The trunks, stems, leaves, and flowers of all the trees and plants that adorn the earth, are composed throughout, of exceedingly small capillary tubes and pores that attract liquid nourishment from the earth, and convert it into their own substance, by the same power which causes the combination of other solids and liquids. And so of all animals.-Every muscle, gland, nerve, bone, and blood vessel, is composed of imperceptibly 
small capillary tubes, through which the blood is circulated by the same power which causes universal attraction.

The subject of capillary attraction has been laboriously investigated by many of the most distinguished votaries of science, for the last 150 years; but without any attempt to explain the cause of the phenomena; if we except a single suggestion of Newton, contained in his letter to Boyle, concerning the ather. He there refers capillarity to the same agent which causes menstruums to dissolve solids, - a most important hint, for which his successors have not given him any credit. It must, however, be acknowledged, that he never gave a satisfactory explanation of what causes solution. Still, his views were more just and comprehensive than those of the present day. That he also referred vital attraction to the same cause which produces ordinary capillary attraction, is evident from the following observation: "The same principle which causes a sponge to suck in water, causes the glands in animal bodies to suck in the various juices from the blood, according to their several natures and dispositions." (Opticks, page 367.)

In the time of Newton, it was ascertained experimentally by Hawkesbee,

1. That water rises to the same height in capillary glass tubes of equal diameter, whether the tubes be thin or thick. 
2. That it rises to the same height in vacuo, as in atmospheric air.

3. That the velocity and elevation to which water ascends in capillary glass tubes, cateris paribus, is inversely as their diameters.

4. That the upper surface of water, spirit of wine, and various other liquids, in capillary glass tubes, was concave; which he rightly attributed to a stronger attraction of the particles of water in immediate contact with the glass for it, than for each other.

In 1805, Dr. Young read a paper before the Royal Society on the cohesion of fluids, in which he reduced all the phenomena to the joint agency of a cohesive and repulsive force, which in fluids, he thought balanced each other. But as he does not explain what causes the particles of liquids to approach or recede from each other, his whole theory is vague, and very difficult to comprehend. .

The following passage taken from a paper on capillary attraction, by Professor Sang of Edinburgh, may be regarded as a specimen of the obscure manner in which this interesting subject has been generally treated; and of the prevalent opinion in regard to the recondite nature of the cause which determines the attraction between liquids and solids. He observes, that " the whole of the phenomena are due to a change in the corpuscular arrangement produced by the simple 
contact of heterogeneous substances, the laws and nature of which change are, and perhaps for ever, will remain unknown to us." (Edinburgh Philosophical Journal, vol. viii. 253.)

Sir H. Davy maintained, " that water is combined with rocks, earths, salts, wood, muscular fibre, \&c. by chemical attraction; but that it combines with glass, porcelain, \&c. by cohesive attraction." This is contrary to his own, and the general view of chemical attraction, which is defined as "the force that unites different elements, and as the antagonist of cohesion," which is supposed to unite homogeneous elements. But there is as much difference between water, and glass or porcelain, as between water and salts, rocks, wood, or muscular fibres.

There is no end to the ambiguities and contradictions that have resulted from regarding cohesion and capillary attraction, as referable to a different cause from what produces chemical affinity. I have already proved that the particles of water and other compound bodies, are held together by the same agent which causes the cohesion of gold, or any other homogeneous body. The same power that unites the atoms of quartz, feldspar, and mica, and holds them together in the form of granite or gneiss, maintains the cohesion of liquids. This principle has been recognized by Laplace, in a supplement to the 10th Book of the Mechanique Céleste, 
in which he treats of capillary attraction, as a modification of chemical affinity.

That this is really the case, would appear from various considerations:-

1. Capillarity is the force by which liquids and solids are made to cohere, whether homogeneous or heterogeneous.

2. Every solution of a solid in a liquid, is the result of a chemical force, by which their particles are united.

3. The force of capillary attraction, by which liquids permeate solids, is always in proportion to their chemical affinity for each other-for example, water has a strong affinity for sugar. It also rises rapidly through it by capillary attraction.

Considering the vast importance of the subject, it is really surprising how imperfect and limited the number of experiments that have been instituted for the purpose of elucidating its nature. Sir David Brewster has given the relative heights to which fifty-two different liquids rose through a capillary glass tube, the bore of which was 0,0561 of an inch-the general result of which was, that water rose to a greater height than any other liquid. The next in order were muriatic, nitric, and nitrous acids; then the volatile oils; after which were alcohol and the æthers; and lastly, sulphuric acid.* But if capillary attraction represent the force by which all liquids and solids cohere, it is obvious, that before we can

* Edinburgh Encyclopædia, Article Capillary Attraction. 
arrive at any just conclusion, the attraction of innumerable other solids for as many liquids must be ascertained.

As if to shew the futility, or uncertainty of all experiments, M. Link states, that distilled water, nitric acid, spirit of wine, sulphuric æther, sulphuric acid, and the aqueous solution of potass, (1 oz. to six of water,) all rose to the same height between glass plates. What is still more remarkable, he states that the above liquids rose to the same height between plates of copper, zinc, copper and zinc soldered together; first, with the zinc surface opposed to the copper ; next, the zinc surfaces opposed; and then the copper surfaces opposed.*

Mr. Challis observes, after recounting the above experiments, that " the heights of ascent under similar circumstances, would seem to be alike independent of the liquids and solids." But if this conclusion were well founded, water ought to rise between plates of sulphur, bees-wax, gum lac, resin, spermaceti, tallow, \&c. as freely as between plates of glass, which is not the fact. The truth is, that liquids rise most rapidly through such porous solids as are most soluble in themthat is, bodies for which they have a strong chemical affinity. Water rises freely through sugar, salts, ashes, and porous rocks, because it has a strong chemical affinity for them. For

* Transactions of the British Association, vol. iv. p. 293, Report on Capillary Attraction, by the Rev. James Challis. 
the same reason, alcohol rises through all such solids by capillary attraction, as are soluble in it; and so of the strong acids. Tallow and water have no tendency to unite chemically when cold. For the same reason, when glass plates are smeared with tallow, and brought close together, water will not rise between them, unless they be first wetted. But in this last case, the water rises, owing to its attraction for its own particles, for the same reason, that they aggregate into spherical drops.

It was observed by Sir John Herschell, that "the discovery of a new law or general fact is scarcely announced when its traces are found everywhere, by which unexpected lights are shed over parts of science that had been abandoned in despair, and given over to hopeless obscurity." (Discourse on the study of Nat. Phil. p. 131.) Nothing could more aptly illustrate this observation than the phenomena of capillary attraction, the cause of which, when once pointed out, may be traced everywhere around and within us. But such is the blinding influence of custom, that men disregard what is common and familiar, - though it be from analysing the most ordinary phenomena, that the greatest discoveries have been made, such as that of steam power, the art of printing, rail-roads, \&c.

It was said by Aristotle, that everything is best seen in its smallest proportions. Such is the admirable simplicity with which Infinite Wisdom 
directs and governs the stupendous frame of nature, that the physical cause of chemical force, and of universal attraction may be recognized in the smallest dew-drop that glitters on the grass.

It has been shewn for example, that the atoms of oxygen and hydrogen, are chemically united by the agency of caloric, making compound particles of water, which are aggregated into the spherical form by the attraction of cohesion-and that it adheres to solid bodies by capillary attraction-all of which, according to Newton and Laplace, are modified effects of the same cause that actuates the vast machinery of the universe.

When a certain proportion of caloric is combined with this little dew-drop, it assumes the solid and crystalline form-in another proportion it renders it liquid, and enables it to combine with other bodies - while an additional quantity of the same æthereal fluid which held its particles together, separates and expands them into thin air.

Again, the phenomena of a burning candle demonstrate the agency of caloric in chemical and capillary attraction, as effectually as a thousand experiments, though contrived with the greatest skill. By the application of heat to the wick, it is ignited, when it attracts oxygen rapidly from the atmosphere, causing combustion. During this process, the tallow is rendered fluid, and attracted by the burning wick, affording a 
continual supply of melted matter, which is decomposed, and expanded into flame, or dense light.*

Other things being equal, the force and rapidity with which the fluid tallow is drawn up, is in proportion to the amount of caloric given out by the wick. Thus, it would appear that the rationale of oxidation, capillary attraction, and the generation of light, are clearly exemplified by a familiar process that has been overlooked by the unreflecting million, and never fully investigated by philosophers. With a view of ascertaining the force of capillary attraction caused by the heat of a burning candle, I performed the following simple experiments :-

1. About five grains of the heaviest coal ashes were placed around the wick of an ordinary sized candle, every particle of which was drawn up in a few minutes, adhering closely to the wick.

2. I next put about the same quantity of iron filings into the bole of a large candle, all of which were soon drawn up and collected around the wick, as in the former experiment.

There can scarely be a doubt that filings of silver, lead, gold, and even platinum, would present the same results under like circumstances;

* But if light and flame be identical, and if flame be gaseous matter raised to a white heat, as maintained by Newton, Davy, and others, it follows, that the light of combustion is an expanded condition of ponderable matter by caloric. 
nor is it a whit more remarkable, than that red hot iron should attract oxygen, sulphur, mercury, and other bodies more strongly than cold iron.

In reply to the above facts, I have been told by grave and learned men, that "fluidity is indispensable to capillary attraction, and that the only agency of caloric in the process is to cause fluidity." But this does not explain why hot water rises far more rapidly through lumps of white sugar, salts, \&c. than cold water, nor why those bodies which have the strongest affinity for caloric, attract and absorb water most rapidly, such as the deliquescent salts that are employed in freezing mixtures.

If it be urged that the absorption of water by sugar and salts, is not owing to capillary attraction, but to chemical affinity, I answer, that hot water passes through numerous porous solids and capillary tubes, with a force and velocity proportionate to its temperature when there is no solution - that boiling water passes much more rapidly through a glass capillary syphon than when cold. This fact may be verified in the following simple manner. Take two bunches of spun glass about four inches long; insert the end of one into water at $50^{\circ} \mathrm{F}$. and the other at $180^{\circ}$, when the latter will be found to rise with far greater force and rapidity than the former-in the ratio of at least 3 to 1 .

The same is true of amianthus, flaxen thread, 
bunches of hair, hemp, and other textile fibres, when arranged in a similar manner. But it would be unphilosophical to maintain, that an agent which augments capillary attraction, is different from its primary and efficient cause.

It has been maintained by Laplace, that an increase of temperature diminishes the elevation of liquids in capillary glass tubes-first, by augmenting their capacity, and secondly, by lessening the density of the liquid. He further regards it as a general law, that the elevation of any liquid that completely wets the sides of a capillary tube at different temperatures, is in the direct ratio of its density. This view of the subject has been partially corroborated by the experiments of Sir David Brewster, who found that cold water rose somewhat higher in a capillary glass tube, than when hot.

Whatever may be the cause of this singular fact, (which I have also verified by repeated experiments,) it is opposed by a thousand others, which demonstrate that the force and rapidity with which liquids pervade porous solids and capillary tubes, cateris paribus, are proportional to the temperature of the liquids.

When I come to treat of the agency of caloric in the phenomena of life, it will be shewn that it is the proximate physical cause of capillary circulation throughout the animal and vegetable world, without which there could be no absorption, secretion, nutrition, and growth; that trees 
and plants are mere aggregations of capillary tubes and pores, through which many hundred million tons of sap are forced up by the power of vital attraction, under the immediate agency of solar heat, and that all the phenomena of life, (which result from an attraction between liquids and solids,) are arrested by cold. The principal difference between ordinary capillary attraction, and the capillary circulation of plants and animals, is, that the vessels or tubes of the latter are almost inconceivably small, while the force of all attraction is inversely as the distance; hence the force with which a moistened rope contracts, and raises immense weights; or the force and velocity with which blood and sap are drawn through their minute vessels.

The mutual interchange of two different liquids, separated by a membrane or other porous body, which has been referred by Dutrochet to the operation of a peculiar force, termed by him endosmose, and exosmose, according to their direction, is doubtless a modification of capillary attraction, or of the force which causes all chemical combinations.

There is another general fact which connects the theory of capillary attraction with that of heat.

Those bodies which have the least attraction for caloric, have the least power of absorbing water, such as furs, silks, woollens, cottons, resins, sulphur, phosphorus, and other non-con- 
ductors of caloric and electricity. Hence it is that when water is poured on a perfectly dry clean silk dress, it runs off, or collects in large globules, while it is rapidly absorbed by linen, which is a much better conductor of caloric. For the same reason, a lock of wool, cotton, down, or fur, will float on water a long time without becoming wet. Or if one end of a perfectly dry skein of silk be suspended in a vessel of cold water, it remains for hours without attracting the water through its fibres; whereas a skein of linen or hemp becomes very soon wetted throughout. But if the water be made hot, it rises through the silk also.

In accordance with the above facts, it has been found that mercury, and other melted metals, instead of rising through capillary glass tubes, are somewhat depressed, because they have a stronger attraction for their own particles than for those of the glass. That they have also a stronger attraction for caloric, is evident from their greater conducting power. Hence, there can be no transition of caloric from liquid metals to the glass, for the same reason that there is none from cold water to silks, resins, \&c. therefore no attraction. But if plates of gold, silver, and tin, be inserted into mercury, the latter is attracted by them, rises above its level, and is incorporated with them by virtue of the same power that causes all other attractions between 
liquids and solids. When mercury is poured on a marble or wooden table, it collects in large globules, for the same reason that water aggregates into large drops when poured upon dry silk, a duck's feathers, and other non-conducting bodies-or for the same reason that when plates of glass are smeared with tallow they do not attract water unless previously wetted.

\section{On the Connexion between Gravity and the} Molecular Forces of Nature.

IT has been said that the attraction of atoms is not like that of gravitation, inversely as the squares of the distance. This assertion is not only refuted by all analogy, but by the well established fact that the elevation and force with which liquids rise in capillary tubes, cateris paribus, is inversely as their diameters. The principal difference between the attraction of atoms and that of masses is, that the former acts at exceedingly small distances, corresponding with the minuteness of atoms; while the power of masses extends to comparatively great distances. The aggregate force of cohesion with which a mass of granite is held together, other things being equal, is proportional to the number of its ultimate particles. The force of gravity with which it presses upon the earth is in the same ratio. 
But if caloric be the physical cause of cohesion, capillary attraction, and chemical solution, as I have demonstrated; and if gravitation result from the aggregate action of atoms, as maintained by Newton, Laplace, and many other philosophers, the annual and diurnal movements of the heavenly bodies must be owing to a modified action of the same cause. $\dagger$

We are so accustomed to the great powers and movements which mark the course of nature, that we are scarcely aware of their existence until aroused by some extraordinary phenomenon. What can be more obvious and familiar than the power of heat in modifying the surface of our planet? a power absolutely incommensurable, though for the most part unobserved. Were it possible to compute the aggregate forces of capillary attraction in the circulation of the

+ According to all the best established canons of philosophizing, that is the most important principle in physics, to which the greatest number of phenomena may be traced. But if we admit that the accelerated motion of falling bodies, the aggregation of planets, with their annual and diurnal revolutions, are resolvable into the Newtonian law of gravity, it is certain that many other equally important phenomena of nature cannot be referred to the principle of gravitation, such as those of heat, light, and electricity, together with the innumerable operations of Chemistry, Geology, and Meteorology, all of which are immediately connected with, and may be traced to that law of caloric by which it produces the opposite effects of contraction and expansion, and without which, we cannot explain the most simple modifications of molecular attraction. 
blood and sap of all the animals and plants that inhabit the earth, we should be amazed at the result. Yet they are all produced by the subtile agency of caloric, a definite amount of which is indispensable to all vital action, from that of the insignificant moss or animalcule, to the most perfect developements of organized existence.

On beholding for the first time so grand a spectacle as the falls of Niagara, the mind is bewildered by an impression of irresistible power. But if we compare this thundering exhibition of might, with the vast but silent power of solar caloric in evaporation, or of subterraneous caloric in upheaving mountains, the ocean cataract dwindles into a fractional item ; for it is demonstrable, as before observed, that about 140 cubit miles of water are daily converted into steam, and carried into the atmosphere by the expansive energy of solar heat, and that all the lakes, rivers, and springs of the earth are supplied by its precipitation.

We are sometimes aroused to a perception of the wonderful powers that are in nature, by the sudden and awful coruscations of the electric fluid, when darting through the heavens like arrows of Omnipotence, rending rocks, trees, and dwellings. But few are aware that it is only a concentrated exhibition of the same agent which causes evaporation, solution, crystallization, and the growth of vegetation. 
It is generally conceded by philosophers, that all the operations of nature are referable to attraction and repulsion, which I have proved in the preceding chapters, are resolvable into the agency of caloric alone. But if the stupendous forces of chemistry, geology, and meteorology, are determined by the agency of solar radiation, why should it not be adequate to produce the annual and diurnal revolutions of planets? That rays of subtile matter, capable of producing heat and light, are continually proceeding from the centre of our system, is self-evident from experience and observation. It would, therefore, be contrary to all analogy, and the indications of common sense, to refer the planetary motions to some unknown hypothetical influence exerted through a vacuum, while there is a known cause sufficient to explain the phenomena. It is impossible to conceive how the sun could exert any agency whatever upon the earth, independent of his potent beams. Besides, what can be more simple and natural than the inference, that the same power which aggregates and holds together the particles of planets, guides their movements round the heavens?

It was laid down by Newton himself, as a fundamental axiom, that no more causes of natural things ought to be admitted, than such as are both true and sufficient to explain the phenomena.-(Principia, Book iii.) 
The safest mode of investigating the cause of planetary motion, is to follow the lights of analogy. When it is found that the quantity and force of light diminish inversely as the squares of the distance, and that the sun operates upon the planets by gravity in obedience to the same law, it is difficult to avoid the conclusion that they are connected together as cause and effect.

When commenting on the Newtonian law of gravity, by which every particle of matter in the universe is supposed to attract every other particle inversely as the squares of the distance, Mr. Whewell asks, "Why do the attractions of masses, or those of their constituent particles, follow this law of the inverse square of the distance?" (Bridgewater Treatise, Chapter X.)

This question admits of a satisfactory answer, in accordance with the hypothesis that solar light is the cause of solar attraction, though we may not fully comprehend the mode in which it operates. The truth is, that the force of all æthereal emanations is inversely as the squares of the distance, for the obvious reason that they are necessarily diffused in the same ratio. Other things being equal, the repulsive force of caloric in gases and vapours diminishes in the ratio of the distance of their particles from each other. Its heating power decreases in the same proportion, while the attractive and repulsive forces of electricity are known to follow the same law. 
That caloric is the active principle in solar light would appear from the fact, that the quantity of light produced by ordinary combustion, cateris paribus, is always in proportion to temperature; and it will be shewn hereafter, that without caloric there could be no electricity nor light.

Newton maintained that light and common matter were mutually convertible into each other; but seems not to have inquired whether solar radiation was connected with the planetary movements. So far was he from recognizing the agency of the sun's heat in maintaining the life of nature, that when speculating on the use of comets, he hints that they may be wandering magazines of vitality, which they distribute to the planets, thus supplying its consumption by vegetable and animal growth.

Such is the love of mankind for the marvellous, that the most obvious causes of natural phenomena are disregarded, and their explanation sought after by resorting to such as are hypothetical and remote, or obscure. Hence it is, that our books on Natural Philosophy are filled with speculations about the vacuum of space, while visible and palpable floods of luminous ather are continually pouring upon the earth from the great fountain of physical motion and life. When Sir H. Davy observed, that it "was absolutely necessary for the explanation 
of the planetary motions, to suppose space in the universe void of all matter," he overlooked the existence of solar light, and even of that subtile medium, the vibrations of which are supposed by some to constitute light. That he did so from authority, and without reflection, would appear from what he says in another part of the same work. "It cannot be doubted that there is matter in motion through space between the sun, and stars, and our globe."-(Chem. Phil. p. 67.)

There is no decisive evidence that any of the ancient philosophers adopted the theory of a perfect vacuum in nature. It was the opinion of Bacon, that the ancient Pan, which all the learned have regarded as an allegorical personation of the universe, "was represented as hairy to denote the rays of things, because every thing which acts at a distance may be said to emit rays." - (Wisdom of the Ancients.)

It was also maintained by Lucretius, who is regarded as the advocate of a vacuum, that subtile streams are perpetually flowing from every thing, without which bodies could not be discovered at a distance.* (De Natura Rerum, Book vi.)

* That the regions of space are filled with subtile matter can no longer admit of doubt or controversy. By a train of analogical reasoning, Pouillet has arrived at the conclusion, that the quantity of heat annually received by the earth from the sun's rays, is sufficient to melt a stratum of ice about forty-six feet in depth over all its surface.-(Elémens de Physique, Tom. ii. p. 204.) It therefore follows, that as the mean temperature of the 


\section{IMPERFEC' STATE OF PHYSICAL SCIENCE.}

It has been repeated a thousand times, that by reducing the phenomena of gravitation to a general law, Sir I. Newton had revealed the whole mechanism of the universe. But he entertained a far more accurate estimate of what he had done, when he compared himself to "a little boy collecting a few choice pebbles and shells on the sea shore; while the great ocean of truth lay all undiscovered before him."

-When he resolved the aggregation of planets into the action of their minutest particles, he left his followers in doubt whether gravitation was a primary agent, or only an expression of the mode in which some universal cause is observed to operate inversely as the squares of the distance; and whether it resulted from the pressure of an all pervading æther, or from the inherent properties of elementary atoms.-(See Opticks, p. 351.)

globe is constant, an equal amount of caloric must be annually radiated into the planetary spaces. Nay, it is highly probable, that if the temperature of space could be reduced $1000^{\circ} \mathrm{F}$. below the minimum of the earth's surface, it would still be an exhaustless ocean of æthereal matter; for it is impossible to conceive the total absence of heat. Under all circumstances, it is perpetually radiated from the sun and fixed stars throughout the boundless regions of space.

In a more advanced condition of human knowledge, it will become an object of inquiry, in what way the movements of the heavenly bodies are connected with this omnipresent æther, which is radiated from the sun to the planets, and reflected from planets to their satellites, and actuates every atom of which they are composed. 
The power of generalization by which he traced remote analogies, and reduced a vast multitude of apparently opposite phenomena to the dominion of one law, displayed an admirable faith in the uniformity of nature. Yet the projectile force, the vacuum of space, and the vis insita which he represents as the cause of attraction and repulsion, were mere hypotheses, wholly unsupported by evidence. And that the illustrious author himself was fully convinced of this during the latter period of his life, is manifest from the whole tenor of his speculations concerning the æther, which, as I have already shewn, he finally regarded as the primary physical cause of cohesion, capillary attraction, and of gravitation; but without explaining how it produces the repulsion of atoms, and the centrifugal force of the heavenly bodies; or in what way the phenomena of chemistry, geology, meteorology, and planetary motion, are connected with the influence of the imponderables, and the relations of the latter to each other.

But in the total absence of caloric, if such a thing were possible, the whole material universe would disappear no less completely than if annihilated: for it is obvious that in their separate state, the chemical atoms of ponderable matter could not be recognized by the senses. And I have proved that caloric is the organizing principle by which they are aggregated into visible 
and tangible forms; consequently, that it is the self-active and universal essence on which all the manifestations of being or existence depend.*

Yet we are told that caloric is not a material substance, because it is imponderable. It is evident, however, that whatever the cause of gravity may be, it must be imponderable without gravity; otherwise we must explain gravity by itself, which would be absurd. The truth is, that when reduced to a state of ultimate diffusion, all matter is imponderable, as in the form of the electric spark, flame, \&c. And if caloric were "motion and nothing else," as maintained by Bacon and other philosophers, it would follow that the prime mover in a steam engine, and throughout all nature, is motion,-a proposition which involves the glaring absurdity of explaining motion by itself.

But without plunging further into the profound abyss of chaos, or practical non-existence that would follow the entire extinction of the organizing principle, it is the legitimate province of science to ascertain how it produces all the phenomena of nature in accordance with the invariable laws of supreme intelligence. Nor is it possible to predict the results which would flow from a searching method of analyzing facts. We often mistake our own inattention

* And if the particles of all bodies be surrounded by a self-active principle, there can be no such thing as absolute inertia in nature. 
and indolence, or the mystical inventions of fanciful theorists for impenetrable obscurities, that would vanish before a bold and determined spirit of inquiry. Could the veil be drawn aside which conceals from our inspection the whole mechanism of the universe, nothing, perhaps, would so much excite our astonishment as its simplicity.

From a careful review of the foregoing Chapters, the following conclusions may be deduced :

1. That cohesion, chemical affinity, and capillary attraction, are modifications of that uni-

In opposition to this view of the subject, we are informed by Dr. Arnott, that " the greater part of the phenomena of nature may be referred to four elementary truths, viz. atom, attraction, repulsion, and inertia." He observes, that "inertia expresses the fact, that atoms, as regards motion, have a stubbornness about them, which tends always to keep them in their existing state, whatever it may be." (Elements of Physics, Vol. I. page $l$ and 2.) In what way atoms have been endowed with this imaginary property has not been explained; nor does Dr. Arnott assign the cause of attraction. Until this is done, let no man flatter the world, that even the foundation of physical science has been established on the solid rock of fixed principles.

If it be true that caloric is the physical cause of attraction as well as repulsion, and that cohesion and gravity are modifications of the same power, it nust be a primum mobile: it therefore becomes the business of philosophy to investigate the mode of its operation in maintaining all the molecular and aggregate movements of nature.

The connexion of caloric with the phenomena of motion has been virtually recognized by all those philosophers who have regarded heat and motion as identical. But it is obvious that there can be no motion without an agent; consequently, that they have confounded the effect with its cause. 
versal force by which planets and all other bodies are held together :

2. That the particles of all bodies are surrounded by, and intimately combined with an exceedingly subtile, active, and mobile principle, which in certain proportions holds them together, but in larger proportions separates or decomposes them:

3. That the prevalent theory of physics which ascribes the phenomena of attraction to the inherent, or immaterial properties of ponderable matter, is fallacious, and wholly unsupported by evidence :

4. That there is no such thing as a perfect vacuum in nature; neither in the pores of bodies, nor in those widely extended pores of the universe, termed the planetary spaces:

5. That the inertia of matter is a philosophical fiction, because there is nothing quiescent in nature, or which possesses the power of not acting-neither in the starry heavens, nor in the frame of the earth. The sun revolves on his axis, and planets around the sun. The air, the ocean, and the solid ground are for ever in motion. The molecules of plants and animals are in a state of rapid circulation and change. Yea, the invisible atoms of inorganic matter are in a state of perpetual oscillation and transformation:

6. That the "unknown hypothetical æther" of Sir I. Newton is identical with a true phy- 
sical agent, the properties of which may be ascertained by the various mechanical, chemical, and physiological effects it produces-that it causes the aggregation and chemical union of bodies, whether simple or compound, by virtue of its attraction for ponderable matter, and not by pressure, as supposed by Newton; while it causes evaporation, gasefaction, explosion, with all the separations and expansions of matter by virtue of its idio-repulsive power :

7. That if the earth were wholly deprived of caloric, it would become a stupid mass of inert and chaotic matter, without form, and void of all power of attraction and repulsion, of solidity, fluidity, \&c.

8. That the total extinction of the solar fluid, (if such a thing were possible,) would mark the reign of everlasting stillness and death-that the same æthereal principle which lights up the universe with radiant glory, directs the planets through their orbits, and preserves them in a state of perpetual motion, circulation, and renovation : finally, that caloric is the first of second causes. 


\section{BOOK III.}

\section{CHAPTER I.}

\section{Electricity.}

" Nature will not deliver her oracles to the crowd, nor by sound of trumpet. We must open our minds to her in solitude, with the simplicity of children, and look earnestly in her face for a reply."

WALTER SAVAGE LANDOR.

THE grand requisite to a right understanding of nature, is to watch attentively all the changes that mark her progress, and the various circumstances by which they are attended. Perhaps there is not a more striking characteristic of the present age, than the vast amount of industry and talent that are devoted to the cultivation of separate branches of science, which cannot be understood but as connected parts of one harmonious system. The leading object of all science is to reduce a multitude of phenomena to some universal principle, or general law, which pervades the entire constitution of matter. But how is it possible to arrive at universal facts or fundamental laws, without regarding nature as a whole? 
The more profoundly we scrutinize her operations, the more we discover of simplicity and unity of power amidst all her diversified movements and transformations. Who could have suspected without a general survey of the widely extended provinces of nature, that the aggregation of liquids into spherical drops, and their adhesion to solids, are resolvable into the same power that determines the solidity and rotundity of the earth ?- which causes rain to descend from on high, rivers to flow towards the sea, and planets to revolve around the sun?-yet these various movements were traced by Newton to one and the same law.

What can be more unlike to the mass of mankind, than the opposite forces of attraction and repulsion, contraction and expansion? Yet I have proved that they are both produced by one and the same agent; which in certain proportions binds the atoms of ponderable matter together, as in cohesion and chemical union; while in other proportions it diminishes or destroys their cohesion, as in liquefaction, vaporization, combustion, \&c., by which the forms, properties, and powers of all bodies are perpetually changed. I have shewn that combustion is the disengagement of that principle by which the earth is maintained in its present form; that it is for ever flowing from the sun throughout the solar system; and that as it is the spring of 
all motion and power throughout the earth, it must also be the cause of the annual and diurnal motions of planets.

If, then, caloric be a universal principle of action in nature, and immediately connected with all the phenomena of motion, what is electricity? Is it a distinct fluid, sui generis? or is it a modification of the igneous principle? These questions, so intimately connected with the whole theory of Physics, have never yet been satisfactorily answered. If electricity were the generic moving power of nature, it ought to be every where present. But so far is this from being the fact, that it is only under peculiar circumstances that it is developed so as to be appreciable by the senses ; whereas, it is impossible to realize the absence of heat, which is indispensable to all the phenomena of climate, season, the growth of vegetation, and the life of nature. (See page 208.)

As the subject is acknowledged by all philosophers of the present day to be involved in the utmost obscurity, I shall offer no apology for endeavouring to place it in a new light. While many regard electricity as the cause of all molecular attractions, and others as the vital principle, almost everything connected with its origin and laws, is either debatable or unintelligible; some maintaining with Franklin, that it is a subtile and inconceivably refined species of mat- 
ter, diffused throughout nature; others, that it is a compound of two fluids, each of which repels its own particles, and is attracted by the other; while a third party maintains that it is neither, but a mere effect or property of ponderable matter.

Such differences of opinion are alone sufficient to show how vaguely and imperfectly it is understood. Since the time of Franklin, many thousand experiments have been repeated, without affording any precise or satisfactory information in regard to its origin, or the mode of its operation in the work of the universe. The discoveries of Galvani, Volta, Davy, Oerstedt, and Faraday, have opened to us an immense store of new facts; but where is the general principle which connects them with the theory of cohesion, capillary attraction, chemical solution, vaporization, and the elastic force of gases? What the present state of the science requires, is not the repetition of experiments that have been performed a thousand times, but a more comprehensive and profound investigation of those properties which connect electricity with the laws of heat and light, and with the general phenomena of nature.

If ever we shall be enabled to lift the veil which nature has spread over the first principles of things, and behold the secret spring of her simple and sublime mechanism, we must first 
learn the relations of caloric and electricity. If it can be shewn, that under all circumstances they are modified effects of one and the same agent, the science of nature will be at once divested of that complexity which has hitherto baffled every attempt to reduce the phenomena of nature to fixed principles.

It is not my object to enter into a detailed examination of the various conflicting hypotheses which have been invented to explain the phenomena of electricity; and which, for the most part, have been founded on the partial, and often ill conceived experiments of a little laboratory. The truth is, that all our experiments are but feeble and imperfect imitations of what is perpetually going on in the laboratory of nature. But who has ever studied the natural history of lightning, by tracing its genealogy or nascent production, as connected with evaporation, and all the phenomena of precipitation? Who has carefully observed the connexion between flashes of lightning, and torrents of rain, hail, tornados, hurricanes, \&c.? The fundamental laws of electricity which connect it with caloric, light, magnetism, or the sublime movements of geology and meteorology, will never be deduced with unerring fidelity from mere artificial experiments. The greater part of those on electricity, are calculated rather to amuse and astonish children, than to edify those who are in quest of useful knowledge. 
It may be proper to observe, before I proceed further, that some of the most enlightened men of the last century, supposed that the pllogiston of Stahl, (which was the undiscovered latent heat of Dr. Black,) was the basis of heat, light, and electricity. Dr. Kirwin, who strangely confounded hydrogen wlth the phlogiston of Stahl, supposed that electricity might be composed of this substance greatly rarefied, in a state of combination with elementary fire; while M. Benedict De Saussure regarded it as a fluid composed of heat and some other unknown principle. (Voyages dans les Alpes, tom. ii. p. 243.) The Abbe Nollet, Dr. Hill, the Rev. W. Jones, and some others, have maintained that heat and electricity were modifications of the same power; but as their opinions were not supported by an extended examination of their recondite analogies, or fundamental laws, philosophers have continued to regard them as distinct imponderables.

\section{Atmospheric Electricity.}

The most direct and compendious method of ascertaining the relations of caloric and electricity, would be a careful history of all the phenomena connected with the origin of lightning. If it can be shewn, that the caloric of aqueous 
vapour is the basis of lightning, their radical identity must follow as a necessary consequence, notwithstanding the widely different properties which they exhibit. The truth is, that diversity of form and external appearance, is no evidence of a difference in the nature and fundamental constitution of things; for it has been demonstrated experimentally by numerous philosophers, that all the varieties of electricity are essentially the same. What can be more different than ice, water, and steam ? Yet they are composed of the same elements, combined with different proportions of caloric. What more opposite in all their properties than nitric acid and the gases of which it is formed? and so of a thousand other bodies.

It was long imagined, that when Franklin verified the identity of lightning and common electricity, he had laid the foundation of its true theory. But it is now evident that many of his opinions in regard to its origin and nature, were partial and erroneous. At one time he supposed that it was generated in the ocean by the friction of salt and water - that oceanic vapour was held in a state of expansion by electricity and heat united, while evaporation from the land was caused by heat alone. He also maintained that the fusion of metals by the electric fluid was a cold fusion; whereas it is now well known that lightning heats, melts, ignites, and volatilizes all 
bodies. And here it may be mentioned, that after the electric fluid combines with metals and other bodies, producing their liquidity and vaporization, it communicates no shock, and loses the power of darting through conductors with instantaneous velocity - that is, its peculiar properties are changed, and merged into those of ordinary caloric.

That the general reader may have a distinct idea of the existing state of knowledge in regard to the origin of lightning, it may not be amiss to present the statements of some of the most distinguished recent writers on the subject.

It is observed by Mr. Daniell, that " since the time of Franklin, atmospheric electricity has been almost entirely neglected;" and that on this most important branch of physical science, he had " nothing decisive to offer." (Meteorological Essays, p. 135 and 374.) The consequence of which is, that he has left unexplained many of the most striking and important phenomena of meteorology, such as hurricanes, tornados, and hail storms, with all those violent movements of the atmosphere which accompany rapid discharges of lightning. Dr. Arnott also states, that tornados, whirlwinds, \&c. are owing to some chemical changes in the atmosphere not fully understood. (Elements of Physics, Vol. I. p. 397.)

Dr. Thomson observes, in his late work on 
Heat and Electricity, that "the formation of vapour seems to be connected with electricity, though in what way we have no conception, and that the change of vapour into clouds is probably connected with electrical phenomena not understood." (Page 275, and elsewhere.) He adds, that "the formation of rain is still involved in impenetrable obscurity."

It is also observed by Professor Forbes, that on the noble science of atmospheric electricity, almost every thing has yet to be done. (Transactions of the British Association, Vol. I.p. 252.)

As the phenomena of lightning have been universally known to be immediately implicated with the production of rain, it becomes necessary to present an outline of the leading facts connected with evaporation, previous to entering upon the history of atmospheric electricity.

That caloric is the true and only cause of evaporation, or the formation of steam, is one of those self-evident propositions which would seem to require no proof. But to remove all doubts upon the subject, the fact has been experimentally demonstrated by Dr. Dalton, to whom the science of chemistry and meteorology is so largely indebted.

He put a little water in a dry glass flask, with a thermometer in it, when he found that a small quantity of vapour was formed at $32^{\circ} \mathrm{F}$. At $40^{\circ}$ the amount was increased: at $50^{\circ}$ it con- 
tained still more vapour; while at $60^{\circ}$ the quantity was yet farther augmented. He also found that when the temperature of the flask was suddenly reduced from $60^{\circ}$ to $40^{\circ}$, a portion of vapour was converted into water, and that the quantity retaining the elastic form was precisely the same as when the temperature nally at $40^{\circ}$.

The above is a simple and befuifuI repre SIT I sentation of what is perpetually going on through out the atmosphere, and in the steam engine

By another series of admirable experiments, he ascertained that the quantity and elastic force of vapour, whether formed in vacuo, or under the pressure of the atmosphere, are the same, and determined by temperature alone-the difference being this, that in the latter case the process goes on much more slowly, because the atmosphere presents a mechanical impediment to its diffusion somewhat analogous to the obstruction of water by porous sand. From which he inferred that vapour is not chemically united with the air, as had been formerly supposed, but mechanically diffused through it, forming a distinct atmosphere of its own, the elastic force of which is always in proportion to temperature.

At $0^{\circ}$ he found the quantity and elastic force of vapour equal to the pressure 064 inch of mercury - that is, about $\frac{1}{15}$ of an inch. At $32^{\circ}$ 
they amounted to $\frac{1}{5}$ of an inch-at $47^{\circ}$, about $\frac{1}{3}$ of an inch, or $\cdot 339$-at $59^{\circ}, \cdot 507$, or $\frac{1}{2}$ an inchat $80^{\circ}, 1$ inch-and at $90^{\circ}, 1 \cdot 360$. $\mathrm{He}$ also ascertained, that the elastic force of vapour at $212^{\circ}$ is equal to the pressure of the whole atmosphere, or 30 inches of mercury.*

From the above experiments it follows, that if the temperature of the earth were $80^{\circ}$, from the equator to the poles, the quantity of vapour would be everywhere the same, and equal to about $\frac{1}{30}$ of the average weight of the whole atmosphere: but that if its temperature were reduced from 80 to $59^{\circ}$, one-half of the vapour would be precipitated in the form of rain-if to $32^{\circ}, \frac{4}{3}$ of it would be converted into snow-and if reduced to $0^{\circ}, 14$ out of 15 parts of the whole would descend to the earth in the form of ice, in obedience to that universal law of attraction by which bodies cohere, and tend towards a common centre.

But as the temperature of the earth dimi-

* Dr. Prout observes, that " atmospheric air, under ordinary circumstances, exerts an elastic force equal to the weight of a column of mercury 30 inches high; and that at $212^{\circ}$ aqueous vapour obeys precisely the same laws, and exerts the same elastic force as atmospheric air under similar circumstances." (Bridgewater Treatise, Chap. V. Section 2.) But it has been shown that the elastic force of atmospheric air is equal to the pressure of more than 1200 atmospheres, (3000 feet of mercury.) It is therefore obvious that Dr. Prout has mistaken the weight of the atmosphere for its elastic force. 
nishes from the equator to the poles, it is obvious that the amount of water which is capable of existing in the atmosphere in the state of transparent elastic vapour, must vary proportionally in different latitudes. There is also more vapour in the atmosphere of the ocean, other things being equal, than over extensive bodies of dry land.

According to the observations of Captain Sabine and Mr. Caldcleugh, as detailed by Professor Daniell, it would appear, that within the tropical ocean, between the western coast of Africa and the eastern coast of South America, the point of deposition, or dew point, is generally about 4 or $5^{\circ}$ below the existing temperature; sometimes only $2^{\circ}$-and rarely more than $8^{\circ}$; while in the interior of large continents it is often 20 or $30^{\circ}$ below the prevalent temperature. As the atmosphere is in a state of nearly constant circulation, it is removed from one place to another before arriving at the point of saturation, and therefore contains less vapour than it is capable of sustaining at the existing temperature. Within the torrid zone, it is perpetually expanded by solar heat, where it rises into the upper regions, whence it flows to higher latitudes; while it is removed by horizontal currents termed sea breezes, from the ocean to the heated land.

If at the temperature of $80^{\circ}$, the atmosphere 
contain an amount of vapour equal to the pressure of only half an inch of mercury, while it is capable of sustaining twice that quantity, it will require a reduction of temperature below $59^{\circ}$ to cause precipitation. Hence it is that the atmosphere often undergoes great reductions of temperature without producing rain. But when the air is full of vapour the process of evaporation is arrested; which explains why a cold dry air is more favourable to evaporation than warm air that is already saturated, especially if the former be in a state of rapid motion.

Dr. Dalton found that when boiling water was exposed to a current of air that carried off its vapour as fast as formed, vaporization went on a third faster than in a room where the air was still. Hence it is, that north-east and east winds, which, in the west of Europe are generally dry, and far below the point of saturation, seldom condense the vapour of France and England; but, on the contrary, often redissolve the clouds already formed, producing clear weather. During summer, when the atmosphere has been for some time comparatively still, it is soon saturated with vapour, which is indicated by heavy dews, and the formation of clouds termed cumuli, when the weather becomes hot and sultry; because the caloric which is usually carried off by evaporation and winds, accumulates on the surface of the earth and heats the superin- 
cumbent air. Such a state of things generally forebodes an approaching thunder storm.

That the condensation of atmospheric vapour is owing to the abstraction of its caloric by colder currents of air, is evident from the fact, that in the tropical ocean far from land, where the trade wind blows steadily in one direction, and where the temperature seldom varies more than 2 or 3 degrees, there is less rain than in the vicinity of continents and large islands, where currents of air of different temperatures frequently meet.

In the great desert of Sahara, there is scarcely any rain, because the wind blowing over it is generally in the same direction; while the vapour transported by it from the ocean is still farther rarefied by the intense heat reflected from the scorching sands, where there are no mountains to condense it. There are also long droughts in Egypt, Palestine, New Holland, and many other parts of the world where the winds blow long in one direction, without encountering colder currents. During summer, in the United States, the atmosphere is often so much heated, that the vapour brought from the ocean by southern winds is not condensed for many weeks, and sometimes two months, but is farther expanded, until it becomes saturated, and meets with a current from the northern 
points of the compass, or with mountains and high lands, when thunder gusts follow.

When I come to treat of winds it will be shown, that the most extensive falls of rain in the middle latitudes are produced by the meeting of immense masses of air from opposite quarters of different temperatures, as during the equinoctial floods and storms. When both contain as much vapour as they can support at their respective temperatures, the amount of precipitation is of course the greatest.

Corresponding with the experiments of Dalton, is the well established fact, that the greatest quantity of rain falls within the tropics, where the average temperature is from 80 to $83^{\circ} \mathrm{F}$, and diminishes on to the regions of lowest mean temperature, where it is about $0^{\circ}$. Hence it is that the largest rivers in the world are found in the tropical regions, as the Amazon, La Plata, and Orinoko of S. America; and the Indus, the Ganges, the Nile, the Tigris, \&c. of the eastern continent. The summer temperature of the Mississippi Valley is also tropical, and it is well known that much more rain falls during summer than winter in the middle latitudes.

The following table exhibits a general view of the relative depths of rain in different latitudes:- 
Lat. N.

Granada......... 12 $12^{\circ} \ldots \ldots \ldots 126$ inches.

Cape François ........ 19.46, .... 120

Calcutta.......... $22 \ldots \ldots \ldots .81$

N. Orleans $\ldots \ldots \ldots \ldots 30 \ldots \ldots \ldots 63$

Philadelphia ........ 39.57'..... 42

Rome............ 41 ....... 39

England (Dalton's mean) $50 \ldots \ldots \ldots 31$

Petersburg........ $59 \ldots \ldots \ldots 13 \frac{1}{2}$

The above results are greatly modified by a variety of circumstances, such as prevalent winds, the relative positions of land and sea, mountain ranges, \&c. For example, the trade wind which blows constantly from east to west over the atlantic ocean within the tropics, deposits a far greater amount of rain on the eastern slope of South America, than on its western coast. But in the middle latitudes of the northern hemisphere, where the prevalent wind is from the opposite direction, the case is reversed. Hence the greater amount of rain which falls on the western coasts of Europe and N. America, than in the interior of those continents, being wafted from the Atlantic and Pacific oceans. There is also more rain in mountainous regions than on extensive plains. It has been ascertained, that about double the quantity of rain falls on Mount St. Bernard, that falls at Geneva; and that the mean annual amount of twenty places in the lower valleys at the base of the Alps, is 58.5 inches, according to M. Schow. 
There is nothing more admirable in the great drama of Nature than the process of evaporation and condensation, by which all the lakes, rivers, and fountains of the earth are elevated from the ocean; transported over continents and islands; attracted by mountains; precipitated by polar currents; and distributed in fertilizing showers to cheer the thirsty lands. Vapour is condensed by cold and lofty mountains, for the same reason that it collects in drops on the sides of bottles filled with cold water on a summer's day.

Notwithstanding the greater amount of evaporation and rain in the tropical than higher latitudes, the atmosphere is more transparent, and there are more clear days in the equatorial regions; and more during summer than winter in temperate climates.

According to the estimate of La Cotte, which may be regarded as an approximation to the truth, the average number of rainy days between Lat. 12 and $60^{\circ} \mathrm{N}$. are in the following ratios:

N.

From Lat. $12^{\circ}$ to $43^{\circ} \ldots \ldots \ldots 78$ days

43 to $46 \ldots \ldots 103$

46 to $50 \ldots \ldots \ldots 134$

50 to $60 \ldots \ldots 160$

It is therefore evident that the transparency of the atmosphere, other things being equal, is in proportion to temperature, which diminishes from the equator to the poles. It is also known 
to decrease from below upwards.* Hence it is, that the lower atmosphere is transparent, even when the sky is overcast with clouds, $†$ the elevation of which is in proportion to temperature - that is, the plains of condensation are higher within the tropical than middle latitudes; while in the latter their elevations vary with the season. From the observations of Mr. Crosthwaite it

* It was supposed by Leslie and Dalton, that the diminution of temperature in the atmosphere, on ascending above the earth's surface, was owing to its increased capacity for heat, caused by augmented rarefaction from diminished pressure. But this is not the only cause; for it is well known, that large portions of Asia, Africa, and South America, are from eight to ten thousand feet above the level of the ocean; whereas their average temperature is much higher than that of isolated mountains of equal elevation in the same latitudes. Mount Lebanon is not much higher than the Plateau of Mexico; yet the former is covered with snow nine months in the year, while there is perpetual spring on the Table lands of Mexico, about the same latitude and elevation. The truth is, that the greater warmth of the lower atmosphere over extensive plains, than that of mountains, is owing to the obstruction of the sun's rays by the earth's surface. The stratum of air in contact with the earth becomes heated and rises, when the next stratum is heated and rises, until the whole atmosphere becomes warmed to a considerable height. Hence it is, that the plain of perpetual congelation varies in height in different parts of the world in nearly the same latitudes.

+ The dryness of the atmosphere is in proportion to the elevation of its temperature above the dew point, which decreases from the surface of the earth to the region of clouds. This explains why rain often ceases about mid-day, when the clouds are redissolved by the increasing power of the sun; and why the lower atmosphere is so often obscured in England by a misty rain after sunset during winter. 
would appear, that the under surface of dense clouds in the north of England, does not exceed 1300 yards during winter, nor 2000 yards in summer.*

To pursue this subject through all the complicated phenomena of meteorology, would far exceed the scope of the present inquiry, the principal object of which is to trace the origin and history of atmospheric electricity.

The cardinal facts which connect the phenomena of lightning with the theory of rain, may be reduced to the following propositions:

1. In the torrid zone, where evaporation and rain are most copious, the amount of lightning is greatest. There is also far more during summer than winter in the middle latitudes, and scarcely any in the polar regions.

2. In those parts of the world where there is no rain, there is no lightning, as at Lima in Peru; nor is there any in Egypt, Palestine, and other parts of the world during the prevalence of dry weather. It therefore follows,

3. That where there is no condensation of aqueous vapour, there is no lightning.

The most superficial observers of nature have been impressed with the immediate connexion between lightning, intense heat, and rapid precipitations of rain. By a careful analysis of the phenomena it becomes self-evident, that if caloric

* Dalton's Meteorological Essays, p. 136. 
be the true and only cause of evaporation, its condensation and precipitation can be effected only by the evolution of the same agent. During winter, the quantity and elastic force of vapour in the atmosphere are comparatively low in the middle latitudes, where it is condensed gradually on meeting with colder air. During spring, evaporation augments with increase of temperature, when masses of warm and cold air often meet, causing frequent showers of rain, and sometimes hail; still without much thunder and lightning. But during summer, when the temperature becomes tropical, and the atmosphere saturated with highly elastic vapour, we have tremendous explosions of thunder and lightning, with rapid precipitations of rain and hail. Corresponding with the temperature of the torrid zone, and the amount of evaporation, thunder storms occur almost daily during the rainy season, on the coasts of India and S. America.

One of the most prominent errors in regard to the natural history of lightning, is the prevalent notion that it collects around the surface of clouds, as if they were solid insulated conductors; and that when it becomes accumulated to a certain extent, it darts from one to another. Nothing could be more in opposition to all analogy and experience. Clouds are only banks or strata of moisture, while it is universally known that electricity cannot be accumulated in a moist atmosphere,-that it is diffused and dissipated by 
moisture, and thus prevented from being collected in a Leyden battery. It is accumulated in transparent aqueous vapour, as I shall proceed to shew by the most decisive facts, and by the experiments of different philosophers,-from which it darts through the neighbouring clouds in such a manner as to present the appearance of proceeding from them; while it is an optical illusion that may be corrected by a philosophical examination,-in short, that a large body of transparent elastic vapour from the tropics, may be compared to an immense Leyden battery, filled with an igneous fluid which is discharged in the concentrated form of lightning on approaching mountains or currents of cold air.

When the inquiry is divested of all extraneous and hypothetical considerations, it may be reduced to the following conditions.

If it can be shewn, that transparent elastic vapour is the vehicle of atmospheric electricity, and that it is rapidly condensed during discharges of lightning, it will necessarily follow, that the caloric of such vapour is given out in the concentrated form of electricity during a thunder storm.

In reply to this reasoning it may be objected, that heavy rains are often unattended with lightning. To which I answer without fear of contradiction, that the formation of clouds and precipitation of rain are far more rapid during thunder storms than when there is no lightning. 
It is stated by Humboldt and others, that within the tropics during the rainy season, the first indication of an approaching storm is generally a light wind, with a few scudding clouds, - but that when it begins to lighten, the whole sky is suddenly obscured by dense clouds that immediately descend in torrents of rain.

That atmospheric electricity is a constituent of aqueous vapour, will appear from the description of a thunder storm among the Alps, as recorded by the celebrated De Luc. He states that it commenced with abundant discharges of electricity from dry transparent air, which contained neither vapours nor the electric fluid, but the constituents of both,-and that clouds were suddenly formed around the summit of the Buet, during each explosion. In other words, that simultaneous with the discharges of lightning from dry transparent air, was the sudden formation of clouds, and precipitation of rain.

From another portion of De Luc's work, entitled, Idées sur la Métćorologie, it is obvious that he mistook transparent aqueous vapour for " dry air." He supposed that clouds were formed by the union of oxygen and hydrogen gases by the agency of electricity, as water is generated by passing an electric spark through them.*

* This hypothesis has been revived by Mr. Murphy of Cambridge, in a recent work on Electricity, the professed object of which is to reduce the science to mathematical laws. Had this ingenious author traced the history of rain from the first process 
According to Seneca, the ancient stoics taught a similar doctrine - " that air was converted into fire and water," during a thunder storm :-(Natural Questions, Book ii.) from which it would appear, that they were ignorant of the process of evaporation, by which water is expanded into elastic vapour like air; or that they confounded the one with the other.

In the 22nd chapter of the same book, in which Seneca gives his own opinion, he maintains that fire and lightning are the same, because the latter produces the same effects as fire, such as the heating and melting of metals, the combustion of forests, \&c.; but that in lightning, fire was greatly condensed.

But to return from this digression, if it be true that caloric is the cause of evaporation, (as proved by De Luc himself,) and if transparent vapour be suddenly condensed into clouds and rain, with a rapidity proportional to the amount of lightning, the conclusion is inevitable, that solar

of evaporation, he would probably not have maintained that heavy showers of rain which accompany lightning, may be produced from the combination of oxygen and hydrogen by electricity, after it had been demonstrated by Dalton that vapour or steam is composed of water and caloric, and that its condensation is owing to the evolution of caloric, whether attended with lightning or not. The supposition of Dr. Darwin was more consistent, who maintained that electricity was the cause of evaporation, because discharges of lightning are attended with rapid precipitations of rain. 
caloric is the real basis of lightning; for it would be a violation of all the rules of philosophizing, to maintain that water is converted into vapour by one agent, and again reduced to water without the evolution of the same agent. No sophistry can evade this simple but rigorous logic. That the rapid precipitation of rain during a thunder storm, is in proportion to the amount of lightning, is attested by all experience and observation. Hence it is that during the fiery tempests of the tropical regions, termed hurricanes, more rain is precipitated in a few hours, than during as many months in colder latitudes.

It may be said that lightning is sometimes unattended with rain: to which $I$ answer, that vivid flashes never occur immediately over head, without a precipitation of rain or hail. This is the most convincing proof, that the caloric of vapour is given out in the condensed form of lightning; and is that kind of evidence from which there is no appeal, being the spontaneous declaration of nature herself, made in the most sublime and ostensible manner.

On the 2nd of June, 1833, the author had an opportunity of observing for himself, that lightning proceeds from transparent vapour, and not from clouds already formed, as many persons suppose. This beautiful display, which was witnessed by hundreds of individuals with admira- 
tion, occurred at New York, about 7 P. M. after a showery day. The wind was from the south, while the western sky was of a brassy hue, through which the descending sun was perfectly visible. In this state of the atmosphere, a vivid streak of lightning was seen to dart from it, when clouds were immediately formed that intercepted the solar rays, as if an immense black curtain had been drawn across the western sky, and attended with copious precipitations of rain. Several showers were thus produced by successive flashes of lightning; and during their intermissions, the sky became partially transparent, but of a brassy hue as at first.

Such facts afford more decisive information in regard to the nature of lightning, than volumes of mere speculation; or than thousands of artificial experiments ; for they completely establish the important fact that elastic vapour and not clouds is the proximate source of atmospheric electricity. Nevertheless, I shall prove by the experiments of De Saussure, Read, and Pouillet, that electricity may be disengaged from all vapours generated by the agency of caloric, whether by natural or artificial means, or by combustion-that it rises from the earth in a latent state of combination with aqueous vapour, which it maintains in the elastic form,-whence it may be withdrawn by conductors, and tested by the electrometer. 
Scarcely one of the older writers on meteorology, clearly understood the simple process of evaporation. Beccaria supposed that the earth was full of electric matter, which rises to the upper regions of the atmosphere, carrying with it water in the form of vapour.-(Priestley's Hist. of Electr. p. 340.)

Franklin also supposed, that vapour was elevated from the sea, by the united agency of heat and electricity. But it is now well established, that caloric is the vaporizing agent all over the world-that wherever there is heat and water in sufficient quantity, vapour is produced, whether from the ocean, fresh water lakes and rivers, or from the surface of the dry land-and that other things being equal, its amount, like that of lightning, is determined by temperature. Had Franklin clearly understood the process of evaporation, and traced the connexion between discharges of lightning and precipitation, he would probably have added to his discovery of the identity of lightning and common electricity, the still more important fact, that caloric and electricity are different manifestations of the same potent element.

The celebrated Volta adopted the opinion of Franklin, with some slight variation. He supposed that all bodies contained electricity, a portion of which was evolved whenever they underwent a change of state; that when water was 
converted into vapour by the agency of solar heat, it acquired a greater capacity for electricity, which it absorbed and carried into the atmosphere during the process of evaporation; that it was liberated whenever the vapour was condensed by cold, and thus accumulated in the upper regions of the air ;* that when clouds are formed, which are good conductors of electricity, they become a medium by which electricity is conveyed back to the earth in a tranquil manner, or in the form of lightning, according as it is more or less abundant.-(Journal de Physique, Août. 1783.)

The experiments of Lavoisier and Laplace, published in the Memoirs of the French Academy in 1781, were intended to prove that electricity is disengaged during the process of evaporation : but their results were vitiated by the agency of

* Seneca informs us that Anaxagoras taught that lightning descended from the ætherial regions, and was collected in clouds, from which it was discharged after being greatly accumulated. The same hypothesis has been recently brought forward as new by $\mathrm{Dr}$. Hare, with this difference, that he supposes the earth to constitute another great reservoir of the electric fluid, and that the atmosphere is situated between two oceans of electricity; while the clouds formed in the non-conducting air, operate as. moveable insulated conductors. He further supposes, that thunder storms are more frequent during warm than cold weather, in consequence of the greater elevation to which the clouds then attain, and their consequent approximation to the celestial ocean of electricity.-(Theoretical suggestions respecting the causes of the tornado, or water-spout, \&c. by Robert Hare, M.D. of Philadelphia.) 
chemical action, which accompanied the process of evaporation in most of their experiments. Besides, they did not extend their researches to the connexion of atmospheric electricity with the phenomena of meteorology : they have therefore been very little attended to by philosophers.

Lavoisier and Laplace found, that when water was poured by drops into an iron vessel heated, while the vessel communicated with an electroscope, it gave signs of positive electricity; that when dilute sulphuric or nitric acid was poured upon iron filings, electricity was evolved; also, during the action of dilute sulphuric acid on chalk, and during the combustion of charcoal. Their experiments tend to shew the relation between chemical action and the evolution of electricity; but throw very little light on the connexion of electricity with evaporation.

The most decisive results are those of De Saussure and Mr. Read, who performed many hundred experiments with the greatest care, for the purpose of ascertaining the source of atmospheric electricity; the result of which led them to the conclusion, that a perpetual circulation of the electric fluid is kept up by means of evaporation and condensation.

De Saussure found that when water, spirit of wine, and æther, were made to boil in silver, or white porcelain vessels heated, and suspended by silk cords, negative electricity was obtained; 
but when a piece of red hot iron was thrown into a vessel containing a small quantity of water, positive electricity was strongly developed. He supposed that the vast quantities of electricity discharged from volcanos, was generated by the action of so great a heat on waters that find their way to those immense furnaces. In all such cases, it is disengaged chiefly by chemical action, as will be noticed when I come to treat of voltaic electricity and volcanic forces.

The following experiments of De Saussure shew, that aqueous vapour, however produced, contains electricity. He caused water to boil in a coffee-pot, by placing it on an insulated chauffer (heater), when the coffee-pot was electrified minus, during the condensation of the vapour. He varied the experiment, by causing the vapour of boiling water to pass into the cap of an insulated alembic, to which he applied snow, causing a condensation of the vapour contained within it, when the apparatus became electrified minus, or negative. The same effect was produced in a more remarkable manner, by applying a mixture of common salt and snow as a refrigerent. He observes, that in all such cases, electricity is disengaged from the vapour, and conducted to the metallic vessel during the process of condensation.-(Voyages dans les Alpes, tome ii. 251.)

De Saussure adds, that the electric fluid is 
generated during the conversion of water into vapour by heat; that it combines with vapour, and contributes to its formation:- "Il monte invisible et inactif, cache dans le sein de ces vapeurs; mais déployant ensuite son energie lorsque ces vapeurs ont changé de forme, il redescend actif, animé de sa force pénétrante et expansive."-(Voyages dans les Alpes, Tom. II. p. 244.) But it is quite evident that his ideas were vague and unsettled in regard to the origin of atmospheric electricity: for he observes in another volume of the same work, that it seemed to be produced by the friction of clouds against the air; by the action of the solar rays ; or by these two causes united.-(Vol. i. p. 241.)

Dr. Thomson has expressed nearly the same opinion in his late work on heat and electricity, "that atmospheric electricity may result from the friction of two currents of dry air moving different ways."-(page 441.)

De Saussure supposed that there were two kinds of vapour; the one vesicular* and visible, which contained electricity; while transparent elastic vapour was combined with, and sustained by, the expansive agency of heat alone, (sans le secours d'aucun autre agent.)-(Vol. ii. p. 259.)

* The vesicular theory originated with Derham, who supposed that vapour was composed of hollow sphericles of water filled with highly attenuated air, which Mr. Leslie terms a "fanciful notion, countenanced by certain dubious optical appearances." 
But I have shewn, from the observations of De Luc on the Alps, and from my own at N. York, that lightning is disengaged rapidly from transparent vapour, by which the latter is condensed into rain. The observations and experiments of De Saussure are highly valuable; while his theoretical views are often inconsistent. He supposed that electricity was destroyed by explosions of thunder; that is to say, it is generated by evaporation, and destroyed by condensation. But I have already shewn, that such phenomena result from changes of state : and it will be seen hereafter, that there are no assignable limits to the metamorphoses of this subtile agent. They are as diversified as the multitudinous forms of external nature. Though invisible per se, it is everywhere busy in all the transmutations of matter. The fabled Proteus of old, is but a feeble representation of the rapid changes through which it passes-now silently bearing the waters of the ocean aloft into the atmosphere in a state of transparent ætherial vapour-now darting in vivid corruscations from its aërial palaces on high-leaping upon the mountains, and cleaving rocks asunder-resounding through the heavens with its great music, and sprinkling the earth with genial showers of fruitful rain. Though constantly changing, it is never destroyed, but is always the same powerful agent by which Infinite Wisdom seems to direct and govern the stupendous frame of the universe. 
Who can refrain from sentiments of profound admiration of its God-like energy, and the wonderful manner in which it produces an endless succession of the most diversified effects?

There is not a more striking evidence of beneficent design in the whole mechanism of creation, than the rapid evolution of heat from atmospheric vapour, in the concentrated form of lightning, during hot and sultry weather. Were it given out in the diffused form, it would cause an inconvenient augmentation of temperature. Besides, were it evolved gradually, as during winter, the number of rainy days would be so far increased, as greatly to interfere with the operations of agriculture. On the other hand, being given out in the form of sensible heat during the formation of clouds, rain, and snow, in the higher latitudes, it moderates the excessive cold which would otherwise prevail during winter.

It was observed by a distinguished writer of the present day, "that the delight with which speculative minds contemplate universal truths, does not so much spring from perceiving that some general principle holds good, and reappears in a great number of instances very nearly, or perfectly resembling one another, as from discovering the occult presence or efficacy of some such principle in a multiplicity of cases which have few points, or perhaps no other point 
of resemblance besides this one of their obedience to some abstract law." (Isaac Taylor, Saturday Evening, p. 131.)

When men shall thoroughly comprehend the agency of caloric in all the diversified forms of electricity, and how they are resolvable into one general principle, innumerable new truths, the existence of which has not been suspected, will gradually open to view, until the vast and complicated machinery of nature shall be fully unfolded, and reduced to an intelligible theory.

I cannot dismiss this subject without noticing the recent experiments of $M$. Pouillet, in connexion with those of $\mathrm{Mr}$. Read, which were performed fifty years ago; because their conclusions are in direct opposition to each other. Mr. Read maintained that electricity is given out by aqueous vapour, (the constituents of which are oxygen, hydrogen, and caloric,) and by the vapours that are exhaled from burning substances, ${ }^{*}$ - while M. Pouillet contends that electricity is never developed by evaporation, unless attended with chemical action.

It was before stated, that De Saussure obtained electricity during the evaporation of water, from silver and porcelain vessels, where no chemical action can be supposed to have existed.

* Mr. Read considered combustion as a species of evaporation, by which solid and fluid bodies were converted more or less rapidly into the gaseous state. 
Mr. Read insulated a large hollow tin cone, with many yards of small wire coiled up within it, one end of which extended from the apex of the cone, which was open, and was connected with a sensible electrometer. Under this cone was placed a vessel of water, the vapour from which, on rising, was condensed and collected by the cone and wire, when positive electricity was produced, (which De Saussure could not obtain without chemical action.) The same result was obtained by burning different substances under the cone. He maintained that the electricity which he derived from the atmosphere in different degrees, at all seasons and times of the day, was elicited from its vapour: He observed that during the formation of thick fogs, electricity was abundant; but scarce during their solution and dispersion. (Spontaneous Electricity, p. 15.) He also found that his lightning rod was less charged with electricity while immediately under a cloud, than when at some distance from it ; and that it acquired more electricity before the rain commenced than afterwards-a fact which was also observed by Beccaria.

These beautiful and important experiments will enable us to comprehend those of $\mathbf{M}$. Pouillet, which he seems not to have rightly understood himself. He placed a cylindrical piece of charcoal in a vertical position, the top of 
which was $2 \frac{1}{2}$ or 3 inches below a plate of brass that was connected with the condenser. When the upper part of the charcoal was ignited, a current of carbonic acid arose and came in contact with the brasss plate, by which the condenser was positively electrified in a few minutes. By placing the inferior end of the charcoal on the condenser, and igniting the upper end, the condenser was charged with negative electricity. From these experiments Pouillet concluded, that during the combination of oxygen with carbon, it gave out positive electricity, while the carbon gave out negative electricity.

During some of his experiments, both positive and negative electricity were evolved by the combustion of charcoal and hydrogen; from which it would seem to follow, that positive and negative electricity are only plus and minus conditions of the same agent; although this seems not to have been suspected by Pouillet. The following experiments are among the most instructive which have been recorded by the French philosopher. He caused hydrogen gas to flow out of a glass tube. When it was ignited, a vertical flame was produced, nearly half an inch in breadth, and three inches in height. A coil of platinum wire was employed to conduct the electricity from the flame to the condenser. When the coil was large enough to inclose the flame, and to be about four inches from its 
external surface, positive electricity was indicated, as in the experiments of Mr. Read, which became more and more intense as the distance diminished, until the coil touched the flame, when nearly all signs of electricity disappeared. Hence it was concluded, that around the flame of hydrogen gas, there is a sort of atmosphere at least 4 inches in thickness, which is always charged with positive electricity.

Now, it is obvious that aqueous vapour is produced during the combustion of hydrogen gas, constituting an atmosphere above and around the flame; which vapour gives out positive electricity as proved by Mr. Read. It is also evident, that in the immediate vicinity of the flame, the vapour cannot be condensed by the platinum coil ; and therefore cannot give out much, if any, electricity. It is for the same reason, that the vapour of the atmosphere gives out but little electricity during the heat of a clear day, which increases in the evening. When Pouillet placed a small coil of platinum wire in the centre of the flame, so that it was enveloped on all sides, and made to communicate with a condenser, the instrument was electrified negatively. This is a thermo-electric phenomenon which has very little connexion with atmospheric electricity, as will be seen hereafter. He found that during the combustion of alcohol, æther, wax, oils, fat, and many vegetable bodies, the same phenomena 
were exhibited as in the experiments with burning hydrogen. (An. de Chim. et de Phys.XXXV. 401, et XXXVI. 5.)

The principal error of M. Pouillet, was in supposing that electricity is never produced by evaporation, unless attended with more or less chemical action-that when water was evaporated from platinum cups, no electricity was evolved. In addition to the evidence of De Saussure, are the recent experiments of $\mathrm{Mr}$. Harris, who has found that the evaporation of pure water from platinum vessels is attended with a distinct evolution of electricity - so that the doctrine of Pouillet cannot be admitted, that atmospheric electricity is wholly supplied by chemical action and the growth of vegetation. It is impossible to conceive that the vast amount of lightning disengaged from aqueous vapour, could be generated by chemical action, which is far more energetic upon the dry land than in the ocean, from which the vapour is obtained: nor can it be maintained that the process by which water is separated from the ocean brine is chemical; for $I$ have shown, that it is a mechanical force, which is proportional to temperature. (See Chap. iii. Book 1. and the subsequent examination of the two electric fluids.)

From the brief history thus presented of atmospheric electricity, it must be obvious to the vintelligent reader, that the knowledge hitherto derived from experimental researches, has been 
extremely vague and imperfect, and that its relations to the caloric of evaporation have scarcely been inquired into. On the other hand, it is equally evident, that if we analyse the phenomena of evaporation and condensation, as they are constantly going on before all eyes, we obtain a simple and satisfactory solution of the problem. The fact which was announced by Dalton, that caloric is the only cause of evaporation, taken in connexion with another fact, that aqueous vapour is condensed into rain or hail, with a rapidity proportional to the amount of lightning, are decisive in regard to the convertibility of caloric into electricity, which, as will be seen hereafter, completely explains the phenomena of hurricanes, tornados, \&c.

The ideas of the ancient Greek philosophers, which were derived from observation without experiments, were more in accordance with nature and reason than the hypotheses of modern times. It was maintained by Lucretius, who gives the doctrines of Epicurus, that lightning consisted of fire alone, and that it was derived from the sun. He represents the igneous particles of fluid as rushing to a focus, by which concentration they acquire the power of instantaneously fusing metals. *-(De Natura Rerum, Lib. vi. 108.) That

* He further states, that it is by the meeting of warm and cold air that they are elicited. It is not very obvious how this subtile matter becomes concentrated into a ball of fire on quitting a mass of vapour; but such is the fact. It is equally difficult to explain 
this subtile agent is greatly concentrated on quitting a mass of vapour in the form of lightning, is proved by the fact, that a single spark or flash, causes a precipitation of rain over several thousand acres-and that it is a material agent, is demonstrated by its mechanical force in rending rocks, buildings, ships, trees, \&c. as effectually as if it were a ball of iron discharged from a cannon.

Lord Bacon supposed, that the greatest heat in nature was that of lightning, from its instantaneous power of fusing metals, and of igniting other combustibles. As an additional proof that it is a concentrated exhibition of the igneous principle, it may be observed, that when solar caloric is greatly concentrated by a large burning-glass, it fuses, ignites, and volatilizes the hardest gems in a few moments, thus approximating the character of lightning. But since

how the electricity of a Leyden battery is condensed on presenting a metallic knob. Perhaps it is owing to all its particles being attracted to the centre of the knob-or that the igneous matter of vapour is attracted to the centre of whatever object excites it. It is worthy of notice, that when a metallic point is presented to the knob of a Leyden bottle charged with electricity, the igneous fluid is drawn off gradually, and no visible spark is produced : but when a larger mass of matter is presented, as a knob of brass, or the knuckle, it is all withdrawn at once. Thus mountains, clouds, buildings, \&c. attract a large portion of the electric fluid at the same moment, producing a concentrated spark many hundred thousand times larger than one from a Leyden jar. 
the time of Bacon, philosophers have discovered, that electricity can produce all the above effects without being a material fluid-others, that it proceeds from the earth to the clouds, and not from atmospheric vapour to the earth-while others again resolve all its mechanical and heating properties into undulations of the " unknown æther."

When I come to treat of Voltaic phenomena, it will be seen that the power of electricity to produce a shock, and the velocity with which it passes through conductors, are modified by the various modes of its disengagement from ponderable matter.

With his well known sagacity, Sir John Herschel has laid down some admirable rules for the purpose of facilitating our research, among a great mass of assembled facts, for their common cause. They are substantially the following :-

1. Invariable connexion of the cause and effect, unless prevented by some counteracting cause.

2. Invariable negation of the effect, with absence of the cause, unless some other cause be capable of producing the same effect.

3. Increase or diminution of the effect, with the increased or diminished intensity of the cause in cases which admit of increase and diminution.

4. Proportionality of the effect to its cause in all cases of direct unimpeded action. 
5. Reversal of the effect with that of the cause. He adds, that we are not to deny the existence of a cause in favour of which we have a unanimous agreement of strong analogies, though it may not be apparent how such a cause produces the effect.-(Discourse on the Study of Natural Philosophy, section 145 and 148.)

The above general rules apply with great force to the connexion between temperature and the phenomena of lightning.

1. It has been shewn, in accordance with the first rule, that a certain range of solar temperature is indispensable to the existence of lightning, which are therefore invariably connected together as antecedent and consequence, or cause and effect.

2. It has also been shewn, in conformity with the second rule, that in the absence of condensation and precipitation of vapour there is no lightning :

3. That other things being equal, the amount of evaporation, condensation, and lightning, are increased and diminished with the augmentation and decrease of temperature.

4. That the quantity and splendour of this wonderful meteor are proportional to the accumulation and intensity of solar heat, from the equator to the poles-and

5. That the effect is reversed on passing from the regions of perpetual cold to the torrid zone, and from winter to summer. 
In reference to the $3 \mathrm{rd}$ and 4 th rules it may be observed, that the quantity of precipitation and lightning are greatly diminished, cateris paribus, by uniformity of temperature, as in the tropical portions of the sea far from land, and other parts of the world where the winds blow long in one direction; whereas changes of temperature are indispensable to the condensation of atmospheric vapour, and to the evolution of its caloric in the concentrated form of lightning.

\section{CHAPTER II.}

\section{Theory of Winds.}

Of all the subdivisions of General Philosophy, there is none so little entitled to the name of science as Meteorology.

Mason Good.

That the reader may comprehend more fully the connexion between caloric, evaporation, and atmospheric electricity, it becomes necessary to present a cursory view of atmospheric currents generally.

The unequal distribution of solar caloric over the earth's surface, together with its annual and diurnal revolutions, determine the periodical movements of the atmosphere which surrounds it. 
It has been long known, that there are three great currents of the aërial ocean, by which it is kept in a state of perpetual circulation : one from the polar regions towards the equator, which is an under current; another from the equator to the poles, which is an upper current; and a third, called the great equatorial current, or trade wind, which blows from east to west around the globe for about $30^{\circ}$ on each side of the equator; thus sweeping over the whole extent of the tropical regions, which are upwards of 3000 miles in width.

There is another general wind, which blows from west to east in the middle and higher latitudes, about two-thirds of the year in the northern hemisphere; while in the middle latitudes of the southern hemisphere, where there is little or no land, it is said to be nearly as uniform as the trade wind. Dr. Hadley, and after him Dr. Franklin, attributed these general currents to the following causes. "The air between the tropics, being constantly heated and rarefied by the vertical sun, rises, when its place is supplied by air from the higher and polar latitudes, which, coming from parts that had less diurnal motion, and not suddenly acquiring the swifter motion of the equatorial regions, becomes an east wind ; the earth moving from west to east, and slipping under the air." - (See Franklin's Works, vol. iii. p. 236.) 
These general views have been greatly extended by Dr. Dalton and Mr. Daniell. The first of these philosophers observes, that the diurnal motion of the earth at the equator is 1040 miles per hour, and diminishes gradually on to the poles, where it is nothing.-(Meteorological Essays, pagé 88.) And Mr. Daniell has demonstrated in the most conclusive manner, that from the greater density of the polar atmosphere than the equatorial, its height is proportionably less; so that the expanded air between the tropics must rise and flow towards the poles as an upper current. Before rising, it has acquired the tropical motion of the earth from west to east, which it retains, until descending in higher latitudes, where the earth's diurnal motion is less, it mixes with the lower air, and gives it a westerly direction.

The force and direction of the trade winds are influenced by the proximity of islands and continents. Along the western side of Africa, their direction is reversed. To the distance seaward of about $\mathbf{3 0 0}$ miles, they blow towards the heated land: they are reversed in a similar manner in the Pacific, west of South America. When the sun is in the northern tropic, they extend several degrees farther north than during our winter; and when the sun is south of the equator, they prevail farther south.

* There is a tract corresponding with the iso- 
thermal division of the globe, which, as will be seen hereafter, is the magnetic equator, where the great polar currents from the north and south meet and neutralize each other. They are characterized by a constant succession of irregular winds and calms, with storms of thunder, lightning, and rain : they are termed by seamen the swamps, or rainy latitudes; and are extremely sultry, owing to the immense quantities of caloric given out during the condensation of so much aqueous vapour.

During winter, in the northern hemisphere, the polar latitudes being deprived of the sun's rays, while the tropical parallels are heated, we have a predominance of northerly winds, the dense polar air pressing towards the tropics, to restore the equilibrium; while the greater velocity of the middle and tropical than that of the northern latitudes; causes a deflection of the polar currents to the south-west and west, making north-east and east winds, which almost uniformly succeed to north winds, and continue blowing until an equilibrium is established between the higher and middle latitudes. In the mean time, under the influence of the solar beams, the land soon becomes more heated than the ocean, even south of it, which causes a south wind until the equilibrium is restored between the sea and land atmosphere.

During summer, in the United States, south- 
icesterly winds predominate, and north-easterly winds during winter, especially if the winter be excessively rigorous. The same thing is true of India, China, and Arabia. They are heated during summer, and the atmosphere over them is rarefied, which causes the air to flow in upon them from the tropical seas, when it is deflected to the east, by passing from latitudes that move rapidly, to those which move more slowly. This is what seamen term the south-west monsoon.

When the sun is south of the equator, the air moves from the northern land, which is cooled down, towards the equator, that has a swifter motion, thus causing the north-east monsoon, which corresponds with the north-east wind of the North American cold season. It was supposed by Volney, that the prevailing south-west wind of the Mississippi valley was a recoil of the tropical trade wind, deflected by the Andes of Mexico; but the fact which he states, of its crossing the Alleghany Mountains, and advancing north-eastward, as far as Montreal and Quebec, is sufficient to prove, that it must be owing to a cause far more extensive and general in its operation than mountain ranges.

During summer in North America, the land is greatly heated, and the air presses from the Atlantic ocean, especially during the day, causing a sea breeze; when from the south, it is changed into a south-west wind, by passing from 
latitudes that revolve at the rate of 8 or 9 hundred miles per hour, to those which move only 6 or 7 hundred miles per hour.* The south west and north east are the prevalent winds in the United States and the west of Europe. In Great Britain they blow about 300 days in the year.

It has been observed in the United States of America, that regular winds generally follow the sun, exhibiting a tolerably uniform succession of circuits from left to right, and blowing from all points of the compass within a few days. For example, the ordinary succession of winds is, first, from the north; next, from the north-east, then from the east; south-east; south; southwest; west; north-west, and so on, in pretty regular succession, and rarely, if ever, performing an entire circuit in the opposite direction. As the greater portion of the United States is more heated by the sun than the ocean, even south of them, (because the surface is stationary,) and for a longer time, the wind blows from the south-west a greater number of days than from any other quarter. At the same time, it is worthy of notice, that during extremely cold winters, the

- It is the meeting of this wind, charged with aqueous vapour from the ocean, with the colder north and north-east currents, -which causes vast precipitations of rain in the United States, during the latter part of summer and beginning of autumn, attended with the most fearful displays of thunder and lightning, when extensive hurricanes sweep the Gulf of Mexico and the southern portions of the Union. 
wind has continued from a month to six weeks from the northern points of the compass.*

In addition to the above winds, opposite currents frequently meet in the higher atmosphere, which are not observed at the earth's surface, and thus cause precipitations of rain. A striking proof of this was witnessed on the 4 th of July,

According to observations made at sixteen different military posts in the United States, from lat. $35^{\circ}$ to the northern extremity of the Republic, including those of Sir Edward Parry, in the Polar regions, winds prevail from the south-west, west, and north-west, nearly two-thirds of the year; or in the ratio of 15830 to 8785 , while the northerly winds are to the southerly as 1190 to 1231. In the southern portion of the Union below $35^{\circ}$, eastern winds predominate over western in the ratio of 3102 to 1717 ; from which it would seem that they are subject to the general influence that governs the regular trade winds of the tropics. In the same section of country, northern winds are to southern in the ratio of 508 to 721 .

As Cincinnati, lat. $39^{\circ} 06^{\prime}$, affords a tolerable specimen of the Ohio valley generally, it may be stated that western winds prevail over eastern in the ratio of 631 to 32.5 ; while at New York, lat. $41^{\circ}$, they are as 580 to 279 . They are also nearly in the same proportions throughout the Atlantic Ocean, between North America and Western Europe.-(See Darby's View of the United States.)

Mr. Daniell states, that upon an average of ten years, westerly winds exceed easterly in the ratio of 225 to 140 in Great Britain; while northerly winds are to southerly, as 192 to 173 . (Meteorological Essays, p. 114.) During spring, the prevalent wind is from the dry, cold, north-eastern regions of Russia, Sweden, and Denmark. Throughout the Mediterranean, Egypt, Palestine, and the south of Europe generally, the wind blows nine months in the year from the northern points of the compass; because situated between the cold regions of Arctic Europe and Asia, and the burning plains of Africa, where the temperature is from $100^{\circ}$ to $115^{\circ} \mathrm{F}$. in the shade. 
1834, at New York. When Robertson, the aëronaut, ascended in a balloon from Castle Garden, the wind was from the east, which carried him westward across the Hudson river. At an elevation of about 4000 feet above the earth he disappeared in a mist or cloud, when he met with a counter current from the west, that brought him back over the city, and landed him ten miles to the eastward on Long Island. It was quite evident that the canopy of clouds, which overspread the city and country in the afternoon, was condensed by the colder upper current from the west.

From the 7 th until the 10th of July $(1834$, ) the heat was excessive, ranging from $86^{\circ}$ to $96^{\circ} \mathrm{F}$. in the shade, while the wind was from the southeast. On the 10th, about noon, the wind prevailed from the west, condensing the vapour of the heated air into floods of rain, attended with violent thunder and lightning. It is thus that a land wind, which usually brings fair weather, causes precipitation, by meeting with a southern wind saturated with aqueous vapour. It is highly probable, that at all times when rain attends a southern wind, and when the land temperature exceeds that of the sea, precipitation is owing to the prevalence of a colder upper current from an opposite direction.

What can be more impressive and sublime than those great movements of the atmosphere, by which the waters of the ocean are wafted over 
continents and islands; pestilential vapours dispersed; the face of nature refreshed, and adorned with living robes of surpassing beauty? By sinking into the earth, they acquire the properties of the various mineral beds through which they pass, and again bubble up in fountains of delicious water for the sustenance of animal and vegetable life.*

If the whole earth were of uniform surface and elevation, its temperature would be the same in given latitudes and seasons, and the currents of the atmosphere would present a succession of

* By the agency of warm southerly winds immense masses of aqueous vapour are transported from the ocean over North America, to the higher latitudes, where, meeting with a body of air from the frozen regions, it is condensed into cold rains, or extensive falls of snow, according to the season of the year; while the northern atmosphere is thus warmed by the disengagement of caloric from southern vapour.

If southern winds prevail for a long time from the ocean during autumn, until the atmosphere is saturated with vapour over a large portion of the northern hemisphere, without meeting with a mass of northern air to condense it, the commencement of winter is marked by an extensive fall of snow, from a foot to eighteen inches, or even three feet in depth, - over which the polar winds pass without being warmed, to the lower latitudes, causing excessive winters. This is one reason why during some winters in the United States the temperature occasionally falls from $30^{\circ}$ to $40^{\circ}$ lower than during others. After such a fall of snow the wind has prevailed, for six weeks together, from the northern points of the compass, as in the winter of 1779 and 80 , and about the same length of time during the winter of 1834 and 35 , when the mercury fell from $-20^{\circ}$ to $-40^{\circ}$, from latitude $35^{\circ}$ to $43^{\circ}$. I shall have more to say on this subject in another place. 
regular movements. There would be no sudden mixing of winds from opposite quarters, and no lightning nor rapid precipitations of rain, because there would be a regular gradation of temperature and density of the atmosphere from the equator to the poles; but, as the surface of the earth is diversified by land and water, mountains and valleys, hills and plains, unequal temperatures in the same latitudes and seasons result, causing all those irregular movements in the atmosphere termed variable winds; and which can never be predicted with unerring certainty until all these modifying circumstances are classified and reduced to general laws.

\section{Theory of Hurricanes, Hail Storms, Water Spouts, and Tornados.}

Having shewn in the preceding chapter, that lightning is always attended with the condensation of atmospheric vapour, I shall proceed to prove that no violent squall, hurricane, tornado, or water-spout, ever occurs without the sudden condensation of aqueous vapour; and that caloric in the concentrated form of lightning, is the active spirit of the storm and tempest, which governs all their powerful movements.

The Typhon, or rupwv of the Greek philosophers, was a hurricane accompanied with vivid 
flashes of lightning, which they called fire,while the tornado was described by the Romans as vortex igne factus, - and was identical with the prester, from $\pi \rho \eta \theta \omega$, inflammo, meaning a fiery whirlwind. It is evident on the slightest reflection, that violent winds which spring up suddenly, and often immediately after a calm,* cannot possibly be owing directly to the rarefying influence of solar heat, like regular winds, the velocity of which rarely exceeds twenty or thirty miles per hour; while the tornado moves at the rate of from one hundred to one hundred and twenty miles per hour. It is during the rainy season, that the tropical regions are visited by those dreadful hurricanes, or fiery tempests which tear up trees by their roots, destroying every thing in their resistless course-and when rain is precipitated in floods with a rapidity proportional to the amount of lightning. Those of the East Indian seas occur during the shifting of the monsoons, and are obviously owing to the condensation of vapour, caused by the meeting of extensive masses of air from opposite quarters of different temperatures. The equinoctial storms that sweep over the West Indies, the

* We often see against some storm

A silence in the heavens, the rack stand still, The bold winds speechless, and the orb below As hush as death: anon the dreadful thunder Doth rend the region.

Hamlet. 
gulf of Mexico, and the southern portions of the United States, are also produced in the same way, and are attended by extraordinary floods of rain, with fearful displays of thunder and lightning. An eye witness of the tremendous hurricane which desolated the island of Barbadoes on the 10th of August, 1831, informed the author, that it began about ten o'clock at night, with torrents of rain and broad sheets of fire in rapid succession, which threatened to overwhelm the inhabitants in a flood, or sweep them away in a tempest of flame.

On the other hand, in the tropical portions of the wide Pacific, where the temperature is uniform, and the winds blow steadily in the same direction, there is but little thunder, lightning, and rain, and no hurricanes. The same is true of the equatorial parts of the Atlantic, which are far from land. It is stated by Capper, in his account of winds and monsoons, that a hurricane was never known to occur at St. Helena, situated as it is, nearly midway between Africa and South America. It is near the continents of Asia, Africa, and America, or in the vicinity of large islands, where immense masses of vapour from the sea, meet with mountains and cold masses of air from the land, that hurricanes of wind, lightning, and rain, are most powerful and frequent, as in the Bay of Bengal, on the coast of Madagascar, Mauritius, \&c. In short, there 
never was a hurricane, tornado, or gale, in any part of the world during the existence of perfectly dry weather. It is therefore evident, that lightning, and all violent winds, are immediately connected with the rapid condensation of aqueous vapour or steam, which owes its existence to the expansive agency of solar caloric. Even the winter gales so fatal to shipping on the coasts of Great Britain and France, are always attended with copious precipitations of rain or snow, and sometimes with lightning.

This may be readily understood when it is remembered, that all the water which falls on the earth, existed previously in the atmosphere in the form of steam,-that its volume is from 1300 to 1500 times that of water, at ordinary temperatures, - (and about 1720 times greater at 212.) All this steam is confined chiefly to the lower regions of the air, and must necessarily augment its volume in proportion to the quantity diffused through it-the consequences of which are, that immense vacuums are produced by its condensation, and a violent rush of the surrounding air from different quarters, until an equilibrium is restored.

Perhaps there is no part of the world, where thunder storms are so frequent as in the Bay of Mexico, and on the borders of the Gulf Stream. It has been said, that of all the vessels in the world, which are annually destroyed by light- 
ning, two-thirds have been lost on the tract of the Gulf Stream.

We may readily comprehend all this when we reflect, that the Gulf Stream is a portion of the great equatorial current, (caused by the trade wind,) which is obstructed by South America, and deflected into the Bay of Mexico, where its temperature is from $70^{\circ}$ to $80^{\circ}$, according to the season. With its tropical temperature it issues from the Bay of Mexico through the Florida Channel, advancing along the southern coast of the United States, north-eastward to the Banks of Newfoundland, and thence to the western coast of Ireland, until it is lost. For the distance of 1500 or 2000 miles its temperature is from $10^{\circ}$ to $20^{\circ}$ higher than that of the ocean on its northern extremity; the consequence of which is, extensive evaporation. The vapour thus formed is perpetually meeting with bodies of cold air, by which it is condensed, causing a succession of vacuums, local storms, water-spouts, \&c.* We are informed by seamen, who navigate the At-

* As many as sixteen water-spouts were seen at the same time by Captain Lawrence on the borders of the Gulf Stream, in Lat. $32^{\circ} 48^{\prime}$, when off Charleston, on a voyage from New Orleans to New York in 1834. They are all formed by the sudden condensation of aqueous vapour, caused by the meeting of opposite currents of air that deflect each other, producing a funnel-shaped cloud, that descends in torrents of fresh, and not salt water, as has been generally supposed. In short, they are what Franklin termed them, whirlwinds at sea. 
lantic between the United States and England, that while one vessel encounters a thunder-storm, others enjoy mild breezes within thirty or forty miles of the same place.

The same general agency, modified by the relative position of land and water, oceanic currents, mountains and valleys, operates to a greater or less extent over all the earth. Off Cape Hatterass, which is washed by the Gulf Stream, there is a constant succession of gales, which are obviously caused by the mingling of warm and cold air, as seamen always observe a sensible change of temperature on passing the Cape. The same cause renders the Cape of Good Hope a theatre of perpetual war of conflicting tempests, occasioned by the difference of temperature between the great equatorial current, as it doubles the Cape, and the colder water of the Southern Ocean.

There can be no doubt, that the amount of caloric discharged in the form of lightning, during extensive hurricanes, is in proportion to the amount of condensation ; but its intensity or concentration is often less than during ordinary thunder-storms; because, during the former, the electric fluid is attracted by a more extensive mass of cloud, and is thus diffused. This also explains why it is that the violence of lightning and thunder usually abate after precipitation becomes general. The electric matter, being 
constantly drawn from the transparent aqueous vapour by the extended surface of falling cloud, prevents it from accumulating into a large ball of fire or thunder-bolt, in the same way that a damp atmosphere prevents us from charging the Leyden battery of a common electrical machine.

The streaked and forked appearance of ordinary lightning are optical illusions, which result from the rapid passage of the electric spark through the air, which makes an impression on the optic nerve that remains during its passage, in the same way that a burning stick when revolved, presents the appearance of a continuous circle of fire. The fork is owing to a division of the original spark or ball into two or more sparks, which diverge from each other. The zigzag appearance is owing to frequent slight deflections of the spark, as it moves through strata of air, of different densities. Whenever an electric explosion takes place near to the spectator, it always presents the appearance of a ball of fire, attended by a simultaneous report, like that of artillery. The reason that the report is usually heard many seconds after the flash is seen, is owing to its distance from the point of observation, and to the slowness with which vibrations are propagated through the atmosphere: while its rumbling or prolonged existence is owing to the space over which it passes. The report itself is probably caused by a sudden collapse of 
the air as it fills the vacuum produced by the passage of the electric bolt through it; or by its violent collision against the air, causing a tremour of the atmosphere to the distance of many miles, which is communicated to buildings and other solid bodies. It is likewise probable that the luminosity of the spark is owing to a sudden combustion of air or vapour by so intense a heat.

It was first observed by Dr. Franklin, that the cold summer gusts of the middle latitudes, generally come from the west; from which he concluded, that they were caused by a descent of cold air from the upper current of the atmosphere, on its passage from the equatorial to the polar latitudes. That this is chiefly the cause of our prevalent west winds, during about twothirds of the year in the middle latitudes, is obvious from what was stated, page 322 .

That this is also the true mode of accounting for many of our thunder storms, would appear reasonable from the following considerations. They occur during the most sultry weather, and hottest time of the day; generally the afternoon, when the lower atmosphere is greatly rarefied, so as to favour a descent of cold air from above, which rapidly condenses the transparent vapour of the lower atmosphere into floods of rain, that are often attended with hail, and always with a great reduction of temperature. In this way clouds are often formed suddenly, the whole sky 
becoming obscured by dense black vapour, accompanied with thunder and lightning, violent winds, and copious precipitations of rain. During such storms, more vapour is condensed into rain in twenty or thirty minutes, than usually falls during a whole day, or even a week, when there is no lightning. All the phenomena partake of the violence which characterizes the electric fluid when greatly accumulated.

Lord Bacon observes in his Natural History of Winds, that "tornados are caused by the sudden breaking of clouds," by which he meant those rapid precipitations of rain that accompany lightning and thunder. He also observes, that "when it lightens in a clear sky, winds and rain are at hand from the quarter where it lightens : but if it lightens in different quarters, there will follow cruel and horrid tempests." He might have added, that they have already begun in the places where the lightning is seen.

\section{Hail Storms.}

On the subject of hail storms, which are intimately related to whirlwinds, water-spouts, \&c. much learning and ingenuity have been expended since the days of Franklin, without any satisfactory explanation of their cause.

The celebrated Volta, supposed that they were 
produced by " a highly electrical condition of the atmosphere-that the frozen masses were kept in a state of reciprocating motion between two clouds, oppositely charged with electricity, until the mass rendered the force of gravity predominant; or until the electric tension of the cloud was exhausted by mutual reaction." In his report on the present state of Meteorology, Professor Forbes observes, that no better solution has yet been offered to the world.-(Transactions of the British Association, vol. i. 1832.)

The leading facts connected with hail storms are the following:

1. They are generally confined to the middle latitudes, where masses of cold air, from the polar regions, meet with warmer air from the tropical latitudes, loaded with aqueous vapour. When such currents encounter each other at the usual height of spring and summer clouds, the vapour of the warm air is condensed into cold rains, or showers of small hail, but without much lightning or violent wind : whereas all the most destructive hail storms are accompanied with tremendous flashes of lightning, and often with fearful whirlwinds, or tornados.

2. They occur chiefly during warm weather in the United States, when the lower atmosphere is full of vapour, and heated for several hundred miles to the temperature of $80^{\circ}$, and sometimes $90^{\circ} \mathrm{F}$. 
3. They usually run in veins of limited extent, and are most frequent in level districts, especially such as are hemmed in by mountains, as in the South of France, where they are very destructive to the crops.

4. They are often attended with the sudden precipitation of immense quantities of ice, that descends in large globular masses; and always with a great reduction of temperature.

Several of the above facts are exceedingly difficult to explain, without admitting the hypothesis of Franklin in regard to the cause of thunder gusts, - that is, a sudden descent of cold air from the upper regions, by which the vapour of the lower atmosphere is rapidly condensed and congealed into globules of ice.

In opposition to this view of the subject, it is maintained by Dr. Thomson, that the upper air cannot descend without undergoing condensation, and giving out a portion of its latent caloric, which he thinks would prevent it from cooling the atmosphere. (Treatise on Heat and Electricity, p. 129.) Whatever may be the just weight of this objection, the fact is certain, that aqueous vapour is suddenly and rapidly congealed by very cold air; by which the temperature of the lower atmosphere is often reduced from $80^{\circ}$ or $30^{\circ}$ down to $40^{\circ} \mathrm{F}$. within a few minutes, during extensive and violent hail storms. 
It is also certain, that a vacuum must be formed in the lower atmosphere proportional to the volume of vapour thus suddenly condensed; the extent of which may be estimated from the vast quantities of hail that are occasionally precipitated in a few minutes, amounting to a depth of nine inches in as many minutes, according to M. Pouillet. The formation of such vacuums is always attended by a rush of air from opposite quarters, creating a gyratory or whirling motion, the force of which is in proportion to the extent of the vacuum and the rapidity of its formation.

That the reader may perceive the more readily how intimate is the connexion between lightning, the condensation of vapour, hail storms, and whirlwinds, it may be proper to present a brief account of a few thunder storms which occurred recently in Great Britain :

On the 10th of August, 1835, Durham was visited by a violent whirlwind, accompanied with incessant lightning and thunder. At 7 o'clock, P. M. a most vivid flash of lightning struck the Cathedral, and hurled down an immense mass of stone, that killed two of a party of students, who at the moment fled from the interior of the Cathedral.

"On the same day Chesterfield was visited by a violent storm of thunder, lightning, rain, and hail. A large ball of fire fell in the Commercial-inn yard, where there was an accumula- 
tion of water, splashing it in all directions into spray, which for a moment seemed to be enveloped in flames.

"Many such storms occurred about the same time in different parts of England, Scotland, and Ireland. On the 10th of June, about 3 o'clock, there was a storm of lightning, thunder, and hail, at Dumfries, - and at Ardach on the following day, there was a violent thunder storm, where the hail was two feet in depth in some places, and remained on the ground for twentyfour hours.

"At Sheffield, during a thunder storm, the electric fluid entered the works of Mr. Ellin, and struck a pile of ivory handled knives, the blades of which were fused into one mass, and splitting off the hafts in a singular manner. Twelve individuals were thrown down, who imagined that the boiler of a steam engine in the room had bursted.*

"On the 6th of June, forty-two head of cattle

* It is related in some of the older books on Natural Philosophy, that Erfurt, a small city of Germany, was struck by lightning during a storm, in forty-two different places. Seven persons were killed, and three houses set on fire, which were quenched by the rain, that fell in torrents.

On the 15th of August, 1836, twenty-eight houses were set on fire by lightning in the town of Grundelbruch : while at Villexon, nineteen dwellings were consumed about the same time, during a thunder storm, attended with hail and a tornado. (Galignani's Messenger.) 
were killed by lightning in one field, at Johnstown, near Tuller. Some had their heads and horns burnt, and some their shoulders. On the lands of Mr. Lynham, at the hill of Talloght, eighteen cattle, twenty-three sheep, and a goat were also killed by lightning." (Bell's Weekly Messenger, June 14, 1835.)

\section{Tornados of the United States.}

It was observed by Lord Bacon, that " all tornados or great whirlwinds have a manifest precipitous motion, or darting downwards more than other winds, so that they seem to fall like torrents, and run as it were in channels."

Such tornados are remarkably frequent in the United States during hot sultry weather, and are attended with the most striking displays of electrical phenomena; always with rapid condensations of vapour, and often with enormous quantities of ice. They generally run in narrow veins from 100 yards to half a mile wide; while the equinoctial hurricanes of the Southern states, like those of the tropics, sweep over a vast extent of surface, and are rarely if ever accompanied with hail. The tornado is sometimes attended by a rapid succession of lightning; at other times it presents the appearance of an inverted fiery pyramid, from which is heard a continuous 
roll or deep roar of thunder, like that of a heavy unremitted cannonade, the sound of which is greatly modified and obscured by the noise of the raging wind, crashing of buildings, falling timber, \&c.

The whirlwind which destroyed a large portion of New Brunswick, in the state of New Jersey, on the 19th of June, 1835, presented many of the above phenomena. Those who witnessed its commencement, observed the formation of several inverted cones of dense black vapour, which descended from the upper regions. Dr. Lewis Beck describes one of these " as resembling in appearance the eruption of a volcano, which produced the impression, at a distance, that some large building had been set on fire by lightning, a vivid flash or two of which had preceded the formation of the cones. But in a few minutes the dense column was dissipated, when another black and well defined cone was formed, which remained stationary for a short time, and then gave place to the eruptory appearance and gyratory movement that characterized the other. The first occurred about three miles west of New Brunswick. But when the second movement commenced, a dense black cloud overshadowed the city. Slight, but distinct explosions were heard from the column in rapid succession, like the bluffing of sails. Volumes of smoke and flame were thought to be issuing forth, and 
rolling over in various directions, when the idea of an extensive and rapid conflagration was suggested. The alarm bells were rung, and the firemen repaired to their engines. But while all eyes were directed to the black and dreadful column that was approaching, no one could fix upon the exact spot to which efforts should be directed. This uncertainty was soon removed by the desolating progress of the whirlwind through the city, prostrating houses, and wafting heavy beams of timber to a great distance." Like most tornados, it was attended with hail, as well as rain. The width of its tract varied from 100 feet to 200 yards, in the neighbourhood of New Brunswick; while three miles eastward it was half a mile wide. A writer in the New York Times states, that on the banks of the Rariton, for 1000 yards, vegetation was scathed, as if a flame had passed quickly over it.

Many other similar storms desolated different portions of the Union about the same time. "Late in June, Lynchburg, in Virginia, was visited by a tremendous whirlwind and tempest of hail, which was preceded for several minutes by a monotonous rumbling sound, resembling the bass tones of distant thunder; or the deep roll of the muffled drum; and reminding us of the ominous notes which precede an earthquake."(Lynchburg Virginian.) Dense black clouds are described as pouring forth immense masses of 
ice, and so darkening the air, that houses within a few paces were totally invisible.

During the summer of 1834 , which was unusually sultry, tornados and hail storms of limited extent, visited almost every state in the Union, from Maine to Louisiana; several of them attended with great loss of lives and property. In most cases, they pursued a course from west to east.

About the 20th of March, 1832, a tornado occurred in the southern portion of Tennessee, lat. $35^{\circ} \mathrm{N}$. which differed in some respects from any of the preceding.

After several remarkably warm days for the season, accompanied with a southerly wind, a tornado came on suddenly; without the slightest warning, about seven o'clock, P.M. It excited great astonishment, as the whole day had been warm, serene, and clear, with the exception of a slight haziness, up to the moment when the crashing noise of falling timber announced the approaching storm from the west. The temperature was immediately reduced from about $70^{\circ}$, to several degrees below $32^{\circ} \mathrm{F}$. and attended with a rapid fall of snow, which continued for several hours; but the tornado blew with violence only about ten minutes. The next morning, the wind was cold and north westerly, and continued northerly for two days.

This storm seems to have been owing to the 
prevalence of a cold upper current from the north, which met and mingled with the warm southern air, and suddenly congealed its vapour into snow. It had not the local character of the summer tornado; for it was followed by great cold over a large extent of country.

I shall close this imperfect history of thunder storms with the account of an extraordinary and sudden coldness which occurred in the island of Cuba, on the 24th of May, 1809, that was evidently caused by a descent of air from the upper regions.

Cornelius Roberts, a sugar and coffee planter, who resided forty years on the island, informed the author, "that after a hurricane had been blowing from the south east and south, from the 22nd, until eleven o'clock, A.M. of the 24th, a calm followed for an hour, when the wind prevailed from the north west. At the same time, the atmosphere became extremely dark, like night, accompanied with a roaring in the air, tremour of the earth, and intense cold. Everything green was killed, and became black, as if a fire had passed over the country for several miles in breadth, and about sixty miles in length:" which proves that a mass of air may descend from above and refrigerate the lower atmosphere of the tropical regions, as in the middle latitudes, though such a phenomenon is extremely rare. 


\section{CHAPTER III.}

\section{Barometer.}

IT has been long known that the fluctuations of the barometer are intimately connected with all the phenomena of meteorology; that during winter, in the middle and higher latitudes, its depressions are followed with rain, snow, and tempestuous weather; while its rising is accompanied with cold, frosty, and dry weather; and that during summer its falling forebodes storms of thunder, lightning, and rain, which are often attended with violent hurricanes; while its rising indicates clear and serene weather. Yet the theory of its variations has never been clearly reduced to the simplicity of established principles. Without stopping to examine the relative merits of those who have devoted their attention to this difficult and important problem, it may be observed without injustice to any, that we are chiefly indebted to the labours of Dr. Dalton for the true mode of investigating it.

The most important facts connected with the barometer may be reduced to the following propositions :-

1. The mean height of the mercurial column at 
the level of the sea, is the same all over the earth, amounting to the average of about thirty inches.

2. The density or specific gravity of the atmosphere, increases gradually from the equator to the regions of lowest mean temperature, corresponding with the decrease of temperature; the consequence of which is, that the height of the atmosphere must diminish from the equator to the poles.

3. Within the tropics, the temperature is always nearly the same: the range of the barometer is also small, varying from two lines to a quarter of an inch.

4. The range of temperature augments from the equator to the regions of maximum cold: the variation of the barometer augments in a corresponding ratio,-amounting to about three inches in the coldest latitudes.

The range of temperature is much greater in North America than in the same latitudes of Europe, as will appear from the following facts. During the winter of 1831 and 32, the thermometer fell to $-20^{\circ}$ at Florence, in the State of Alabamo, lat. $35^{\circ} \mathrm{N}$. and $-40^{\circ}$ at Plattsburg, lat. $44^{\circ}$, where it sometimes rises to $95^{\circ}$, and even $100^{\circ}$ during summer, making its extreme annual range from $130^{\circ}$ to $140^{\circ} \mathrm{F}$.* The diurnal variation

* It is however but seldom, that the temperature falls below $0^{\circ}$ in the States, south of Philadelphia and New York; so that the usual annual range of temperature does not much exceed that of England, which is about $80^{\circ}$, according to Mr. Daniell; 
is also very great, as the thermometer often rises to $90^{\circ}$ in September and October, during the hottest part of the day, and falls below $32^{\circ}$ at night, making the daily range of temperature $60^{\circ} \mathrm{F}$.

Still more extraordinary are the changes from heat to cold in those extensive regions of North America beyond the limits of the United States, which have been explored by Scoresby, Parry, Franklin, Ross, and other British navigators. We are informed by Captain Back; that on the 17 th of January, 1834, the thermometer stood - $70^{\circ}$ F. at 6 A. M. on the Great Slave Lake, lat. $62^{\circ} 46^{\prime}$; but rose to $45^{\circ}$ in the afternoon of the same day,-making a diurnal range of $115^{\circ}$. He also states, that on the preceding day, the temperature rose to $52^{\circ}$; while the long summer days were often oppressively warm. Hence it is, that as we approach the polar regions, we find the winds so irregular and variable, coinciding with

that is, from $11^{\circ}$ to $90^{\circ}$. Hence it is, that the mean range of the barometer is about the same in Great Britain that it is in the middle States of America, as observed by Dr. Dalton forty years ago. Perhaps there is no part of the world where the fluctuations of temperature are more frequent than in England; the reason of which is obvious from its insular and geographical position, being situated about midway between the burning plains of Africa to the south, and the frozen regions of the north ; while on the east and north east it is influenced by Sweden, Poland, Russia, and the cold elevated plains of Tartary; and by the Atlantic ocean on the west; all of which contribute their share successively in forming the climate of Britain. 
the frequent changes in the density of the atmosphere, and consequent fluctuations of the barometer.

5. Corresponding with the foregoing facts, the barometer rises to the greatest height during cold northerly winds in the middle latitudes, and falls during warm southerly winds. That is, a mass of air from the torrid zone is specifically lighter than one from the polar regions, and must cause a proportional fall of the mercurial column, until the equilibrium is restored.

But in addition to the immediate agency of temperature in modifying the specific gravity of the atmosphere, the amount of aqueous vapour diffused through it exerts a material influence. It has been already shewn, that the quantity of vapour in the atmosphere, ceteris paribus, is proportional to temperature, the greater part of which is confined to its lower strata, (within two or three miles of the earth's surface); and that at the temperature of $80^{\circ} \mathrm{F}$., it is capable of containing an amount of vapour equal to the pressure of an inch of mercury, or $\frac{1}{30}$ th of its whole weight. If, then, we take the estimate of Gay Lussac, that the specific gravity of aqueous vapour is less than that of air at the same temperature, in the ratio of six to ten, it is evident, that the specific gravity of the atmosphere must be diminished in proportion to the quantity of vapour diffused through it. Hence it is, that 
warm southerly winds, which have been expanded by heat and saturated with vapour, cause the barometer to fall. It also follows, that as rains are supplied chiefly by warm southerly winds, in the middle and higher latitudes of the northern hemisphere, the sinking of the barometer must be an indication of falling weather: and as it has been shewn, that all violent winds, such as hurricanes, tornados, \&c. are owing to the rapid condensation of aqueous vapour, the falling of the barometer must also forebode tempestuous weather. It is equally evident, that currents of cold air raise the barometer, not only because of their greater specific gravity, but because they condense the steam of warm air. Hence it is, that for two or three days before storms of thunder and lightning, wind and rain, during the prevalence of warm southerly winds, the barometer falls; but rises during cool and serene dry weather.*

* From several passages in Mr. Daniell's work, on the atmosphere, it would seem that he referred the sinking of the barometer to the evolution of caloric from aqueous vapour during its condensation, by which the atmosphere is expanded where it takes place. (See page 126, \&c.) But it has been shown, that within the tropics, where the amount of condensation is greatest, the fluctuation of the barometer is very small; while it is obvious from the foregoing facts and observations, that the barometer is depressed by the accumulation of aqueous vapour in the atmosphere, and elevated by its condensation.

Dr. Dalton ascertained by a series of observations continued for five years at Kendal, in the north of England, that the barometer fell below twenty-nine inches during forty days; only 
6. The range of the barometer is greater during winter than summer in the middle latitudes.

The reason of which is, that the advancement of the sun towards the pole, brings the temperature of the higher latitudes to nearly an equality over forty or fifty parallels, and almost to the same state as within the tropics, as observed by Dr. Dalton : whereas during winter, the warm and rarefied air of the tropical regions is often encountered by widely extended currents of cold dense air from the polar latitudes; the consequence of which is, that the barometer will rise or fall at the same time, over a great extent of

two of which were fair; but that when it stood above its mean monthly height, there was but little rain, and generally fair weather.

$\mathrm{He}$ also found, that the heaviest rains fell when the barometer was about $29 \cdot 47$, and not when at a minimum, as might have been expected, a priori. His explanation of this fact is simple and satisfactory. He observes, that "when the barometer is above the mean high extreme for the season of the year, the air must, relatively speaking, be extremely dry or cold, or both. If extremely dry, it is in a state for absorbing vapour; and if extremely cold, no further degree of cold can be expected, and therefore in neither case can there be any considerable precipitation. On the contrary, when the barometer is very low for the season, the air must relatively be extremely warm, or extremely moist, or both; if extremely warm, it is in a similar state to dry air for imbibing vapour ; and if extremely moist, there must be a degree of cold introduced to precipitate the vapour, which cold, at the same time, raises the barometer. From which it follows, that no very heavy and continued rains can be expected to happen whilst the barometer remains about the lowest extreme." --(Meteorological Essays, p. 143.) 
country, according as the warm and vapoury, or cold and dry currents of air predominate, and will be greatest when the extremes of temperature in the opposing currents are at a maximum.

7. The regular elevations and depressions of the barometer, termed its horary oscillations, follow the daily fuctuations of temperature.

According to the observations of Mr. Daniell, the daily average height of the barometer at London, is $\cdot 010$ inch higher at night than the afternoon,-and .005 inch higher in the morning than at night; it is therefore 015 inch higher in the morning than the afternoon. (Essay on the Climate of London.) The daily variation is still greater in the interior of N. America, lat. $41^{\circ} 25^{\prime}$ at the rocky mountains, where Colonel Long found the mean height of the barometer, in March, 28.713 inches in the morning -28.609 at noon-and 28.630 at night.

From the observations of Captain Sabine, and others, it would seem that the diurnal variation of the barometer is greatest at the equator, where the power of the sun's heat is a maximum, and diminishes on approaching the Polar circles, as shown in the following Table, given by Mr. Daniell:

At St. Thomas, lat. $0 \cdot 24^{\prime}$ the diurnal variation was $\cdot 074$ inch.

Trinidad .. 10.39 .063 do. Jamaica ..17.56 . . . . . . 058 do. Paris, ..48.50 . . . 028 do. 
Finally, all the variations of the barometer are greater at the level of the sea than in high situations, corresponding with the greater fluctuations of temperature of the lower atmosphere.

\section{Dew and Frost.}

After the setting of the sun, the surface of the earth is cooled down by radiation from 12 to $15^{\circ}$ F. below the temperature of the superincumbent atmosphere, when it abstracts caloric from the stratum of transparent aqueous vapour immediately over it, by which it coalesces into dew, or crystallizes into frost, according to the temperature of the surface.

If the atmosphere be full of vapour, there is a large deposition of dew during summer, on perfectly clear nights : but during spring and autumn, instead of heavy dews, we have large white frosts, that are generally followed in two or three days by rain ; of which they are regarded by the people as a sure indication. As a general rule, the quantity of dew is in proportion to the amount of invisible vapour in the air; and to the difference between the temperature of day and night. It is profuse in hot climates, and more abundant on continents than islands, $c a-$ teris paribus: while on the ocean, far from land, there is little or no dew; because the difference between the temperature of day and night at sea is 
only two or three degrees. In the United States of America, the difference is sometimes $60^{\circ} \mathrm{F}$. the consequence of which is copious depositions of dew, resembling the effects of a shower of rain. They are also copious in England, during the prevalence of warm winds from the ocean.

All other things being equal, a greater amount of dew is condensed between midnight and sunrise, than between sun-set and midnight, according to the observations and experiments of Dr. Wells-obviously because the surface of the earth is then colder, from the loss of caloric by radiation. Dew, then, is not condensed and precipitated like rain by the coldness of the atmosphere; but by the coldness of the earth's surface, which is proved by the well known fact that dew and frost are formed on the under surface of planks, \&c. as well as the upper.

It has been long known, that little or no dew is formed under a cloudy canopy; but that it is abundant during clear nights. Dr. Wells referred this circumstance to the obstruction of caloric radiated from the earth's surface by clouds. It is extremely probable, however, from his own statement of facts, that he mistook a mere concomitant for the real cause of the phenomenon. He informs us, that when clouds begin to form during the night, the surface of the earth rises several degrees, and that dew formed during clear intervals, often evaporated again when the sky becomes thickly overcast; 
from which it would appear, that the caloric evolved from aqueous vapour during its condensation into clouds, warms the atmosphere and prevents the surface of the earth from being cooled to the dew point. Admitting that a portion of the caloric radiated from the surface of the earth, is reflected back, instead of being absorbed by clouds, it is insufficient to produce so decided a change of temperature. During clear and serene nights, when no caloric is given out to the atmosphere by the condensation of vapour, the earth is cooled down by radiation, because it receives nothing to compensate for the loss of what is given off; so that the transparent aqueous vapour of the lower strata of the atmosphere, is condensed into dew. There is no dew on windy nights, for the same reason that evaporation is accelerated by wind : or that a renewal of water and agitation promote the solution of salts.

It was before stated, that caloric is radiated more copiously from rough surfaces than from such as are smooth. In accordance with that general fact, we find that dew is formed more copiously on swansdown, wool, cotton, raw silk, flax, tine shavings of wood, \&c. than upon compact pieces of the same materials. It forms more copiously on rough metals than on polished ones ; doubtless because the former present a more extended radiating surface. See Theory of Radiation. Book II. Chap. I. 
Mists and Fogs.

The formation of all fogs is owing to a partial condensation of aqueous vapour, caused by the abstraction of caloric from colder bodies-often by the mixture of air of different temperatures near the earth's surface. For example, during autumn, the temperature of the Mississippi, Ohio, and other great rivers, is nearly the same during night and day; while that of the land is greatly reduced at night by radiation, especially towards morning, when it is at the extreme of reduction. Under such circumstances, the intermixture of the land atmosphere at the temperature of 35 or $40^{\circ} \mathrm{F}$. with that of the water, which is from 50 to $60^{\circ}$, produces a fog or mist. The same effect is produced on the eastern coast of the United States during autumn. The land is cooled down by radiation at night, while the temperature of the ocean and the air over it remains nearly the same. During this state of things, whether the wind blows from the sea or land, a mixture of warm and cold air produces fogs.

Over the banks of Newfoundland, where the warm air from the gulf stream is intermixed with that of the cold water and icebergs of the north, they prevail throughout the year. Nova Scotia is, proverbially, the region of fogs. The dark and thick fogs of England occur during the latter part of autumn and winter,--owing to the 
more rapid cooling of the land by radiation, than of the surrounding ocean.

The frost rime of the Polar seas is produced in the same manner as fogs, but by the agency of a lower temperature.

During summer, mountains are generally covered with fog in the morning, when the weather is serene and clear. Being cooled down at night by radiation below the dew point, they abstract caloric from the transparent aqueous vapour that is always mixed with the atmosphere in greater or less quantity, by which it is condensed into huge volumes of mist or fog, that envelope the mountains with giant folds of majestic drapery ; and which are not redissolved by the solar rays before 9 or 10 o'clock in the morning. The greater quantity of rain and snow which fall on mountains than on plains, is also owing to their greater coldness as before explained.

\section{Indian Summer.}

In all parts of the United States, there is an autumnal period of most delightful weather, which usually commences late in October, and continues with occasional intermissions through the greater part of November-some seasons in the Mississippi valley, until Christmas. It is generally attended with a southerly wind, which, being warm, is filled with transparent aqueous 
vapour. But as the earth becomes gradually cooler on the approach of winter, by radiating more caloric than it receives from the sun, the air over it is also cooled down; the transparent vapour is slightly condensed into a fine hazy mist, that reflects and refracts the solar rays in such a manner as to produce the most rich and softened Justre of the bluish purple and golden air; which continues until there is a change of wind-sometimes, for three weeks in succession. As the Indian summer is generally a dry season, and as the mountains and prairies are frequently on fire during such weather, the hazy appearance of the atmosphere has been attributed by many persons to the vapour of burning substances diffused through the air. But this cause is altogether too limited in its operation to account for the prevalence of Indian summer throughout the greater part of the American continent; and often many hundred miles from burning prairies. The conflagrations that occur during this season are local and transitory; while the gradual cooling down of the earth, during the prevalence of warm southerly breezes, is all sufficient to account for the phenomenon. The same cause produces in England the most dense and gloomy fogs, during the same beautiful season in America. This is readily understood, when we reflect that England is surrounded by the ocean, - that its atmosphere is much nearer 
to the point of saturation by aqueous vapour, than that of a large continent-and, therefore, that the same, or even a less reduction of temperature must occasion denser fogs and darker days in Great Britain and other insular countries of the higher latitudes, than in continental regions.

The Indian summer of the United States is closed by the commencement and predominance of northerly winds, which condense the aqueous vapour that has been borne from the ocean by southern breezes, causing dark cloudy weather, and general rains or snows, according to the latitude and elevation; after which, the reign of winter is established-and the air becomes dry, clear, and cold, except in the neighbourhood of the lakes, or of the ocean, where it partakes of an insular character.

\section{Aurora Borealis.}

Before concluding this general and imperfect survey of the agency of caloric in meteorological phenomena, it may not be improper to notice the leading facts connected with the aurora borealis and australis, or the northern lights, as they are commonly called on this side of the equator.

It has been already shewn, that the atmosphere 
and all gaseous bodies owe their volume and elastic force to the agency of an igneous æther which surrounds their atoms-and that after being greatly accumulated in aqueous vapour, it is given out in the form of lightning on the meeting of warm and cold currents of air. We have also seen, that the great aërial ocean is in a state of perpetual circulation, from the poles to the equator by under currents; and from the equator to the poles by upper currents ; and that the density of the atmosphere increases as we advance from the tropics, to the points of lowest mean temperature: from which it follows, that caloric must be evolved by the tropical atmosphere as it passes from a rarer to a denser state. It is equally certain, that the tropical air must carry with it a considerable proportion of aqueous vapour, that must be condensed into fogs or clouds, rain or snow ; which accounts for a very common attendant of the aurora, viz. a low black cloud, apparently beyond it, and near to the horizon.

M. Hansteen, who has travelled much in the north of Europe and Asia, observes, "that while the auroræ are streaming, the sky becomes opaque or misty." He further states, that " it is a matter of common observation in the arctic regions, confirmed by long experience, that the aurora is usually followed by intense cold, especially after a mild day ;" doubtless, for the same reason, that warm and sultry weather in the 
middle latitudes is rendered cool by a thunder storm; viz. by the mixture of cold with warm air.

M. Hansteen has given a singular explanation of the aurora, which shews how vague and indefinite the views of philosophers still are in regard to the origin and nature of this beautiful meteor. He observes, that " it is probably the result of a struggle of powers put in activity by the variously constituted substances composing the mass of the earth, which we may one day, perhaps. learn to know." He thinks, that "it produces the arctic fogs, by decomposing the aqueous vapour of the polar atmosphere."-(Edin. Phil. Journal, vol. 12.)

It has been asked, why the auroræa are not continually formed, as the atmosphere is constantly flowing from the tropical to the higher latitudes? We might as well be asked, why there is not perpetual thunder and lightning while the atmosphere is moving from the sea over the land, charged with aqueous vapour. The condensations which occur in both cases are local and temporary, and depend on the relative temperatures of different aërial masses. When the upper current of rarefied air from the tropics, charged with vapour, comes in contact with the cold air of the polar regions, it gives out a large portion of caloric or electric matter, where, not being compressed as in the lower atmosphere, it 
expands like the electric spark in an exhausted glass tube, into broad bands, or zones and columns; filling the sky with halos and crowns of lambent light, or undulating corruscations. It is highly probable, that the aurora is given off, during the condensation of the upper equatorial currents with the vapours which they contain, in a mode similar to the evolution of silent lightning on a summer's evening, which is generally many miles off, and is seen through numerous strata of atmospheric air, producing a diffused or lambent phosphorescence, that resembles the aurora much more than it does lightning which is near at hand.

Sometimes the whole northern hemisphere presents that kind of luminosity which announces the dawn of morning in the east. At other times the auroræ seem stationary during changes of temperature from heat to cold. They often present the appearance of a bank of light, (resembling the effect of a distant conflagration,) resting on, or flanked by a low dark cloud, which is occasionally illuminated by broad flashes. Captain Bonnycastle, of Toronto, in Upper Canada, observes, that during the formation of all remarkable auroræ, dark volumes of vapour suddenly appeared within the space comprehended by the arch.-(Silliman's Journal, vol. xxx. p. 132.) Sometimes, though rarely, the aurora presents the appearance of a wide arch extending 
across the firmament, which breaks up into columns or streamers that extend towards the zenith.

Various conjectures have been offered in regard to the height at which the auroræ are formed,-nearly all of which have been founded on imaginary data. For example, some philosophers have supposed that they must be formed at a great elevation, because they have been seen at the same time in very distant countries, as England and America. But it would be quite as reasonable to conclude, that ordinary lightning is given off at a great elevation, because it lightened at the same time in England and America. There is no rational ground for supposing, that the auroræ are formed above our atmosphere; and probably never beyond a few miles, - while there is every reason to believe, that they may be formed in hundreds of places over different parts of the earth at the same time.

It was the opinion of Franklin, Parry, Ross, Hood, and Dr. Richardson, that the auroræ of the arctic regions were frequently not higher than ordinary clouds-and Dr. Richardson thinks that they are always attended with the formation of clouds, or of that kind of haziness which causes a halo around the moon-a very important fact, which would seem to establish their connexion with the condensation of aqueous vapour, as suggested by Dr. Franklin. 


\section{They are most probably in the upper regions} of the atmosphere, what thunder storms are near to the surface of the earth.* The aurorre are seldom, if ever, seen between the tropics, because the upper atmosphere is not condensed there, being of uniform temperature. Even near

* Most of the appearances presented by the auroræ have been imitated by artificial means. Dr. Priestley inserted with cement, into the top of a tall receiver, a wire not very acutely pointed. He then exhausted the receiver, and presented the knob of the wire to the conductor, when every spark passed through the vacuum in a broad stream of light, which often divides into a variety of beautiful rivulets, that are continually changing their course, uniting and dividing again in the most pleasing manner : thus representing in miniature what has been called the streamers of the aurora. When the wire is electrified minus, or negatively, instead of streams of fire, there is a uniform luminous appearance like a white cloud, or like the milky way in a star light night, which remains for a considerable time, representing the apparently stationary and diffused light of the aurora. (Priestley's History of Electricity, p. 524.)

We can assign no limits to the various phenomena which the electric fluid may exhibit under different circumstances. The medium in which it is formed, in the upper regions of the atmosphere, is doubtless greatly rarefied; perhaps equal to that of a receiver which has been rarefied 100 times. It would seem, however, that the aurora sometimes reaches the surface of the earth. It is related by Bergman, that persons travelling over the high mountains of Norway, have been enveloped in it; and Captain Ross states, that he has witnessed it very near to the surface of the earth ; and that it has caused the deflection of his compass needle as much as thirty and forty degrees. M. Hansteen also found that when the auroræ were vivid, the horizontal needle was restless, quivered, and varied from three to five degrees from its ordinary place. 
the earth's surface, there is comparatively little lightning where the temperature is uniform, as over the tropical ocean, and where the wind blows uniformly in the same direction.

It is highly probable, that the electric fluid is nearly all given out, before the upper current reaches the centre of maximum cold; which explains why the aurora is less brilliant at Melville Island, than at Bear Lake, the Shetlands, Orkneys, and many other places in lower latitudes. It also explains why in the coldest regions, as at Port Bowen, Winter Island, \&c. the magnetic needle is less often disturbed by it than in lower latitudes; and why in the former places, it was almost always seen by the British navigators southward of them.*

Another important fact, that shows the intimate connexion between the auroræ and the change of temperature which the equatorial air undergoes, is, that the northern lights are more numerous and brilliant during the coldness of winter, when the upper currents from the tropics, in their passage to the Polar regions are greatly condensed; and that they are then

* It is stated by Captain Scoresby, that the aurora was discovered more frequently south than north of Spitzbergen-and by Sir Edward Parry, that it was generally seen south of Melville Island-from which we may conclude, that the upper current of the atmosphere has acquired nearly its maximum density, and deposited nearly all its vapour, before arriving at the limits of greatest cold. 
formed in much lower latitudes than during summer.

It is also an important corroboration of this theory, that they are seen in lower latitudes in the middle and eastern portions of America and Europe, than on their western coasts; while the former are known to be much colder than the latter in the same latitudes; which is owing to the prevalence of west winds, that blow from the Pacific and Atlantic oceans, and thus temper the middle latitudes of western coasts, by giving them an oceanic or insular climate.*

The northern lights are seen much oftener in Vermont, which is a cold mountainous state, between latitude 42 and $44^{\circ} \mathrm{N}$. than in France or England; though they are much farther north. This is evidently owing to the excessive

* The effect is increased by the condensation of aqueous vapour which is brought from the ocean by westerly winds, and which gives out caloric during its condensation and precipitation on the western coasts. Hence, the greater amount of rain which falls on the western coasts of N. America and Europe, than on the interior and eastern portions. Hence also, the dryness of west winds in the United States, east of the rocky mountains, which deposit their vapour on the western slope, before reaching the interior. In the great Mississippi valley, the east wind is dry, while in the Atlantic States it is often moist during winter and spring. On moving westward, it deposits most of its vapour on the eastern slope of the Alleghany mountains. These facts enable us to understand why in the vast regions drained by the Mississippi, west winds are dry; while in Britain and France they are wet, and east winds dry. 
coldness of winter in Vermont. General Martin Field has recorded, in the American Journal of Science, that, during the year 1830-31, the winter of .which was excessively rigorous, the aurora was perceived on fifty-six nights; and that during ten years previously, it was observed eighteen nights on an average, annually, at Fayetteville in the above State. Besides which, it must have existed during many cloudy nights, when it was invisible.

The arched appearance of the aurora is an optical illusion, produced by the limits of vision, according to the laws of perspective; for the same reason that the sky presents a vaulted appearance - or, that clouds present the appearance of a canopy, while in reality they are suspended in horizontal strata. The different apparent heights of the auroræ are owing to their various distances from the points of observation. When the lower atmosphere between the observer and the lights is hazy, they appear irised or rose-coloured; probably for the same reason that the sun rises and sets red, when the lower air is filled with vapours.

Siberia, Lapland, and the Norwegian Alps, are distinguished by the frequent display of this beautiful and mysterious phenomenon, which I have thus endeavoured to explain in accordance with the best established principles of Meteorology. After all, it is quite probable, 
that some very important facts have been overlooked, which, if known and rightly considered, might place the whole subject in a new light. It is to be hoped, that fifty years hence, we shall have fifty accurate observers of natural phenomena for one at the present time.

Very little is known of the auroræ in the southern hemisphere, except what has been observed by Captains Cook and Weddel, who relate that they have been frequently seen south of Van Dieman's Land, and off Cape Horn, where the cold is excessive.*

* From a general view of the foregoing chapters, it must be obvious :

1. That all the phenomena of evaporation and rain, lightning and winds, hurricanes and tornados, fluctuations of the barometer, and formation of the auroræ, are immediately connected with the theory of caloric, and those fundamental laws which govern its distribution over our planet:

2. That the aurora is a thermo-electric phenomenon, produced during the condensation of vapour contained in the equatorial upper current of the atmosphere, on its passage to the polar latitudes, in a mode analogous to the evolution of lightning from the more elastic vapour of the lower and denser atmosphere, on mixing with colder currents, as during thunder storms.

In opposition to this theory, it is maintained by Dr. Faraday and others, that " the electric equilibrium of the atmosphere is preserved by the aurora conveying electricity from the poles to the equator." Can it be possible that the vast amount of lightning perpetually disengaged within the tropics, and during summer in the middle latitudes, is thus obtained? With sentiments of unaffected and profound humility, the preceding facts are offered as an answer to this query. 


\section{CHAPTER IV}

\section{Galvanic Electricity.}

The first discovery connected with this branch of physical science is found in a German work, published in 1767, by Sultzer, entitled The General Theory of Pleasures. He observed, that if two metals be applied, one above, and the other below the tongue, and brought in contact, a peculiar taste was perceived, attended with a gentle flash of light; but that if applied separately, no such effects were produced.

It was next discovered accidentally by Galvani, a distinguished professor of anatomy at Bologna, that on touching the crural nerve of a recently killed frog, which lay on a table, near the conductor of an electrical machine in action, with the point of a scalpel, all its muscles were thrown into convulsions, as if seized with tetanus. By repeating the experiment on different animals, he found that the effect was most remarkable in those which are cold blooded, and have white muscles. He ascertained afterwards, that when the nerves and muscles of such animals were armed with small pieces of 
different metals, similar phenomena were produced on bringing the metals in contact.

From these obscure results, Galvani arrived at the conclusion, that there is a peculiar species of electricity residing in all animals,-which is secreted by the brain, and conducted to different. parts of the body by the nerves, causing animal motion, secretion, \&c. He supposed that this fluid is conducted from nerves to muscles by the metallic arc, as the electricity of a Leyden battery is conducted from it by means of a common discharger.

In opposition to the views of Galvani, it was maintained by the celebrated Volta, professor of natural philosophy at Pavia, that the phenomena were due to the agency of common electricity, which he supposed was accumulated by the contact of different metals.

Finding that when sticks of zinc and copper, zinc and silver, \&c. were made to touch at one of their extremities, and the other brought in contact with the spine and muscles of a newly killed frog, excited convulsions, it occurred to Volta, that by a repetition of circles, or series, composed of two different metals and moistened cloth, he might greatly increase the electrical effects. This led to the construction of the well known pile, and the couronne de tasses, which have been modified into different forms of the battery. In reply to the hypothesis of Volta, 
that the convulsions of the frog were owing to the agency of common electricity, and generated by the contact of different metals, Galvani objected that he had succeeded in producing convulsions by means of a single metal. And it was further shown by Aldini, a nephew of Galvani, that by bringing a portion of a warm blooded animal in contact with a cold blooded one, as the nerve and muscles of a frog with the bloody flesh of a newly decapitated ox, energetic contractions were produced. When he held a prepared frog in his hand, moistened with a solution of salt, and applied the crural nerves of the animal to the tip of his tongue, convulsions were also excited*-from which he inferred, with Galvani, that there is a peculiar electricity in animal bodies which does not require the contact of metals for its developement. It is somewhat surprising that he was never led to suspect, from these curious experiments, the identity of animal heat with the cause of muscular contraction-and still more remarkable, that neither Galvani nor Volta ever suspected the connexion of the phenomena with chemical action.

The agency of caloric in exciting convulsions

* The experiments were successfully repeated before a Committee of the National Institute of France, and afterwards at the Anatomical Theatre in London, Great Windmill Street. 
in recently killed fish, was strikingly demonstrated by some experiments of Mr. Clift, who found, that four hours after the head of a carp had been cut off, and its heart taken out, (the fish being considered as perfectly dead,) when put in hot water, it leaped out of the vessel with a degree of vigour equal to the struggles of a living fish. (Phil. Transactions for 1815.)

A similar fact was observed by Lord Bacon, who relates that he saw, with his own eyes, the heart of a criminal taken out of his body some time after execution, and thrown into the fire, when it leaped up several times to a considerable height. Without commenting on these facts, which belong to another portion of the present work, it may be observed that they demonstrate the agency of heat in animal motion, at least as clearly as that of electricity,--even admitting (what has never been proved,) that electricity could exist independent of caloric.

The first philosopher who referred the phenomena observed by Sultzer, Galvani, and Volta, to chemical action, was Fabroni, in a paper communicated to the Academy of Florence, in 1792. He had often observed that fluid mercury retained its lustre for a long time when alone; but that when amalgamated with other metals, it speedily tarnished by oxidation; and that similar effects were produced on some alloys of tin. He had remarked in the Museum of 
Cortona, inscriptions engraved on plates of pure lead in a perfect state of preservation; while in the Gallery of Florence, he found that medals composed of lead and tin, or lead and some other metal, were entirely reduced to a white powder, though carefully wrapped up in paper, and preserved from the atmosphere in drawers. He had further noticed, when in England, that the iron nails then employed in fastening together the copper sheathing of ships, caused so much corrosion of the copper, that the holes made by them were sometimes larger than the heads of the nails-all of which he referred to chemical action produced by the mutual contact of different metals exposed to moisture, atmospheric air, \&c. That this was the case in the experiment of Sultzer, he thought was proved by the fact, that when the tongue was wiped dry, scarcely any perceptible sensation was excited.

In another set of experiments, Fabroni put different metals in vessels filled with water, two and two, in contact, when he found that the most oxidable metal was visibly oxidized at the moment of contact. A month afterwards, the connected metals had acquired so strong a degree of cohesion as to require a considerable force to separate them. Not only were the metals oxidized, but covered over with small crystals of various forms, which had been deposited from a state of solution. (Traité de 
l'Electricité et du Magnétisme, par M. Becquerel, vol. i. p. 88.)

The above passages are sufficient to show that Fabroni clearly recognized the necessity of chemical action in all galvanic phenomena, and that his views were much more accurate than those of his contemporaries. Still it must be acknowledged, that he never explained why two metals in contact oxidize more rapidly than when isolated-and that no satisfactory account has yet been given of the primary source of galvanic action by his successors - the consequence of which is, that the theory of the pile, like that of universal chemistry, is still involved in profound obscurity.

This much, however, is certain, that all the different elements of ponderable matter have various degrees of attraction for caloric; and that during all chemical combinations, there is a transition of caloric from one to the other.

When treating of freezing mixtures, it was shown that when chloride of sodium, chloride of lime, potass, and many other salts are brought in contact with ice, there is a rapid abstraction of caloric from the ice to the salts, by which both are dissolved and chemically united-that when lead, tin, and bismuth are brought in contact, they dissolve at a much lower temperature than when isolated, and thus unite chemically into an alloy. For the same reason, 
many other metals, rocks, and gems are rendered more fusible, and combine more readily with each other by the addition of what has been termed a flux. Clay is more fusible when mixed with fluor spar, and quartz with lime, than when separately exposed to the action of heat.

Whatever may be the true explanation of these phenomena, it is evident that caloric is essential to oxidation, solution, and to all chemical combinations, whether of gases and liquids with each other, and with solids; or of solids with each other. It therefore follows, that if chemical action be indispensable to the disengagement of galvanic electricity, caloric must be the primary source of all the resulting phenomena. Passing over the long and idle controversy between the partisans of Volta, (who maintained that galvanic electricity results from the contact of different bodies; and those of Fabroni, who contend that it is wholly the result of chemical action,) it may be sufficient to state, that the combined researches of nearly all the most distinguished philosophers of modern times demonstrate, that there can be no galvanic action without chemical decomposition.

For a long time it was supposed by Sir $\mathbf{H}$. Davy that contact was necessary to its commencement, and that it was kept up by chemical action. But from the experiments of Wollaston, Gautheraut, Delarive, Avogadro, Parrot, 
Becquerel, and Faraday, the question may now be regarded as decided. Davy himself observes in the Bakerian Lecture, read before the Royal Society on the 8th of June 1826, that there is no instance of electro-motion, (by which he meant galvanic action,) without chemical decomposition. He also states, that when oxidizing liquids are employed in maintaining the action of the battery, the more oxidable metal always afforded positive electricity in relation to a less oxidable one-that potassium, which is the most oxidable of all the metals, is positive in relation to all others; and so of its amalgams - that barium and its amalgams are positive in relation to an amalgam of zinc, which is positive in relation to pure zinc, zinc to cadmium, the latter to tin, tin to iron, and iron to bismuth.

Corresponding with the above results are those of Delarive, who found that the direction of a galvanic current is not determined by metallic contact, nor by the nature of the metals relatively to each other, but by their chemical relation to the exciting liquid - that of two metals composing a voltaic circle, the one which is most energetically attacked is positive with respect to the other. Thus, when tin and copper are placed in acid solutions, the former, which is most actively corroded, gives a positive current through the liquid to the copper: but if put into a solution of ammonia, which acts most on the 
copper, the direction of the current is reversed. Copper is positive in relation to lead in nitric acid, which oxidizes the former most rapidly; whereas, in dilute nitric acid, by which the lead is most speedily dissolved, the lead is positive. He found that even two plates of copper, when immersed in solutions of the same acid, but of different strength, form a voltaic circle, the plate on which chemical action is most energetic, giving a current of positive electricity to the other-and that a compound circle might be formed solely of zinc plates and one acid, provided the same side of each plate be more rapidly oxidized than the other.

The following experiments are decisive against the theory of Volta. M. Delarive ascertained that when zinc and copper plates were brought in contact in an atmosphere of hydrogen or nitrogen, wholly deprived of oxygen, moisture, and other bodies, no electricity was evolved; and when he purposely increased chemical action by exposing the zinc to acid fumes, or by substituting for zinc a more oxidable metal, such as potassium, the electrical effects observed, on contact with copper, were greatly augmented, the amount being in proportion to the chemical action. (Ann. de Chim. et de Phys. XXXVIII. et IX.)

The above facts have an important bearing on the general theory of electricity; for they seem 
to prove that what are termed positive and negative electricity, are only plus and minus conditions of one and the same rthereal element : consequently, that the oxygen, chlorine, fluorine, iodine, and bromine of acids, salts, \&c. are attracted by the minus or negative pole of the battery; and hydrogen, metals, and alkalies to the positive pole, because in their natural state, these two classes of bodies are combined with different proportions of thermo-electric æther. But as I have before shewn, (p. 204 and 5,) that bodies are neither essentially positive nor negative, but vary according to circumstances, and that those which belong to the electro-positive class, unite with each other, as well as with those that belong to the opposite class, it is evident that chemical attraction is not wholly the result of electric polarity, as maintained by Davy.

It has been often said, that the energy of the voltaic battery is in proportion to the conducting power of the liquid that acts on the plates. The absurdity of this hypothesis will appear in a striking point of view, when it is remembered, that of all liquids mercury is the best conductor, -yet when employed between the plates of a battery, no electricity whatever is disengaged. The simple matter of fact is, that the quantity of electricity evolved is proportional to the rapidity with which the intervening liquid is decom- 
posed by the metallic plates; and that when the chemical action ceases, the disengagement of electricity also ceases.*

* From the experiments of Ritter, Davy, and others, it would appear that two different metals are not requisite to the disengagement of the galvanic fluid, but to its concentration. Sir Humphrey Davy formed galvanic series of a single plate of zinc, one side of which was exposed to an acid, and the other side to water-also by a single metal acted upon one side by an acid, and on the other side by hydro-sulphurets. (Philosophical Transactions for 1821.)

It has been further shewn by M. Becquerel, that electricity is evolved whenever metals are immersed in acid solutions that act chemically on them. The same effect was produced during the combination of acids and alkalies, - when nitrate of iron acts on leaves of platinum foil; or nitro-muriatic acid upon gold; and even on mixing a concentrated acid solution with a diluted solution of the same acid. (Ann. de Chem. et de Phys. xxxv. 120.)

From such experiments it bas been inferred, that electricity is disengaged during all chemical actions. But it is certain that all chemical combinations and decompositions are attended with changes of temperature - that is, by the absorption or evolution of caloric. The disengagement of electricity during the action of the strong acids on metals, alkalies, \&c. has been deduced from the fact, that when the two ends of a multiplying wire are made to communicate with the combining bodies, the magnetic needle is deflected, as it is during the passage of a current of voltaic electricity through it. But the same effect is produccd when one end of the multiplying wire is made to communicate with melted silver, and the other end with a portion of the same metal in the solid state; or when the two extremities of the multiplier are made to communicate with different parts of other metals when of different temperatures-from which it would appear that the magnetic phenomena are independent of chemical action, and result from the transition of caloric through the multiplying wire, as will be proved further on. 


\section{Theory of Galvanic, or Voltaic Electricity.}

ON the first introduction of the Voltaic pile into Paris, Napoleon was so strongly impressed with its importance, that he offered $60,000 \mathrm{fr}$. to the individual, of whatever nation, who should make a decided advancement in the knowledge of its theory, as Franklin did in common electricity. Had this extraordinary man devoted himself to the task, it is probable that he would have gained the prize. He proposed several interesting points of inquiry in regard to the theory of its action. He wished that experiments should be made on the pile at very different temperatures, for the purpose of ascertaining whether caloric created any remarkable difference in its power of producing electricity. On witnessing the transport of the elements of salts to its respective poles, he is represented to have said to his physician Corvisart, "Docteur, voilà l'image de la vie." (Traité de l'Electr. et du Magnétisme, vol. i. p. 108, par M. Becquerel.)

It sometimes happens, that new discoveries retard the general progress of science for a time, by withdrawing the attention of philosophers from a general and comprehensive survey of nature, to that of some obscure and petty province.

The brilliant discoveries of Galvani, Volta 
and Davy, directed the inquiries of men to the chemical and physiological properties of electricity, to the neglect of the still more obvious agency of caloric. Had philosophers studied the cause of solution, combustion, fermentation, and ordinary decomposition, with half the attention bestowed on Electro-Chemistry, they would have discovered that caloric is indispensable to the chemical union of oxygen with combustibles; of salts with water; metals with acids, and with each other; in short, that without caloric, there is no chemical attraction.

This would have led them to investigate the relations of caloric and electricity, one of the most important problems in physics, from its intimate relation to the whole constitution of nature. If they be only modifications of one and the same universal element, we cannot expect fully to comprehend the most simple phenomena of attraction and repulsion, without understanding its general laws.

When treating of chemical solution, it was demonstrated that metals are dissolved by the caloric of the strong acids, and combined chemically with them, as certainly, as that salts are dissolved by the caloric of water, and thus chemically combined with it.

If then there be not two causes of chemical attraction, it is evident, that the same agent 
which causes sulphuric acid to combine with copper, making a transparent solution of copper, causes the same acid to combine with the plates of the voltaic battery, by which they are oxidized and dissolved, when a portion of the latent caloric of the acid is given out in the concentrated form of electricity, conducted from the plates by the connecting wires, and thence to the extremities of the battery.

I have already shown that sulphuric acid is composed of oxygen, sulphur and caloric-that nitric acid is composed of oxygen, nitrogen and caloric-and so of other compounds. When solutions of nitric, sulphuric, or hydro-chloric acids are poured upon metals, there is a rapid transition of caloric from the acids to the metals, by which they are made to combine chemically, with great diminution of volume, and evolution of heat. When they are poured on copper and zinc filings, they are decomposed, and the metals oxidized still more rapidly. But when the same metals are arranged in the form of a galvanic battery, and immersed in the same solutions, electricity is evolved : from which it would seem to follow, that the latent caloric of acids is given out in the form of calorific or electric power, according to the mode of its disengagement.

Another fact of fundamental importance to a 
right understanding of the nature of voltaic electricity, and its relation to caloric is, that its character is modified by the size and number of plates composing the battery. For example, when it is composed of a few large plates of zinc and copper, an imponderable fluid is evolved, possessing all the properties of highly concentrated caloric,-which fuses and ignites the hardest gems and densest metals submitted to its action; while it is destitute of nearly all the properties by which common electricity is characterized. The largest battery of this description ever constructed, was that of Mr. Children, which was composed of twenty plates of zinc and copper, six feet long, and thirty-two inches broad. When immersed in a strong acid solution, it melted, ignited, and fused a large platinum wire, six feet in length; but communicated little or no shock to the system; would not charge a Leyden jar; produced no sensible effect on the electrometer; and, unlike common electricity, was conducted slowly by metals, minerals, fluids, \&c.*

When the battery is composed of two extensive coils of zinc and copper; or of many plates,

* The large battery of the Royal Institution, employed by Sir H. Davy, which consisted of 2000 pairs of 4 inch plates, melted platinum, quartz, the sapphire, magnesia, and lime, like wax, both in vacuo and in the atmosphere; while charcoal, plumbago, and the diamond were rapidly dissipated in the form of vapour.

c C 
so arranged as to constitute only a single pair of zinc and copper plates of enormous dimensions, as in Dr. Hare's calorimotors, the calorific effects are still more remarkable.

On the other hand, when the battery is composed of a large number of metallic plates of small size, and immersed in the same solutions, electricity is evolved, which affects the electrometer, communicates a shock, and passes through conductors with a speed approaching that of lightning.*

These striking facts led Dr. Hare to suppose that both caloric and electricity are developed during all galvanic operations; and that they

- When the battery is composed of a few large plates, and immersed in an acid solution, caloric is evolved until the acid is decomposed, or until the metallic plates are consumed. But if the battery be composed of a large number of small plates of the same metals, and immersed in the same acid, electricity is produced, until the plates or acid are consumed by oxidation; which demonstrates the identity of caloric and electricity beyond the possibility of a doubt; for it would be a perversion of common sense to suppose, that by merely changing the size and number of the plates, a radically different fluid could be evolved, while the metals, and solutions in which they are immersed, are the same. Shall I be asked for clearer proofs that the latent caloric of acids is the basis of electricity? We might as well be asked to prove that the sun is the fountain of light and heat; or that rain accompanies lightning.

It is generally known that the most powerful batteries are composed of bodies which act with the greatest energy upon each other, such as zinc, copper, and nitric acid; and that such as undergo no chemical changes exhibit no electrical effects, such as gold, silver, and water. 
are combined with each other by what he calls "the reciprocal attraction of imponderables." He supposed that when two or more large plates were employed, caloric predominated; but that when a large number of small plates were used, electricity predominated. One thing is certain, that the character of the galvanic fluid is modified by every variation in the size and number of the plates composing the battery. But if we suppose that caloric is combined with galvanic electricity, because it fuses and ignites metals, or other bodies, we shall be forced to admit that it is also a constituent portion of common electricity, for it fuses and ignites bodies like voltaic electricity. He further supposes, that " electricity fuses and ignites metals, \&c. by combining with their latent caloric; thus augmenting its repulsive agency, and causing it to overcome their cohesion." But he omits the important fact, that electricity also increases their temperature, and that its former properties are changed and merged into those of caloric, as it fuses and ignites bodies.

The unavoidable conclusion from the above facts is, that caloric and electricity are only different forms of the same elementary agent, varied by the numerous modes of its separation from ponderable matter: or, that there are two distinct and universal agents combined with ponderable matter, and with each other, "by the 
reciprocal attraction of imponderables," as maintained by Dr. Hare. It need scarcely be observed, that there has never been the slightest evidence adduced that such an attraction exists between caloric and electricity, admitting them to be distinct fluids; while it is contrary to the simplicity which characterizes all the operations of nature to suppose the existence of two universal agents, endowed with the same fundamental properties. There cannot be two universal principles of action in nature; because if they were different they would interfere with each other, and produce discord-and if they were alike they would produce like results, which amounts to the same thing as if they were radically identical.* If every apparent difference between caloric and electricity be taken as an argument against their identity, it would be easy to prove that there are more than one hundred electricities. There is a far greater difference between the voltaic fluid disengaged by Children's battery, and that from a common electrical machine, than between the former and the caloric evolved by ordinary combustionwhile the deflagration of steel wires in oxygen

* Sir Isaac Newton thought it " inconceivable that two cethers could be diffused through all nature, one of which acts upon the other, and by consequence is reacted upon, without retarding, shattering, dispersing, and confounding one another's motion."(Optics, p. 339.) 
gas, and the detonation of gunpowder, are more like an electric explosion than any thing else.

The ordinary process of combustion by which heat is evolved; consists in the combination of oxygen with other elements. The galvanic fluid is decomposed by the same process: while it would be contrary to all the rules of a sound induction, to suppose that two or more distinct ethereal agents could be disengaged from the same elements. If we reject this simple mode of reasoning, we shall be compelled to admit the existence of as many electricities as there are modes of separating it from ponderable matter, which would be absurd. It is far more consistent with facts and the harmonious simplicity of nature to suppose that one agent produces all the diversified powers and activities of matter-that it exhibits different properties and appearances under different circumstances, according to its diffusion, concentration, compression, \&c.- and to the mode of its combination with different substances, in a solid, liquid gaseous, or imponderable state, as in the matter of light.

We have already seen, that a certain temperature is indispensable to combustion, fermentation, putrefaction, and to every process of oxidation, however slow, as the rusting of metals, that when atmospheric oxygen is thus made to combine with metals, its volume is dimi- 
nished, and a portion of its latent caloric liberated, in the form of radiant matter, by which the process of oxidation is kept up. I have also proved, that when metals are exposed to the action of strong acids, there is a transition of caloric from the acids to the metals, by which the latter are dissolved and chemically combined with the menstruum; that caloric is the cause of all attraction between fluids and solids; that the solvent power of water, acids, \&c. is greatly augmented by heat; and that when metals are dissolved in the strong acids, caloric is given out in great abundance, as in ordinary combustion. So nearly does the operation of a voltaic battery resemble combustion, that more or less heat is always disengaged by its action. When the acid solution is strong, and chemical action energetic, the whole apparatus becomes warm; viz. a portion of the latent caloric of the acid is conducted from the plates to the connecting wire in the form of electricity; while another portion is liberated in the diffused form of sensible heat, as when water and acids are poured upon burnt lime.

That the caloric of liquids is the cause of their chemical action on the plates of the battery, is proved by the fact, that when the apparatus is supplied with hot solutions of the strong acids, its energy is greatly augmented, and the metallic plates rapidly dissolved; in other words, the battery is very soon burnt out. 
It is stated by Singer, Donné, and others, that the energy of De Luc and Zamboni's columns* is greatly augmented by an elevated temperature, and diminished by a reduction of temperature; that they are more active during summer than winter; and in a warm than a cold room. Dr. Jaegar found, that after the dry pile had lost its energy, it was restored by a temperature of from 104 to $140^{\circ} \mathrm{F}$. That the energy of this pile is owing to chemical action, like every other form of the battery, is proved by the oxidation which it undergoes, and by the total loss of its power when perfectly dry.

When isolated plates of zinc and copper are immersed in dilute nitric acid, they are oxidized and dissolved, when caloric is liberated as during combustion; but when they are connected by means of a metallic wire, galvanic electricity is evolved. There can scarcely be a doubt that if the caloric evolved by ordinary combustion could be concentrated and conducted off like the galvanic fluid, it would exhibit electrical phenomena. Pouillet has actually shown that electricity is disengaged during nearly all combustions, though in a slight degree, as had been

* The first is formed of disks of writing paper, interposed between thin leaves of zinc and silver; while that of Zamboni was composed of paper disks gilt or silvered on one side, and the other side covered with a layer of black oxide of manganese mixed with honey. 
proved long ago by Lavoisier and Laplace, De Saussure, and by Mr. Read. Were it not for the caloric contained in nitric acid, it would not dissolve zinc and copper filings. For the same reason, it would not combine with the plates of the battery; nor would it enter into chemical combination with any other substances. The battery owes all its energy to chemical action, as certainly as that combustion is a chemical action. Can common sense admit that caloric causes atmospheric oxygen to combine with combustibles, and that some other agent causes the oxygen of acids to combine with the plates of a voltaic battery? The supposition is wholly unphilosophical, and is contradicted by all the analogies of nature. Combustion is a chemical process to all intents and purposes, and is produced by the same agent which causes all other chemical actions. Another important general fact, showing the intimate relation between combustion and galvanic action, is, that the action of the pile, like that of combustion, is far more energetic in oxygen gas than in atmospheric air; and ceases in vacuo, in nitrogen, and other gases that do not act chemically on it.

If we compare the effects of galvanic electricity with those of caloric evolved by ordinary combustion, we find that they are the same. When voltaic electricity fuses, ignites, and volatilizes, metals, gems, and all other combustibles, 
does it not produce the same effect as that of an oxy-hydrogen blow pipe? or the concentrated heat of a forge? and if it produce the same effects, must it not be the same agent? Can electricity render bodies hot, and yet not be an igneous fluid? When charcoal is submitted to the action of a galvanic current under water, it is ignited, and decomposes the water as when heated by ordinary combustion : and if an iron wire, connecting the extremities of a battery in action, be made to pass through water, it becomes hot and boils. When the wire is thus heated, it attracts oxygen from water, as when rendered red hot by other means. Like caloric, electricity causes oxygen and hydrogen to combine to form water, and again causes its decomposition.

If then it be an established axiom in philosophy, that the same effects should be ascribed to the same cause, caloric and electricity must be essentially the same agent.

The recent experiments of Dr. Faraday have furnished many important facts, which show the intimate relation between combustion and the evolution of electricity by galvanic action.

It is very well known, that oxygen is not indispensable to combustion; that during the rapid combination of chlorine, fluorine, iodine, \&c. with carbon, hydrogen, sulphur, phosphorus, and the metals, caloric is evolved in the 
form of radiant heat, as in ordinary combustion ; in short, that caloric is evolved during nearly all rapid chemical combinations. By following up the experiments of Sir H. Davy, Dr. Faraday has shown, that when chlorides, iodides, fluorides, oxides, cyanides, nitrate of potass, chlorate of potass, sulphate of soda, and various other compounds were fused by heat, and interposed between the plates of copper and platinum of a voltaic battery, electricity was evolved as when acids were employed; and in some cases much more freely. He adds, "there are hundreds of bodies which evolve electricity in the same manner, when in a state of fusion; but that when they became solid, the decomposition and the electric currents ceased." He thinks that solidification prevents decomposition, \&c. " merely by chaining the particles to their places, under the influence of aggregation." (Experimental Researches in Electricity, 4th Series.) Had this distinguished experimenter recognized the agent by which particles are aggregated and chained together, he would have found that it is the alpha and omega of chemical action, without which there could be no voltaic electricity,-and that it is the source of all electro-chemical combinations and decompositions.

But there are certain minute philosophers, who maintain that the sliglutest difference between any two agents destroys their identity. 
If such objections to the unity of caloric and electricity were well founded, we should be compelled to admit the existence of more than a hundred species of electricity; for it differs with every modification of the process by which it is produced, from thermo-electricity of the lowest tension, to that of the Leyden battery, which darts through metals and the living body with the speed of lightning.

It is known, that the different forms of voltaic electricity pass with different degrees of velocity through the same conductors; and that in this respect there is an almost infinite variety in the properties which it presents. Yet these differences have not prevented Wollaston, Faraday, and many of the most distinguished philosophers of the continent, from maintaining the identity of electricity under every variety of form and appearance which it exhibits, from that of Children's battery, to De Luc and Zamboni's pile -and from a flash of lightning to the magnetic spark, or the shock of a torpedo. Surely there is a far greater difference between the electricity developed by a common machine and Children's battery, than between the latter and solar heat concentrated by means of a large burning glass. It was shown by Mr. Parker of Fleet street, that the most intense heat of a burning glass three feet in diameter, though sufficient to fuse and volatilize gems and metals in a few 
seconds, passed through water without heating it like electricity -and that when it was made to strike upon the finger, it produced little or no sensation of heat, but that of a sharp cutting instrument.

\section{Analogies between Voltaic Action, and Subter- ranean. Chemical Forces.}

From a general view of the foregoing facts and observations, it would appear, that the galvanic or voltaic pile affords a miniature representation of nearly all the chemical changes perpetually going on throughout nature; while it exhibits the relations of caloric and electricity in all their multiform states, in the most instructive manner. There is also a striking resemblance between the phenomena of galvanic heat and that developed by volcanic agency; not only in the chemical mode of their production, but in the effects they afterwards exhibit. In both cases the radiating power of the igneous rther evolved is exceedingly small, compared with its power of fusing rocks, metals, gems, \&c. while they are both attended with thermotic and electrical phenomena. A large voltaic battery, capable of producing a current sufficiently powerful to fuse and ignite the most obdurate bodies, excites no sensation of warmth beyond 
the apparatus. It is stated by M. Pouillet Scrope, on the authority of Dolomieu, corroborated by his own observations, that very little heat is radiated from a mass of red hot lavathat at the distance of a few feet, the thermometer is scarcely affected by it, which induced Dolomieu to suppose that its fluidity was due to some other cause than caloric. (Scrope on Volcanos, p. 20.)

The reason why incandescent lava does not radiate heat like coal, wood, \&c. when in a state of ignition, is doubtless owing chiefly to the greater attraction of metallic and rocky masses for caloric, than combinations of animal and vegetable matter, as explained under the head of radiation.

It has been long known, that the most intense electrical phenomena are displayed during volcanic eruptions. If it be inquired why persons near to a mass of incandescent lava experience no electric shock, it may be answered, that no shock is received from a voltaic battery of large plates; nor should we be able to discover that any electricity was evolved were it not conducted off by the connecting wires to the extremities of the pile: even then, it exhibits chiefly the phenomena of concentrated caloric, and but slight indications of electricity.

Mr. Scrope has given a highly graphic description of the electrical action that accom- 
panied an eruption of Vesuvius that he witnessed in October, 1822; and which resembled the awful displays of lightning that attended its eruption in 89, when Pompeii and Herculaneum were overwhelmed with lava; and by which his father lost his life. "From every part of the immense cloud of ashes that hung suspended over the mountain, flashes of forked lightning darted continually. They proceeded in greatest number from the edges of the cloud. They did not consist, as in the case of a thunder storm, of a single zigzag streak of light, but a great many corruscations of this kind appeared suddenly darting in every direction, from a central point, forming a group of brilliant rays, resembling the thunder bolts placed by the ancient artists in the liands of the cloud compelling Jove." (Scrope on Volcanos, p. 81.)

It is also related by Sir William Hamilton, that the eruptions of Vesuvius in 1767,79 , and 94, were attended with the most tremendous exhibitions of lightning; and the two latter with extremely loud explosions of thunder. Zigzag lightning darted incessantly from the enormous black clouds that hung over the crater, resembling in all respects that of ordinary thunder storms; and accompanied by heavy showers of rain, with whirlwinds, like those which attend water spouts. Sometimes balls of fire issued from the black cloud, which burst into serpen- 
tine streams of fire. He thought that the violence of the subterranean action might be known from the height to which the vapour and smoke ascended, and by the amount of ferilli, or volcanic lightning. (Philosophical Transactions of the Royal Society, for 1795.)

Dr. Daubeny further relates, on the authority of M. Monticelli, and other persons who witnessed the eruption of Vesuvius in August, 1834, that from a current of lava which overwhelmed one hundred and fifty houses, and covered about five hundred acres of ground, there arose a black cloud, from which emanated very vivid flashes of lightning, sometimes followed by thunder, but not always. (Philosophical Transactions, 1835.) It is also related in the American Journal of Science, that on the 20th of January, 1835, Nicaragua, in central America, was visited by a tremendous earthquake, and followed by an eruption of the volcano of Cosiguina, by which the atmosphere was filled to a great height and distance with phosphoric sand, smoke, and vapour,-from which issued perpetual flashes of lightning throughout the night of the 20th, and the whole of the next day. On the 23rd, towards morning, tremendous loud thunder claps were heard in succession, like the firing of the largest cannon,- - from which it was supposed by the inhabitants at the Port of Balize, on the Bay of Honduras, that a naval action was going 
on ; or that a ship was in distress. It is stated that during this earthquake, the country was convulsed for more than a thousand miles.

It is here worthy of special notice, that nearly all the volcanos of our planet that are situated on dry land, amounting to about two hundred, have been found in the vicinity of the ocean; while it is probable, from the vast number of volcanic islands, that there are at least three times as many beneath the sea.

It is well known to modern geologists, that submarine eruptions are exceedingly frequent. On the 12th of June, 1811, immense volumes of smoke were observed to arise from the sea, near the island of St. Michael, one of the Azores, by Captain Tillard of the Sabrina, from which issued at intervals, for several days, the most vivid flashes of lightning, and sometimes a continual blaze. During these eruptions an island was formed, about a mile in circumference, and two hundred and eighty feet high, which Captain Tillard visited, in company with several of his officers, on the 4 th of July, when he named it Sabrina, after his ship. By the middle of October, it had disappeared, leaving a dangerous shoal.

During an earthquake on the 9 th of July, 1757, eighteen small islands emerged from the sea, near the $\mathbf{N}$. west corner of St. George, another of the Azores; which also disappeared in a few months. 
The destruction of the town of Conception in Chili, by an immense wave of the sea, twentyeight feet in height, which rolled over it, must have been caused by a submarine volcano, as we are informed by Mr. Caldcleugh, that two eruptions of dense smoke were observed to issue from the sea, with violent ebullition, and the evolution of large quantities of gas.

About the same time, flame and smoke burst from the sea, near the island of Juan Fernandez, over which the waves rolled to a great height, as at Conception.* (Phil. Trans. 1835.)

But to return; it has been shown that the voltaic fluid, whether thermal or electrical, is disengaged from nearly all bodies when in a liquid state-from water, acids, saline solutions,--from oxides, chlorides, iodides, \&c. when in a state of fusion, during their chemical decomposition by the plates of a battery. The resemblance of this process to that of subterranean chemical action is somewhat remarkable. For example, the products of volcanic eruptions render it almost certain, that subterranean caloric is disengaged from sea water, which finds its way to the interior through fissures and submarine craters,-where its oxygen combines with sulphur, metals, \&c. as the oxygen of acids unites with

* It is singular enough that, while this sheet was in the press, news arrived from South America, that the Island of Selkirk had sunk beneath the ocean. 
the plates of a common battery.* That volcanos are in some way abundantly supplied with sea water, is evident from the vast quantities of steam discharged during their eruptions, which contains chloride of sodium, hydro-chloric acid, chloride of copper, iron, \&c. as well as from their geographical positions near the sea. In short, the earth may be regarded as a huge galvanic pile, kept in a state of perpetual subterranean chemical action by the waters of the ocean, as our little batteries are maintained in action by various solutions.

When the plates of a common battery are completely oxidized, chemical action ceases: so when all the materials within a given range of subterranean territory become saturated with oxygen, sulphur, chlorine, \&c. chemical action ceases, and the volcanic forces become quiescent, to be renewed elsewhere for indefinite periods of time, until exhausted or burnt out like the plates of a voltaic battery.

In North America, they have been nearly

* The hydrogen of water may unite with sulphur, making sulphuretted hydrogen; while the union of oxygen with sulphur, makes sulphurous acid, which combines with lime, and drives off carbonic acid, a common product of hot springs and volcanos. The nitrogen of atmospheric air which is admitted through craters, and is mixed in greater or less quantity with all water, combines with hydrogen, forming ammonia. In fine, there is no limit to the play of affinities that take place in this grand laboratory, under the agency of so intense a heat. 
extinct since the elevation of the rocky and Alleghany mountains above the ancient sea that once covered the northern hemisphere: while in South America, and on the eastern continent, volcanos are numerous, but confined chiefly to the borders of the ocean. The only feeble remains of subterranean chemical action in North America are its warm springs, which convey off whatever heat is generated below the surface, in a tranquil manner.

The same observations apply to the greater part of Europe and Asia. The Alps, the Appenines, the Himalayas, and many other mountain ranges of the old world, afford no evidence of existing subterranean combustion, except the numerous warm springs that issue from their sides. Were it not for this continual discharge of heat, it is probable that they might still be convulsed at long intervals by volcanic explosions, or by earthquakes, which are owing to the confinement of volcanic steam by superincumbent pressure. Warm springs may therefore be regarded as "safety valves of the globe," still more emphatically than volcanos. It is very well known that when the great Geyser of Iceland is obstructed by throwing stones into its funnel, its temperature rises rapidly, which is soon followed by eruptions of steam and water to a great height. It is equally certain, that if the obstruction were equal to the pressure of 
two or three thousand feet of rocks or lava, earthquakes would follow.

It was before stated, that the rapidity with which acid, alkaline, and other solutions are decomposed by the plates of the battery, is augmented by increasing their temperature,- that the amount of chemical action, like that of evaporation and rain, is greatest on the surface of the earth within the tropics, cateris paribus; and diminishes as we approach the regions of perpetual frost.

The same thing would seem to be true of subterranean chemical action: which points out the agency of solar heat in the production of volcanos, and connects the whole theory of geological dynamics with that of solution, combustion, and of universal chemistry. It is a remarkable fact, which has never been explained by geologists, that the highest mountains of the earth are within the torrid zone, where they rise to an elevation of from four to five miles above the ocean level; while in the middle latitudes they do not exceed the height of fifteen or sixteen thousand feet; and not more than five or six thousand feet beyond the polar circles, although they are nearer to the centre of the globe than any other part of its surface. The islands of the Pacific and Atlantic oceans are also far more numerous within the tropical than the higher latitudes; while it is certain that nearly 
all of them have been elevated by submarine volcanos.

All the chemical and geological operations of our planet would seem to be in proportion to the energy of solar radiation. Within the tropical regions, the aggregate quantity of earthy and metallic matter conveyed from the interior of the earth in a state of chemical solution by springs, is immense. The amount of evaporation and rain being great, the rivers are large, and rapidly destroy rocks, hills, and mountains, by mechanical agency, which are transported to lakes and seas, that are rapidly filled up by fluviatile deposits of sand, gravel, clay, pebbles, boulders, \&c. forming new lands. The waters of the ocean, that find their way to the interior are warm, and rapidly oxidize its metals and other minerals, by which a corresponding amount of heat is disengaged.

Thus it is evident that all the phenomena of meteorology, chemistry, and geology, are resolvable into the agency of caloric, or thermoelectric power. If rocks and hills are dissolved by running water, and transported to lakes and seas, caloric is the universal solvent. And here must end for ever the long and idle controversy between the Plutonian and Wernerian geologists. If caloric be indispensable to fluidity and solution, it is as necessary to the formation of sedimentary rocks as to the generation of granite, 
basalt, and other volcanic products, which are composed chiefly of metallic oxides, such as those of silicium, calcium, aluminum, iron, potassium, and sodium, the oxygen of which is derived mostly from sea water.

There is something great and sublime in the simplicity of the idea, that the same familiar power which "warms in the sun," and clothes the world with enchanting beauty, raises mountains from the ocean, and keeps the whole stupendous fabric of the universe in a state of perpetual motion and circulation.

It was supposed by some of the older geologists, that in the earlier periods of the world, there were no volcanos-by others, that they were far more active than at present-while Descartes, Leibnitz, Buffon, Fourier, and a multitude of more modern philosophers, have maintained that the earth originally existed in a state of fusion or incandescence throughout; and that it has been gradually cooling down ever since. To those who believe in the uniformity of nature's laws, it is needless to insist, that none of these opinions have any foundation in fact; and that they are discountenanced by all analogy. We are rather authorized to believe that the amount of chemical action going on throughout the earth is the same in all given periods of time, and in proportion to the amount of matter. But if volcanic agency were due to a 
central fire, it is difficult to comprehend why the tropical mountains should be from five to six times higher than those of the polar regions, why volcanos are confined chiefly to the vicinity of the ocean,-why they should discharge enormous quantities of steam saturated with muriatic salts,- why they should continue in action at intervals for unknown periods of time, and then become extinct, - why volcanic islands are more numerous in the tropical than higher latitudes,and why hot springs should not be equally distributed all over the earth.

The facts collected by M. Cordier and others, proving that the temperature of the earth increases as we descend below the surface, have been regarded by many geologists, as conclusive evidence that earthquakes and volcanos are caused by a central fire. It is true, that in many parts of the world, the temperature of rocky strata, and of the water that issues from them, is higher at the bottom of deep mines than at the surface, varying greatly however in different places. Mr. Fox found that in the Dalcoath copper mine, in Cornwall, at the depth of two hundred and thirty fathoms, a thermometer placed in a hole in the rock, stood at $76^{\circ} \mathrm{F}$., and at $82^{\circ}$ in water, ten fathoms deeper; the mean annual temperature of the surface being $50^{\circ}$. But the same gentleman states that about two million gallons of water are daily pumped from 
the Poldice mine, at the temperature of from $90^{\circ}$ to $100^{\circ}$; while the mine is only one hundred and seventy-six fathoms deep. It is therefore evident that the temperature is not proportional to depth.

On the other hand, when we reflect that water is continually acting upon metals, causing their oxidation, and that chemical action is the grand process by which latent heat is disengaged, we need be at no loss to account for its accumulation at great depths beneath the surface, where metals are abundant.

It is impossible to know with certainty how far the waters of the ocean penetrate beneath the surface-probably not beyond the depth of a few miles; nor is there any good reason to suppose that there is much chemical action at greater depths, owing to the superincumbent pressure; while it is known that on the surface of the earth there is very little chemical action without moisture. This much however is certain, that so far as we can trace back the history of our planet, it has been composed as at present, of mountains and valleys, seas and plains, and stocked with plants and animals that have successively arisen and passed away, leaving their fossil remains as a record of their former existence. We have the most indubitable proofs, that our mountains of granite, gneiss, basalt, \&c. were formed during long geological epochs, by successive volcanic movements, and contempo- 
raneous with the deposition of our stratified rocks; while there is not the slightest evidence that ever the earth was in a state of liquid fusion throughout. According to the estimate of Mr. Lyell, there are about two thousand volcanic eruptions every century, which in six thousand years would make 120 thousand.

If then it be admitted, that an equal amount of caloric is removed by thousands of hot springs, it is evident that such an enormous loss, if not compensated by the waters of the ocean, (which receive their temperature from the sun,) would cause a sensible diminution of the internal heat of the globe, and consequently, of its volume. But it is acknowledged by Fourier, Laplace, and Arago, that the temperature of the earth has not varied the $\frac{1}{300}$ th of a degree in two thousand years. This conclusion was deduced from the fact, that the length of the day has not diminished perceptibly since the time of Anaxagoras, which it is maintained must have been the case, had any diminution of the earth's volume taken place.

With the exception of Mr. Lyell and Dr. Daubeny, nearly all geologists of the present day have embraced the hypothesis of a central fire,-maintaining that the superficial crust of the earth is supported by a mass of incandescent lava. Baron Fourier supposed, (for he certainly never proved it,) that the earth was originally projected in a state of fusion or of incande- 
scence, into the planetary space,- the temperature of which he estimates at about $-58^{\circ} \mathrm{F}$. due to radiation from the sun and fixed stars.

By a long and laborious series of mathematical investigation, he arrived at the conclusion " that the earth once heated to any temperature whatever, and thus plunged into a colder medium than itself, would cool no more in $1,280,000$ years, than a globe of a foot in diameter composed of the like materials, and placed in the same circumstances would in a second of time, - that is to say, in this immense time, no appreciable variation would take place." (Ann. de Chim. et de Phys., October, 1834.)

The absurdity of supposing that "all the caloric of the earth below the invariable stratum (which does not extend much beyond one hundred feet below the surface,) comes from a central fire," is too obvious to require a serious refutation.

If there have been two thousand volcanic eruptions every century, according to the estimate of Mr. Lyell, it would give $25,600,000$ eruptions in $1,280,000$ years : yet the temperature of the globe has not sensibly diminished in that time according to the estimate of Fourier. But if $25,600,000$ volcanic eruptions, together with several thousand times as many hot springs, had proceeded from a central fire, the reduction of the earth's temperature must have been enormous. It is therefore evident, that the whole 
theory is not only hypothetical, but incompetent to explain the phenomena.

There is nothing so remarkable in the natural history of our planet, as the great revolutions of climate and organic life which it has undergone during the countless ages of the past. The most fertile imagination never conceived anything so wonderful as the varied scenes which the surface of the earth has exhibited during different epochs, before it was inhabited by man, or any of the higher orders of animals. The rationale of these mutations is by far the most comprehensive and important problem in geology; for it involves the whole theory of organic life, and its immediate relation to the vast science of physical astronomy. The leading facts hitherto discovered, may be reduced to the following general propositions :-

1. That throughout the northern hemisphere, from the shores of the Mediterranean to the north of Europe and Asia, and from the southern United States to Melville Island, in lat. $75^{\circ} \mathrm{N}$. the transition, secondary, and tertiary formations are filled with the fossil remains of plants and animals, which could have existed only in a uniformly warm climate, analogous to that of our present tropics :

2. That at different epochs, the land and sea were inhabited by totally different orders, genera, and species of organized beings, which successively arose, flourished for a time, and then gradually passed away, leaving only their pet- 


\section{rified remains as a lasting record of their exist-} ence :-

3. That the more ancient the formations, the more simple are the organisms they contain, and the more unlike any which now inhabit the earth, ${ }^{*}$ - until we arrive at the newer secondary, in which have been found a few birds and marsupial remains :-

4. That during the uniformly elavated temperature which prevailed in the middle and higher latitudes, there was a corresponding uniformity in the zoological and botanical character

* For example, from the commencement of the transition to the termination of the coal formation, (supposed to represent three subdivisions, or geological epochs, ) the sea every where abounded with encrinites, polypi, terebratulæ, trilobites, orthoceratites, and other testacea, with a few species of strange fishes, which seem to have been the only vertebrated animals then existing. But all of these passed away, (unless we suppose what has not yet been proved, that they underwent a gradual change under the influence of a different climatic condition of the earth,) and gave place to animals wholly different from any that have existed since the newer secondary eras, such as the huge icthyosauri, plesiosauri, pterodactyli, turtles, and other reptiles. As we advance towards the present epoch, we find in the older tertiary formation, the palæotherium, the anoplotherium, and remains of cetacea resembling the manati. These also passed away, and were succeeded by a still greater variety of warm blooded animals, some of which are represented by living species; such as the elephant, rhinoceros, hippopotamus, fragments of the ape, and several species of the feline genus; to which may be added, the dinotherium, the megatherium, the gigantic mastodon, and the elasmotherium, (a strange quadruped resembling both the horse and rhinoceros,-) all of which belonged to the newer tertiary epoch, and which have also long since been numbered with the myriads of extinct animals. 
of the earth, from the equator to the polar regions.*

In his recent excellent work on geology, Mr. Lyell refers all the past revolutions of organic life to changes of climate, and the latter to geological causes alone; such as the gradual shifting of sea and land, brought about by the agency of volcanos, earthquakes, hot springs, currents and waves of the ocean, the corroding action of rains, rivers, springs, and chemical decomposition. But if we admit with Mr. Lyell, that the greater part of the dry land now scattered over the northern hemisphere, may have been formerly confined within the tropics, and the mean temperature of the whole earth thus

* For example, nearly all the fossil plants hitherto discovered in the older formations consisted of ferns, coniferæ, Equisetaceæ, and Cycadeæ; which in all, comprised only about five hundred species, that presented very little diversity of form. It is even asserted by the most intelligent botanists who have carefully examined the subject, that for a long period, during which the climate of the middle latitudes seems to have exceeded the present temperature of the tropics, cycadeæ alone formed about one third of the entire Flora; whereas they now constitute only one two thousandth of the whole. But in the present diversified condition of the earth, as regards temperature, it contains about one hundred thousand species of plants, and above five hundred thousand species of animals. It would therefore appear that diversity in the generic and specific character of organized bodies, depends chiefly on varieties of climate and season, which differ in all the higher latitudes, and owing to the influence of local causes, are scarcely ever exactly alike, even in the same latitudes, as will be shewn in the first chapter of Book V. This subject opens a vast field of inquiry to those physiologists who may be disposed to investigate the origin of organic species. 
elevated 20 or $30^{\circ}$, as he maintains; it is still evident, that the polar regions would be excluded from the sun several months in the year, during which time, all vegetation would be arrested; for it ceases whenever the mercury sinks below $52^{\circ}$, according to Humboldt. It is therefore evident, that such a climatic condition of the earth would be wholly incompatible with the existence of a tropical vegetation, which is known to require a mean temperature of about $80^{\circ}$ throughout the year.

Among all the causes which modify the temperature of our planet, the most influential by far is the obliquity of the earth's axis. In reality, this condition determines chiefly, the vast difference between the climate of the tropical, temperate, and frigid zones, together with all the varieties of season. The question therefore naturally arises, whether all the great changes of climate which the earth has undergone, may not have been owing to modifications of the same cause, such as variations in the inclination of its axis, or even a gradual transposition of the equator and poles? In support of this natural view of the subject, it may be observed, that the successive generation and extinction of tropical plants and animals in the higher latitudes, would seem to require the repeated occurrence of such astronomical changes, which in their turn, afford a complete explanation of all the phenomena. And that such changes are not inconsistent with 
the laws of nature is evident from the fact, that the obliquity of the ecliptic has been constantly diminishing for the last 4000 years.

It has been often asserted by writers on astronomy, that great changes in the planetary inclinations would be inconsistent with the stability of thesystem, - as if all the operations of the universe were not maintained by unceasing changes and revolutions. But as Mr. Whewell observes, " the cause of perturbation has the whole extent of time to work in,-" there is reason to believe, that in the progress of long astronomical cycles, every part of the earth has successively been exposed to a vertical sun, and that such changes are absolutely essential to the conservation of the system in its existing state. For if the equatorial protuberance of the planets be owing to the greater amount of light which falls upon the tropics than upon the higher latitudes, it is obvious that they would in time lose their present spherical forms, by which their rotary motions would be deranged,-unless prevented by a gradual transposition of the equator to higher latitudes, or even to the polar circles. And that such a transposition has actually taken place, is strongly corroborated by the high and uniform temperature which prevailed throughout the middle and higher latitudes of the northern hemisphere when it was the abode of tropical plants and animals. 
Nor is it less obvious, that if the inclination of the earth's axis should go on augmenting from $0^{\circ}$ to $40^{\circ}$, there would be such a general refrigeration, as would destroy nearly all the pre-existing organisms of the middle latitudes,-where the mountain valleys would be filled with ice, perhaps to the level of the sea; as in Greenland, Spitzbergen, and the southern polar continent. In short, there would be what has been called the Glacial Period by Dr. Louis Agassiz, who has traced the evident marks of moving glaciers on the polished and scoriated rocks of Switzerland, the Tyrol, Germany, Scotland, Ireland, England, and France. And they have since been observed in the United States.*

If we extend our view to the solar system, we perceive that floods of æthereal matter in the form of light, are perpetually flowing from the sun, and

* I cannot, however agree with M. Agassiz, that during what he calls the glacial period, the whole surface of the earth presented a vast field of ice, from which projected only the highest mountain ridges; nor that a cold by which every living being was benumbed, suddenly appeared, and destroyed the myriads of organisms which but a moment before had been enjoying existence; because it is impossible to account for such " a catastrophe" in accordance with any of the known laws of nature. For example, whence came all the waters required to produce a field of ice many thousand feet in thickness? And what had become of the heating power of the sun, when the earth was seized with that sudden fit of the ague? Yet there is ample proof, that immediately antecedent to the existing order of things, a climate of polar severity prevailed throughout the middle latitudes of the northern hemisphere, and quite sufficient to destroy nearly all the preexisting orders of tropical plants and animals. 
keeping the air, the ocean, and the earth, in a state of unceasing circulation-converting solids into liquids, gases and vapours, which are successively changed into plants and animals. The atmosphere is continually wasted by oxidation, combustion, and the respiration of animals. But is it not as constantly reproduced by vegetable and animal decomposition? and are we not authorized to conclude, that if the whole atmosphere were annihilated, it would be again reproduced? or that if all the waters of the ocean were extinguished, they would be gradually regenerated by igneous chemical agency? Wherever there is chemical action there must be liquids and gases generated.* During respiration and putrefaction carbonic acid is generated, the appropriate of food of living vegetation, which returns a portion of oxygen to the atmosphere under the influence of solar light. During the decomposition of organic matter, a portion of atmospheric oxygen combines with its hydrogen, forming water,-and so on through all the endless ramifications of nature, we perceive that death is only a transformation of matter, by which the earth is perpetually renovated, and crowned with immortal beauty.

* Hence the improbability of the astronomical hypothesis, that the moon, Vesta, and some other planets, have no atmospheres; or that the atmosphere of Ceres is more than 668 miles high, and that of Pallas 465 miles, according to the observations of Shröeter and others. 


\section{CHAPTER V.}

\section{Hypothesis of two Electric Fluids.}

Is the electric fluid one and the same in all bodies? or is it a compound fluid? Each of these hypotheses have been zealously maintained since the time of Dufay and Franklin. But the controversy has consisted rather in pointing out frivolous distinctions in the phenomena produced, than in tracing the fundamental laws by which they are governed. After a patient examination of the facts adduced by the British and Continental philosophers, I have not been able to discover any decisive evidence that there are two electricities. On the contrary, it might as well be maintained that there are fifty, or an indefinite number; for this Protean agent exhibits an endless diversity of appearances and effects under different circumstances, according to the various bodies from which it is obtained, the mode of its developement, \&c.

It was discovered by Dufay, about a century ago, that when glass, rock crystal, diamond, precious stones, and many other substances, were 
warmed and rubbed with silk or woollen cloth, they repelled light bodies in their vicinity; but that when resinous bodies were made electric by friction in the same manner, they attracted light bodies which had been electrified by excited glass. Having caused a piece of gold leaf to be repelled, and suspended in the air by an electrified glass tube, and meaning to chase it about the room by a stick of excited gum copal, he found that, instead of being repelled by it as it was by the glass tube, it was eagerly attracted. From which he concluded that there were two kinds of electricity, residing in two different classes of bodies; one of which he termed vitreous, and the other resinous, - and that bodies charged with either kind repel bodies charged with the same kind, but attruct bodies charged with the other kind. But when it was afterwards discovered by Dufay, that all bodies acquired the power of attracting and repelling the same substances, according to the manner in which they were electrified, he frankly acknowledged that vitreous and resinous electricity were only different degrees of one and the same fluid.(Priestley's Hist. of Electricity, pp. 43 and 412.) Yet the doctrine of two electricities has been constantly imputed to Dufay by nearly all writers on the subject for the last 70 years.

It is said by those who still maintain the doctrine of two fluids, that if the gold leaves of an 
electrometer are made to diverge by means of an electrified stick of resin, they will collapse on the approach of an excited glass tube; when all signs of electricity disappear as if annihilated. Nothing could be more fallacious than such experiments; for I have often found, that after the gold leaves were made to diverge by excited glass, they expanded still farther on the approach of excited wax, and vice versa. The result is evidently modified by the degree of friction employed, and by the quantity of electricity thus disengaged.

It was long since observed by Dr. Watson, that the rubber of a common electrical machine, exhibited the same electricity in all respects as that which had been produced by the friction of sealing wax, sulphur, rosin, \&c. and afterwards by Canton, Franklin, Beccaria, and Wilson, that whenever two vitreous bodies were equally electrified they repelled each other, but when unequally, they attracted each other; and that the same was true of resinous bodies. Dr. Franklin also found, that when glass globes were excited by friction, the spark was larger and longer than when a sulphurous globe was used, and made a louder noise; from which he inferred that the glass contained on its surface more electricity than sulphur; he therefore denominated that of the glass plus or positive, and that of the sulphur negative-terms which are now in general use. 
It . was subsequently ascertained, that whenever two different bodies are rubbed against each other, they are in different states of electricity - that when a glass tube is rubbed with a dry silk handkerchief, the former is rendered positive and the latter negative; but if an insulated metal be brought near to the glass, the latter becomes negative and the metal positive. Hence it was concluded by Franklin, that during the action of a common machine, electricity is evolved from the rubber, and attracted by the cylinder of glass, from which it is attracted by the prime conductor, and thence to other conducting bodies. When amber and the tourmaline are rubbed together, the latter becomes plus or positive in relation to the amber; but when the tourmaline is rubbed against the diamond, it is minus or negative, and the diamond positive-and so of many hundred other bodies.

The above facts are exceedingly important, and are alone sufficient to prove that positive and negative are only different degrees of one and the same fluid, which accumulates in various proportions on different bodies, according to the relative degrees of their attraction for it. There are no two bodies in nature which have the same degrees of attraction for electricity; nor are there any two bodies which exhibit the same electrical state when rubbed against each other. It has even been found that the same 
bodies exhibit positive or negative electricity according to their colour, or the condition of their surface-that smooth glass is rendered positive by friction with woollen cloth, and negative when made rough by grinding it with emery, all other things being equal.*

It cannot be denied that the electricity of a common machine is derived chiefly from the rubber; for it is well known that its quantity is greatly increased by spreading over the rubber an amalgam of zinc or tin, the oxidation of which supplies electricity freely, as in the action of a voltaic battery; while amalgams of silver and platina, which do not oxidize at ordinary temperatures, are of no use. But is it not evident, that if the prime conductor receive its electricity from the rubber, that positive and negative are only different proportions of the same fluid?-that it accumulates and becomes plus on the prime conductor, because of its greater attraction for it? $\uparrow-$ and that whether positive or negative, its essential properties are

* Is not the attraction of rough glass for electricity less than that of smooth glass, for the same reason that caloric escapes more rapidly from rough than from smooth metals? and does it not accumulate upon insulated metals in greater quantities than on electrics for the same reason that the former are good conductors? (See page 194.)

+ Something analogous takes place during the action of the Galvanic pile. When the battery is composed of zinc and silver, 
the same under all circumstances? Is it not owing to the attraction of metals for electricity, that during the concretion of melted sulphur, chocolate, calomel, and glacial phosphoric acid from a state of vapour, in insulated metallic vessels, the latter become electrified plus, and the former minus?

It was before stated, that the more oxidable metal in the galvanic circle furnishes positive electricity in relation to the less oxidible one, which is in direct opposition to the theory of two fluids. M. Becquerel regards it as a proof of two galvanic fluids, that positive electricity permeates imperfect conductors more readily than negative. But this is just what might be expected from the plus and minus conditions of the same agent. In accordance with this view, it has been found, that other things being equal, the heating effect of voltaic electricity is in proportion to its quantity, and that the heating effect of positive electricity exceeds that of negative.

It was maintained by Winterl, Oersted, Berzelius, and at one time by Davy, that heat and light were produced by the union of positive and. negative electricity. After what has been al-

and immersed in an acid solution, the zinc is oxidized, by which electricity is disengaged; and passes to the silver, which is rendered plus; while the zinc, like the rubber from which the electricity proceeds, is negative. 
ready offered in regard to the relations of caloric and electricity, it would be useless to multiply arguments against so bald an hypothesis. It was afterwards shown by Sir Humphry Davy himself, that both heat and light are produced by either positive or negative electricity alone, though he adopted the doctrine of two fluids.

The following experiments of De Saussure clearly illustrate the identity of positive and negative, with plus and minus conditions of the electric fluid. On pouring water into heated iron or copper vessels when insulated, and connected with an electrometer, rapid oxidation was produced, and positive electricity evolved; but after the metal became covered over with a coating of oxide, less electricity was disengaged, which was negative. (Voyages dans les Alpes, tom. ii. p. 244.)

It is also worthy of special notice, that he procured electricity from the vapour of water without any chemical decomposition-(a fact which has been recently controverted by Pouillet, as before stated, p. 316, ) - that the evaporation of water from heated silver and white porcelain vessels was attended with a disengagement of electricity, that was generally positive, but sometimes negative. The same thing was observed on placing incandescent pure white quartz in water.

The advocates of two fluids explain the phe- 
nomena of electrical attractions in a singularly gratuitous manner. They say that when an electrified glass tube, or stick of wax, is brought near to light bodies, it communicates to them the opposite electricity from its own; and that they are brought together by the mutual attraction of the two electricities for each other-that when they touch the excited electric, they acquire the same kind of electricity which it has, and consequently are repelled. (Thomson on Heat and Electricity, p. 362.) It might as well be said, that liquid metals attract the same metals when solid, because they are in opposite states of electricity; or that the attraction of the living body by frozen mercury is owing to the combination of the former with positive, and the latter with negative electricity; and that the effect is produced by the mutual affinity of the two fluids : whereas I have proved that the attraction of frozen mercury, and other cold metals, for the living body is in proportion to their affinity for caloric, which is plus in the one, and minus in the other; and that all such phenomena are owing to the attraction of caloric and electricity for ponderable matter.

The whole train of Dr. Thomson's reasoning in favour of two fluids is founded on groundless assumptions. 1. That there is no attraction between electricity and ponderable matter: 2. that there is an attraction between positive and negative 
electricity: 3. that matter does not repel matter: and, 4. that nothing but the pressure of the ambient atmosphere prevents the escape of electricity from bodies. (Idem p. 424.) Feeling some doubt in regard to the last position, he elsewhere speaks of "the unknown cause which prevents it from leaving them." (Page 431.) Dr. Thomson maintains, that " matter does not repel matter, because, in the motions of the heavenly bodies, no such repulsion has ever been observed,"from which it would seem that he denies the existence of a repulsive agency in nature. Having assumed the above premises, he adds, " if matter does not repel matter, and if there does not exist any attraction or affinity between electricity and matter, then the Franklinian theory of positive and negative electricity cannot be correct." (Page 425, on Heat and Electricity.)

* It is somewhat remarkable, that Espinus, who first gave to Franklin's theory a mathematical form, should have regarded it as incapable of explaining the phenomena of electrical attractions and repulsions, without also admitting that " matter repels matter." What does he mean by this? Has it not been recognized by all the most distinguished writers on Natural Philosophy, from Newton to Laplace, that all matter is endowed with a power of repulsion as well as attraction? And I have proved that both these effects are produced by one and the same active principle, which surrounds the particles of all bodies-which, in certain proportions maintains their solidity, in others their liquidity, vaporization, and gasefaction-and without which there could be no contraction and expansion of matter, consequently no motion. 
In accordance with the hypothesis, that there are two electric fluids which have a mutual attraction for each other, it has been maintained by several writers on Natural Philosophy, that when a cloud passes over a mountain, or any other portion of the earth, it communicates to the mountain, \&c. the opposite electricity from its own, when the two fluids attract each other, producing a discharge of lightning. Such is the mystic jargon of which this great and beautiful science is composed at the present day. The truth is, that, notwithstanding the many new facts which have been discovered within the last 35 years, the theory of electricity is far more unintelligible than it was left by Franklin, Canton, Wilson, Beccaria, and Priestley; for they did recognize the important fact, that all the attractions and repulsions produced by electricity are owing to its affinity for common matter, and repulsion of its own particles. Many of its phenomena are yet involved in profound obscurity. We know not why it is, that when an insulated oblong conductor is brought near to an electrified body, the end nearest to it becomes negative, and the opposite end positive, while in the centre there is no sign of electricity. We do not comprehend clearly why a Leyden bottle cannot be charged and discharged while insulated-nor why the electricity of a large battery, or of an immense mass of aqueous vapour, becomes con- 
centrated into a spark or ball of fire. Much also remains to be done before the theory of the voltaic pile is thoroughly understood.

If, however, it be true, that all the forms and modifications of this mysterious agent are convertible into caloric, the theory of both will be greatly simplified, and must shortly be reduced to a very few fundamental axioms.

I have proved from the most elaborate series of experiments on record, performed by De Saussure and Read, that all atmospheric electricity, even that of the most serene weather, is disengaged from aqueous vapour-and by the experiments of Dalton, that caloric is the true and only cause of evaporation. There is also a perpetual flux and reflux of the electric fluid, corresponding with the diurnal variations of temperature, and fluctuations of the barometer. According to De Saussure, it diminishes from 9 or 10 o'clock in the morning until 5 or 6 P. M., and increases until 8 , when it again decreases until sunrise, when it is almost nullthat is, it is most abundant when the vapour of the air is undergoing condensation, (for the same reason that it is plus or positive during the formation of clouds, and during rain or snow;) but diminishes during the heat of the day, while the vapour of the air is undergoing expansion, by which it is connected with the whole theory of evaporation, condensation, and 
lightning. It is further stated by De Saussure and many others, that atmospheric electricity is constantly changing from positive to negative, which is also quite inconsistent with the hypothesis of two fluids.*

\section{Theoretical Views of Caloric and Electricity.}

It is only by extending our knowledge of nature, that we are enabled to trace an endless diversity of apparently isolated effects to some principle which connects and governs them; or to distinguish an unknown cause from the individual and ever varying phenomena it produces. The most signal and delightful triumphs of philosophy spring from the perception of analogies that seem remote and obscure, until closely analyzed. From the imperfect outline which has been already presented of this vast and complicated subject, it is obvious that all the operations of nature are so intimately connected, that we cannot make any substantial progress in the discovery of general principles without ascending to the primary source of all physical power.

* It is related by Van Marum, that the doctrine of two electric fluids became general in France from the fact, that M. Hauy was ordered by Napoleon to prepare a Treatise on Natural Philosophy for the use of the Polytechnic School, and not having time for reflection, he hastily adopted Coulomb's version of the two fluids. Well might Count Oxenstiern say, to his son, come and see with how little wisdom the world is governed. 
Until this is done, it cannot be said that even the foundation of physical science has been laid on a durable basis.

In a strict and philosophical sense, it must be admitted, that the words heat, caloric, igneous fluid, electricity, \&c. convey extremely limited and imperfect ideas of that all-pervading principle of action which preserves this universal frame of things in a state of perpetual motion and transformation. According to general acception, the term heat or caloric points to some very general and important phenomena, such as the sensation of warmth, or rather temperature, liquefaction, vaporization, combustion, expansion, \&c. But these are transitory and occasional effects, that are produced by its union with ponderable matter in certain proportions, and by no means universal under all circumstances.

The term electricity is still farther from conveying an adequate idea of an universal agent, than caloric. If we admit the existence of an electric fluid, sui generis, which darts through conducting bodies with immeasurable velocity, and communicates a shock to the living frame, it will not account for the phenomena of climate. It is not in the form of electricity that it warms in the solar beams. We cannot trace to its action the melting of winter snows and polar icebergs, - the evaporation of water from the ocean, and the elastic force of the atmosphere,-the 
contraction and expansion of gaseous bodies; combustion, solution, the production of winds, rain, snow, dew, mists, and fogs, with all the multitudinous phenomena of chemistry, geology, and physiology. It is, therefore, idle to regard electricity as a primum mobile, or as an universal principle of action. Besides, it has been proved, that when solar caloric is greatly accumulated in aqueous vapour, as in the tropical regions, and during summer in the middle latitudes, it is often disengaged suddenly in the form of lightning, attended with rapid precipitations of rain, or hail, - and that, without the caloric of aqueous vapour, there could be no lightning; consequently, that the sun is the great fountain of atmospheric electricity. The truth is, that if cold be regarded as only an abstraction or diminution of caloric, it follows that temperature is an universal attribute of this principle; and $I$ have shown that the attractive and repulsive powers of all bodies are modified by every change of temperature which they undergo. It is therefore evident, that caloric is not only far more diffused throughout nature than electricity, but that it is a permanent source of power, which is perpetually attracting and repelling the atoms of ponderable matter, and maintaining their solidity as well as fuidity.

I have shown that every form and variety of voltaic electricity are the results of chemical 
action, and that without caloric there could be no chemical action, - from which it also follows, that all the electrical phenomena of the battery are modified and subordinate effects of the omnipresent igneous principle.

The term ather is yet more vague and indefinite than caloric or electricity, as it does not very clearly indicate any of the foregoing properties, unless it be extreme subtilty. It is true that the Greek philosophers regarded it as an igneous principle, and as the source of power; but without explaining the manner in which it operates. We have also seen that Sir I. Newton referred cohesion, capillary attraction, solution, and even universal gravity to its agency; but without recognizing the law by which it produces the opposite effects of attraction and repulsion; or the mode in which it exhibits the various phenomena of heat and electricity.

This much is certain, that whatever form the spirit of matter assumes, or by whatever name we designate it, it is under all circumstances an æthereal essence, capable of uniting and separating the elements of nature, and of communicating to organized beings the sensation of heat. There cannot, therefore, be any serious objection to the use of caloric as a generic term, while we keep in mind, that it is an universal source of physical power, and the first of second causes. I have shown that nearly all the most distin- 
guished philosophers, ancient and modern, have recognized the existence of such a power. It

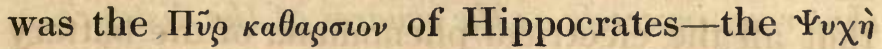
of Aristotle,-or the form of forms, - by which he meant the cause of causes - the anima mundi of the Romans-the archeus of Paracelsus and Van Helmont-the materia subtilis of Descartes-the pneumatical power of Bacon-the phlogiston of Beccher and Stahl-the electric fluid of Franklin, Priestley, and Beccaria-the latent heat of Dr. Black - and the caloric of modern times.

\section{Analogies of Caloric and Electricity.}

All that we can possibly know of either caloric or electricity, must be derived from a careful study of their fundamental properties, as exhibited in the various phenomena which they produce under different circumstances. Any hypotheses concerning their essential nature are beyond the scope of this inquiry.

For the sake of those who have not sufficiently directed their attention to the intimate relations of caloric and electricity, it may be of importance to bring under one general view some of their most striking analogies.

It has been shewn throughout the preceding portion of this work, that all the motive powers of caloric are resolvable into the primary and 
universal law by which it repels its own particles, and is attracted by ponderable matter, with forces that vary inversely as the squares of the distance.

The phenomena of electrical attractions and repulsions are clearly resolvable into the same law.

It would be a needless waste of time to bring forward the numerous proofs, that all the forces of attraction and repulsion are inversely as the squares of the distance. It has been demonstrated by Buffon, Laplace, Coulomb, and other philosophers, that the power of all emanations, such as light, caloric, and electricity in the diffused state, are subject to the same law, like that of gravity. The ringing of electric bells, the dancing of pith balls under an electrified tumbler, of paper images, and many other similar experiments, performed for the amusement of popular assemblies, are reducible to the above law. When light leaves of gold, copper, silver, zinc, \&c. are brought near to the wire that connects the extremities of a battery in action, or to insulated metals when electrified by a common machine, they are attracted by them.

When treating of chemical attraction, (Book II. Chap. II.), it was shown that caloric causes oxygen to combine with all other elements, from the slowest process of oxidation, as in the rusting of metals, fermentation, \&c. to the most rapid combustion. Electricity produces the same 
effects. It was first observed by Dr. Franklin, that when iron or steel wires were submitted to a few electrical shocks, they became covered over with a coating of rust. Dr. Priestley observed the same effect on other metals-after which Cuthbertson proved by a great variety of experiments, that all the known metals might be rapidly oxidized by common electricity,-even gold and platina, which are difficult to oxidize by the ordinary modes of applying heat.

By the attraction of caloric for ponderable matter, it combines with various solids, produces their fusion, and causes them to cohere with each other. By its repulsion of its own particles, it decomposes oxides, chlorides, iodides, bromides, alloys, and all other compounds.

The same is true of electricity, which dissolves and decomposes the most refractory bodies, such as the earths, alkalies, and all other metallic oxides, and again causes their elements to recombine. In short, there is no combination or decomposition which may not be effected by caloric and electricity, when sufficiently concentrated, and in due proportions.

When treating of cohesion, it was shewn that all bodies have different degrees of attraction for caloric; and that their.conducting power was in proportion to that attraction, - that the lightest known solids give out large quantities of caloric during combustion, and are bad conductors; 
while metals and other dense bodies that evolve much less caloric, are good conductors,-and that other things being equal, the conducting power of metals is augmented in proportion as they are deprived of caloric.

It is also known that the lightest solids, cateris paribus, afford the largest amount of electricity by friction,- and that they are bad conductors of electricity. It was further ascertained by Sir H. Davy, that the conducting power of metals for voltaic electricity is diminished in proportion to their temperature; (Phil. Trans. 1821:) (and I have shewn that their cohesion is diminished in the same ratio.) It is therefore evident, that the conducting power of bodies for both caloric and electricity is modified by every alteration in the relative proportions of rethereal and ponderable matter of which they are composed; and that as a general rule, with few exceptions, the same bodies are conductors and non-conductors of both.* (See Theory of Conduction.)

It was before observed, that no two series of

* It may be objected, that some bodies which are non-conductors of electricity when solid, become conductors in the liquid state. But it is doubted by Dr. Faraday whether such bodies ever do conduct electricity without undergoing decomposition, as he found that, whenever they act chemically on the plates of a battery, electricity is disengaged. Query. Is it not more probable that the non-conducting power of such bodies in the solid state is owing to the crystalline arrangement of their particles, as in the form of ice or snow? (See p. 190.) 
experiments, hitherto instituted for the purpose of ascertaining the relative degrees of cohesion and conducting power of the different metals, have presented the same results. (See p. 180.) It is however certain, that copper, gold, silver, platina, iron, and zinc, are the best conductors of electricity,-and it has been shown by $\mathbf{M}$. Becquerel, that potassium is of all others the worst conductor. (Ann. de Chim. et de Phys. xxxii. 420.)

In opposition to the simple and rational theory of Franklin, that electricity repels its own particles, and is attracted with various degrees of force by different species of ponderable matter, it has been maintained by Coulomb, Poisson, and other philosophers, that there is no affinity between electricity and ponderable matter,-and that it is confined to the surface of bodies by the pressure of the atmosphere.

Nothing could more clearly illustrate the tendency of mankind to take things upon trust, and without examination, than the general adoption of this partial and erroneous doctrine, by numerous modern writers on physical science. It seems to have been founded chiefly on the fact, that electricity escapes from the surface of bodies more readily in vacuo than under the pressure of the atmosphere. But it has been demonstrated by Morgan, Cavallo, Ampére, and Sir Humphrey Davy, that electrical attractions 
and repulsions take place in vacuo as well as under the pressure of the atmosphere. See Philosophical Transactions for 1822, where the experiments of Davy are recorded.

It is very true, that electricity in the diffused state, moves more freely over the surface of bodies, than through their substance; and that atmospheric air, when perfectly dry, assists in preventing its escape from other bodies, because it is a bad conductor. It was before stated, that an electric spark expands in an exhausted receiver into a diffused lambent light-and $\mathbf{M r}$. Harris of Plymouth, has proved, that the striking distance of the spark varies inversely as the density of the air through which it passes, the charge being the same. But these experiments afford no proof that electricity is not attracted by ponderable matter. The important practical application of metallic conductors, as lightning rods by Franklin, was founded wholly on their attraction for the electric fluid. It never entered into the imagination of this eminent philosopher, that flashes of lightning are determined to the earth and its conductors by the pressure of the atmosphere.

That electricity, when concentrated, is capable of passing through the substance of bodies, was proved by Jallabert of Geneva 70 years ago, who found that it might be readily transmitted through metals, covered over with pitch. (Priest- 
ley's Hist. of Electricity, p. 127.) But the same thing is fully demonstrated by the fusion of metals, rocks, gems, and all other bodies by lightning and other forms of electricity, and by the transmission of shocks through living bodies.

Notwithstanding the mathematical demonstrations of the Coulombian theory, it is founded on hypothetical and false assumptions; and, when applied to the explanation of natural phenomena, is evidently of no practical value. It is therefore not surprising, that Sir John Leslie should have observed, in his history of physical science, that it deserved the Dunciad.

To trace the analogies of caloric and electricity through all their diversified effects would be an endless task. They are both disengaged from all bodies by friction, pressure, percussion, and by chemical action; but vary according to the manner in which the operation is performed. It was proved by Becquerel, that the intensity of electricity evolved by pressure was in proportion to the force employed-from which it would seem, that, when the particles of bodies are forced nearer together suddenly, a portion of their latent caloric is disengaged in the concentrated form.

The greatest of all mysteries connected with electricity is the protean power, by which it assumes an endless variety of forms, and thus evades our inspection. We have seen that vol- 
taic electricity, evolved from a single pair, or from a few series of large plates, with an interposing liquid, differs greatly from that which is obtained from a battery composed of the same materials, but consisting of a great number of smaller plates,-and that the latter is equally different from the electricity of the atmosphere, or that procured from a common machine. In fine, that these differences are as numerous as the circumstances are various under which the phenomena take place. What then? Shall we assume the existence of an indefinite variety of electric fluids? Nothing could be more absurd, or in opposition to the fundamental laws by which they are governed.

It has been supposed, that electricity is far - more subtile and refined than caloric, because of the ease and rapidity of its passage through metals and other conductors. This also is a partial view of the subject; for caloric passes freely through mica, glass, and some other transparent bodies, which arrest the electric fluid when in the concentrated form. Nor is it true that glass is altogether impervious to the electric fluid. Compared with lac, it may be regarded as a conductor; for electricity produces attractions and repulsions through glass. If a small pith ball be suspended within a glass jar by a fine silk thread, it will be attracted by an electrified glass tube on the outside. It is further 
stated by Dr. Priestley, that electricity escapes through some species of glass, like water through a sieve, (History of Electricity, p. 592); and there is a medical electrician in New York, by the name of Humbert, who often amuses his friends by discharging a Leyden jar of immense size, through the coats of the glass without fracturing it. Besides, if a metallic wire be inserted into a glass receiver, exhausted of air, and connected with an electrical machine in action, a stream of electric light is seen to proceed from the wire in a straight line to the plate of the airpump : but if a conductor be presented to the side of the glass, the electric light is drawn towards it, which shows that electricity is attracted through glass. The same thing is true, to a certain extent, of sealing wax, as shown by Dufay . a hundred years ago; it is therefore evident, that all bodies are permeable to this subtile æther. The rapid passage of electricity through conductors, and its power of communicating a shock, are the most remarkable properties which distinguish it from caloric. But this difference vanishes when we perceive, that it is only electricity of a peculiar tension or concentration, that exhibits these powers; and that many of its forms produce no such effects. That the passage of electricity through living bodies, without producing the sensation of heat, is chiefly owing to its velocity, would appear from the fact, that a 
spark from a Leyden battery may be passed through gunpowder without igniting it, unless retarded in its progress by an imperfect conductor, such as water, when it inflames gunpowder. When electricity of high tension passes without interruption through conductors, it does not heat them; whereas, if they be too small to allow its free passage, or if the conductors be imperfect, they are heated, fused, and volatilized. The same is true of solar caloric, when concentrated by a large burning glass,--which passes through water and other transparent substances without heating them; but if made to act on bodies that obstruct its passage through them, they are fused, ignited, and dispersed in the form of flame.

It has been a leading object of this inquiry to show how partial and erroneous is the prevailing notion, that the agency of caloric is limited to the production of temperature, liquefaction, combustion, \&c. It is to its power of producing motion, and of maintaining the harmonious action of all the elements, that we are to seek for the laws which connect it with the science of universal nature.

I have pointed out its mechanical agency in steam, by which it produces every variety of motion, horizontal, vertical, and rotatory-and by which it has given to man a power over matter superior to all the achievements of ancient or 
modern times-in gunpowder and other fulminating compounds-in volcanic eruptions-and in that process of evaporation by which the rains of heaven are distilled from the ocean, transported through the atmosphere, and deposited in fertilizing showers-that it holds together the atoms of solids with inconceivable force, and disaggregates them with equal force-in short, that it is the grand instrument of Almighty Power in executing the laws of nature.

The mechanical agency of electricity is equally striking, though less constantly exerted. It overcomes the cohesion of all bodies, whether simple or compound, and acts equally on particles or masses. It transports the different elements of bodies to opposite poles of the battery. Acids may be conveyed through alkalies, and alkalies through acids, to their respective poles without neutralizing each other. It has been shewn by M. Fusinieri, that electric sparks issuing from the brass conductors of ordinary machines, contain incandescent particles of zinc and copper. When drawn from silver, they contain impalpable particles of silver, that may be seen with a good microscope, and discovered by chemical tests. When a spark issuing from a knob of gold passes through a plate of silver, a circular spot, or stratum of gold is seen on the surface of the plate where the spark entered and emerged, which soon volatilizes and disappears-and when 
it issues from a ball of copper, similar phenomena occur. The spark also acquires new particles from the metal through which it passes. In all such cases, the colour of the spark depends on the nature of the metal thus ignitedfrom which Fusinieri concludes, that electric light is always combined with ponderable matter; and that lightning owes its luminosity and odour to the combustion of such matter. (Giornale del Pavia, 1825.)

Dr. Priestley relates, that when the steeple of St. Bride's church in London was torn by a flash of lightning, it acted as an elastic fluid; and that its effects were exactly similar to what would have been produced by gunpowder pent up in the same places and exploded.

It is also related by Mr. Lyell, on the authority of Dr. Hibbert, that at Funzie, in Fetlar, one of the Shetlands, about the middle of the last century, a rock of mica schist, one hundred and five feet long, ten feet broad, and in some places four feet thick, was torn in an instant, by a flash of lightning, from its bed, and broken into three large, and several smaller fragments. One of these, twenty-six feet long, ten feet broad, and four feet thick, was simply turned over. The second, which was twenty-eight feet long, seventeen broad, and five in thickness, was hurled across a high point, to the distance of fifty yards. Another broken mass, about 
forty feet long, was thrown still further, in the same direction, quite into the sea, while many smaller fragments were scattered up and down. (Principles of Geology, vol. i. p. 260.)

A similar effect of lightning was related, not long since, in the German papers. It was stated that an enormous rock had been removed from the bed of a stream in Prussia, by boring a deep hole in it, into which was inserted a bar of iron twenty-eight feet long. The consequence was, that soon after, during a thunder storm, the lightning was directed to the bar, and the rock shattered to fragments. It would be useless to dwell on the mechanical effects of electricity in rending rocks, trees, buildings, \&c. were it not that there are still numerous writers on natural philosophy, who affect to doubt its materiality; and some who resolve it into undulations of the unknown æther, - as if it could not be bottled up in a Leyden battery like water, or any other material fluid,-or as if it did not act upon the sense of sight, hearing, feeling, smelling, and even of taste, like other material agents - and as if undulations were capable of causing horizontal, vertical, and rotatory motion.

It was shown in Book II. Chap. ii. that other things being equal, the chemical effects of caloric are uniformly in proportion to its absolute quantity.

It has also been shown by Davy, Children, 
and many other modern experimenters, that both the heating and chemical powers of voltaic electricity are in direct proportion to its quantity ; and that the quantity evolved is in proportion to the amount of chemical action-which corresponds with the universally acknowledged fact, that the heat of combustion is in the same ratio.

Without deciding whether electricity be a material agent, sui generis, or mere motion of ordinary matter, Dr. Faraday maintains, that "the atoms of matter are in some way endowed or associated with electrical powers, to which they owe their most striking qualities, and amongst others, their mutual chemical affinity," - - and he has endeavoured to ascertain experimentally, the absolute amount of this agent, motion, or power, which is associated with the particles or atoms of matter. He found that "one grain of water required an electric current to be continued for three minutes and forty-five seconds to effect its decomposition; which current must be powerful enough to retain a platina wire $\frac{1}{10^{4}}$ of an inch in thickness, red hot in the air, during the whole time." From which he concluded, that an equal quantity of electricity is employed in holding the particles of one grain of water together; and that it is probably equal to a very powerful flash of lightning. (Experimental Researches in Electricity, Sixth Series, Phil. Transactions, 1834.)

$\mathrm{He}$ adds, in another section, (873), that "the 
chemical action of a grain of water upon four grains of zinc, can evolve electricity equal in quantity to that of a powerful thunder storm."

If this inference were well founded, the chemical action of a pound of water upon four pounds of zinc, would afford as much electricity as many thousand thunder storms, - each of which is often attended with from twenty to fifty or more flashes of lightning: so that if the Doctor should devise a mode of disengaging it in the concentrated form, and in rapid succession, his experiments would rival the thunders of Jove.

But this is not the climax of modern discoveries : for if we are to credit the account of Professor Ritchie, "Dr. Faraday has found from a recent experiment that, by the action of electricity on a copper wire, as much light was given out in the course of a few days, as could be emitted from the sun in a year." (Records of Science, vol. i. p. 315.) And that this miraculous story was not intended as a satire, would appear from the gravity with which Dr. Ritchie adduces it " as a strong argument in favour of the undulatory theory of light," - of which he was known to be a strenuous advocate. But I must return to the sober and legitimate facts of science.

Like caloric, we have found that electricity fuses the most hard and refractory bodies. As an example of this, we are informed by Becquerel, on the authority of Dr. Fiedler, that in eastern 
Prussia and Silesia, large glass tubes are frequently found in banks of sand, from twenty to forty feet in length, formed by the sudden fusion of silicious matter by flashes of lightning; and, as might naturally be supposed, that the inner surface of these fulminary tubes is smooth, while the outside is rough. In regard to the mechanical effects of lightning in rending trees, displacing large rocks, and perforating the walls of buildings, the community is generally more or less informed.

Again ; like caloric, electricity expands all bodies into flame or light. But Sir I. Newton, and after him Sir H. Davy, defined flame as gaseous matter raised to a red or white heat : from which it would seem that they both regarded flame as a modification of ponderable matter. And I have already shewn that all bodies may be converted into light, whether by heat or electricity; and that its colour varies according to the nature of the ponderable matter employed; * that potassium, strontium, lithium, boron, and some other bodies, burn with a red light; hydrochlorate of calcined soda, with an orange light; oil, tallow, and resins, with a yellow light; hydrogen

* Much additional information might be obtained on this important subject, by submitting all the elements of ponderable matter to the agency of voltaic electricity, separately in succession; and by analyzing their light with a prism, or by causing it to pass through differently coloured transparent media. 
and some others, blue light; and iodine, violet light,-but that when different elements are burnt together, the result is a compound light, which may be decomposed with a prism into different primitive colours like the solar rays -in short, that there is no essential difference between electric light and that of ordinary combustion,-and that electricity is never luminous or visible, except when in a state of combination with ponderable matter, as maintained by Fusinieri.

Since the discovery of CErsted, that a metallic wire which connects the extremities of a voltaic battery in action, is capable of deflecting a magnetic needle placed near it from its ordinary position; and of Davy and Arago, that it is capable of attracting iron filings during the passage of an electric current through it, philosophers have seemed to suppose that the production of magnetic effects was a peculiar and distinctive attribute of electricity. But if it were established, that electricity is a distinct fluid, sui generis, it is nevertheless demonstrable, that caloric is capable of producing magnetic phenomena in a still more remarkable and universal manner-and that electricity of high tension, which produces a shock, and darts through metals with the greatest velocity, produces very feeble and partial effects on the magnetic needle, during its passage through a multiplying wire. 
It was first remarked by Davy, that the magnetic influence of a voltaic current was in proportion to the heat developed in the wire connecting the extremities of the battery. (Philosophical Transactions, 1821.) And it is now universally known, that batteries composed of a few large plates of zinc and copper, or even of a single pair of plates, are the best adapted for exhibiting magnetic phenomena - in fine, that the magnetic power of voltaic electricity is proportional to the quantity evolved, and inversely as its tension, or power of communicating a shock - that thermo-electricity which affords none of the usual signs of common electricity, such as diverging the gold leaves of an electrometer, and passing rapidly through conductors, deflects a delicate magnetic needle. It was long since observed by M. Ersted, that common electricity passed too rapidly through metallic wires to affect the needle-an hypothesis which has been confirmed by M. Colladon of Geneva, who found that when the wire was covered with three folds of silk, (which must have retarded the velocity of the electric current through it,) the needle was deflected as by a current of voltaic electricity.

The most important application of Ersted's discovery was the invention of what has been termed an electric multiplier, or galvanometer, by M. Schweigger of Halle, which has been variously modified by other philosophers. Before the in- 
vention of this beautiful instrument, a prepared frog was considered the most delicate test of galvanic electricity. But it has been found, that the multiplier is not only a far nicer test of electricity, but that it is also the most delicate thermoscope ever invented-that $\frac{1}{500}$ part of a degree of Fahrenheit's thermometer produces a sensible movement of a small needle suspended by a fibre of silk. From which it follows, that magnetic phenomena are not confined to the action of electricity, but also result from the agency of caloric in quantities too small for measurement by any other test.

It is therefore not a little surprising, that when Dr. Faraday offered as a proof, that all the varieties of electricity are essentially the same, because they all produce magnetic effects, that he did not recognize the identity of caloric and electricity.

Guided by the general fact discovered by Ersted, that a magnetic needle placed over the wire connecting the poles of a battery in action has a tendency to arrange itself at right angles to the conducting wire, Schweigger covered a common brass wire with silk thread, for the purpose of insulating it. This wire was then lapped round a piece of wood, 50, 100, or 200 times. When its two extremities were connected with the poles of a battery in action, the galvanic current passes through all the windings of the wire, by which the magnetic effects are multi- 
plied with every turn of the wire; so that when a magnetic needle is suspended in the middle of the hank of wire, it is placed at right angles to it. In this way the power of the multiplier was made to detect, not only minute portions of electricity that could not be otherwise appreciated, but the smallest changes of temperature, as before observed.*

By an improvement of this important instrument, MM. Nobili and Melloni were enabled to detect the heat of phosphorescent wood, dead fish, living insects, and that of the different coloured rays of the solar spectrum. But it was previously discovered by Dr. Seebeck of Berlin, that when a circuit is formed by soldering together two metals, and applying the heat of a lamp to one of the junctions, a needle placed within it was deflected from the magnetic meridian, and placed at right angles to the metals forming the circuit. It was afterwards found by Dobereiner, that the heat of the hand was sufficient to cause a deflection of the needle, when applied to the junction of the two metals - and by others, that the same effect was produced by applying ice, æther, or any thing which alters the temperature in one part of the circuit from that of the

* It was also by wrapping a piece of soft iron, bent in the form of a horse shoe, with insulated copper wire, and connecting its extremities with the poles of a galvanic battery, that Professor Moll of Utrecht was enabled to convert it into a temporary magnet of great power. 
rest. M. Becquerel found, that when one end of the multiplying wire was heated and brought in contact with the other end, the needle was deflected. Hundreds of similar experiments might be adduced, all of which demonstrate the agency of caloric in producing magnetism, where there is no sign whatever of electric tension; and that the magnetic needle is a true test of the smallest quantities of caloric that have ever been measured.

Some of the most delicate experiments on record were performed by Dr. Locke of Cincinnati. By interposing one quarter of a grain of antimony between the two copper wires of a multiplier, and applying the warmth of his finger, the needle was deflected $22^{\circ}$. In: another experiment, one of the copper wires was laid upon the other, without the interposition of any other metal, and the warmth of the hand applied as before, when the needle was deflected $6^{\circ}$. The same results were obtained by substituting the warmth of the breath instead of that of the hand. The temperature of the room in which the experiments were made was $65^{\circ}$. F. (American Journal of Science, April, 1834.)

But the most decisive proof that caloric and electricity are only modifications of one and the same agent is, that they are mutually convertible into each other; and that the electric fluid obtained from a permanent natural magnet, fuses, volatilizes, and ignites charcoal, metals, and 
other solids, like ordinary caloric, as may be daily witnessed at the Adelaide Gallery in London.

From a general review of the foregoing chapters, the following conclusions have been deduced:

1. That the latent caloric of aqueous vapour is the true and only basis of lightning :

2. That the latent caloric of liquids is the basis of voltaic electricity in all its various forms :

3. That they are both governed by the same universal law of attraction for ponderable matter, and repulsion of their own particles:

4. That the essential properties of positive and negative electricity are the same under all circumstances :

5. That when metals are made red hot by electricity, whether it be disengaged from a galvanic battery, a common machine, or from a magnet, it immediately loses its peculiar power of darting through conductors and producing a shock, being transformed into caloric, when it excites the sensation of heat, and converts solids into liquids, vapours, and gases, which present the same properties as if generated by the action of ordinary caloric :

6. That if caloric and electricity be not modifications of one power, and the cause of all mechanical and chemical action, the whole of modern science is a perfect chaos of contradictions. 





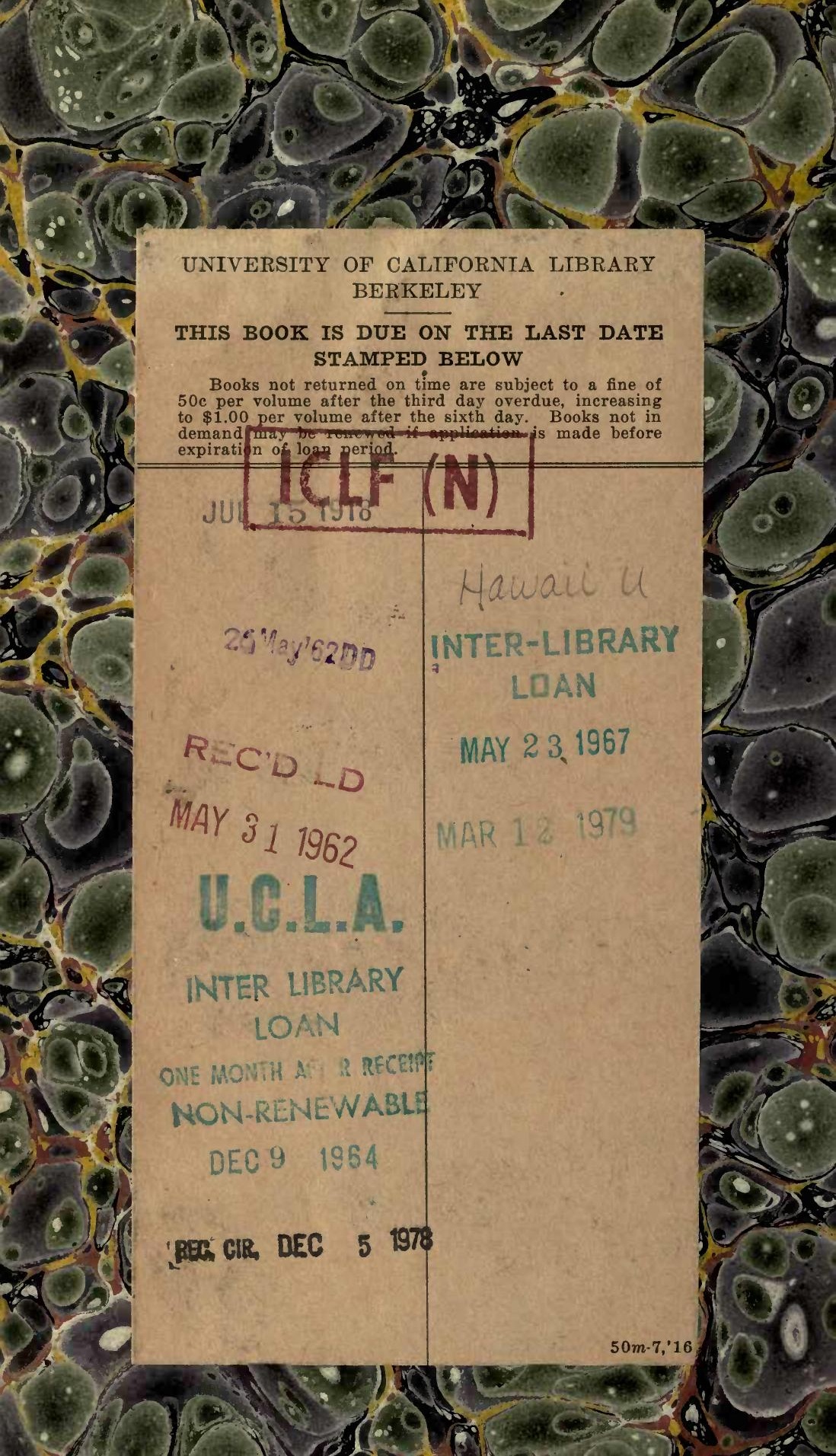


$30 \%$

a( $\left.\because)^{\prime} 8\right)$ YC 22472

Sic -620

- v10.0.

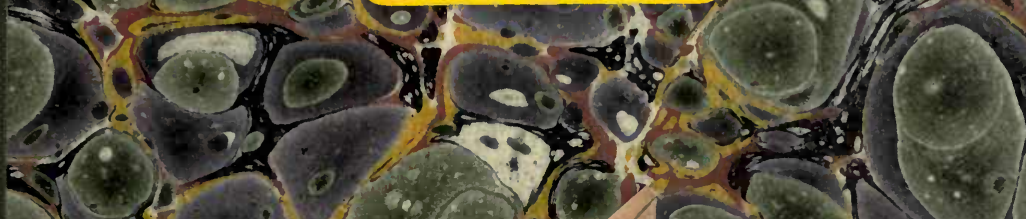
I.

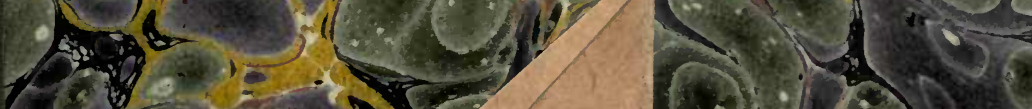

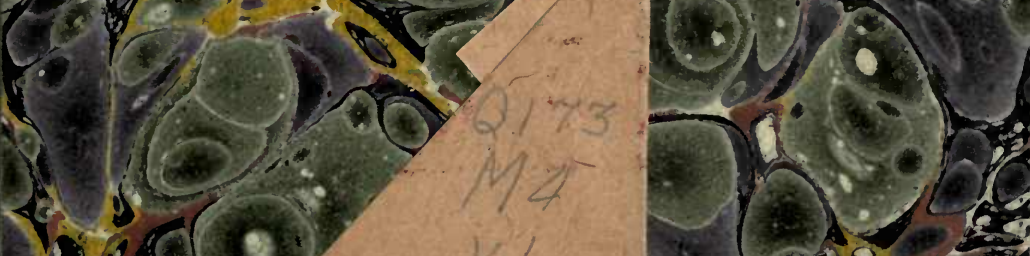
$1.0 \times 0$

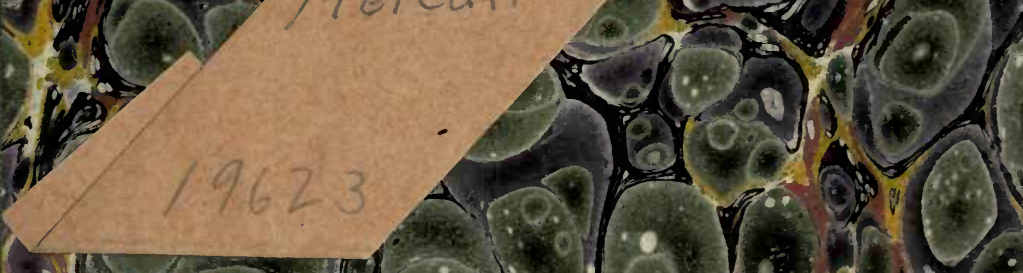

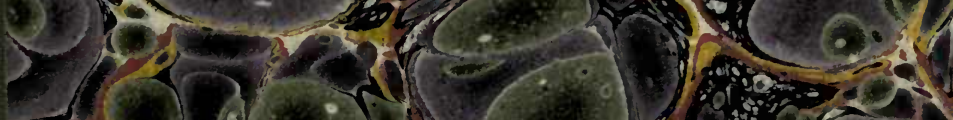

25.

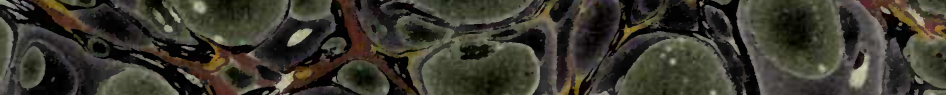
(1.)

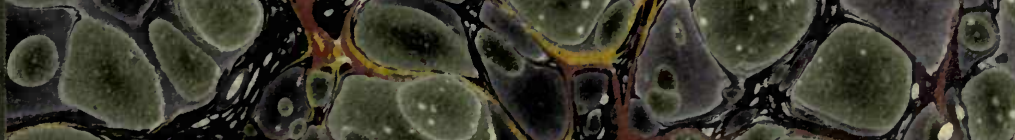

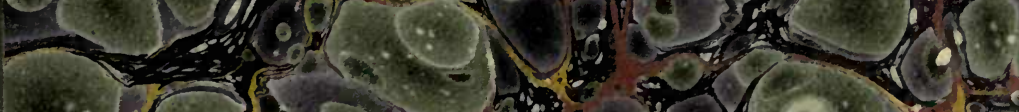
$\sqrt{12(09)}$ 
4 